\title{
Solar Reforming of Carbon Dioxide to Produce Diesel Fuel
}

Type of Report:

Reporting Period Start Date:

Reporting Period End Date:

Principal Authors:
Final Scientific/Technical Report

January 15, 2010

December 31, 2010

Dennis Schuetzle, Greg Tamblyn and

Matthew Caldwell

Renewable Energy Institute International

3028 Peacekeeper Way, McClellan, CA 95652

Robert Schuetzle

Pacific Renewable Fuels and Chemicals

3028 Peacekeeper Way, McClellan, CA 95652

Report Date: December 31, 2010

DOE Award / Task Number: DE-FE0002558

Other Participating Organizations:

Sandia National Laboratories

1515 Eubank SE

Albuquerque, NM 87123

Desert Research Institute

2215 Raggio Parkway

Reno, NV 89512 


\section{Disclaimer}

This report was prepared as an account of work sponsored by an agency of the United States Government. Neither the United States Government nor any agency thereof, nor any of their employees, makes any warranty, express or implied, or assumes any legal liability or responsibility for the accuracy, completeness, or usefulness of any information, apparatus, product, or process disclosed, or represents that its use would not infringe privately owned rights. Reference herein to any specific commercial product, process, or service by trade name, trademark, manufacturer, or otherwise does not necessarily constitute or imply its endorsement, recommendation, or favoring by the United States Government or any agency thereof. The views and opinions of authors expressed herein do not necessarily state or reflect those of the United States Government or any agency thereof. 


\section{TABLE OF CONTENTS}

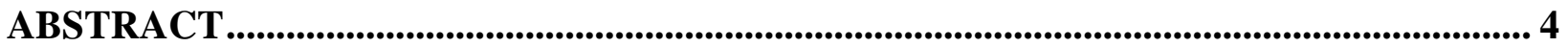

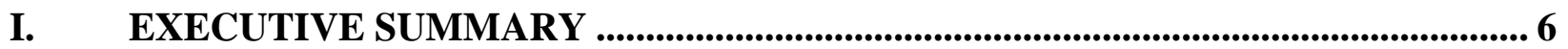

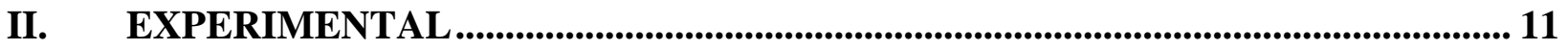

A. Design and Modeling of the Sunexus Solar Reformer SR1 ……………………........... 11

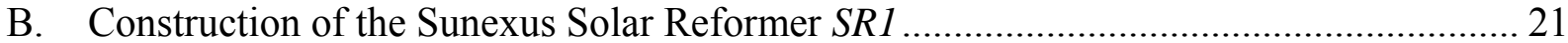

C. Development of the Sunexus $\mathrm{CO}_{2}$ Solar Reforming Catalyst .........................................2 25

D. Laboratory Testing of the Sunexus $\mathrm{CO}_{2}$ Reforming Catalyst and SR1 Reformer .............2 27

E. Design \& Integration of the Sunexus Solar Reformer SR2 with the 12kW Solar Dish.... 48

F. Testing of the Sunexus Solar Reformer SR2 with the $12 \mathrm{~kW}$ Solar Dish.......................... 51

III. COMMERCIALIZATION PLAN .................................................................................... 57

A. Integrated Process Model for the Commercial Deployment of Sunexus Technologies ... 57

B. Process Flow Diagram .......................................................................................... 58

C. Geographical Information System (GIS) Analysis for the Applicability of Sunexus to Industrial Sources in the United States......................................................................... 75

D. Applicability of Sunexus Technologies to a Variety of Industrial Applications ............... 78

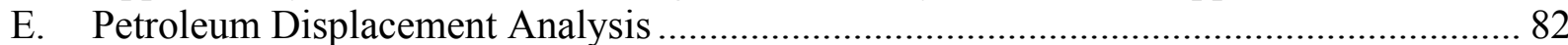

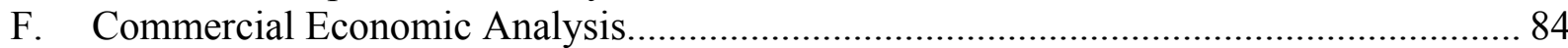

G. A Comparison of Sunexus $\mathrm{CO}_{2}$ Conversion Technology with Other Processes ............... 91

H. Lifecycle Assessment for the Capture and Conversion of $\mathrm{CO}_{2}$ to Diesel Fuel ................. 97

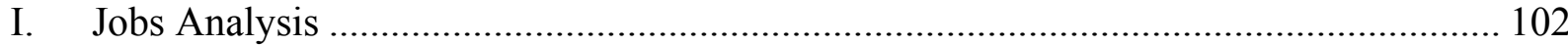

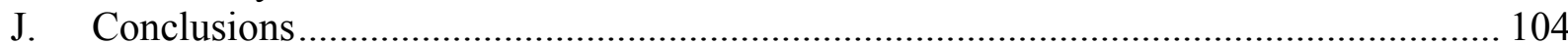

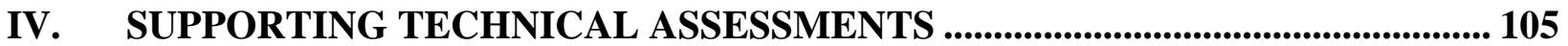

A. An Assessment of Contaminants in Captured $\mathrm{CO}_{2}$ Gas Streams from Various Industrial Processes and Their Possible Effect on Sunexus $\mathrm{CO}_{2}$ Reforming Catalysts . 105

B. Recommended Methods for Assessing Contaminant Levels in Captured $\mathrm{CO}_{2}$ Streams 112

C. An Assessment of Current Commercial Scale Fischer-Tropsch (F-T) Technologies for

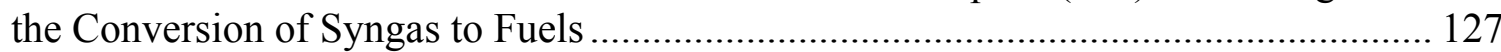

D. An Overview of $\mathrm{CO}_{2}$ Capture Technologies from Various Industrial Sources ............... 147

V. PROPOSED FUTURE EFFORTS........................................................................ 148

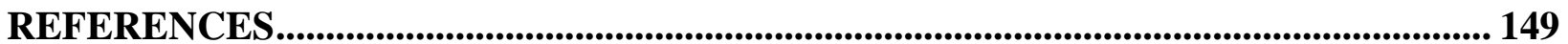

LIST OF ACRONYMS AND ABBREVIATIONS ...................................................... 151

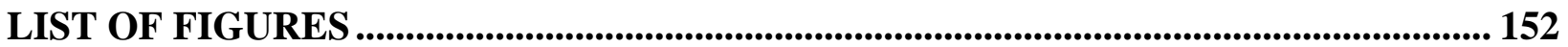

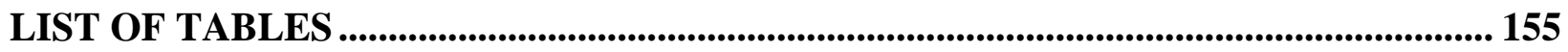




\section{ABSTRACT}

This project focused on the demonstration of an innovative technology, referred to as the Sunexus $\mathrm{CO}_{2}$ Solar Reformer, which utilizes waste $\mathrm{CO}_{2}$ as a feedstock for the efficient and economical production of synthetic diesel fuel using solar thermal energy as the primary energy input. The Sunexus technology employs a two stage process for the conversion of $\mathrm{CO}_{2}$ to diesel fuel. A solar reforming system, including a specially designed reactor and proprietary $\mathrm{CO}_{2}$ reforming catalyst, was developed and used to convert captured $\mathrm{CO}_{2}$ rich gas streams into syngas (primarily hydrogen and carbon monoxide) using concentrated solar energy at high conversion efficiencies. The second stage of the system (which has been demonstrated under other funding) involves the direct conversion of the syngas into synthetic diesel fuel using a proprietary catalyst (Terra) previously developed and validated by Pacific Renewable Fuels and Chemicals (PRFC). The overall system energy efficiency for conversion of $\mathrm{CO}_{2}$ to diesel fuel is $74 \%$, due to the use of solar energy.

The results herein describe modeling, design, construction, and testing of the Sunexus $\mathrm{CO}_{2}$ Solar Reformer. Extensive parametric testing of the solar reformer and candidate catalysts was conducted and chemical kinetic models were developed. Laboratory testing of the Solar Reformer was successfully completed using various gas mixtures, temperatures, and gas flow rates/space velocities to establish performance metrics which can be employed for the design of commercial plants.

A variety of laboratory tests were conducted including dry reforming $\left(\mathrm{CO}_{2}\right.$ and $\left.\mathrm{CH}_{4}\right)$, combination dry/steam reforming $\left(\mathrm{CO}_{2}, \mathrm{CH}_{4} \& \mathrm{H}_{2} \mathrm{O}\right)$, and tri-reforming $\left(\mathrm{CO}_{2}, \mathrm{CH}_{4}, \mathrm{H}_{2} \mathrm{O} \& \mathrm{O}_{2}\right)$. $\mathrm{CH}_{4}$ and $\mathrm{CO}_{2}$ conversions averaged $95-100 \%$ and 50-90\% per reformer cycle, respectively, depending upon the temperatures and gas space velocities. No formation of carbon deposits (coking) on the catalyst was observed in any of these tests.

A $16 \mathrm{ft}$. diameter, concentrating solar dish was modified to accommodate the Sunexus $\mathrm{CO}_{2}$ Solar Reformer and the integrated system was installed at the Pacific Renewable Fuels and Chemicals test site at McClellan, CA. Several test runs were conducted without catalyst during which the ceramic heat exchanger in the Sunexus Solar Reformer reached temperatures between $1,050{ }^{\circ} \mathrm{F}\left(566^{\circ} \mathrm{C}\right)$ and $2,200^{\circ} \mathrm{F}\left(1,204^{\circ} \mathrm{C}\right)$ during the test period.

A dry reforming mixture of $\mathrm{CO}_{2} / \mathrm{CH}_{4}(2.0 / 1.0$ molar ratio) was chosen for all of the tests on the integrated solar dish/catalytic reformer during December 2010. Initial tests were carried out to determine heat transfer from the collimated solar beam to the catalytic reactor. The catalyst was operated successfully at a steady-state temperature of $1,125^{\circ} \mathrm{F}\left(607{ }^{\circ} \mathrm{C}\right)$, which was sufficient to convert $35 \%$ of the $2 / 1 \mathrm{CO}_{2} / \mathrm{CH}_{4}$ mixture to syngas. This conversion efficiency confirmed the results from laboratory testing of this catalyst which provided comparable syngas production efficiencies $\left(40 \%\right.$ at $\left.1,200^{\circ} \mathrm{F}\left[650^{\circ} \mathrm{C}\right]\right)$ with a resulting syngas composition of $20 \% \mathrm{CO}, 16 \% \mathrm{H}_{2}, 39 \% \mathrm{CO}_{2}$ and $25 \% \mathrm{CH}_{4}$. As based upon the laboratory results, it is predicted that $90 \%$ of the $\mathrm{CO}_{2}$ will be converted to syngas in the solar reformer at $1,440{ }^{\circ} \mathrm{F}\left(782^{\circ} \mathrm{C}\right)$ resulting in a syngas composition of $50 \% \mathrm{CO}: 43 \% \mathrm{H}_{2}: 7 \% \mathrm{CO}_{2}: 0 \% \mathrm{CH}_{4}$. 
Laboratory tests show that the higher catalyst operating temperature of $1,440{ }^{\circ} \mathrm{F}\left(782^{\circ} \mathrm{C}\right)$ for efficient conversion of $\mathrm{CO}_{2}$ can certainly be achieved by optimizing solar reactor heat transfer, which would result in the projected $90 \% \mathrm{CO}_{2}$-to-syngas conversion efficiencies. Further testing will be carried out during 2011, through other funding support, to further optimize the solar dish $\mathrm{CO}_{2}$ reformer.

Additional studies carried out in support of this project and described in this report include:

- An Assessment of Potential Contaminants in Captured $\mathrm{CO}_{2}$ from Various Industrial Processes and Their Possible Effect on Sunexus $\mathrm{CO}_{2}$ Reforming Catalysts;

- Recommended Measurement Methods for Assessing Contaminant Levels in Captured $\mathrm{CO}_{2}$ Streams;

- An Assessment of Current Commercial Scale Fisher-Tropsch (F-T) Technologies for the Conversion of Syngas to Fuels;

- An Overview of $\mathrm{CO}_{2}$ Capture Technologies from Various Industrial Sources;

- Lifecycle Analysis for the Capture and Conversion of $\mathrm{CO}_{2}$ to Synthetic Diesel Fuel.

Commercial scale Sunexus $\mathrm{CO}_{2}$ Solar Reformer plant designs, proposed in this report, should be able to utilize waste $\mathrm{CO}_{2}$ from a wide variety of industrial sources to produce a directly usable synthetic diesel fuel that replaces petroleum derived fuel, thus improving the United States' energy security while also sequestering $\mathrm{CO}_{2}$. Our material balance model shows that every $5.0 \mathrm{lbs}$ of $\mathrm{CO}_{2}$ is transformed using solar energy into $6.26 \mathrm{lbs}$ (1.0 U.S. gallon) of diesel fuel and into by-products, which includes water. Details are provided in the mass and energy model in this report.

Techno-economic models, developed for this program, show that the commercial scale plants described in this report should be able to provide $>18 \%$ Internal Rate of Return (IRR) and $>18 \%$ first year Return On Investment (ROI), without including incentives. It is estimated that the Sunexus technology could supply $16.3 \%$ of U.S. petroleum needs by 2030 .

An economic analysis was used to predict the number of jobs that could be created from the commercial deployment of Sunexus plants. It is estimated that an average of 17 plants could be deployed each year from 2015-2030. Therefore 255 plants could be operational by the end of 2030 which would capture and convert 45,900,000 tons of $\mathrm{CO}_{2}$ per year to $1,818,000,000$ gallons of diesel fuel. Assuming a conservative wholesale value of $\$ 2.50 /$ gallon gives the total value of this fuel at $\$ 4,545,000,000$. Section III.I provides details on how these 255 plants would support the creation of 132,445 new jobs from 2015 through 2030.

Based on a detailed commercial analysis, the Sunexus technologies will be ideal for use with $57.6 \%$ of U.S. stationary industrial emissions sources that currently emit a total of 2,073 million tons of $\mathrm{CO}_{2}$ per year. Design and deployment of commercial Sunexus plants at selected industrial sites, including coal power plants, natural gas and oxy-combustion power plants, natural gas processing facilities, ethanol plants, cement production plants, municipal landfills can begin as early as 2013 . 


\section{EXECUTIVE SUMMARY}

This Technical Report summarizes the work completed during this program from January 15, 2010 through December 31, 2010 and is prepared in accordance with the guidelines set forth in the Federal Assistance Reporting Checklist instructions of the cooperative agreement.

The most immediate path to rapid greenhouse gas (GHG) reduction is to turn carbon dioxide $\left(\mathrm{CO}_{2}\right)$ capturing from an expense liability into a feedstock for the production of profitable energy products by implementing effective technologies and business models. The appropriate technologies must be applicable to a variety of industrial sources, be able to utilize diverse $\mathrm{CO}_{2}$ feed gas streams, and the commercial deployment of these technologies must be profitable without relying on state and federal incentives. Under this scenario, private capital markets will be able to finance commercial plants, which can be operated at a profit while sequestering $\mathrm{CO}_{2}$.

This project is focused on demonstration of the Sunexus technology which will utilize waste $\mathrm{CO}_{2}$ as a feedstock for the efficient and economical production of diesel fuel. A feed stream consisting of $\mathrm{CO}_{2}$ and methane (or natural gas) is first converted, at high conversion efficiencies, into syngas using concentrated solar energy. This syngas is then directly converted into clean, synthetic diesel fuel using demonstrated catalytic processes. The heart of this system is the Sunexus Solar Reformer which has been modeled, designed, constructed, and successfully tested.

Commercial Sunexus plants have the capability of utilizing waste $\mathrm{CO}_{2}$ from a wide variety of industrial sources to directly produce a usable diesel fuel that replaces petroleum derived fuel, thus improving the United States' energy security while also sequestering $\mathrm{CO}_{2}$. The density of the diesel fuel produced from the syngas is $6.26 \mathrm{lbs} / \mathrm{gallon}$ or $0.75 \mathrm{~g} / \mathrm{cc}$. Our material balance model shows that every $5.10 \mathrm{lbs}$ of $\mathrm{CO}_{2}$ is transformed using solar energy into $6.26 \mathrm{lbs}(1.0$ U.S. gallon) of diesel fuel and into by-products, which includes water. Details are provided in the mass and energy model in this report.

This Scientific/Technical Report includes the following sections:

\section{Design and Modeling of the Sunexus Solar Reformer SR1 (Section II.A)}

The project team designed the Sunexus Solar Reformer $S R 1$ for the conversion of a $\mathrm{CO}_{2}$ rich gas stream to syngas $\left(\mathrm{H}_{2}\right.$ and $\left.\mathrm{CO}\right)$ using solar energy. The objective was to design a solar reformer that could be tested with candidate catalysts in the laboratory using electric heaters configured to simulate solar energy. Solid models for each component of the system were completed, a ray tracing and heat transfer model for the reformer was produced, a general arrangement (GA), process \& instrumentation drawing (P\&ID), bill of materials, and associated design drawings were completed. Manufacturing vendors were engaged to ensure that major components will be produced economically when commercial systems are deployed. Our Project partner, Sandia National Laboratories, performed the heat transfer (FLUENT) and ray tracing (ASAP) modeling of the SR1 Reformer. 


\section{Construction of the Sunexus Solar Reformer SR1 (Section II.B)}

The Sunexus solar reformer SR1 was constructed, a control system platform was built, and software was developed for reformer system control, and for on-line data acquisition of operating conditions and gas composition.

\section{Development of the Sunexus $\mathrm{CO}_{2}$ Reforming Catalyst (Section II.C)}

Various formulations of a proprietary, Ni-based $\mathrm{CO}_{2}$ reforming catalyst were tested to identify the best candidate catalyst for more extensive testing under various $\mathrm{CO}_{2}$ reforming conditions in this Phase I project.

\section{Laboratory testing of the Sunexus $\mathrm{CO}_{2}$ Reforming Catalyst and Solar Reformer SR1 (Section II.D)}

Extensive laboratory testing of the Sunexus candidate catalyst and Sunexus Solar Reformer SR1 was conducted and kinetic data was developed. Catalyst testing was conducted under a range of temperatures, gas mixtures, gas flow rates, and other parameters in order to establish performance metrics. Parametric studies on the candidate catalysts were conducted for 1) Dry reforming $\left(\mathrm{CO}_{2}\right.$ and $\left.\mathrm{CH}_{4}\right)$; 2) Combination dry/steam reforming $\left(\mathrm{CO}_{2}\right.$, water, and $\left.\mathrm{CH}_{4}\right)$; and 3) Tri-reforming $\left(\mathrm{CO}_{2}\right.$, water, $\mathrm{O}_{2}$, and $\left.\mathrm{CH}_{4}\right)$ reforming processes.

Design and Integration of the Sunexus Solar Reformer SR2 with the $12 \mathrm{~kW}$ Solar Dish (Section II.E)

The data generated from the parametric testing in Section II.D was used to design the next generation Sunexus Solar Reformer SR2. This reformer was integrated with an Infinia $12 \mathrm{~kW}$ solar dish and the Sunexus Solar Reformer SR 2 control and measurement system.

\section{Testing of the Sunexus Solar Reformer SR2 Integrated with Solar Dish (Section II.F)}

The Integrated Sunexus Solar Reformer $\boldsymbol{S R} \mathbf{2}$ was successfully tested on sun using a dry reforming mixture of $\mathrm{CO}_{2} / \mathrm{CH}_{4}(2.0 / 1.0)$ during December, 2010 at our McClellan Park engineering and testing facility. The catalyst was operated successfully at a steady-state temperature of $1,125^{\circ} \mathrm{F}\left(60{ }^{\circ} \mathrm{C}\right)$, which was sufficient to convert $35 \%$ of the $2.0 / 1.0$ $\mathrm{CO}_{2} / \mathrm{CH}_{4}$ mixture to syngas. This conversion efficiency confirmed the results from laboratory testing of this catalyst which provided comparable syngas production efficiencies $(40 \%$ at $1,200{ }^{\circ} \mathrm{F}\left[650{ }^{\circ} \mathrm{C}\right]$ ) with a resulting syngas composition of $20 \% \mathrm{CO}, 16 \% \mathrm{H}_{2}, 39 \% \mathrm{CO}_{2}$ and $25 \% \mathrm{CH}_{4}$. 
Integrated Process Model for Commercial Deployment of Sunexus Technologies (Section $\underline{\text { III.A) }}$

A fully integrated process model was developed using test data generated from this project. This integrated process model includes mass and energy balance results. The results from this analysis are summarized in Table 1:

Table 1 - Sunexus System Metrics

\begin{tabular}{|l|c|}
\hline \multicolumn{1}{|c|}{ Sunexus System Metric } & Value \\
\hline Overall system energy efficiency: & $74.4 \%$ \\
\hline $\begin{array}{l}\mathrm{CO}_{2} \text { Utilized per Gallon of Diesel } \\
\text { Fuel Produced: }\end{array}$ & $2.3 \mathrm{~kg}(5.0 \mathrm{lbs})$ \\
\hline Overall Life-Cycle $\mathrm{CO}_{2}$ balance: & $90.7 \%$ Reduction \\
\hline
\end{tabular}

\section{Process Flow Diagram (Section III.B)}

Based on the integrated process model, a process flow diagram for commercial systems is provided.

Geographical Information System (GIS) Analysis of the Applicability of Sunexus to Industrial Sources in the United States (Section III.C)

A geographic information system (GIS) model was developed that shows that the Sunexus $\mathrm{CO}_{2}$ Solar Reforming process could effectively convert $\mathrm{CO}_{2}$ to diesel fuel from $57.6 \%$ of industrial $\mathrm{CO}_{2}$ sources in the United States. These industrial sources include power plants, cement plants, ethanol production plants, and natural gas processing plants.

\section{Applicability of Sunexus Technologies to a Variety of Industrial Applications (Section}

\section{$\underline{\text { III.D) }}$}

The Applicability of Sunexus to the capture and conversion of $\mathrm{CO}_{2}$ to diesel fuel is summarized for coal-fired power plants, natural gas processing plants, ethanol production plants and cement production plants.

\section{Petroleum Displacement Analysis (Section III.E)}

A petroleum displacement analysis was completed which forecast that the Sunexus technologies have the opportunity to displace 185 million barrels of oil per year by 2020 (or $3.4 \%$ of total petroleum consumed in the U.S.) and 931 million barrels of oil per year by 2030 (or 
$16.3 \%$ of total petroleum consumed in the U.S.). In addition, a jobs analysis was conducted that demonstrates the potential development of 250 jobs per plant.

\section{Commercial Economic Analysis (Section III.F)}

Economic models for several commercial plants were developed for typical, operating ethanol and cement production plants. This economic analysis indicates that target profitability metrics $(>18 \%$ Internal Rate of Return and $>18 \%$ first year Return on Investment) can be achieved for these plants.

\section{A Comparison of the Sunexus $\mathrm{CO}_{2}$ Capture and Conversion (CCC) Technology with other CCC Technologies (Section III.G)}

In this section, the Sunexus $\mathrm{CO}_{2}$ Capture and Conversion (CCC) technology is compared with emerging $\mathrm{CCC}$ technologies including: the production of biodiesel fuel from algal oil; the production of carbonate products; and the production of synthetic natural gas.

\section{Lifecycle Analysis (LCA) for the Capture and Conversion of $\mathrm{CO}_{2}$ to Synthetic Diesel Fuel} (Section III.H)

A complete lifecycle assessment (LCA) was carried out to help evaluate the effectiveness of the Sunexus process for the capture and conversion of $\mathrm{CO}_{2}$ to diesel fuel. The total $\mathrm{CO}_{2}$ utilized by the Sunexus process was first calculated (including inputs and outputs/emissions) using an integrated mass and energy model. Overall the Sunexus process resulted in $90.7 \%$ consumption of $\mathrm{CO}_{2}$ for a standard commercial plant design. Then, the Argonne National Laboratories' GREET model was used to analyze the transport and utilization of the fuel. Comparisons with petroleum derived diesel fuels show significant GHG reduction benefits over the use of petroleum derived fuels.

\section{Jobs Analysis (Section III.I)}

A jobs analysis was carried out for the deployment of Sunexus plants, each of which utilizes 180,000 tons of $\mathrm{CO}_{2} /$ year to produce 71.3 million gallons of diesel fuel per year. It is projected that an average of 17 plants could be deployed each year in the U.S. from 2015-2035. Therefore 255 plants could be operational by the end of 2030 which would capture and covert $45,900,000$ tons of $\mathrm{CO}_{2} /$ year to $1,818,000,000$ gallons of diesel fuel. If a conservative wholesale value of $\$ 2.50 /$ gallon is used then the total value of this fuel is $\$ 4,545,000,000$. Details are provided that demonstrate that the deployment of these 255 plants would support 132,445 new jobs by the end of 2030 .

\section{An Assessment of Contaminants in Captured $\mathrm{CO}_{2}$ from Various Industrial Processes and Their Possible Effect on the Sunexus $\mathrm{CO}_{2}$ Reforming Catalysts (Section IV.A)}

This assessment summarizes possible gas contaminants from commercial flue gas streams (e.g., coal power plants, cement production, etc.). The maximum recommended concentrations of several key catalyst contaminants are presented for the $\mathrm{CO}_{2}$ reforming catalyst and 
syngas to synthetic diesel fuel production catalyst. Under a separately funded project, PRFC has developed and demonstrated cost-effective and efficient technologies for the removal of these contaminants in gas streams. It was determined that costs associated with feed gas cleanup would not have a major effect on commercial plant economics.

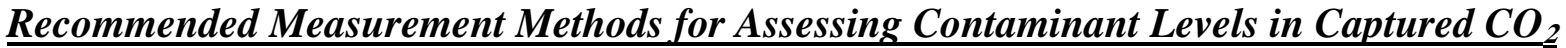
Streams (Section IV.B)

Analytical methods for monitoring and measuring contaminant levels in captured $\mathrm{CO}_{2}$ streams and $\mathrm{CO}_{2}$ containing flue gases are recommended by our Project partner, the Desert Research Institute. Under a separately funded project, these recommended analytical techniques have been shown to accurately measure contaminants in gas streams down to ppb levels.

\section{An Assessment of Current Commercial Scale Fischer-Tropsch (F-T) Technology for the} Conversion of Syngas to Fuels (Section IV.C)

This section summarizes the state of various commercial F-T technologies in use today. The advantages/disadvantages of tubular and slurry-based catalytic reactors are summarized. As based upon this comparison, it was determined that tubular catalytic reactors have several advantages over slurry-based catalytic reactors for small to medium scale plants (less than $\$ 1.0-\$ 2.0$ billion in plant capital costs). Our partner, PRFC, has designed and validated tubular catalytic reactors for the direct production of synthetic diesel fuel from the syngas (under previously funded efforts).

An Overview of $\mathrm{CO}_{2}$ Capture Technologies from Various Industrial Sources (Section IV.D)

A brief summary is provided for $\mathrm{CO}_{2}$ capture technologies that are being used and/or are under development for flue gases from various industrial sources. 


\section{EXPERIMENTAL}

This Experimental section describes the design, modeling, construction and testing of the first prototype Sunexus Solar $\mathrm{CO}_{2}$ Reformers (SR1) in the laboratory. As based upon what was learned from design, construction and testing of the Sunexus Solar $\mathrm{CO}_{2}$ Reformer $\boldsymbol{S R} \mathbf{1}$, an improved design was developed (SR2) for integration with the $12 \mathrm{~kW}$ solar concentrating dish. This integrated system was successfully tested during December 2010 using solar radiation as the only source of energy.

\section{A. Design and Modeling of the Sunexus Solar Reformer SR1}

This section describes the methods used to design and model the first prototype of the Sunexus Solar $\mathrm{CO}_{2}$ Reformer which was designated as $\boldsymbol{S R}$. The solar reactor/receiver (hereinafter called the "Solar Reformer") is the heart of the Sunexus process. The Solar Reformer uses concentrated solar energy to reform a $\mathrm{CO}_{2}$ rich gas stream into syngas for the subsequent conversion to synthetic diesel fuel. The Sunexus Solar Reformer was designed to operate with either of two concentrating solar technologies - a concentrating parabolic dish or a power tower. The key design goals for the Solar Reformer SR1 included the following:

- Ability to scale from demonstration scale to commercial scales with minimal risk

- Ease of manufacturing at commercial scale for mass production with acceptable costs

- Ability to achieve high $\mathrm{CO}_{2}$ conversion at a high energy efficiency

- Ability to achieve required throughput of gas for commercial plant designs

- Ability to achieve target activity and gas selectivity for the Sunexus project

- Combination of the above goals to achieve a commercial IRR $>18 \%$ and first year ROI of $>18 \%$

The $\boldsymbol{S R 1}$ solar reformer design was developed so that it had the ability to function efficiently and economically at the pilot demonstration scale and be able to scale to large commercial facilities. To accomplish this goal, a tubular design was used that consisted of parallel u-tubes packed with catalyst. A proprietary, Ni-based reforming catalyst was developed that provided excellent conversion at high space velocities under a range of feed gas conditions (see test results in Section II.C). The SR1 mimics designs that are used commercially in industry today in steam methane reforming (SMR) and other reforming applications. However, instead of a top, side, or bottom fired heat source, the $\boldsymbol{S R} \mathbf{1}$ parallel tubes lay within a cavity that is heated using concentrated solar energy. This first design is shown in Figure 1. 


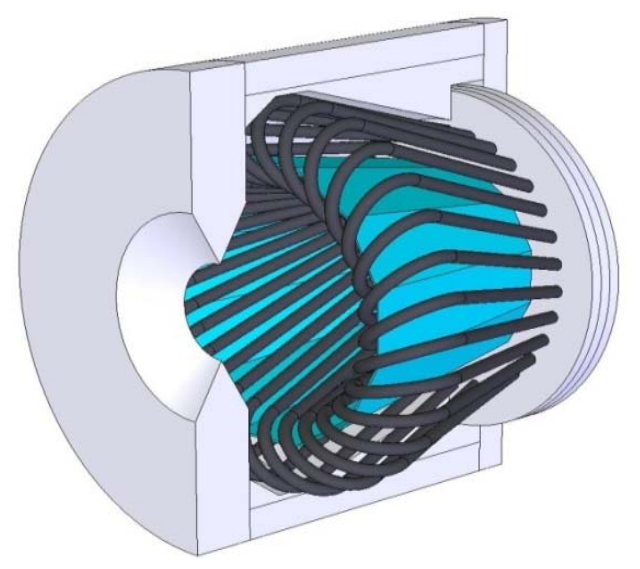

Figure 1 - Sunexus Solar Reformer Design $S R 1$

The $\boldsymbol{S R} \mathbf{1}$ design consists of 30 parallel u-tubes positioned at an angle in order to optimize the catalyst volume in the solar heated cavity. A back plane consists of three plates that have integrated gas entry and gas exit channels. In operation, gas enters the outer portion of the utube and is preheated as it travels towards the front. After the turn the gas enters the catalystpacked tube section in the interior of the reformer (Figure 2). An aperture allows for the concentrated solar energy to enter the Sunexus Solar Reformer to heat the internal chamber with reduced radiation losses.

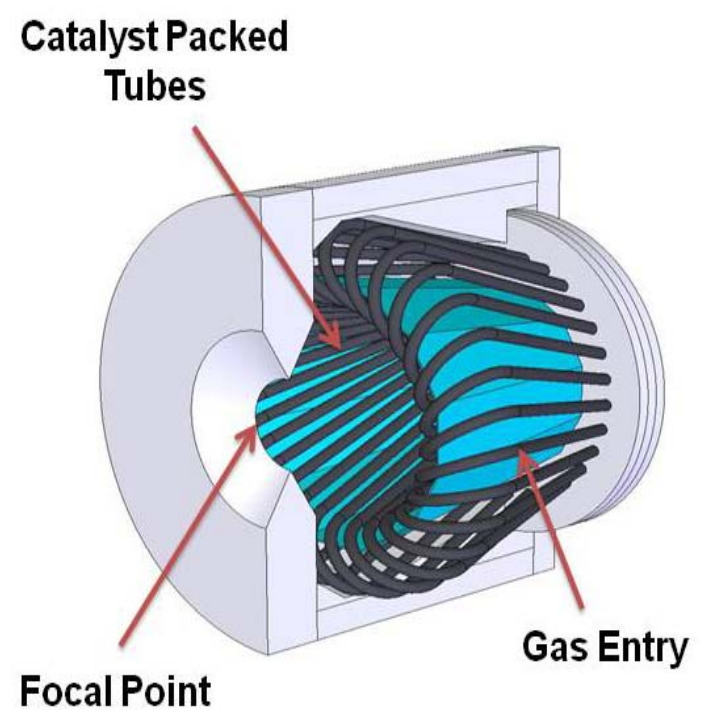

Figure 2 - Sunexus Solar Reformer Design SR1 Features

The catalyst packed tubes of the SR1 Solar Reformer form a tapered cavity into which concentrated solar energy is focused to conduct the reforming reaction. The cavity is approximately 16 inches in diameter at the front and tapers to 10 inches in diameter at the rear. The cavity tapered side length is 16.9 inches. The tubes have a diameter of $3 / 4$ an inch. A reflector in the cavity allows for the back side of the tubes to be heated by concentrated solar energy. Figure 3 shows a front view and solar cavity dimensions of the SR1 Solar Reformer. 


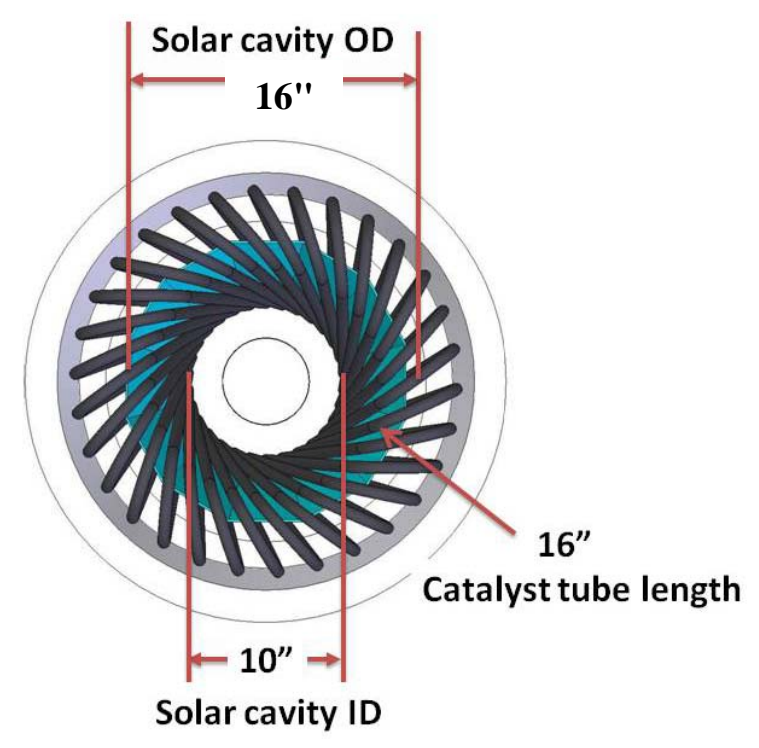

Figure 3 - Solar Reformer SR1 Dimensions (front view)

The multi-tubular design is used to provide easy scalability to commercial platforms. Gas Hourly Space Velocity (GHSV), which is a function of gas flows and catalyst volume, will stay the same from bench testing, demonstration scale testing, and commercial scales while tube length will be longer and tube diameter may increase for some commercial platforms. Optimal GHSV was studied over a variety of test conditions (see Section II.C) and results vary based on operating conditions (gas mix, temperature, etc.). A GHSV of up to $18,000 \mathrm{hr}^{-1}$ was achieved during the testing. These relatively high gas flows allow for good throughput in this small reactor system.

Concurrent with design efforts, detailed modeling on the Sunexus Reformer was conducted. The goal of the modeling was to compute the incident and absorbed solar heat flux profiles that will be achieved during the actual on sun testing (using dish-concentrators) and also that will be experienced for commercial plants and then simulate this environment in the Sunexus Solar Reformer testing. Modeling efforts are described below.

Figure 4 shows the computational mesh used to compute the incident and absorbed radiative flux distributions via the discrete ordinates algorithm using the FLUENT model. Rotational symmetry of the reformer geometry was exploited to reduce the computational requirements. A 12-degree section was modeled which reduced the model size by a factor of thirty. The mesh shown in Figure 4 is a 12-degree section of the interior volume of the reformer cavity (the air) and consists of 496,000 tetrahedral elements. 


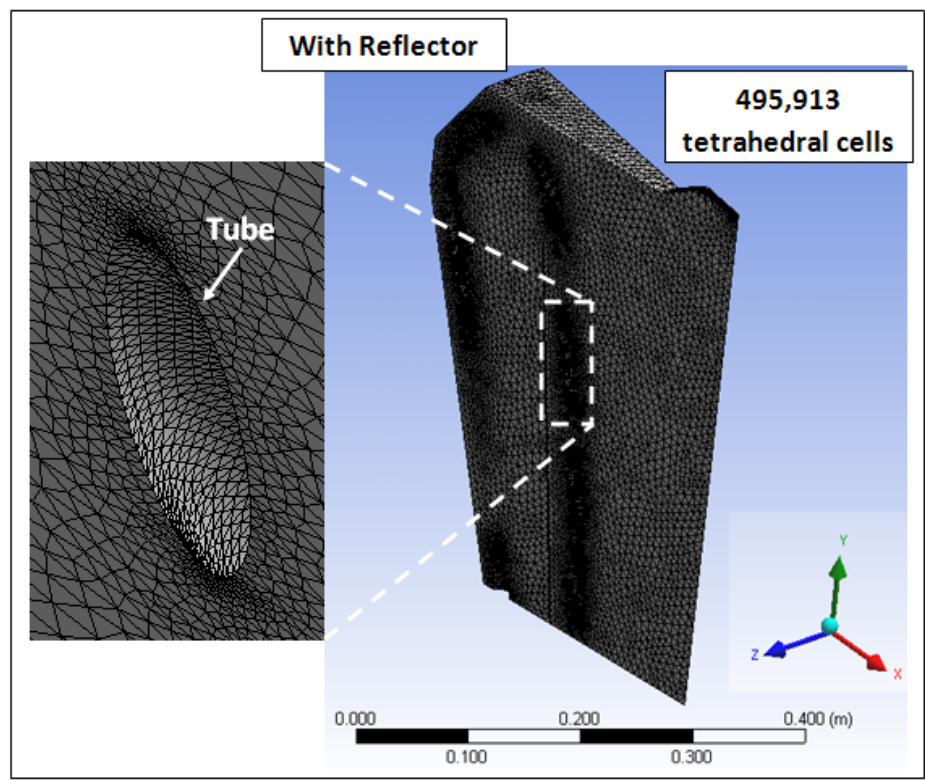

\section{Figure 4 - FLUENT Computational Mesh Used with Symmetry Boundary Conditions to Compute the Radiative Solar Flux Distribution}

The solar radiative flux at the aperture of the reformer was computed using the ASAP ray tracing software. A methodology was developed for applying the radiative flux distribution computed with ASAP as a "virtual radiative boundary" over the aperture of the Sunexus Solar Reformer in the FLUENT numerical model. Figure 5 shows the incident solar flux on the receiver tubes and the reflector computed with FLUENT using the "virtual radiative boundary" over the aperture.

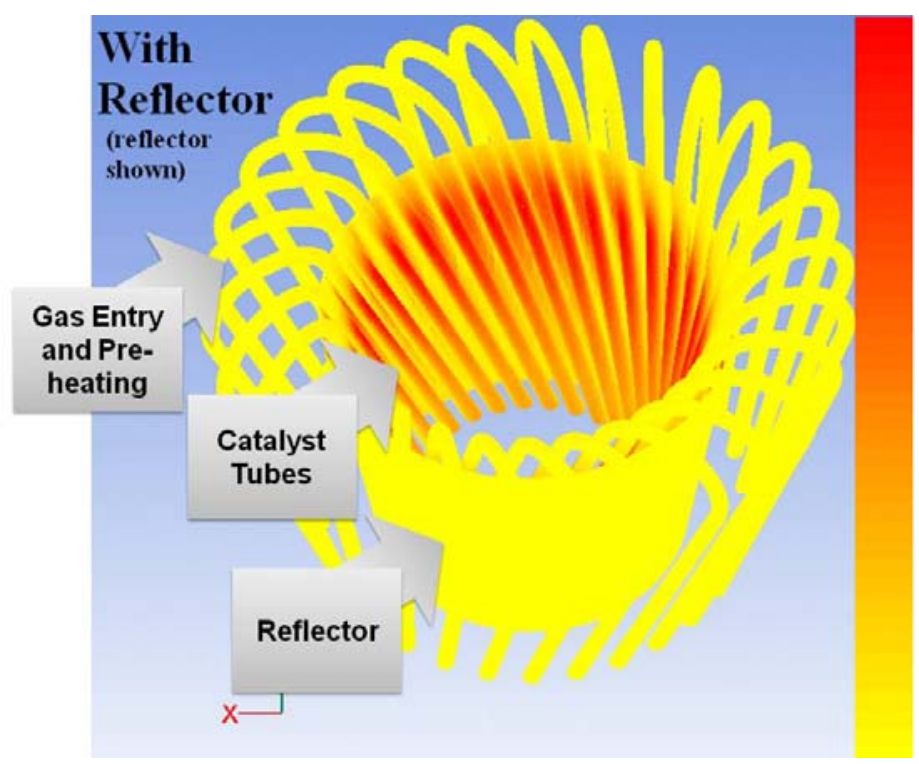

Figure 5 - Incident Solar Flux on Receiver Tubes 
Figure 6 shows the model with the cavity reflector hidden to show the heat flux on the back of the tubes. The reflector allows for tubes to be exposed to a more even heat flux distribution around the entire circumference of the tube.

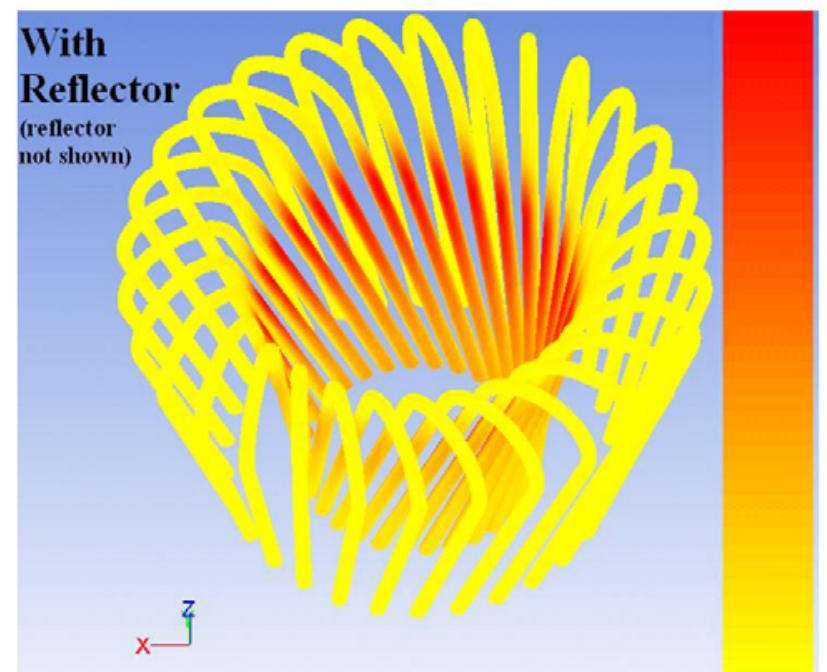

Figure 6 - Incident Solar Flux on Receiver Tubes

(Reflector not shown to show back of tubes)

Figure 7 shows the "virtual radiative boundary" flux profile that was representative of the distribution of solar flux entering the aperture as computed with ASAP. To assess the methodology of representing a dish concentrator using the "virtual radiative boundary" in FLUENT, comparisons of the FLUENT and ASAP computed radiative distributions within the reformer cavity were conducted. This comparison was conducted by evaluating the computed radiative flux on two planes within the reformer cavity. The comparisons are acceptable in terms of the flux distribution and the total energy intercepted by the planes.

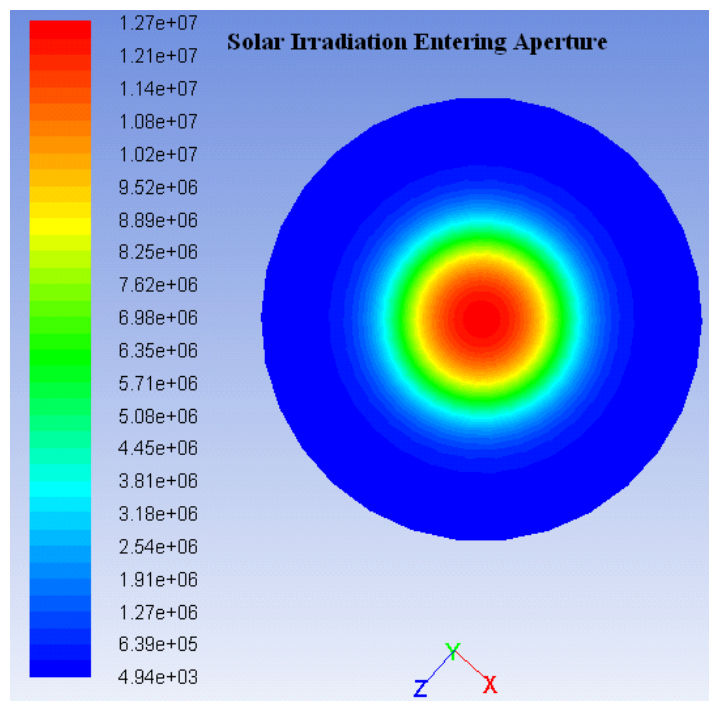

Figure 7 - Solar Irradiation Entering Aperture Applied as a "Virtual Radiative 
Figure 8 shows the radiative flux field as a function of radius from the cavity centerline (beam centroid) for the two planes considered (labeled as "middle" and "back" planes). The discreteordinates solution shows more spread near the outer radii, partly due to a loss of directional resolution which is better resolved in the ray-tracing algorithm. However, the FLUENT model captures more than $90 \%$ of the total energy in the ASAP beam. The comparisons are acceptable in terms of the flux distribution and the total energy intercepted by the planes.

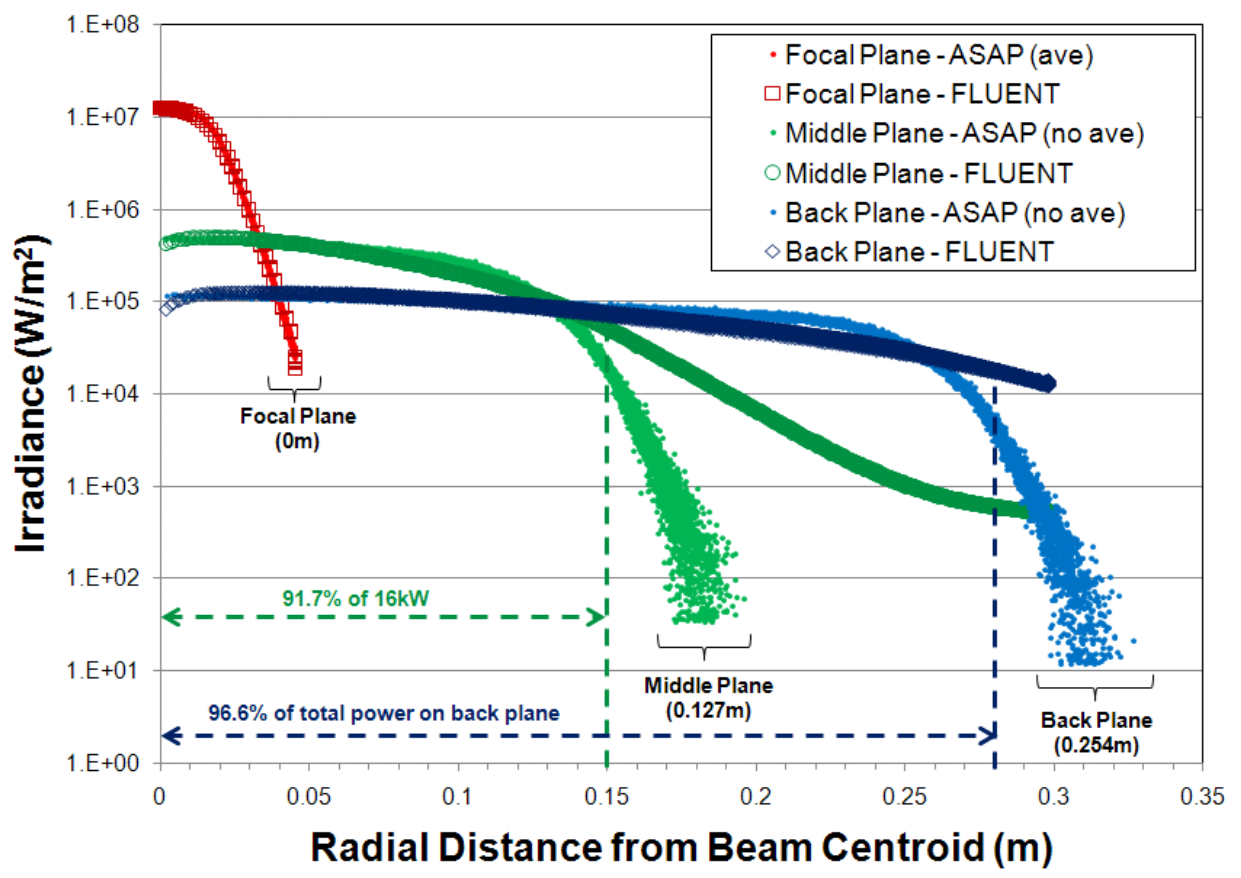

Figure 8 - Comparison of Radiative Flux Fields within the Reformer

Following design and modeling activities, a final solid model and CAD drawings were completed and materials of construction were selected in order to enable the fabrication of the Sunexus SR1 Solar Reformer.

In order to test Sunexus Solar Reformer in the lab, an electric heater was custom designed to provide the same power and heat flux to the interior of the Sunexus Solar Reformer. This heater uses Starbar ${ }^{\circledR}$ elements and was designed, fabricated, and installed in the Sunexus test skid, shown below in Figure 9. 

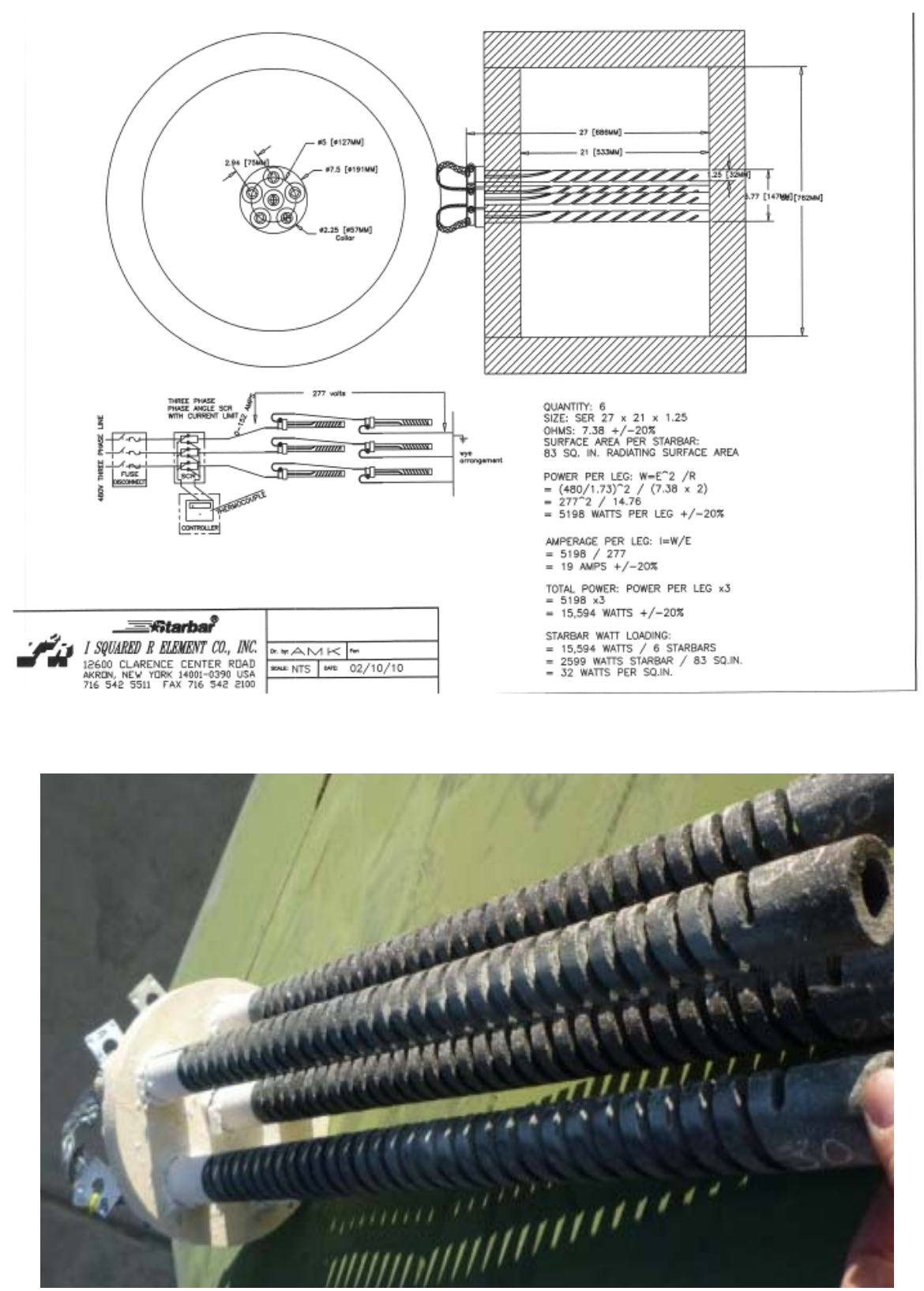

Figure 9 - Sunexus SR1 Heater constructed of six Starbar ${ }^{\circledR}$ elements

Figure 10 shows an exploded view of the reformer unit displaying the gas distribution plenums in the back planes. 


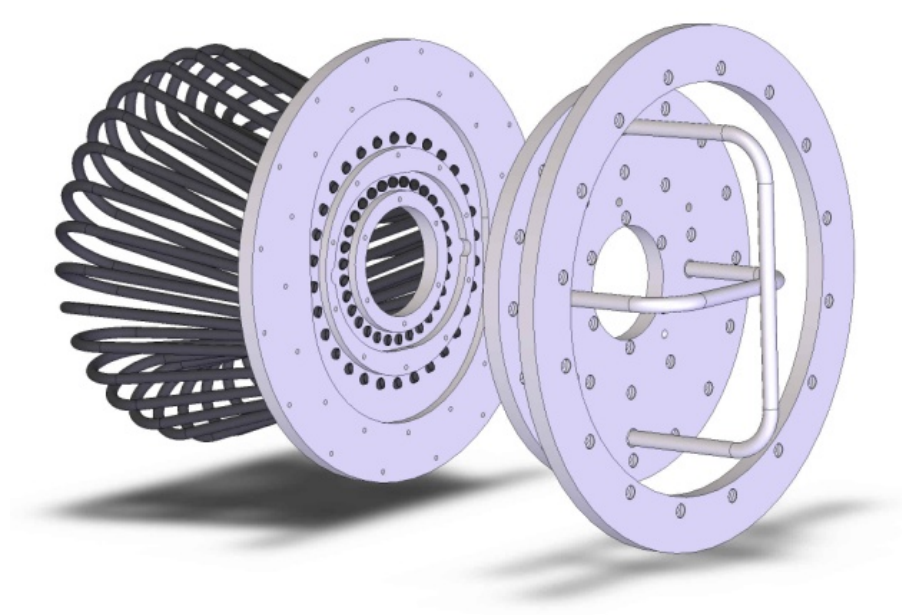

Figure 10 - Solid Model Showing Tubes and Back Plane Construction

Additional images of the reformer construction are provided below in Figure 11.
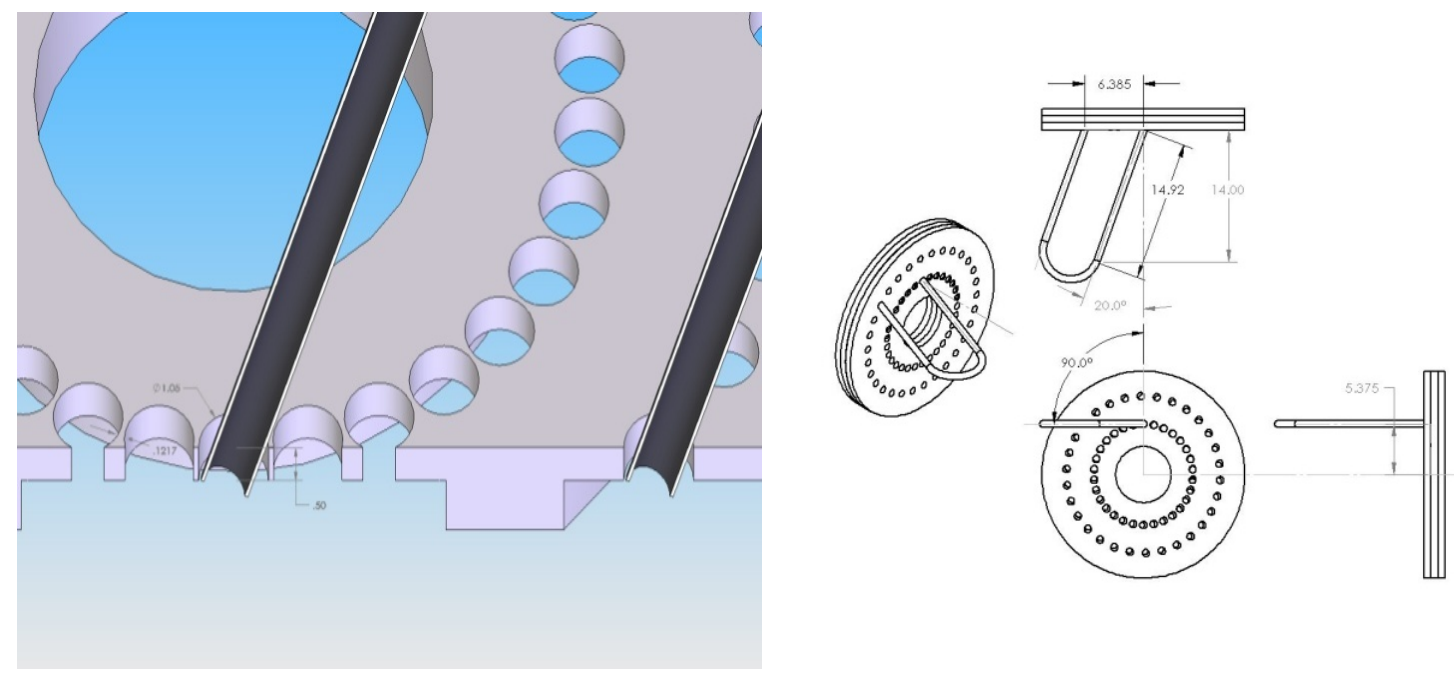

Figure 11 - Additional Design Detail for the Sunexus Solar Reformer SR1

To support the solar reactor testing, a test platform was designed with the required instrumentation and controls to facilitate the test plan. The test enclosure houses the Sunexus Solar Reformer and provides the data necessary to conduct parametric testing. When housed in the test enclosure, over 40 temperature points can be analyzed on the Sunexus Solar Reformer during parametric testing. Pressure, gas flows, product and reactant gas mix, and other details are logged once per second during testing and enable detailed analysis following a test campaign. Figure 12 shows the Sunexus test platform design that houses the Sunexus Solar Reformer for testing. 

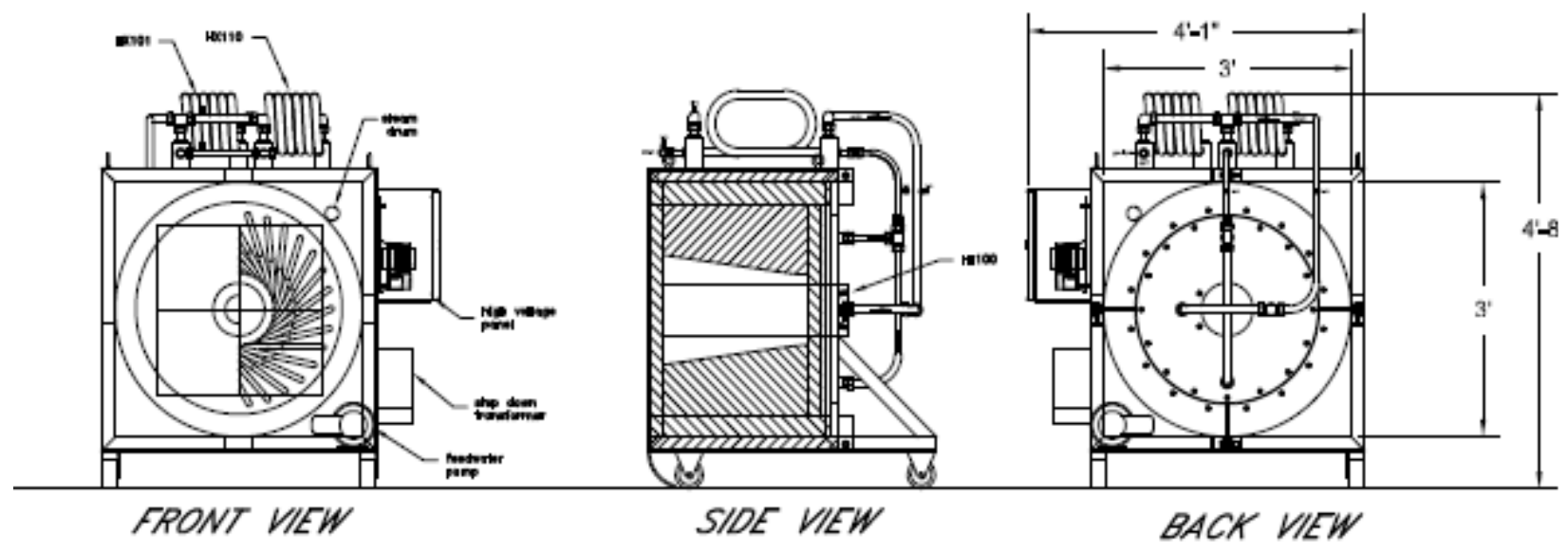

Figure 12 - Sunexus SR1 Test Platform Design

In addition to the test skid, a control skid was constructed that includes mass flow controllers, water storage, gas analysis and other items necessary to successfully complete the parametric testing. The P\&ID and GA for the test skid are shown below in Figure 13 and Figure 14. 


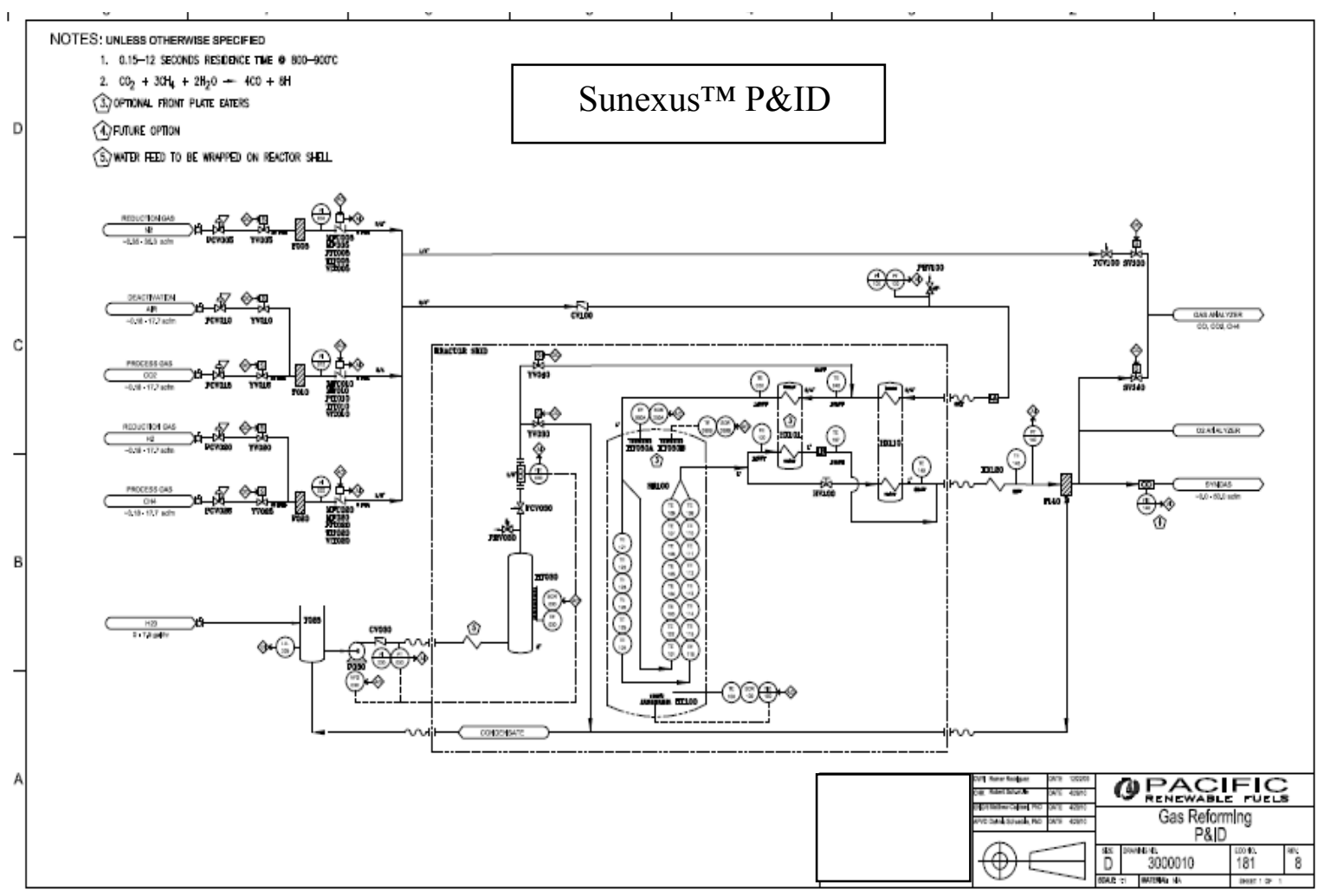

Figure 13 - Sunexus Test Platform P\&ID

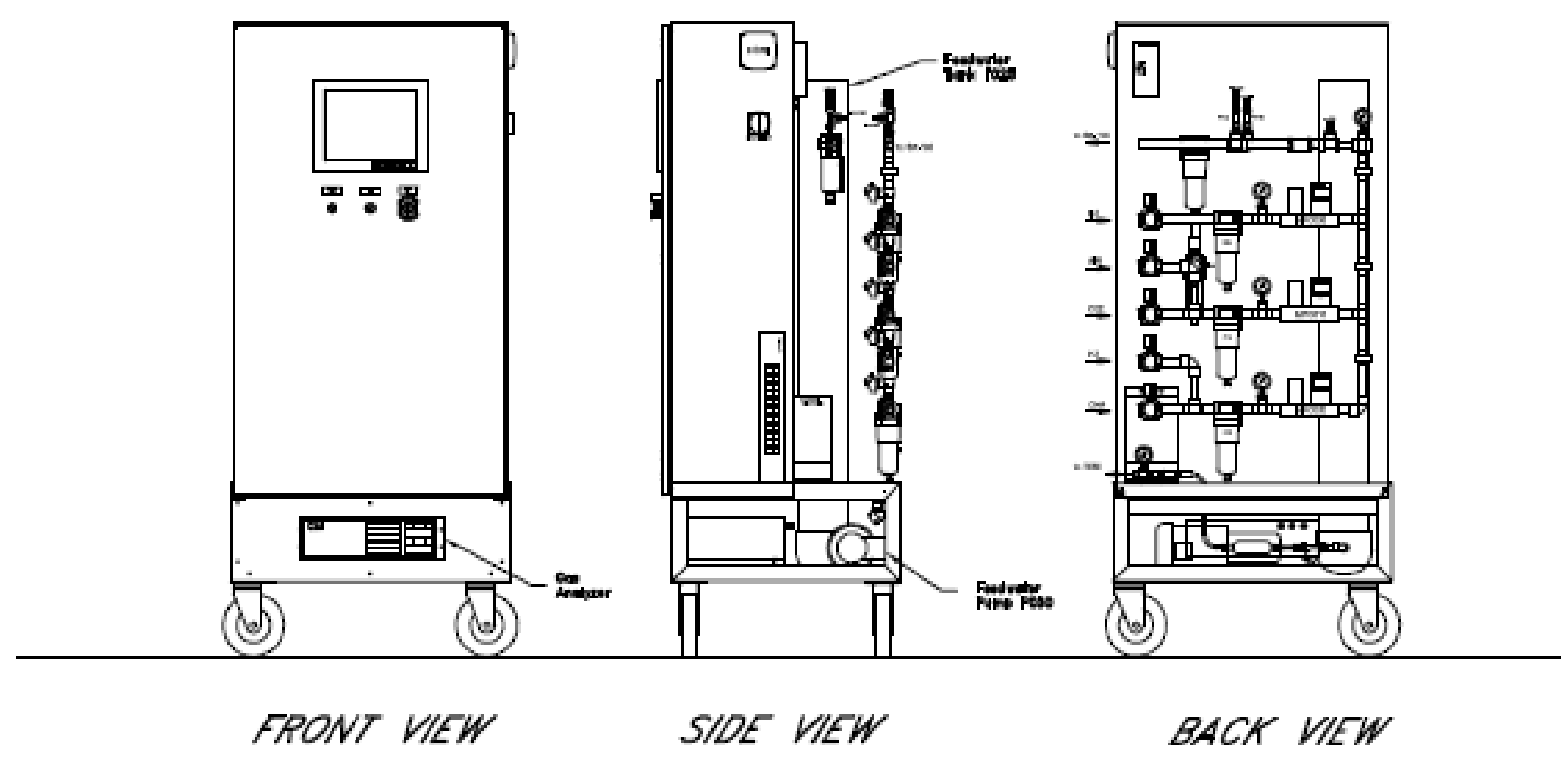

Figure 14 - Sunexus Test Platform Control Panel 


\section{B. Construction of the Sunexus Solar Reformer SR1}

The test skid and control panel were constructed at the Pacific Renewable Fuels and Chemicals engineering and test facility in Sacramento, California. Photos of this equipment are shown below in Figure 15.
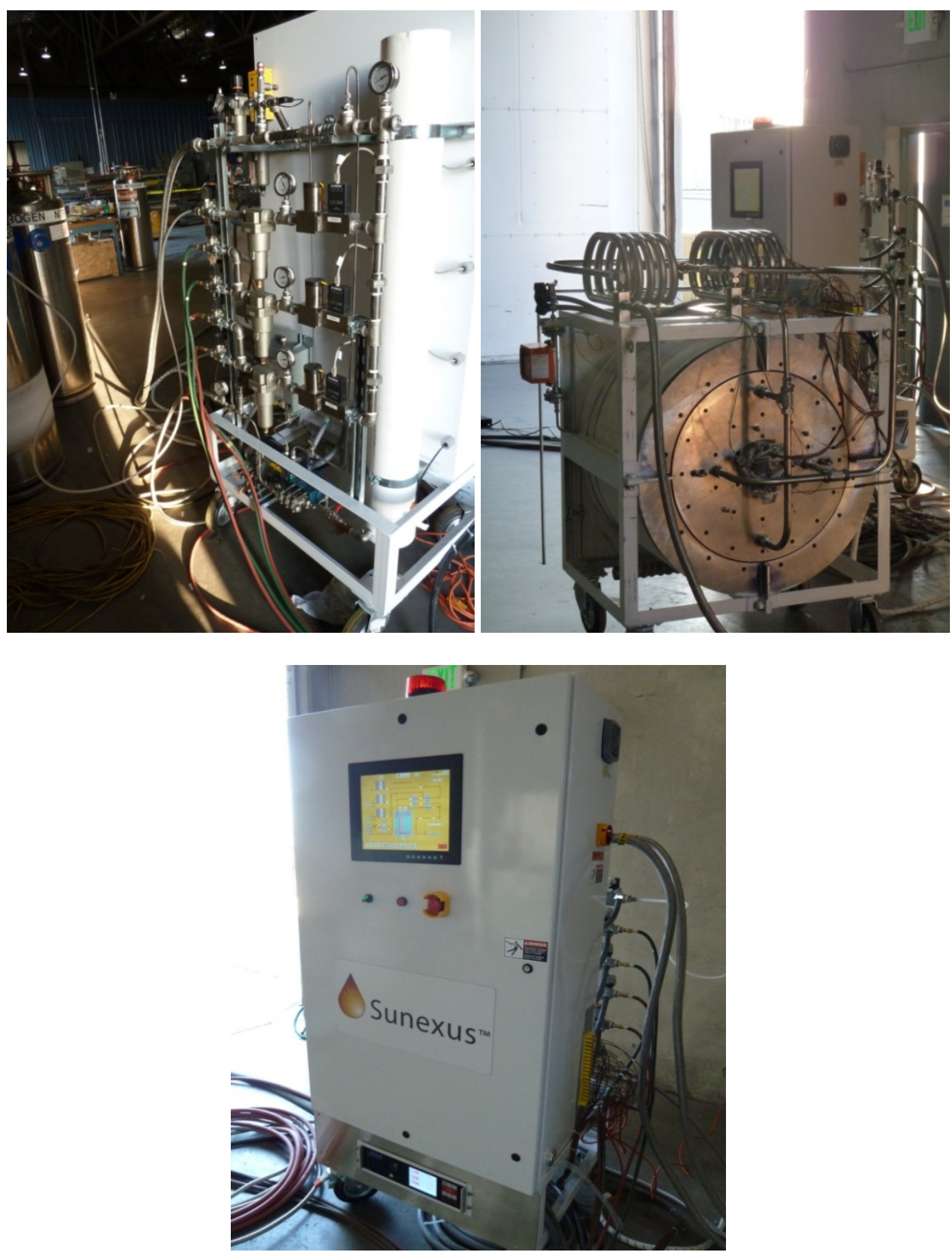

Figure 15 - Sunexus $S R 1$ Test Platform 
Due to the angling of the u-tubes in the Sunexus SR1 design, the tubes enter the back plane at a complicated compound angle. This was fabricated in a time efficient and cost effective manner using high pressure water cutting. Figure 16 shows a photo of the Sunexus back plane.

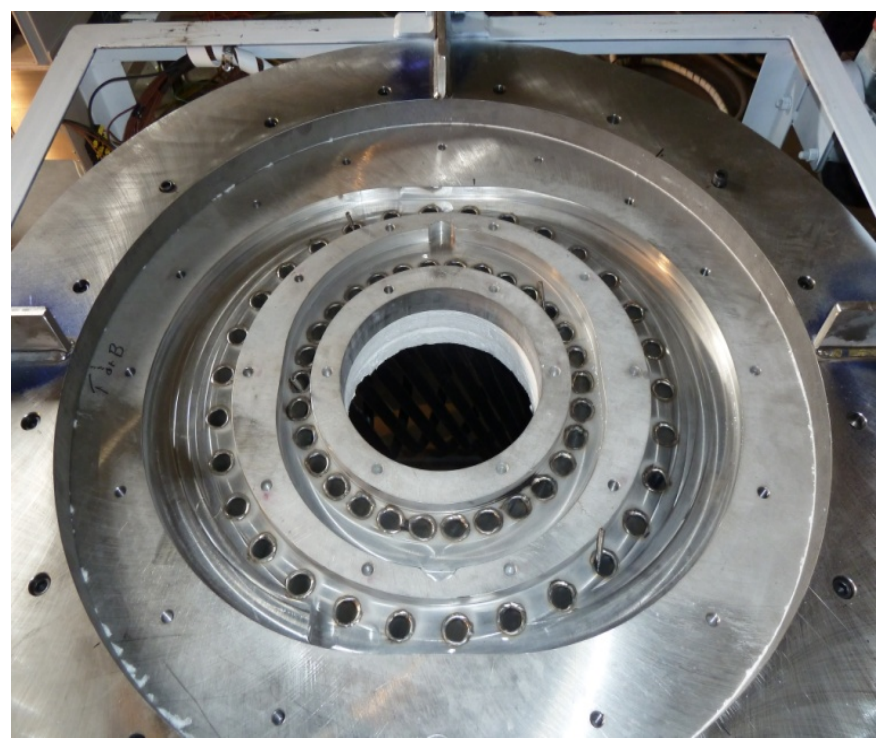

Figure 16 - Sunexus SR1 Back Plane

The Sunexus Reformer tubes were constructed on Inconel ${ }^{\circledR} 325$, a high temperature alloy. These tubes were coated with Pyromark ${ }^{\circledR}$ 2500, a super black material that allows for more efficient heat absorption. Materials selection was based on known practices in the concentrating solar industry and direct experience and success with these materials over time on previous and current Sandia concentrating solar projects. The reformer was mounted in an insulated cavity as part of the test platform. Photos of the assembled Sunexus Solar Reformer next to the design drawing are shown below in Figure 17.
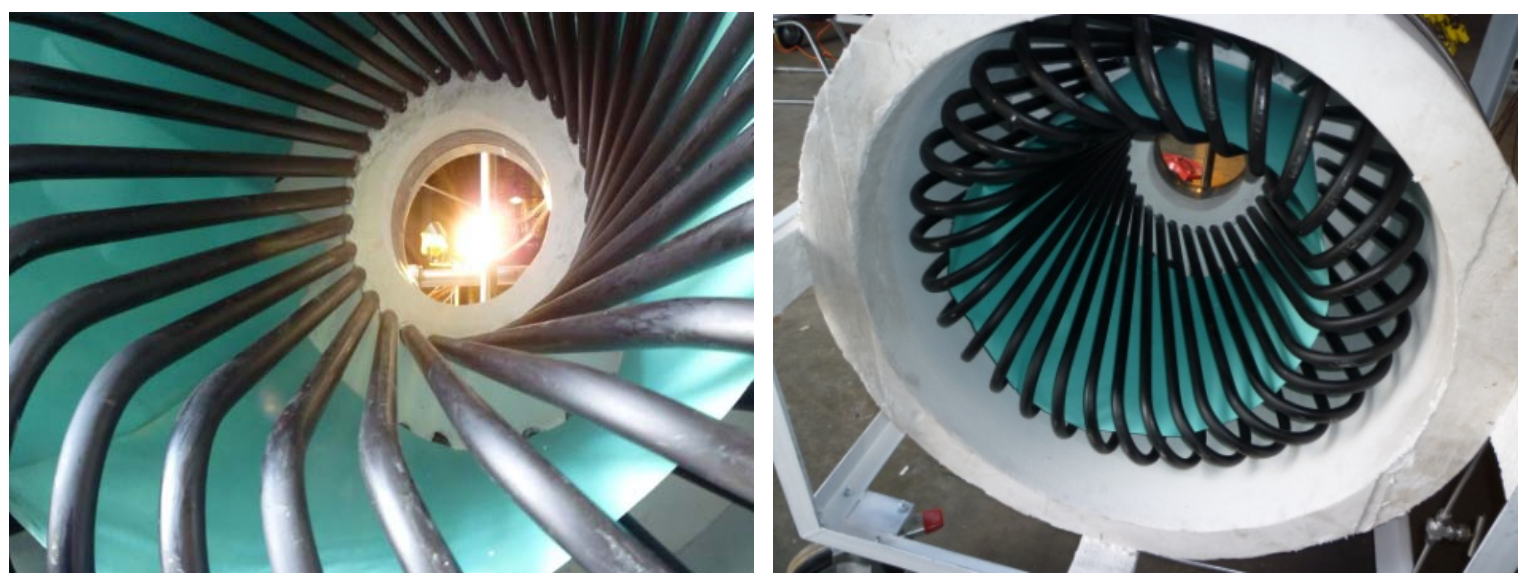

Figure 17 - Sunexus Solar Reformer SR1 
Catalyst is loaded into the Sunexus Solar Reformer through the back plane. Figure 18 shows the Solar Reformer being loaded with the reforming catalyst.

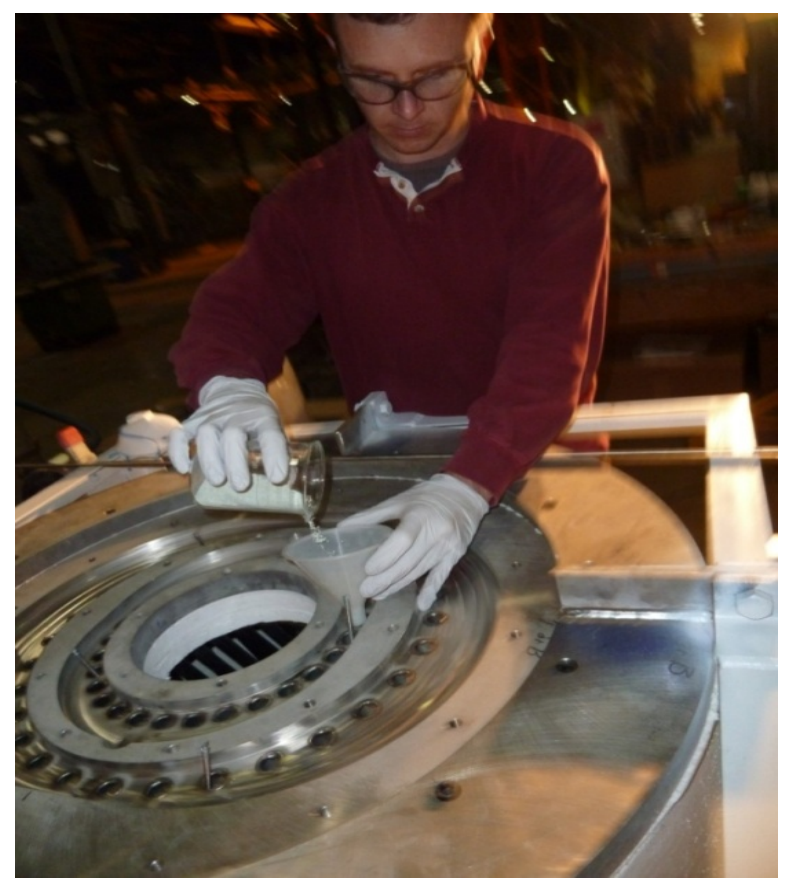

Figure 18 - Catalyst Loading into the Sunexus Reformer SR1

A control system panel was built and programming to perform the required tests and to $\log$ and analyze data from the test platform was completed. Screen shots and photos of the Sunexus test skid control platform are shown below in Figures 19-24.

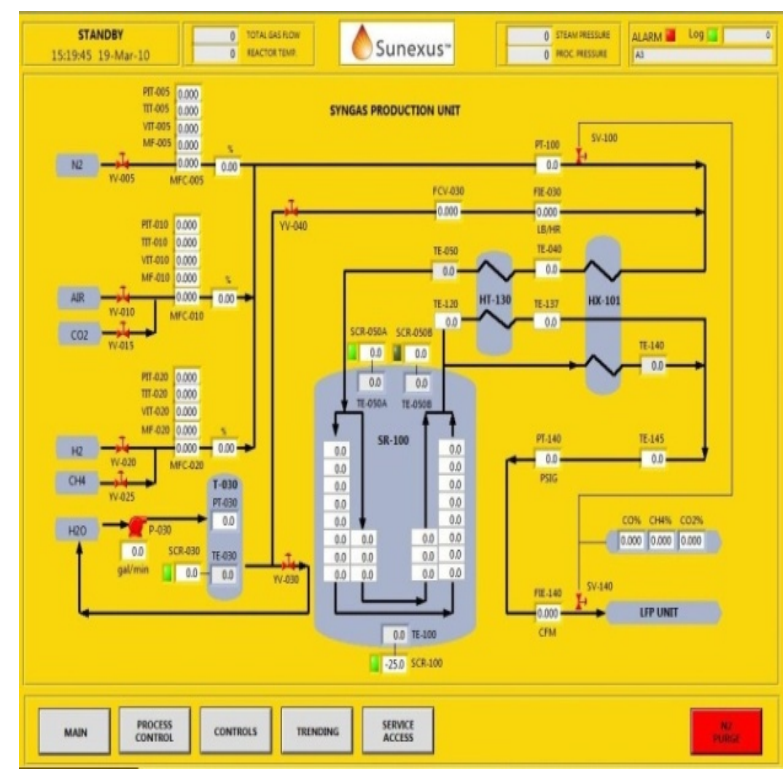

Figure 19 - Main Control Screen

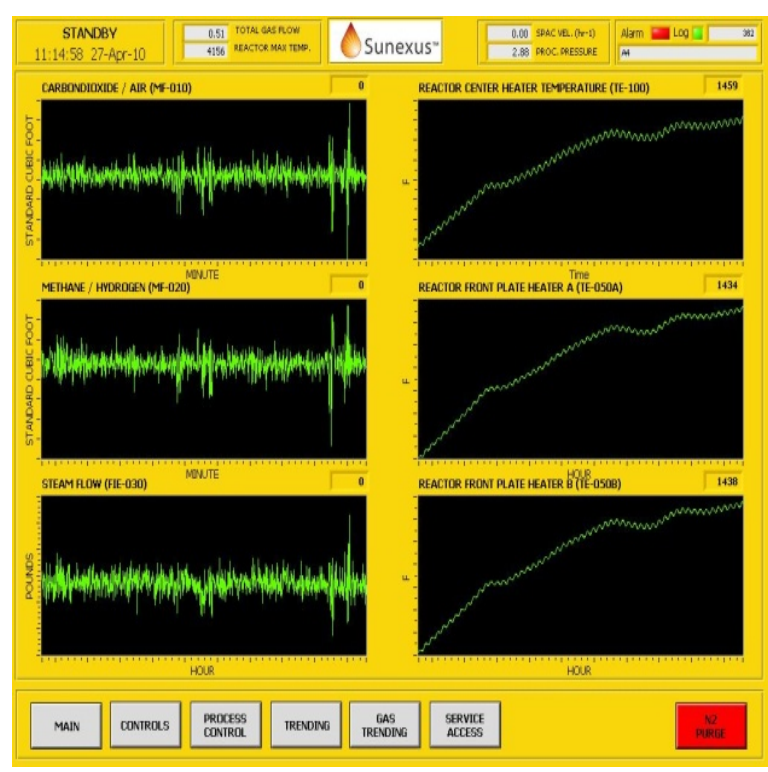

Figure 20 - Trend Analysis 


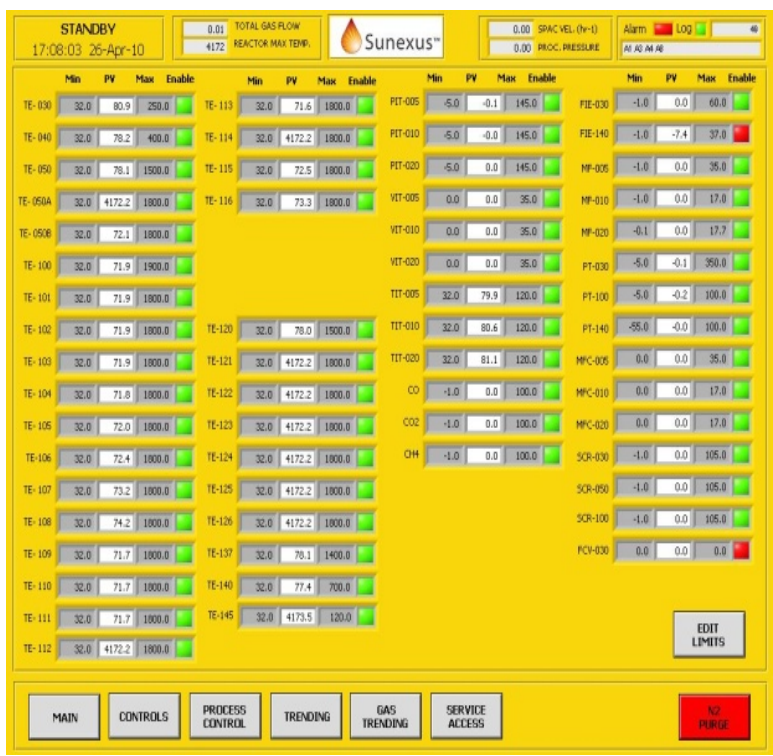

Figure 21 - Limits/Alarms

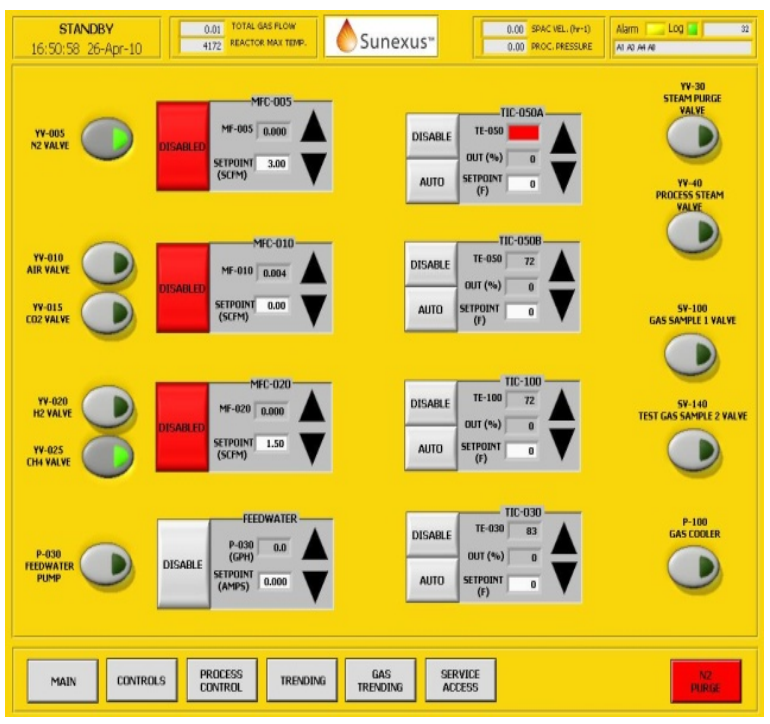

Figure 23 - Set Points and Manual Process Control

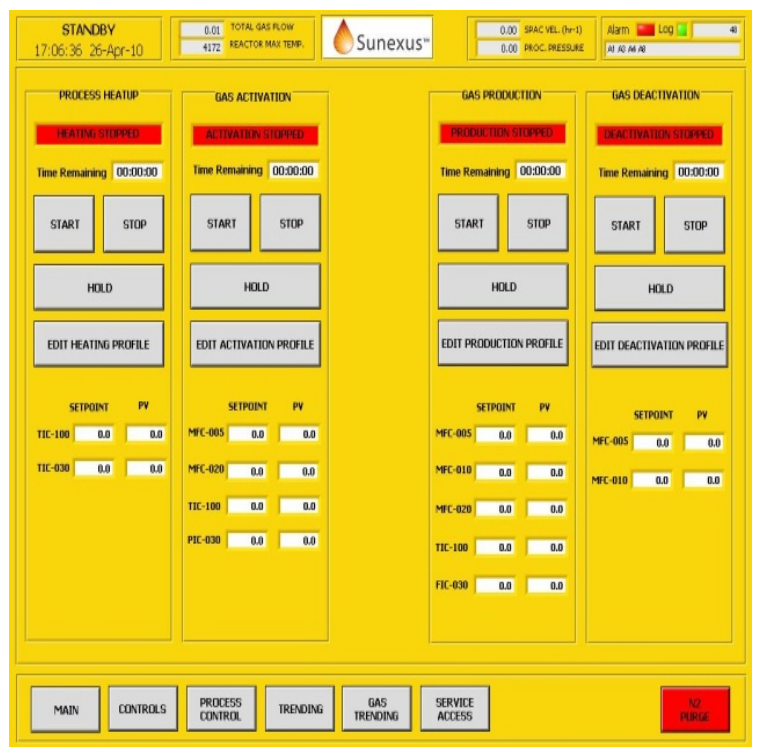

Figure 22 - Automated Process and Test Scripts

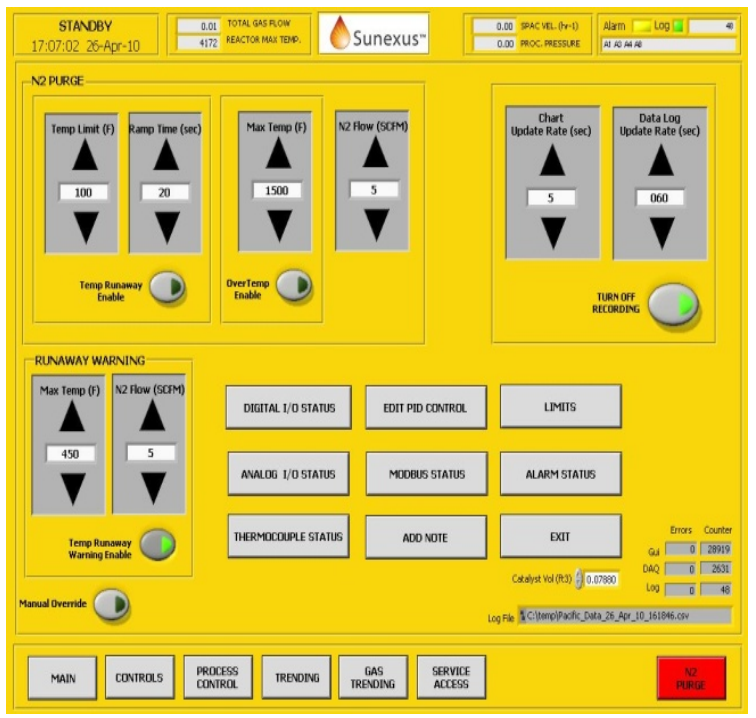

Figure 24 - Safety, Logging, and Maintenance Settings

As part of the test platform, several types of gas analysis are used to analyze reactants and products during the test runs. First, an infrared analyzer (NDIR) is used to analyze $\mathrm{CO}_{2}, \mathrm{CO}$, and $\mathrm{CH}_{4}$ in real time (Figure 25). Next, a gas analyzer is used to look at hydrogen, higher hydrocarbons (if any), and to validate the $\mathrm{CO}_{2}, \mathrm{CO}$, and $\mathrm{CH}_{4}$ results from the infrared detector (Figure 26). For some tests, a mass spectrometer was also used as a final check that gas composition data results are accurate (Figure 27). When oxygen was used as part of the feed gas for the tri-reforming studies (see Section II.D for test results and discussion), a real time oxygen analyzer was used (Figure 28). 


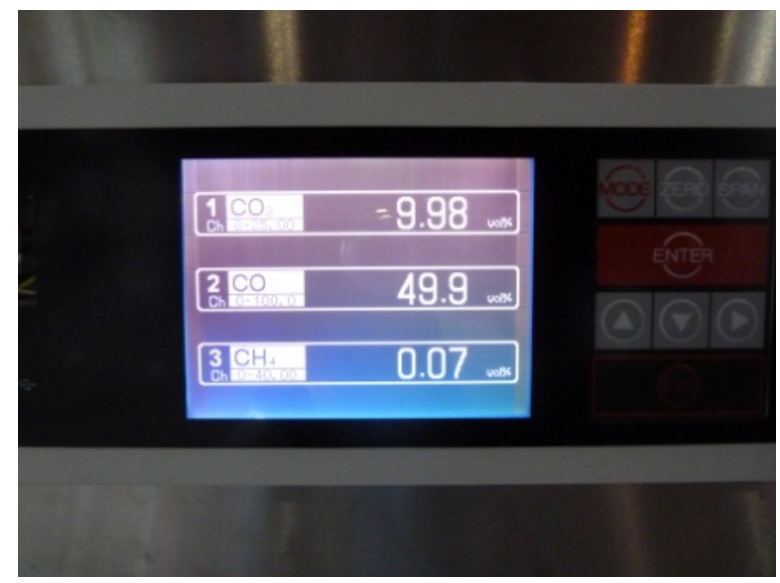

Figure 25 - Infrared Detector (real time $\mathrm{CO}_{2}, \mathrm{CO}, \mathrm{CH}_{4}$ )

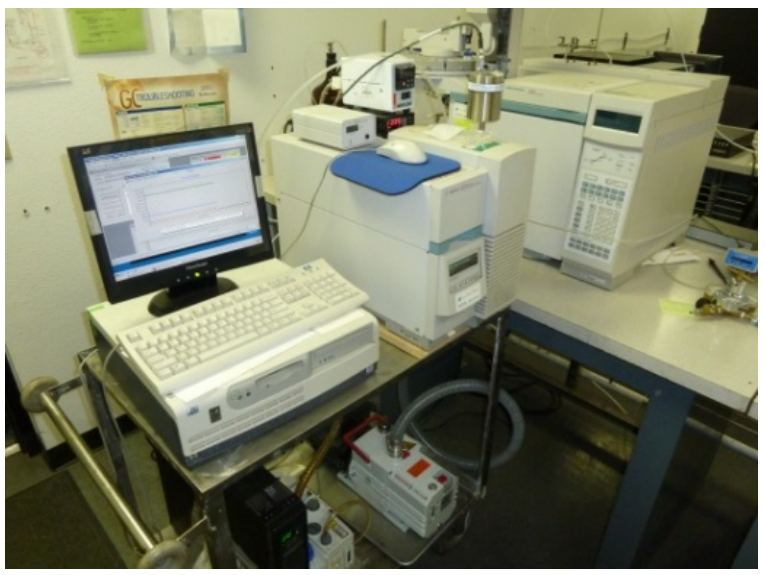

Figure 27 - Mass Spectrometer

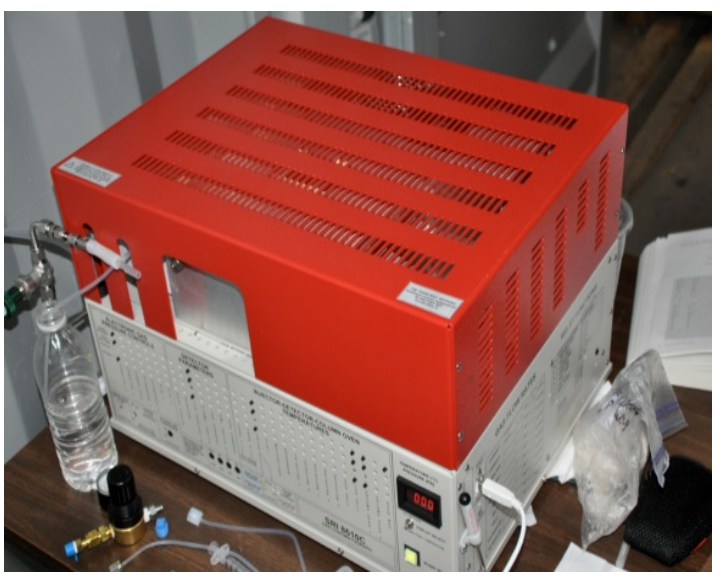

Figure 26 - Gas Chromatograph

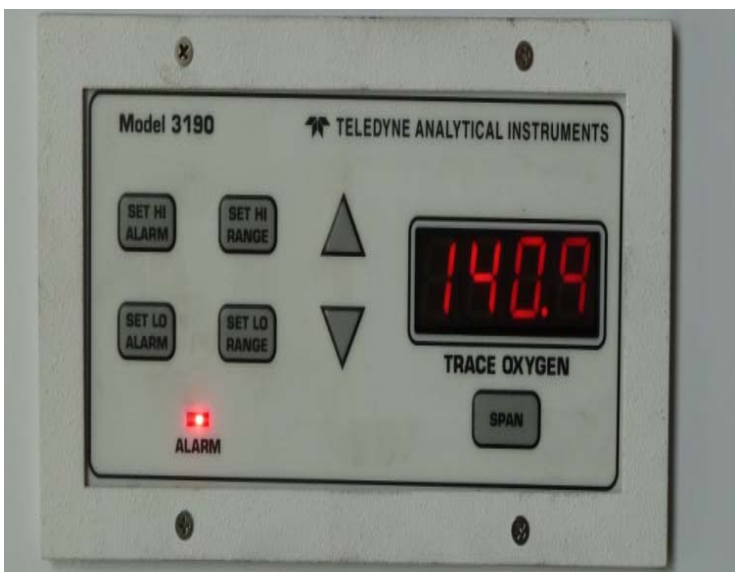

Figure 28 - Oxygen Analyzer

Over 500 data points (temperature, pressure, gas flows, gas mix, gas composition, etc.) are logged every second by the Sunexus control system in order to allow for detailed analysis of the data. Upon completion and check out of the Sunexus Solar Reformer and associated test platform and controls, bottled gases were supplied and parametric testing was conducted as described below in Section IID.

\section{Development of the Sunexus $\mathrm{CO}_{2} \underline{\text { Solar Reforming Catalyst }}$}

Many types of catalyst formulations have been reported in the literature for the reforming of $\mathrm{CO}_{2}$. However, these catalyst formulations did not meet the following criteria for this project:

- Exhibits high thermal stability up to $1,100{ }^{\circ} \mathrm{C}$

- Does not produce elemental carbon when operating under a variety of test conditions.

- Has good resistance to contaminants that may be present in captured $\mathrm{CO}_{2}$ streams.

- Can be reduced in-situ

- Exhibits good physical hardness and will not physically degrade over time

- Will efficiently convert $\mathrm{CO}_{2}$ with the following gas mixtures. 
A number of $\mathrm{CO}_{2}$ reforming catalysts were prepared and tested under a variety of conditions to identify the best candidate catalyst for testing in Phase I of this NETL project. As a result, a proprietary, Ni-based reforming catalyst was identified which appeared to meet the six criteria listed above. This catalyst will be referred to as the "proprietary Ni-based catalyst" in this paper.

The recommended maximum contaminant levels that we have established for captured $\mathrm{CO}_{2}$ and $\mathrm{CO}_{2}$ in flue gas streams is summarized in Table 2.

\section{Table 2 - Maximum Recommended Contaminant Levels for the} Proprietary Ni-Based Reforming Catalyst

\begin{tabular}{|l|l|}
\hline $\begin{array}{l}\text { Catalyst } \\
\text { Contaminants }\end{array}$ & $\begin{array}{l}\text { Average Maximum } \\
\text { Recommended } \\
\text { Contaminant Levels }\end{array}$ \\
\hline Total $\mathrm{H}_{2} \mathrm{~S}, \mathrm{COS}$ and $\mathrm{SO}_{2}$ & $<200 \mathrm{ppb}$ \\
\hline Oxygen $\left(\mathrm{O}_{2}\right)$ & $<60,000 \mathrm{ppm}$ \\
\hline Total Non-Methane HC's & $<50,000 \mathrm{ppm}$ \\
\hline Ammonia $\left(\mathrm{NH}_{3}\right)$ & $<1,000 \mathrm{ppb}$ \\
\hline Hydrogen Chloride $(\mathrm{HCl})$ & $<20 \mathrm{ppb}$ \\
\hline Total Particulate Matter $(\mathrm{PM})$ & $<500 \mu \mathrm{g} / \mathrm{m}^{3}$ \\
\hline
\end{tabular}

Since the Pacific Renewable Fuels and Chemicals (PRFC) Terra ${ }^{\mathrm{TM}}$ "designer" catalyst chosen for this project is more sensitive to contaminants than the proprietary Ni-based reforming catalyst (Table 3), it will be necessary to reduce the concentration of some of these contaminants before $\mathrm{CO}_{2}$ reforming. PRFC has developed an efficient gas scrubber that can reduce the potential catalyst poisons to acceptable levels. 


\section{Table 3 - Maximum Recommended Contaminant Levels for the PRFC Terra Designer Catalyst for the Conversion of Syngas to Synthetic Diesel Fuel}

\begin{tabular}{|l|l|}
\hline Catalyst Contaminants & $\begin{array}{l}\text { Maximum Recommended } \\
\text { Contaminant Levels }\end{array}$ \\
\hline $\mathrm{H}_{2} \mathrm{~S}$ and COS & $<20 \mathrm{ppb}$ \\
\hline Sulfur Dioxide $\left(\mathrm{SO}_{2}\right)$ & $<20 \mathrm{ppb}$ \\
\hline Oxygen $\left(\mathrm{O}_{2}\right)$ & $<1,000 \mathrm{ppm}$ \\
\hline Toluene $\left(\mathrm{C}_{7} \mathrm{H}_{8}\right)$ and Xylenes $\left(\mathrm{C}_{8} \mathrm{H}_{10}\right)$ & $<5 \mathrm{ppm}$ \\
\hline Ammonia $\left(\mathrm{NH}_{3}\right)$ & $<50 \mathrm{ppb}$ \\
\hline Hydrogen $\mathrm{Chloride}(\mathrm{HCl})$ & $<50 \mu \mathrm{g} / \mathrm{m}^{3}$ \\
\hline Nitric Acid $(\mathrm{HNO})$ & $<50 \mu \mathrm{g} / \mathrm{m}^{3}$ \\
\hline Total Particulate $\mathrm{Matter}(\mathrm{PM})$ & $<500 \mu \mathrm{g} / \mathrm{m}^{3}$ \\
\hline
\end{tabular}

\section{Laboratory Testing of the Sunexus $\mathrm{CO}_{2} \underline{\text { Reforming Catalyst and SR1 Reformer }}$}

The Sunexus solar reformers are designed to convert $\mathrm{CO}_{2}$ rich gas streams into syngas using a custom reforming catalyst. Extensive parametric testing on the solar reformer and associated catalysts was conducted. Temperatures, gas flow rates, gas mix, and other parameters were varied in order to establish performance metrics for commercial plants. Kinetic models for the catalysts were developed and these were integrated into the process model for the integrated system. A fully integrated process model was completed based on actual test results.

Over 1,750 hours of testing was conducted on the Sunexus reformer/reactor and associated catalysts. Data and summaries are provided below. The goals of the Sunexus solar reformer testing were as follows:

- Maximize the single pass $\mathrm{CO}_{2}$ conversion of the solar reformer

- Minimize the amount of $\mathrm{CH}_{4}$ needed as a reactant (as this effects commercial economics for some industrial sources - see discussion on commercial economics)

- Produce a suitable syngas for subsequent liquid fuel production

- Assess the lifetime of the catalysts in commercial operation by assessing known deactivation mechanisms such as carbon deposition (coking), sintering, and deactivation due to gas contaminants

- Determine optimal operating conditions (GHSV, temperature) and test under a range of temperatures that exist under solar reforming conditions

- Maximize reactor throughput by finding the optimal GHSV during testing 
- Achieve target commercial economics by using a cost effective catalyst and reactor design materials

A key advantage of the Sunexus Solar $\mathrm{CO}_{2}$ Reformer design is that it can accept a range of feed gas streams and still produce acceptable syngas for the subsequent production of diesel fuel. The ability to use a range of feed gases provides flexibility in co-locating Sunexus plants at a variety of industrial emissions sources that have different flue gas compositions or different techniques and costs for $\mathrm{CO}_{2}$ separation.

A variety of experiments were conducted to determine the ideal operating conditions. The matrix of experimental tests was carried out under a variety of pressures, space velocities and temperatures as follows:

- Dry reforming $\left(\mathrm{CO}_{2} \& \mathrm{CH}_{4}\right)$

- Combination dry-steam reforming $\left(\mathrm{CO}_{2}+\mathrm{H}_{2} \mathrm{O} \& \mathrm{CH}_{4}\right)$

- Tri-reforming $\left(\mathrm{CO}_{2}+\mathrm{H}_{2} \mathrm{O}+\mathrm{O}_{2} \& \mathrm{CH}_{4}\right)$

- Long term stability tests

Each test mixture contained nitrogen which was used as an internal standard to assist in quantitative analysis of the gas products. The analytical instruments used to measure the composition of the syngas products (after water removal) were illustrated in Figures 25-28.

The matrix of differential tests conducted for the candidate catalyst is summarized in Table 4. Kinetic data was derived by running catalysts under a variety of conditions in a single tube/channel. As is typical in deriving kinetic data, the tests were conducted at high space velocity to limit conversion to below a target of $20 \%$. Kinetic data was also gathered on-sun during subsequent tests and the data generated from these on-sun tests closely matched the data generated in the lab. Kinetic data was also used to help determine the performance of the candidate catalyst under a wide variety of target conditions. Some results from the activity testing are plotted in Figure 29 and 30 in the form of Arrhenius plots.

Based upon the Arrhenius plots generated under the various testing conditions, it is possible to model catalyst performance under a range of conditions. First, the slope and intercept of the Arrhenius plots were used to determine the activation energy and pre-exponential factors for the catalyst under different conditions.

In addition to the conditions shown, water gas shift activity was also tested. For each condition, at least four data points were collected and averaged over the course of a minimum of two hours. 


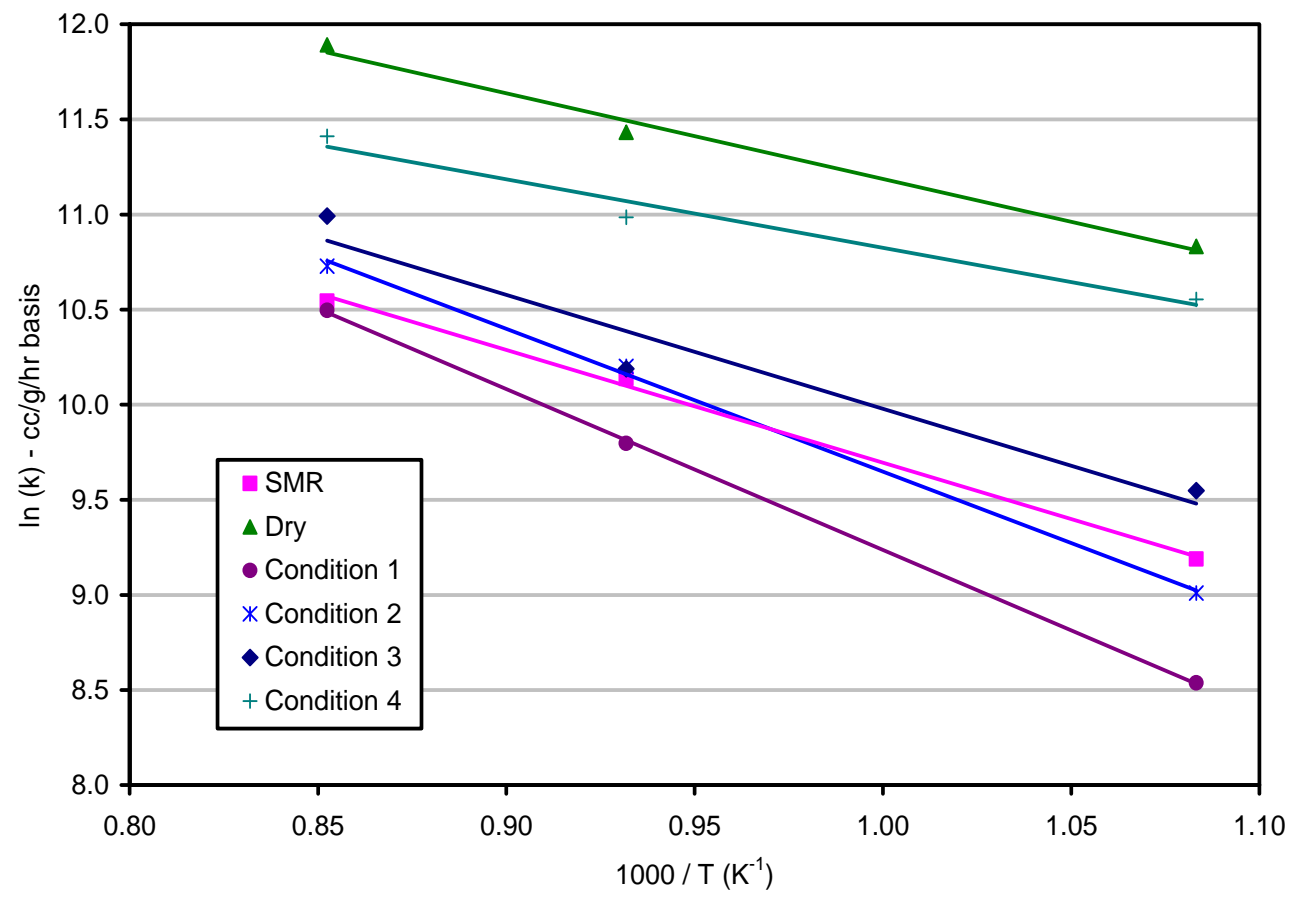

Figure 29 - Arrhenius Plot Results for the Sunexus Solar $\mathrm{CO}_{2}$ Reforming Catalyst

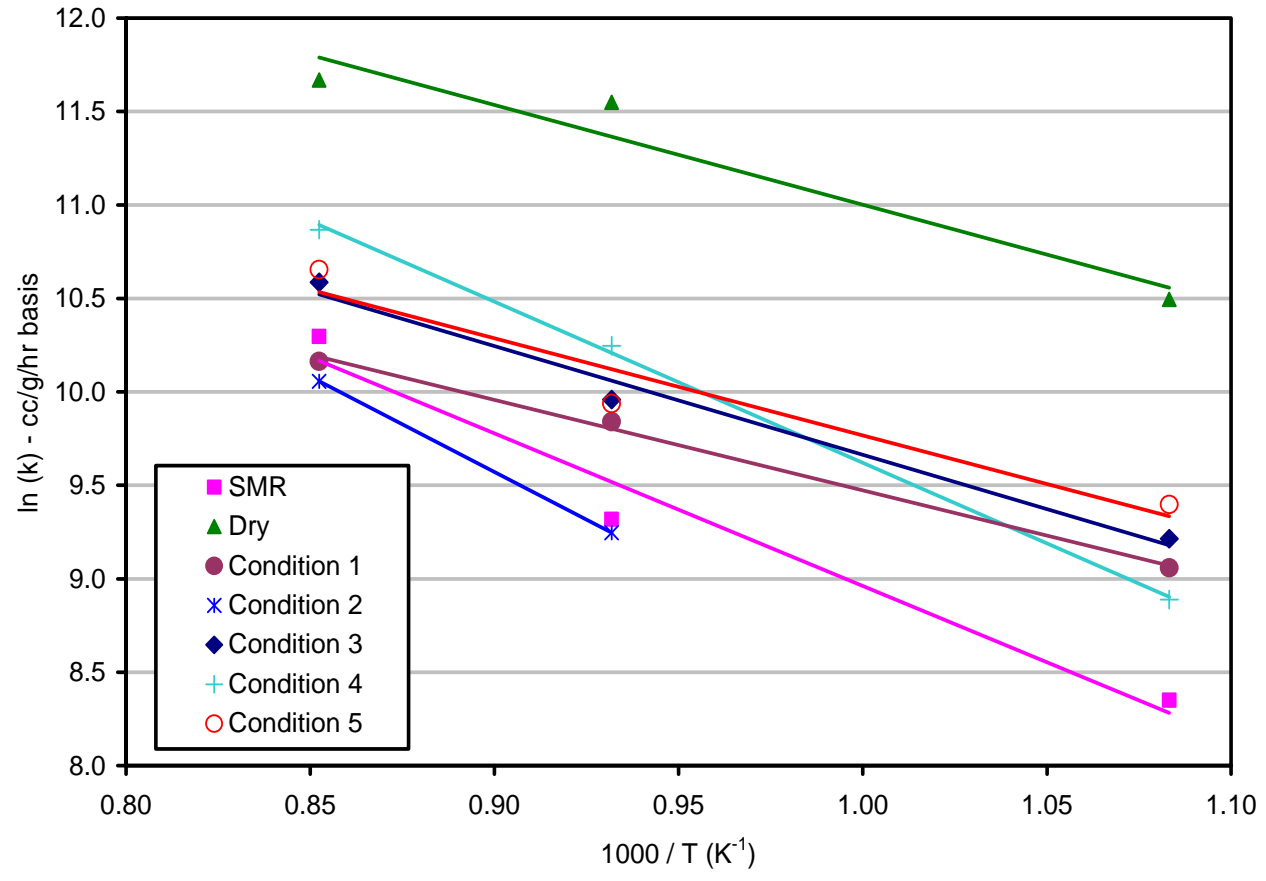

Figure 30 - Arrhenius Plot Results for the Sunexus Solar $\mathrm{CO}_{2}$ Reforming Catalyst 
Table 4 - Matrix of Kinetic Catalyst Tests

\begin{tabular}{|c|c|c|c|c|c|c|c|}
\hline \multirow{2}{*}{$\begin{array}{l}\text { Temp. } \\
\left({ }^{\circ} \mathrm{C}\right)\end{array}$} & \multirow{2}{*}{$\begin{array}{l}\text { Reforming } \\
\text { Condition }\end{array}$} & \multicolumn{4}{|c|}{ Gas Feed } & \multicolumn{2}{|c|}{ Ratios } \\
\hline & & $\mathrm{CH}_{4}$ & $\mathrm{CO}_{2}$ & $\mathrm{H}_{2} \mathrm{O}$ & CO & $\mathrm{CO}_{2} / \mathrm{CH}_{4}$ & $\mathrm{H}_{2} \mathrm{O} / \mathrm{CH}_{4}$ \\
\hline 650 & SMR & $25.0 \%$ & $0.0 \%$ & $75.0 \%$ & $0.0 \%$ & - & 3 \\
\hline 800 & SMR & $25.0 \%$ & $0.0 \%$ & $75.0 \%$ & $0.0 \%$ & - & 3 \\
\hline 900 & SMR & $25.0 \%$ & $0.0 \%$ & $75.0 \%$ & $0.0 \%$ & - & 3 \\
\hline 650 & Dry & $25.0 \%$ & $75.0 \%$ & $0.0 \%$ & $0.0 \%$ & 3 & - \\
\hline 800 & Dry & $25.0 \%$ & $75.0 \%$ & $0.0 \%$ & $0.0 \%$ & 3 & - \\
\hline 900 & Dry & $25.0 \%$ & $75.0 \%$ & $0.0 \%$ & $0.0 \%$ & 3 & - \\
\hline 650 & 1 & $25.0 \%$ & $25.0 \%$ & $50.0 \%$ & $0.0 \%$ & 1 & 2 \\
\hline 800 & 1 & $25.0 \%$ & $25.0 \%$ & $50.0 \%$ & $0.0 \%$ & 1 & 2 \\
\hline 900 & 1 & $25.0 \%$ & $25.0 \%$ & $50.0 \%$ & $0.0 \%$ & 1 & 2 \\
\hline 650 & 2 & $28.6 \%$ & $14.3 \%$ & $57.1 \%$ & $0.0 \%$ & 0.5 & 2 \\
\hline 800 & 2 & $28.6 \%$ & $14.3 \%$ & $57.1 \%$ & $0.0 \%$ & 0.5 & 2 \\
\hline 900 & 2 & $28.6 \%$ & $14.3 \%$ & $57.1 \%$ & $0.0 \%$ & 0.5 & 2 \\
\hline 650 & 3 & $31.3 \%$ & $6.3 \%$ & $62.5 \%$ & $0.0 \%$ & 0.2 & 2 \\
\hline 800 & 3 & $31.3 \%$ & $6.3 \%$ & $62.5 \%$ & $0.0 \%$ & 0.2 & 2 \\
\hline 900 & 3 & $31.3 \%$ & $6.3 \%$ & $62.5 \%$ & $0.0 \%$ & 0.2 & 2 \\
\hline 650 & 4 & $33.3 \%$ & $33.3 \%$ & $33.3 \%$ & $0.0 \%$ & 1 & 1 \\
\hline 800 & 4 & $33.3 \%$ & $33.3 \%$ & $33.3 \%$ & $0.0 \%$ & 1 & 1 \\
\hline 900 & 4 & $33.3 \%$ & $33.3 \%$ & $33.3 \%$ & $0.0 \%$ & 1 & 1 \\
\hline 650 & 5 & $40.0 \%$ & $20.0 \%$ & $40.0 \%$ & $0.0 \%$ & 0.5 & 1 \\
\hline 800 & 5 & $40.0 \%$ & $20.0 \%$ & $40.0 \%$ & $0.0 \%$ & 0.5 & 1 \\
\hline 900 & 5 & $40.0 \%$ & $20.0 \%$ & $40.0 \%$ & $0.0 \%$ & 0.5 & 1 \\
\hline
\end{tabular}

Table 5 provides the activation energy and pre-exponential factors calculated from those plots. The dry reforming parameters were determined for each catalyst; however, due to the spread and instability of the steam tests, average activation and pre-exponential values were determined for the steam reactions. The activation energy was similar for each catalyst and each reaction. 


\section{Table 5 - Activation Energy and Pre-Exponential Factor Results for the Sunexus Solar $\mathrm{CO}_{2}$ Reforming Catalyst}

\begin{tabular}{|l|l|c|c|}
\hline Catalyst & Reaction & $\mathbf{E}_{\mathbf{A}}(\mathbf{k J} / \mathbf{m o l})$ & $\mathbf{A}(\mathbf{c c} / \mathbf{g} / \mathbf{h r})$ \\
\hline $\begin{array}{l}\text { Sunexus } \\
\text { Catalyst }\end{array}$ & Dry Reforming & 44.3 & $1.24 \mathrm{E}+07$ \\
\hline $\begin{array}{l}\text { Sunexus } \\
\text { Catalyst }\end{array}$ & $\begin{array}{l}\text { Steam/Dry } \\
\text { Reforming }\end{array}$ & 40.2 & $1.64 \mathrm{E}+06$ \\
\hline
\end{tabular}

Based on the activation energy, pre-exponential factors and the reaction order, a reactor can be sized for a range of conditions. The first step is to calculate the rate constant for the reaction, as is shown in Equation A below:

$$
\mathrm{k}(\mathrm{T})=\mathrm{A} \exp \left(-\mathrm{E}_{\mathrm{A}} / \mathrm{RT}\right) \quad(\text { Equation } \mathrm{A})
$$

Where:

$\mathbf{k}(\mathrm{T})$ is the rate constant as a function of temperature in units of standard cubic centimeters of methane per gram catalyst per hour.

A is the pre-exponential factor for the reaction and catalyst

$\mathbf{E}_{\mathbf{A}}$ is the activation energy for the reaction and catalyst

$\mathbf{R}$ is the gas constant

$\mathbf{T}$ is the absolute temperature

After $\mathbf{k}(\mathbf{T})$ is determined, the space velocity (and consequently the catalyst loading per given flow rate) can be calculated for a first order reaction from Equation B.

$$
\mathrm{t}^{-1}=\mathrm{k}(\mathrm{T}) / \ln (1-\mathrm{X}) \quad(\text { Equation } \mathrm{B})
$$

Where:

$\mathbf{t}^{-1}$ is the space velocity

$\mathbf{k}(\mathbf{T})$ is the rate constant as a function of temperature

$\mathbf{X}$ is the conversion ratio of the reactant $\left(\mathrm{CH}_{4}\right)$

Using this procedure, the maximum space velocity for $99 \%$ conversion of methane was predicted for a range of reactant feeds and temperatures, as shown in Table 6. For these calculations it had to be assumed that the reaction rate was first order with respect to methane, which would be consistent with methane activation being the rate limiting step. 


\section{Table 6 - Prediction of Space Velocity for $99 \%$ Methane Conversion at Various Conditions}

\begin{tabular}{|l|l|l|l|l|}
\hline Catalyst & Reaction & $\begin{array}{l}\text { Temp. } \\
\left({ }^{\circ} \mathrm{C}\right)\end{array}$ & $\begin{array}{l}\mathrm{k}_{\mathrm{CH} 4} \\
\left(\mathrm{cc} / \mathrm{g}_{\mathrm{cat}} / \mathrm{hr}\right)\end{array}$ & $\begin{array}{l}\text { Target SV } \\
\left(\mathrm{hr}^{-1}\right)\end{array}$ \\
\hline $\begin{array}{l}\text { Sunexus } \\
\text { Catalyst }\end{array}$ & Dry Reforming & 800 & $8.63 \mathrm{E}+04$ & 24,985 \\
\hline $\begin{array}{l}\text { Sunexus } \\
\text { Catalyst }\end{array}$ & Dry Reforming & 900 & $1.32 \mathrm{E}+05$ & 38,160 \\
\hline $\begin{array}{l}\text { Sunexus } \\
\text { Catalyst }\end{array}$ & $\begin{array}{l}\text { Steam/Dry Combo } \\
\text { Reforming }\end{array}$ & 800 & $1.81 \mathrm{E}+04$ & 5,237 \\
\hline $\begin{array}{l}\text { Sunexus } \\
\text { Catalysts }\end{array}$ & $\begin{array}{l}\text { Steam/Dry Combo } \\
\text { Reforming }\end{array}$ & 900 & $2.66 \mathrm{E}+04$ & 7,690 \\
\hline
\end{tabular}

Thermodynamic calculations were performed to help guide predictions with respect to product selectivity and to determine limits for methane conversion. Table 7 lists the equilibrium product compositions for the activity test matrix, as determined by Gibbs free energy minimization of the possible products. Full methane conversion is expected at $800^{\circ} \mathrm{C}$ and $900^{\circ} \mathrm{C}$, but several percent may remain at $650^{\circ} \mathrm{C}$ depending on the feed ratio. At $800-900^{\circ} \mathrm{C}$, in order to obtain a product with the target $\mathrm{H}_{2} / \mathrm{CO}$ ratio of $1.8 / 1.0$ to $2.2 / 1.0$, equilibrium calculations predict that a ratio of $\sim 2.0 / 1.0 \mathrm{H}_{2} \mathrm{O} / \mathrm{CH}_{4}$ and $1.0 / 1.0 \mathrm{CO}_{2} / \mathrm{CH}_{4}$ will be required in the gas feed. 
Table 7 - Predicted Equilibrium Product Calculation Results for Activity Test Conditions

\begin{tabular}{|c|c|c|c|c|c|c|c|c|c|}
\hline \multirow{2}{*}{$\left({ }^{\circ} \mathrm{C}\right)$} & \multirow{2}{*}{ Condition } & \multicolumn{2}{|c|}{ Feed Ratios } & \multicolumn{5}{|c|}{ Equilibrium Product } & \multirow{2}{\mathrm{CO}_{2}/}{} \\
\hline $\mathrm{CH}_{4}$ & $\begin{array}{c}\mathrm{H}_{2} \mathrm{O} / \\
\mathrm{CH}_{4}\end{array}$ & $\mathrm{H}_{2}$ & $\mathrm{CH}_{4}$ & $\mathrm{CO}$ & $\mathrm{CO}_{2}$ & $\mathrm{H}_{2} \mathrm{O}$ & $\mathrm{H}_{2} / \mathrm{CO}$ \\
\hline 650 & $\mathrm{SMR}$ & - & 3 & $54.7 \%$ & $1.6 \%$ & $7.6 \%$ & $8.0 \%$ & $28.1 \%$ & 7.2 \\
\hline 800 & $\mathrm{SMR}$ & - & 3 & $55.7 \%$ & $0.0 \%$ & $10.8 \%$ & $5.8 \%$ & $27.6 \%$ & 5.1 \\
\hline 900 & SMR & - & 3 & $54.8 \%$ & $0.0 \%$ & $11.8 \%$ & $4.8 \%$ & $28.5 \%$ & 4.6 \\
\hline 650 & Dry & 3 & - & $22.6 \%$ & $2.0 \%$ & $38.8 \%$ & $28.6 \%$ & $8.1 \%$ & 0.6 \\
\hline 800 & Dry & 3 & - & $22.6 \%$ & $0.0 \%$ & $44.0 \%$ & $22.7 \%$ & $10.7 \%$ & 0.5 \\
\hline 900 & Dry & 3 & - & $21.0 \%$ & $0.0 \%$ & $45.6 \%$ & $21.0 \%$ & $12.3 \%$ & 0.5 \\
\hline 650 & 1 & 1 & 2 & $43.9 \%$ & $2.4 \%$ & $16.4 \%$ & $16.2 \%$ & $21.2 \%$ & 2.7 \\
\hline 800 & 1 & 1 & 2 & $44.8 \%$ & $0.1 \%$ & $21.8 \%$ & $11.6 \%$ & $21.9 \%$ & 2.1 \\
\hline 900 & 1 & 1 & 2 & $43.3 \%$ & $0.0 \%$ & $23.4 \%$ & $10.0 \%$ & $23.4 \%$ & 1.9 \\
\hline 650 & 2 & 0.5 & 2 & $50.5 \%$ & $3.2 \%$ & $14.1 \%$ & $11.7 \%$ & $20.5 \%$ & 3.6 \\
\hline 800 & 2 & 0.5 & 2 & $53.1 \%$ & $0.1 \%$ & $19.5 \%$ & $7.8 \%$ & $19.6 \%$ & 2.7 \\
\hline 900 & 2 & 0.5 & 2 & $52.0 \%$ & $0.0 \%$ & $20.8 \%$ & $6.5 \%$ & $20.7 \%$ & 2.5 \\
\hline 650 & 3 & 0.2 & 2 & $55.4 \%$ & $3.8 \%$ & $12.2 \%$ & $8.9 \%$ & $19.7 \%$ & 4.6 \\
\hline 800 & 3 & 0.2 & 2 & $59.2 \%$ & $0.1 \%$ & $17.4 \%$ & $5.6 \%$ & $17.6 \%$ & 3.4 \\
\hline 900 & 3 & 0.2 & 2 & $58.4 \%$ & $0.0 \%$ & $18.5 \%$ & $4.6 \%$ & $18.5 \%$ & 3.2 \\
\hline 650 & 4 & 1 & 1 & $42.9 \%$ & $5.4 \%$ & $24.1 \%$ & $14.8 \%$ & $12.8 \%$ & 1.8 \\
\hline 800 & 4 & 1 & 1 & $48.0 \%$ & $0.2 \%$ & $31.5 \%$ & $8.4 \%$ & $11.8 \%$ & 1.5 \\
\hline 900 & 4 & 1 & 1 & $47.1 \%$ & $0.0 \%$ & $32.9 \%$ & $7.1 \%$ & $12.9 \%$ & 1.4 \\
\hline 650 & 5 & 0.5 & 1 & $49.8 \%$ & $8.2 \%$ & $20.8 \%$ & $9.8 \%$ & $11.4 \%$ & 2.4 \\
\hline 800 & 5 & 0.5 & 1 & $58.8 \%$ & $0.5 \%$ & $29.1 \%$ & $4.1 \%$ & $7.6 \%$ & 2.0 \\
\hline 900 & 5 & 0.5 & 1 & $58.7 \%$ & $0.1 \%$ & $30.1 \%$ & $3.2 \%$ & $8.0 \%$ & 1.9 \\
\hline
\end{tabular}

While kinetic and predictive models are important in developing a baseline for testing, catalysts perform somewhat differently under full conversion tests so a variety of additional tests and full conversion testing using the Sunexus solar reformer were conducted to determine the ideal operating conditions for commercial plants including: 
- Dry reforming $\left(\mathrm{CO}_{2} \& \mathrm{CH}_{4}\right)$

- Combination dry-steam reforming $\left(\mathrm{CO}_{2} \& \mathrm{CH}_{4} \& \mathrm{H}_{2} \mathrm{O}\right)$

- Tri-reforming $\left(\mathrm{CO}_{2} \& \mathrm{CH}_{4} \& \mathrm{H}_{2} \mathrm{O} \& \mathrm{O}_{2}\right)$

- Long term stability tests

As outlined above, since oxygen is available in some future commercial flue gas streams, a tri-reforming approach would be used. Tri-reforming is typically defined as a combination of three techniques (dry and steam reforming plus partial oxidation). This combination of reactions produces syngas with a $\mathrm{H}_{2} / \mathrm{CO}$ ratio in the appropriate range for subsequent diesel fuel production. The reaction overall is still highly endothermic, since only a small percentage of oxygen is used in the feed.

As shown in Table 6, good conversion efficiencies were observed at high gas space velocities (high gas flows). For example, the change in the catalytic reforming rate $\left(\mathrm{dR}_{\mathrm{f}}\right)$ is directly proportional to gas space velocity as follows:

$$
\mathrm{dR}_{\mathrm{f}}=\left(\mathrm{SV}_{2} / \mathrm{SV}_{1}\right)^{1 / 2}
$$

Therefore, if the gas space velocity is increased by a factor of 4 , the catalytic reaction rate (e.g., conversion of $\mathrm{CO}_{2}$ to syngas) is increased by 2 times. The importance of this finding is that the amount of catalyst needed to reform a specific amount of $\mathrm{CO}_{2}$ will be greatly reduced when compared to catalysts that are only efficient at lower space velocities.

Note again that oxygen is not required for achieving the appropriate syngas ratio or for stable operation of the catalyst, but will be used for the demonstration since oxygen already exists in the flue gas stream. Reactions for the tests that were conducted are summarized below:

Dry Reforming: In Dry (or $\mathrm{CO}_{2}$ ) Reforming, methane and carbon dioxide are reacted and produce a syngas with low $\mathrm{H}_{2} / \mathrm{CO}$ ratio of 0.7-1.0:

$$
\begin{array}{ll}
\mathrm{CH}_{4}+\mathrm{CO}_{2} \stackrel{\text { heat }}{\longrightarrow} 2 \mathrm{CO}+2 \mathrm{H}_{2}, \quad & \Delta H_{298 K}^{o}=247 \mathrm{~kJ} \mathrm{~mol}^{-1} \\
& \Delta H_{1173 K}=258.5 \mathrm{~kJ} \mathrm{~mol}^{-1}
\end{array}
$$

Steam Reforming: Steam Methane Reforming (SMR) is an endothermic process where methane is reacted with steam at high temperatures to produce a syngas with a high $\mathrm{H}_{2} / \mathrm{CO}$ ratio:

$$
\begin{array}{ll}
\mathrm{CH}_{4}+\mathrm{H}_{2} \mathrm{O} \stackrel{\text { heat }}{\longrightarrow} \mathrm{CO}+3 \mathrm{H}_{2}, \quad & \Delta H_{298 K}^{o}=206 \mathrm{~kJ} \mathrm{~mol}^{-1} \\
& \Delta H_{1173 \mathrm{~K}}=225.7 \mathrm{~kJ} \mathrm{~mol}^{-1}
\end{array}
$$

Partial Oxidation: Reactions for the exothermic oxidation of methane are shown below: 


$$
\begin{aligned}
& \mathrm{CH}_{4}+2 \mathrm{O}_{2} \longrightarrow \mathrm{CO}_{2}+2 \mathrm{H}_{2} \mathrm{O} \\
& \mathrm{CH}_{4}+1.5 \mathrm{O}_{2} \longrightarrow \mathrm{CO}+2 \mathrm{H}_{2} \mathrm{O} \\
& \mathrm{CH}_{4}+1 / 2 \mathrm{O}_{2} \longrightarrow \mathrm{CO}+2 \mathrm{H}_{2}
\end{aligned}
$$

$\Delta H_{1173 K}=-802.5 \mathrm{~kJ} \mathrm{~mol}^{-1} \quad 3$

$\Delta H_{1173 \mathrm{~K}}=-520.6 \mathrm{~kJ} \mathrm{~mol}^{-1} \quad 4$

$\Delta H_{1173 \mathrm{~K}}=-23.1 \mathrm{~kJ} \mathrm{~mol}^{-1} \quad 5$

Water-Gas-Shift Equilibrium: The Water-Gas Shift (WGS) equilibrium reaction, equation 6, also occurs during reforming and will adjust the final syngas product ratio depending on how the equilibrium is influenced. If, for instance, dry reforming is conducted in an excess of $\mathrm{CO}_{2}$, then the reverse WGS will be favored which will increase the CO content and produce water. Likewise, excess steam in the SMR reaction will tend to drive the forward water gas shift resulting in higher $\mathrm{H}_{2}$ and some $\mathrm{CO}_{2}$ products.

$$
\mathrm{CO}+\mathrm{H}_{2} \mathrm{O} \leftrightarrow \mathrm{CO}_{2}+\mathrm{H}_{2} \quad \Delta H^{o}{ }_{298 \mathrm{~K}}=-34.3 \mathrm{~kJ} \mathrm{~mol}^{-1} \quad 6
$$

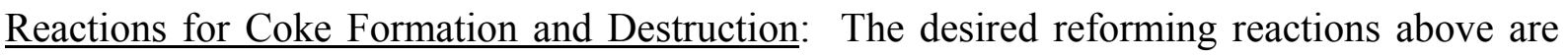
often accompanied by side or intermediate reactions that involve elemental carbon (or coke). The equations below show some of the ways that carbon can be formed and reformed from the reactants and products. One possible pathway to the desired products of $\mathrm{CO}$ and $\mathrm{H}_{2}$ is methane decomposition on the catalyst (Eq. 7) and or carbon monoxide disproportionation (Eq. 8) followed by carbon reforming (Eq. 9-11). However, it is the buildup of elemental carbon in reactors that is one of the main factors of catalyst lifetime and much research is focused on limiting its formation. Catalysts were analyzed for carbon formation during test runs.

$$
\begin{array}{lll}
\mathrm{CH}_{4} \stackrel{\text { heat }}{\longrightarrow} \mathrm{C}+2 \mathrm{H}_{2} & \Delta H^{o}{ }_{298 \mathrm{~K}}=74.9 \mathrm{~kJ} \mathrm{~mol}^{-1} & 7 \\
2 \mathrm{CO} \longrightarrow \mathrm{C}+\mathrm{CO}_{2} & \Delta H^{{ }^{o}}{ }_{298 \mathrm{~K}}=-172.2 \mathrm{~kJ} \mathrm{~mol}^{-1} & 8 \\
\mathrm{C}+\mathrm{CO}_{2} \stackrel{\text { heat }}{\longrightarrow} 2 \mathrm{CO} & \Delta H^{{ }^{o}}{ }_{298 \mathrm{~K}}=172.2 \mathrm{~kJ} \mathrm{~mol}^{-1} & 9 \\
\mathrm{C}+\mathrm{H}_{2} \mathrm{O} \stackrel{\text { heat }}{\longrightarrow} \mathrm{CO}+\mathrm{H}_{2} & \Delta H^{o}{ }_{298 \mathrm{~K}}=131.4 \mathrm{~kJ} \mathrm{~mol}^{-1} & 10 \\
\mathrm{C}+\mathrm{O}_{2} \longrightarrow 2 \mathrm{CO}_{2} & \Delta H^{o}{ }_{298 K}=-393.7 \mathrm{~kJ} \mathrm{~mol}^{-1} & 11
\end{array}
$$

As discussed above, the Sunexus catalyst performed well under mixed reforming conditions and was selected based on several reasons. First, the catalyst shows high thermal stability and zero carbon formation under a variety of target reforming conditions including dry reforming, which is typically a challenge for commercial reforming catalysts. Another benefit of the catalyst is that the base material has high thermal stability and shock resistance, both of which are important for direct solar reforming applications where the temperatures can fluctuate unexpectedly with cloud cover. Also, the catalyst provides acceptable commercial costs and good conversion efficiencies and stability over time show that this commercial catalyst can be used successfully for the demonstration system and commercial platforms. In addition, another benefit is that this catalyst performs well in the reformation of the small percentage of higher hydrocarbons that are in the feed stream from both natural gas and the wax in the water. Tests results on the catalyst for tri-reforming, dry-reforming, and combination reforming are summarized below. 


\section{$\underline{\text { Tri-Reforming Tests }}$}

Tri-reforming is typically defined as a combination of endothermic $\mathrm{CO}_{2}$ (or Dry) reforming (Eq. 3) and steam reforming (Eq. 4) with exothermic oxidation of methane (Equations 5, 6, 7 described above).

Tri-reforming utilizes a single catalyst and the reactions outlined above occur in a single Solar Reactor system. This combination of reactions produces syngas with a $\mathrm{H}_{2} / \mathrm{CO}$ ratio in the proper range for subsequent diesel fuel production. Note again that oxygen is not required for achieving the appropriate syngas ratio and for stable operation of the catalyst, however since oxygen is available at in some flue gas applications and operation with some oxygen in the feed stream can allow for the flue gas to be used directly without separation.

When tri-reforming is used oxygen levels should be kept under $6 \%$ of the total feed gas. Higher oxygen levels start to negatively affect $\mathrm{CO}_{2}$ conversion. This fact has been recognized by several groups ${ }^{1,2}$ and this is one of the reasons that under auto-thermal reforming (ATR), $\mathrm{CO}_{2}$ conversion is poor even at elevated temperatures.

In the first test, reforming was conducted at $\mathrm{CH}_{4}(1.0) / \mathrm{CO}_{2}(1.0) / \mathrm{H}_{2} \mathrm{O}(1.0) / \mathrm{O}_{2}(0.1)$ at $900^{\circ} \mathrm{C}$ at $13,333 \mathrm{hr}^{-1}(10,000 \mathrm{cc} / \mathrm{g}-\mathrm{hr})$ and data is shown in Figure 31.

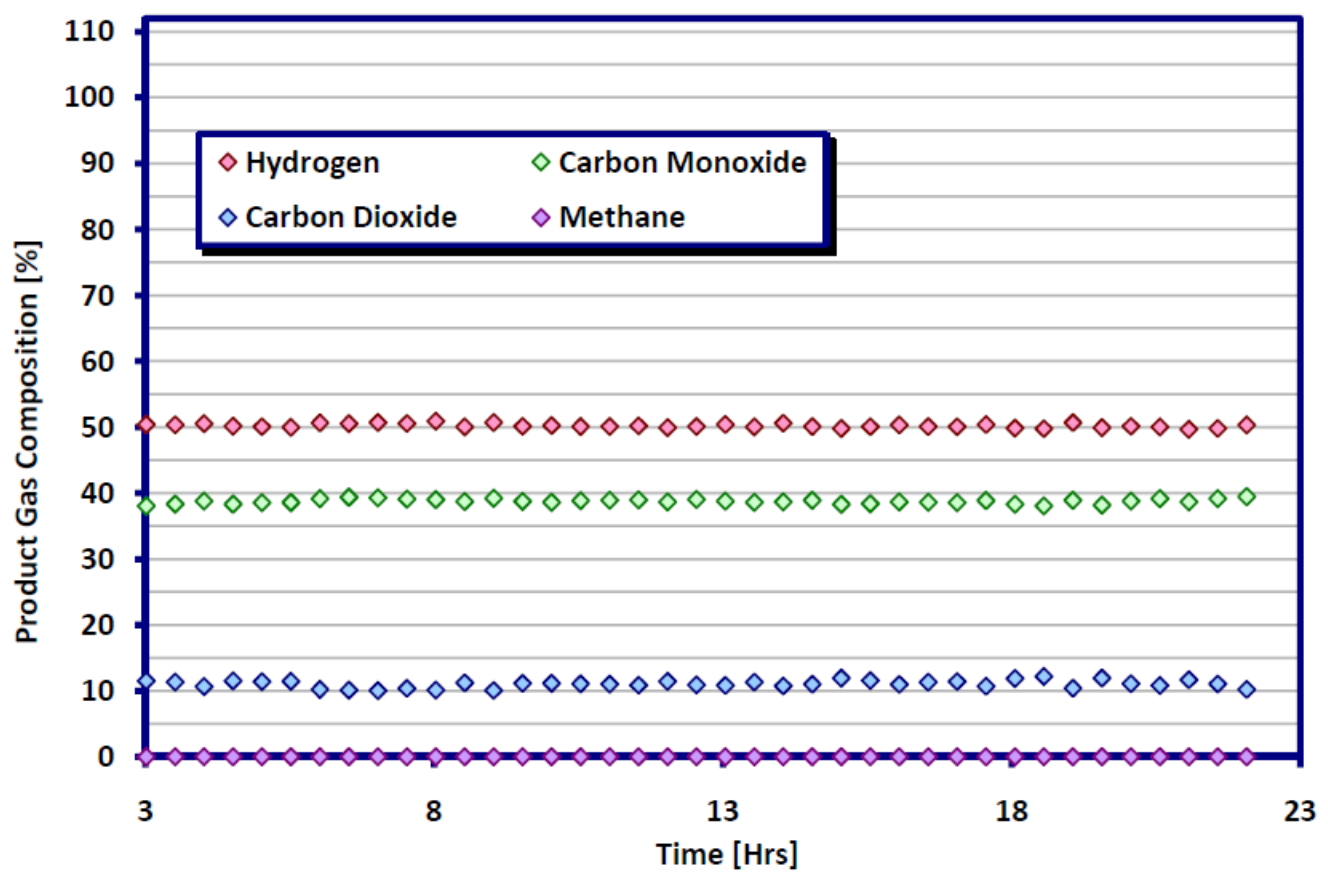

Figure 31 - Tri-reforming Test 1

Figure 32 shows results for a feed gas composition $\mathrm{CH}_{4}(1.0) / \mathrm{CO}_{2}(1.0) / \mathrm{H}_{2} \mathrm{O}(1.0) / \mathrm{O}_{2}(0.05)$ at $900^{\circ} \mathrm{C}$ and $16,000 \mathrm{hr}^{-1}(12,000 \mathrm{cc} / \mathrm{g}-\mathrm{hr}$ ) (oxygen levels at $50 \%$ of Tri-reforming Test 1 ). 


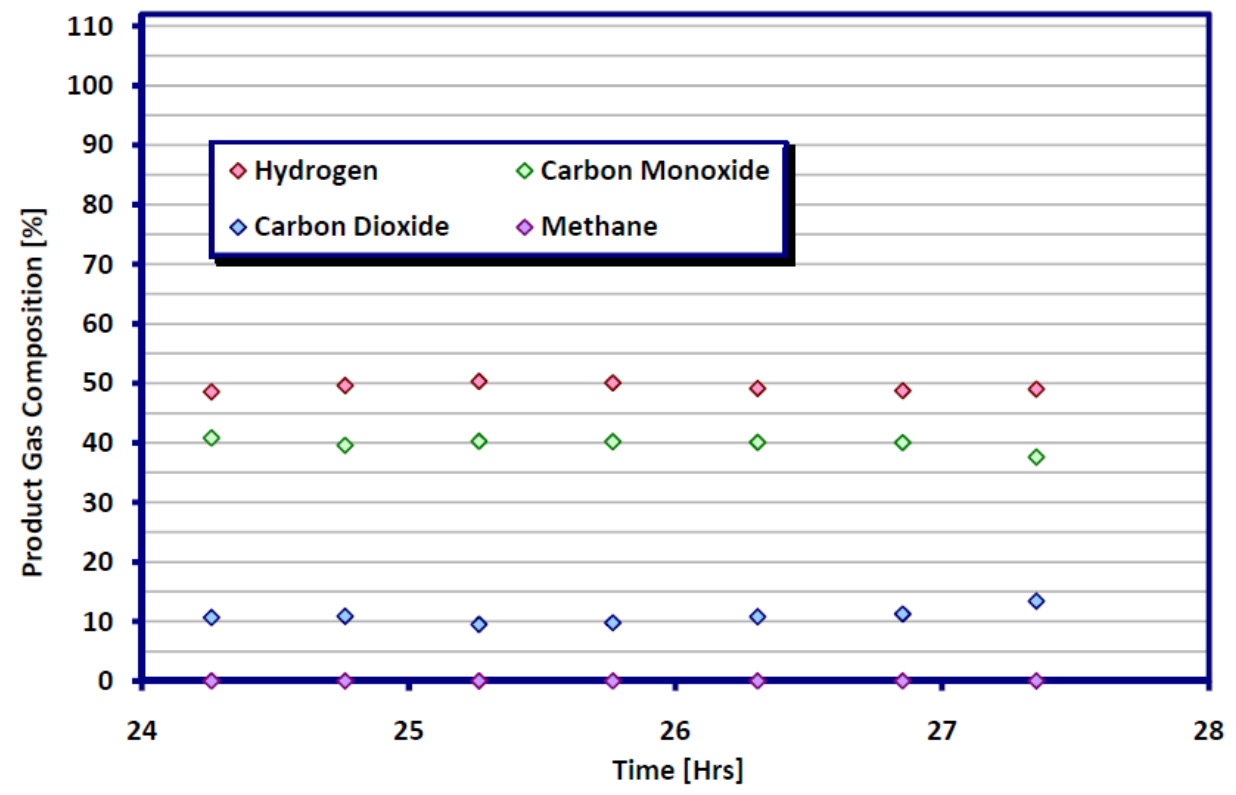

Figure 32 - Tri-reforming Test 2

Figure 33 shows results for a feed gas composition of $\mathrm{CH}_{4}(1.0) / \mathrm{CO}_{2}(1.0) / \mathrm{H}_{2} \mathrm{O}(1.0) / \mathrm{O}_{2}(0.2)$ at $900^{\circ} \mathrm{C}$ and $17,333 \mathrm{hr}^{-1}(13,000 \mathrm{cc} / \mathrm{g}-\mathrm{hr}$ ) (Oxygen levels were $200 \%$ of Tri-reforming Test $1)$.

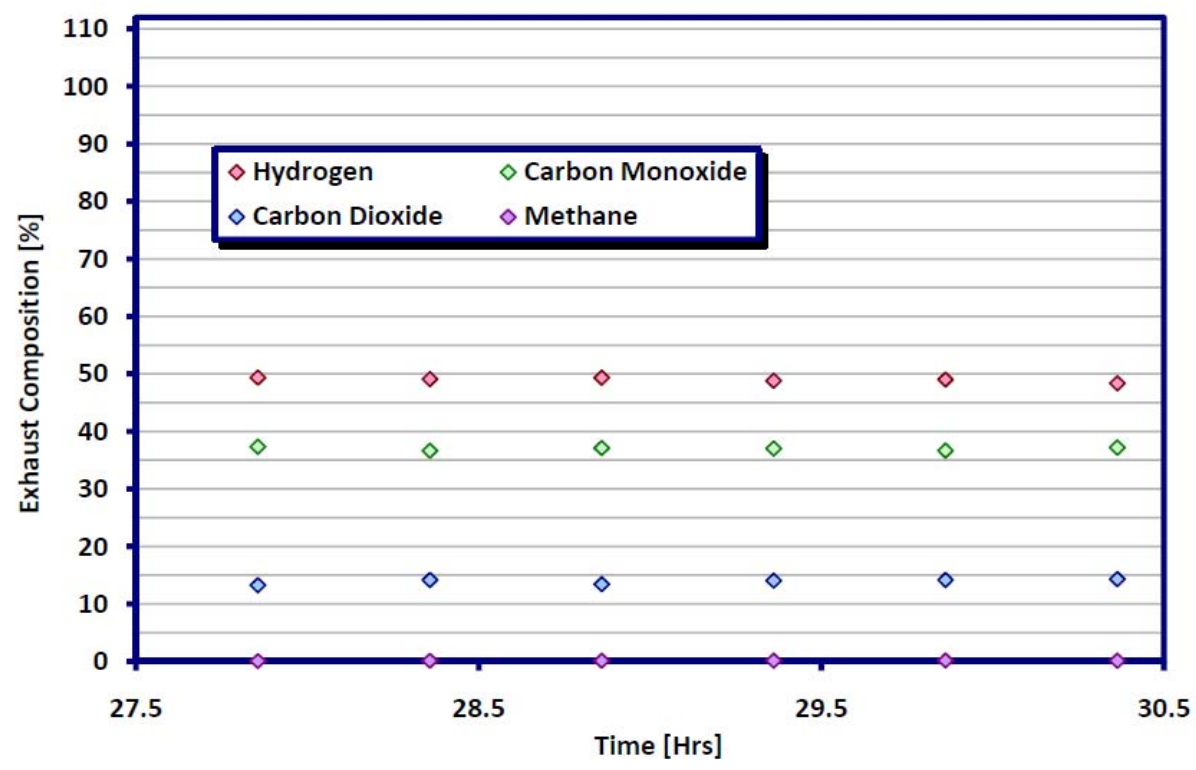

Figure 33 - Tri-reforming Test 3

In the next test, the catalyst was run at $\mathrm{CH}_{4}(1.0) / \mathrm{CO}_{2}(0.5) / \mathrm{H}_{2} \mathrm{O}(1.0) / \mathrm{O}_{2}(0.1)$ (see Figure 34). The sample showed ideal stability and good $\mathrm{CO}_{2}$ conversion under these conditions. 


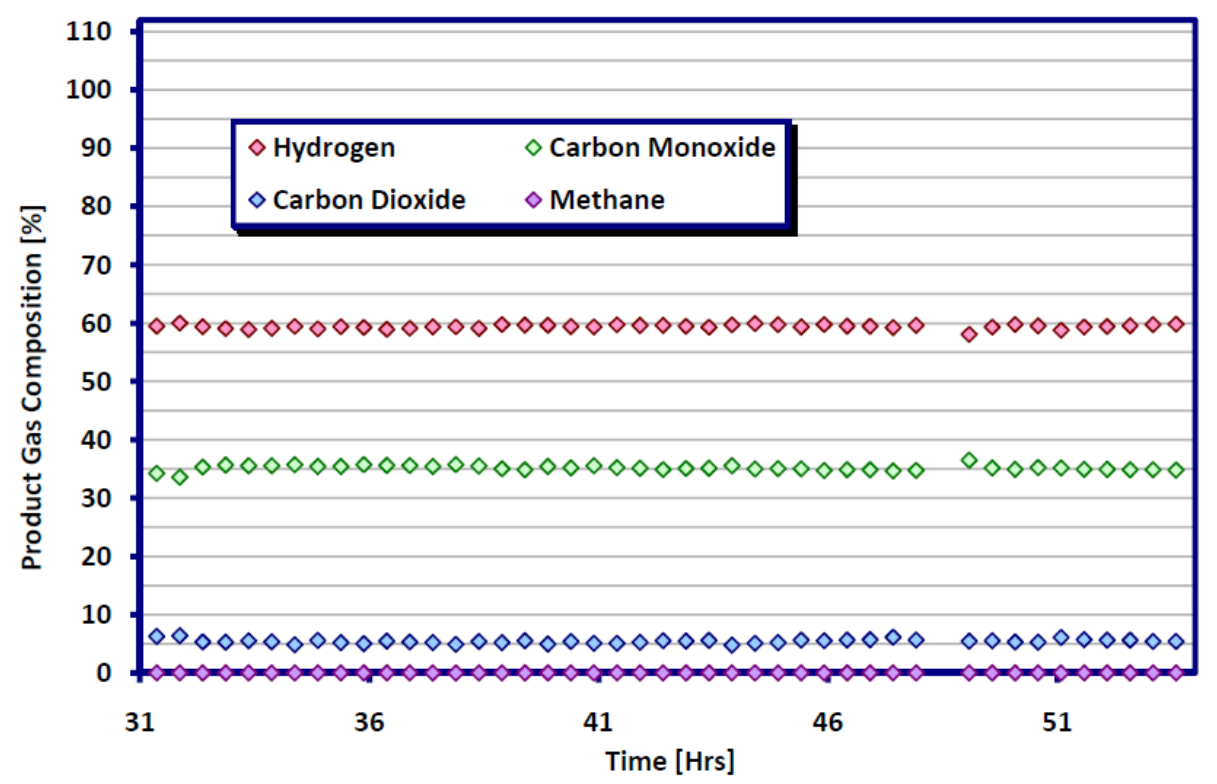

Figure 34 - Tri-reforming Test 4

In the next test (Figure 35), the $\mathrm{CO}_{2}$ ratio was increased to 0.6 , the steam ratio was increased to 1.7 , and $\mathrm{O}_{2}$ increased to 0.2 . Gas hourly space velocity was $18,666 \mathrm{hr}^{-1}(14,000 \mathrm{cc} / \mathrm{g} \mathrm{hr})$.

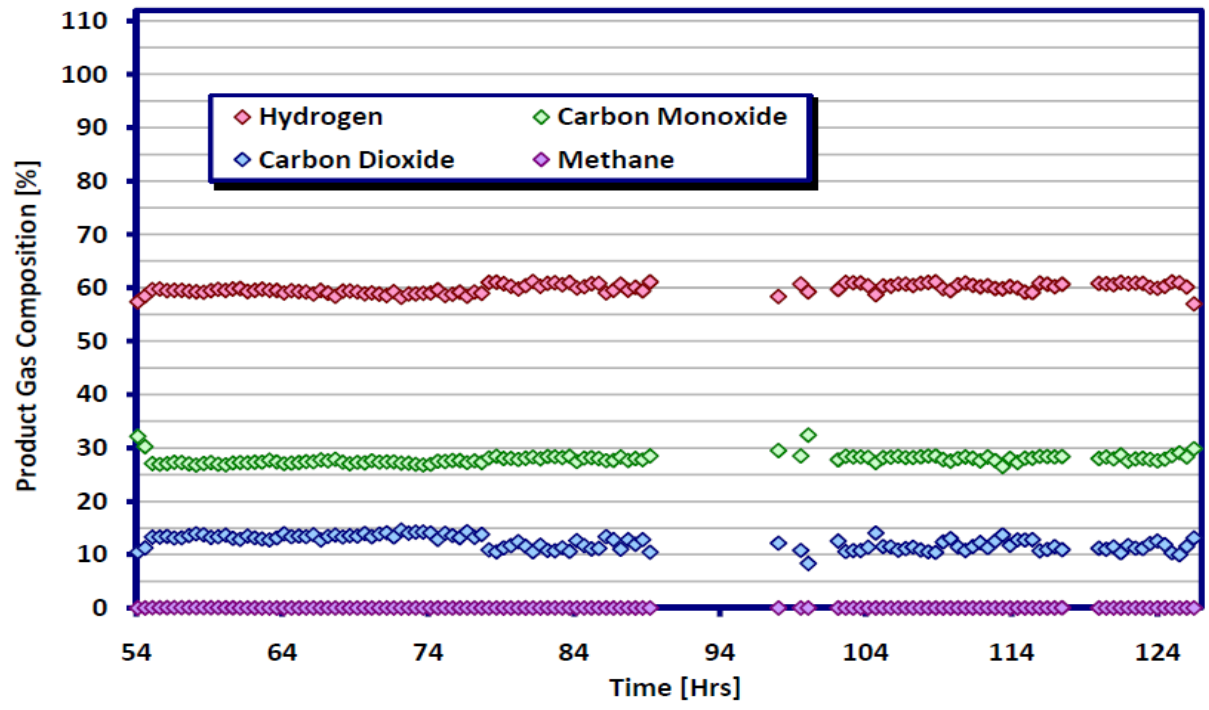

Figure 35 - Tri-reforming Test 5

Under the final two conditions, the carbon dioxide ratio was increased to 0.8 , the steam to methane ratio was varied between 1.7 and 1.35, while keeping $\mathrm{O}_{2}$ at 0.1 . The results of these tests are shown in Figure 36 (GHSV $=16,333 \mathrm{hr}^{-1}$ or 12,250 cc/g hr) and Figure 37 (GHSV = $18,000 \mathrm{hr}^{-1}$ or $13,500 \mathrm{cc} / \mathrm{g} \mathrm{hr}$ ). Both tests were stable during the 20 hours of testing at $900^{\circ} \mathrm{C}$ for each condition. Decreasing the steam in the feed improves carbon dioxide conversion. Overall, the catalyst was very stable for all of the tri-reforming conditions examined. No carbon formation or deactivation of the catalyst was observed. 


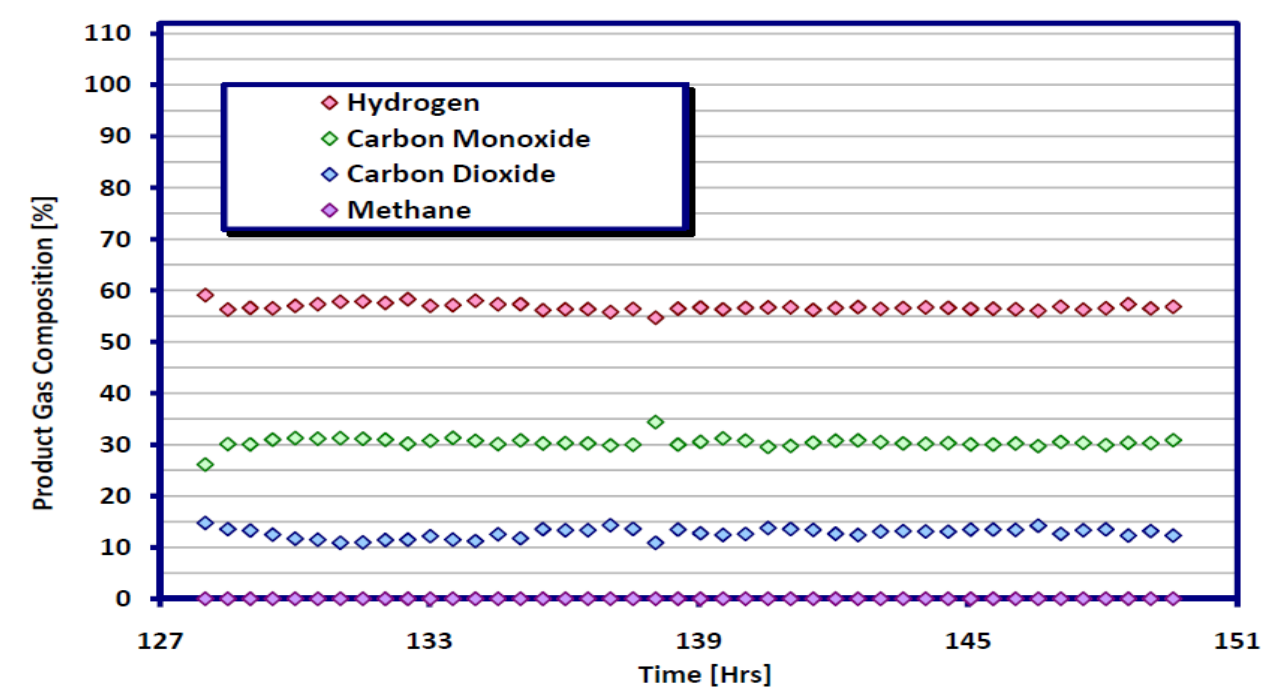

Figure 36 - Tri-reforming Test 6

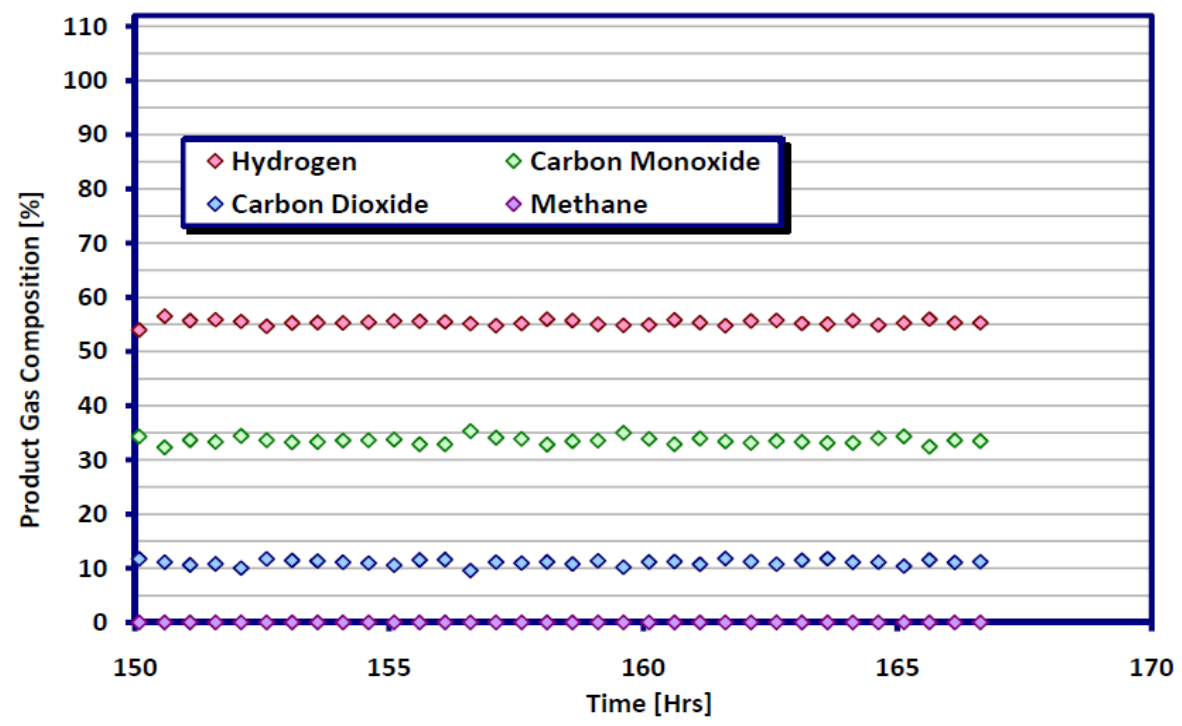

Figure 37 - Tri-reforming Test 7

In conclusion, tri- reforming was found to provide high gas hourly space velocities (GHSV), stable catalyst performance, and the proper $\mathrm{H}_{2} / \mathrm{CO}$ ratio $(\sim 2.0)$ for subsequent conversion to diesel fuel.

\section{Dry Reforming Tests}

The first dry reforming tests were commenced at $1.75 / 1.0 \mathrm{CO}_{2} / \mathrm{CH}_{4}$ and $900^{\circ} \mathrm{C}$. Results are shown in Figure 38. The ratio of $\mathrm{CO}_{2} / \mathrm{CH}_{4}$ changed slightly as the space velocity was altered due to insufficient calibration of the flow meters. This problem was discovered during data analysis and was corrected in later runs. At $900^{\circ} \mathrm{C}$, full methane conversion was achieved, and the sample operated without loss of activity or pressure increase. At $650^{\circ} \mathrm{C}$, the methane 
conversion was low. The catalyst achieved $95 \%$ methane conversion at $800^{\circ} \mathrm{C}$ and demonstrated stable performance without pressure increase.

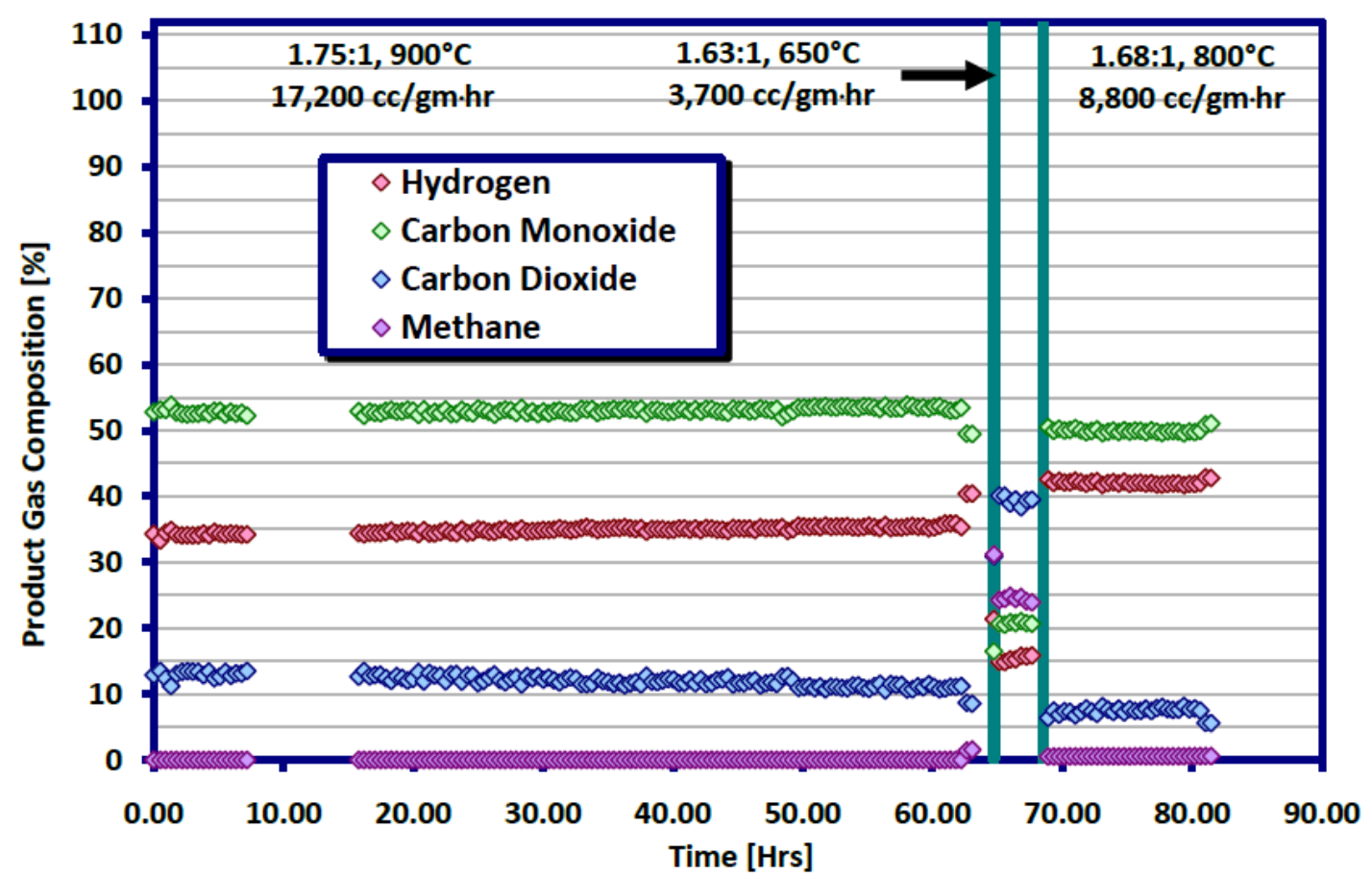

Figure 38 - Dry Reforming Test 1

In the next set of tests, the performance of the catalyst under more challenging conditions was examined (see Figure 39). The performance of the catalyst with a $\mathrm{CO}_{2} / \mathrm{CH}_{4}(1.1 / 1.0)$ feed was attempted. At $900^{\circ} \mathrm{C}$, the complete conversion of methane and carbon dioxide was observed over the first several hours, and complete conversion continued overnight at $800^{\circ} \mathrm{C}$ for 18 hours. There was no loss in performance at the higher temperatures, although the pressure drop through the reactor increased from 2 psi to about 4 psi overnight.

The catalyst was tested at $650^{\circ} \mathrm{C}$ the following day, but immediate loss in performance and reactor blockage quickly ensued. Analysis of the sample, as discussed in the following section, confirmed that the catalyst coked (produced carbon that plugged the reactor). This is typical for reforming catalysts at lower temperatures under dry reforming conditions and the Sunexus catalyst performed well, without carbon deposition, at $\mathrm{CO}_{2} / \mathrm{CH}_{4}$ ratios greater than 1.5/1.0 and temperatures greater than $800^{\circ} \mathrm{C}$. 


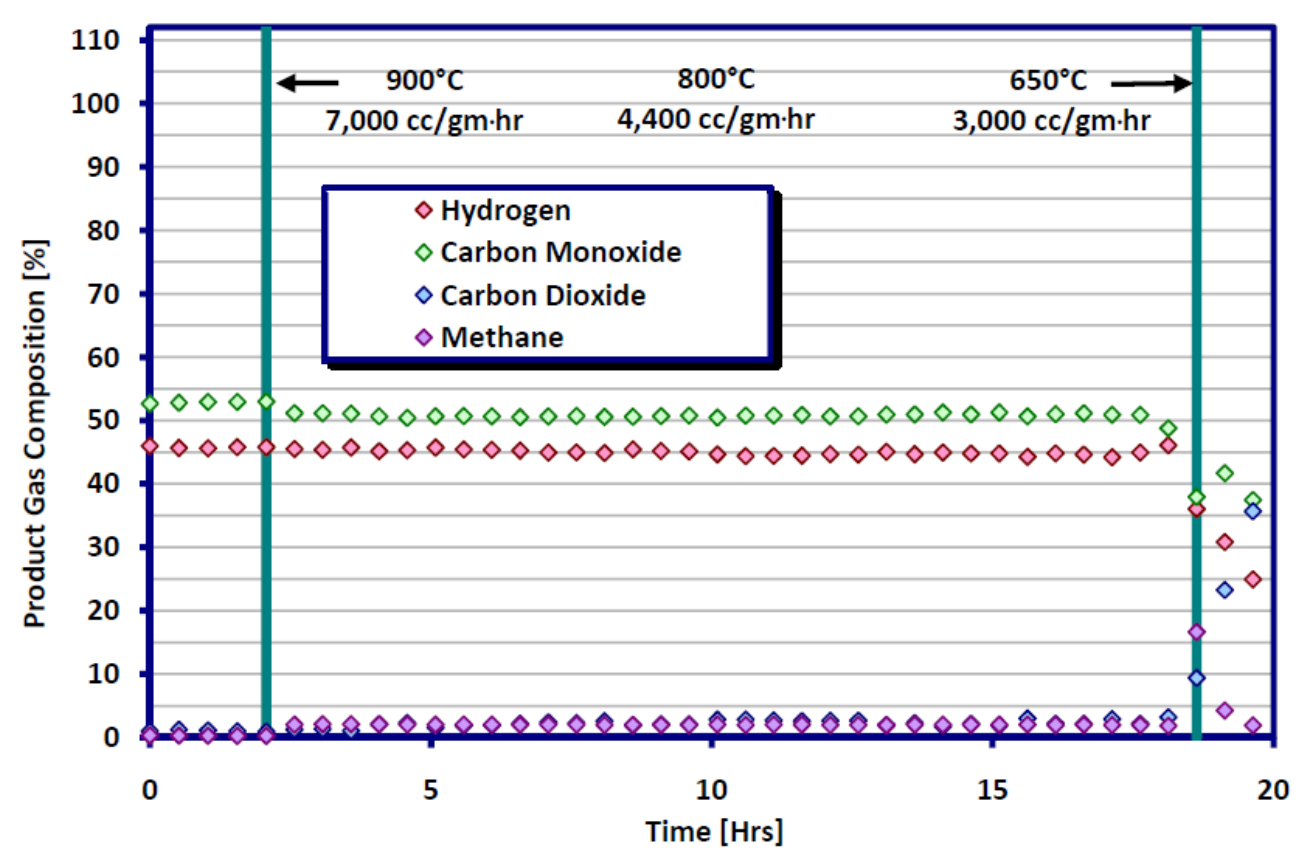

Figure 39 - Dry Reforming Test 2

Finally, dry reforming was run at an intermediate ratio of $\mathrm{CO}_{2} / \mathrm{CH}_{4}(1.5 / 1.0)$ as shown in Figure 40. At $900^{\circ} \mathrm{C}$, the catalyst was stable for 2 days of operation before the run was terminated to analyze the catalyst for carbon. The pressure did not increase during the test, and activity did not change.

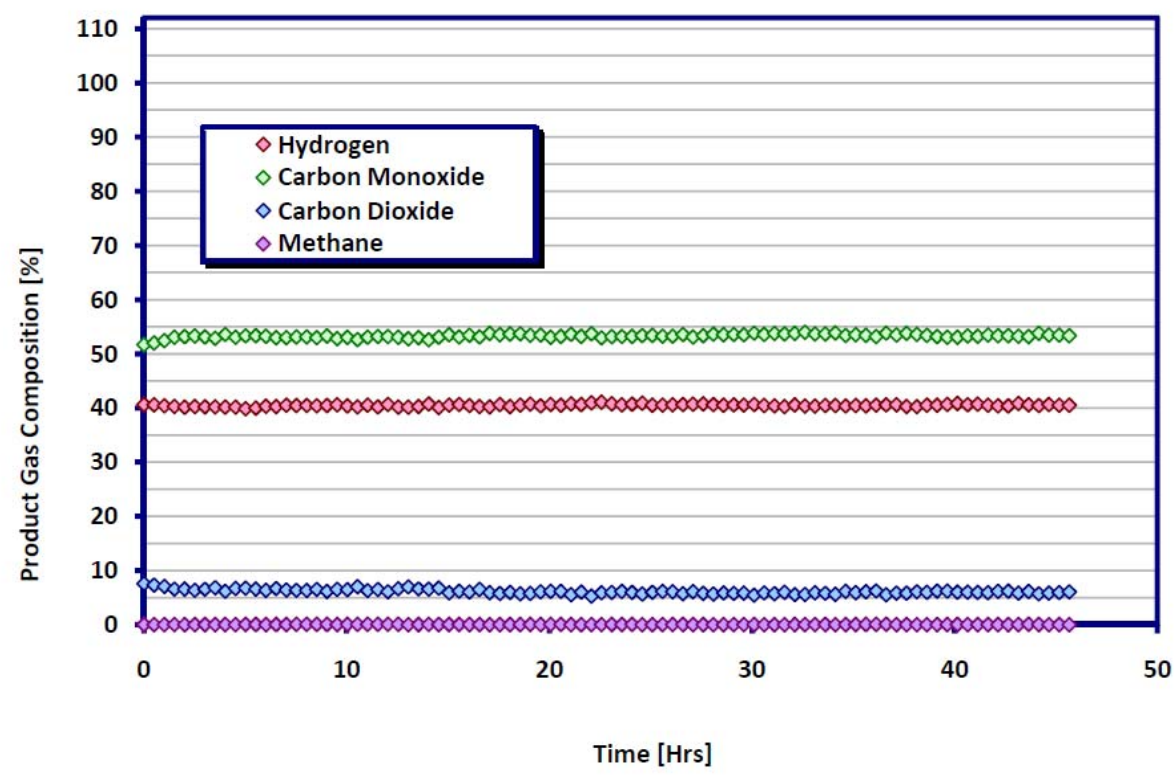

Figure 40 - Dry Reforming Test 3

Dry reforming, under all of the conditions described above, produces a syngas with a $\mathrm{H}_{2} / \mathrm{CO}$

$<1.0$ that is not entirely suitable for subsequent conversion to diesel fuel. However, if a 
source of external renewable hydrogen was available or if hydrogen already exists in the flue gas stream from a stationary emissions source (for example in IGCC power plants), then dry reforming is an attractive option for use in the Sunexus system which provides high $\mathrm{CO}_{2}$ conversion efficiencies and a methane to carbon dioxide input ratio that provides very attractive commercial economics (since the feed gas can contain up to $\sim 70 \% \mathrm{CO}_{2}$ ).

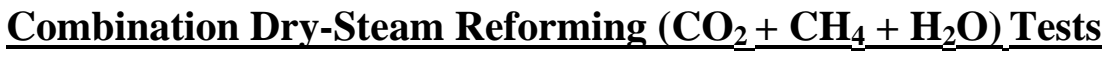

Combination dry reforming/steam methane reforming tests includes $\mathrm{CO}_{2}, \mathrm{CH}_{4}$ and $\mathrm{H}_{2} \mathrm{O}$ reactants in various molar ratios. In addition to the dry reforming reactions, Steam Methane Reforming (SMR) also occurs and is an endothermic process where methane reacts with steam at high temperatures to produce syngas.

By combining dry and steam reforming, a syngas with an ideal $\mathrm{H}_{2} / \mathrm{CO}$ can be produced. Mixed steam and dry methane reforming tests were conducted to demonstrate activity and determine product composition with methane, $\mathrm{CO}_{2}$, and steam in the feed. In the first test, the reforming mixture was run with the following gas composition: $\mathrm{CO}_{2} / \mathrm{CH}_{4} / \mathrm{H}_{2} \mathrm{O}(0.9 / 1.0 / 2.2)$ at $900^{\circ} \mathrm{C}$. However, the catalyst was not stable due to the high water content and it appeared to lose activity within 4 hours (results not shown).

It is believed that the instability was caused from fluctuations in the water feed, resulting in oxidation of the catalyst. At higher water flow rates, it wasn't possible to reactivate the catalyst.

The samples were found to be stable with lower water content in the feed (at $<2.0 / 1.0$ $\mathrm{H}_{2} \mathrm{O} / \mathrm{CH}_{4}$ ) as demonstrated in subsequent tests.

The test was repeated with $\mathrm{CO}_{2} / \mathrm{CH}_{4} / \mathrm{H}_{2} \mathrm{O}(0.6 / 1.0 / 1.4)$ at $900^{\circ} \mathrm{C}$, and stable catalyst performance was achieved. The test results are shown in Figure 41. 


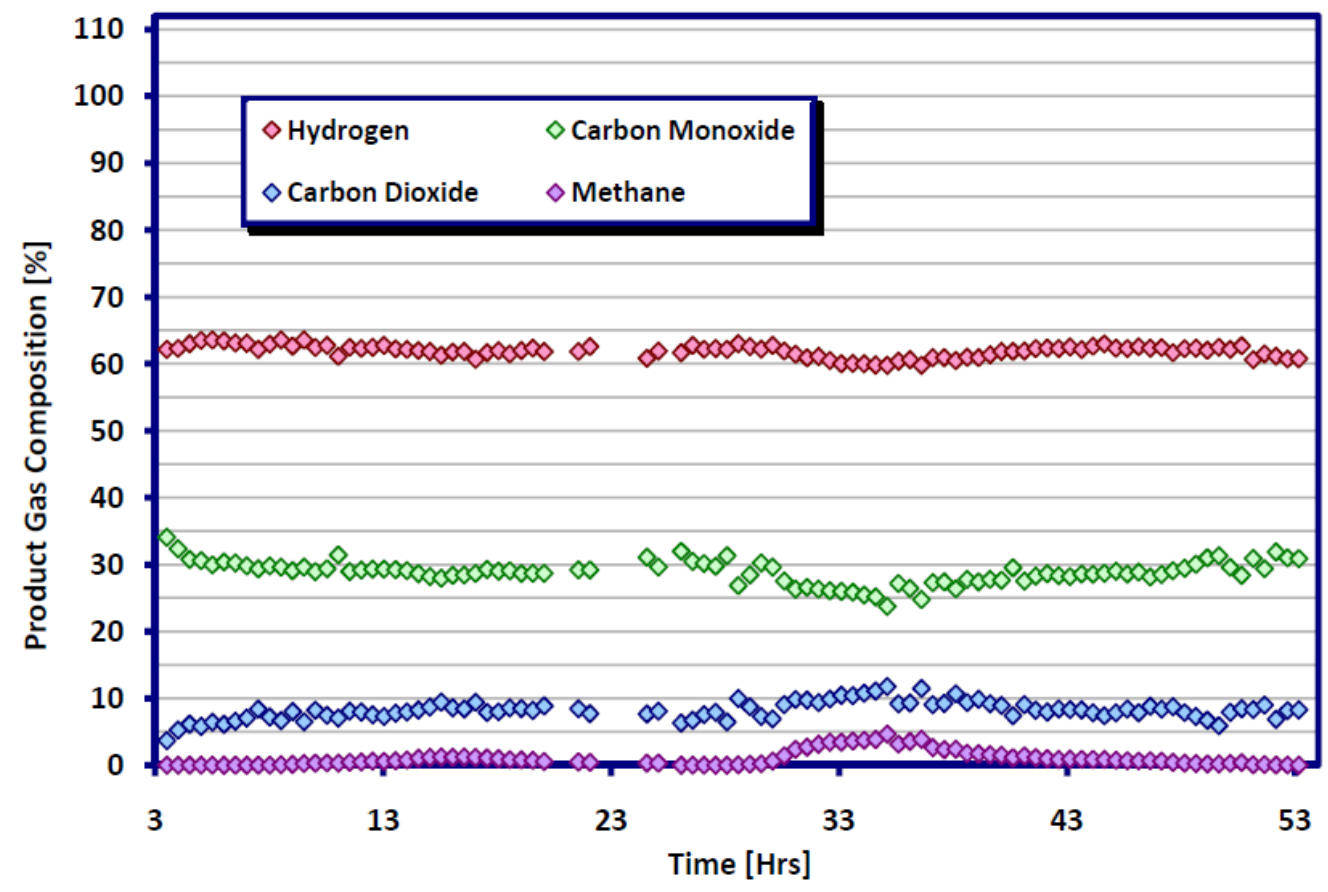

Figure 41 - Combination Reforming Test 1

In the next set of test conditions using a gas composition of $\mathrm{CO}_{2} / \mathrm{CH}_{4} / \mathrm{H}_{2} \mathrm{O}(0.4 / 1.0 / 0.93)$, the catalyst was tested at $900^{\circ} \mathrm{C}$ and $10,400 \mathrm{hr}^{-1}\left(7,800 \mathrm{cc} / \mathrm{g}\right.$-hr) at $850^{\circ} \mathrm{C}$ (see Figure 42).

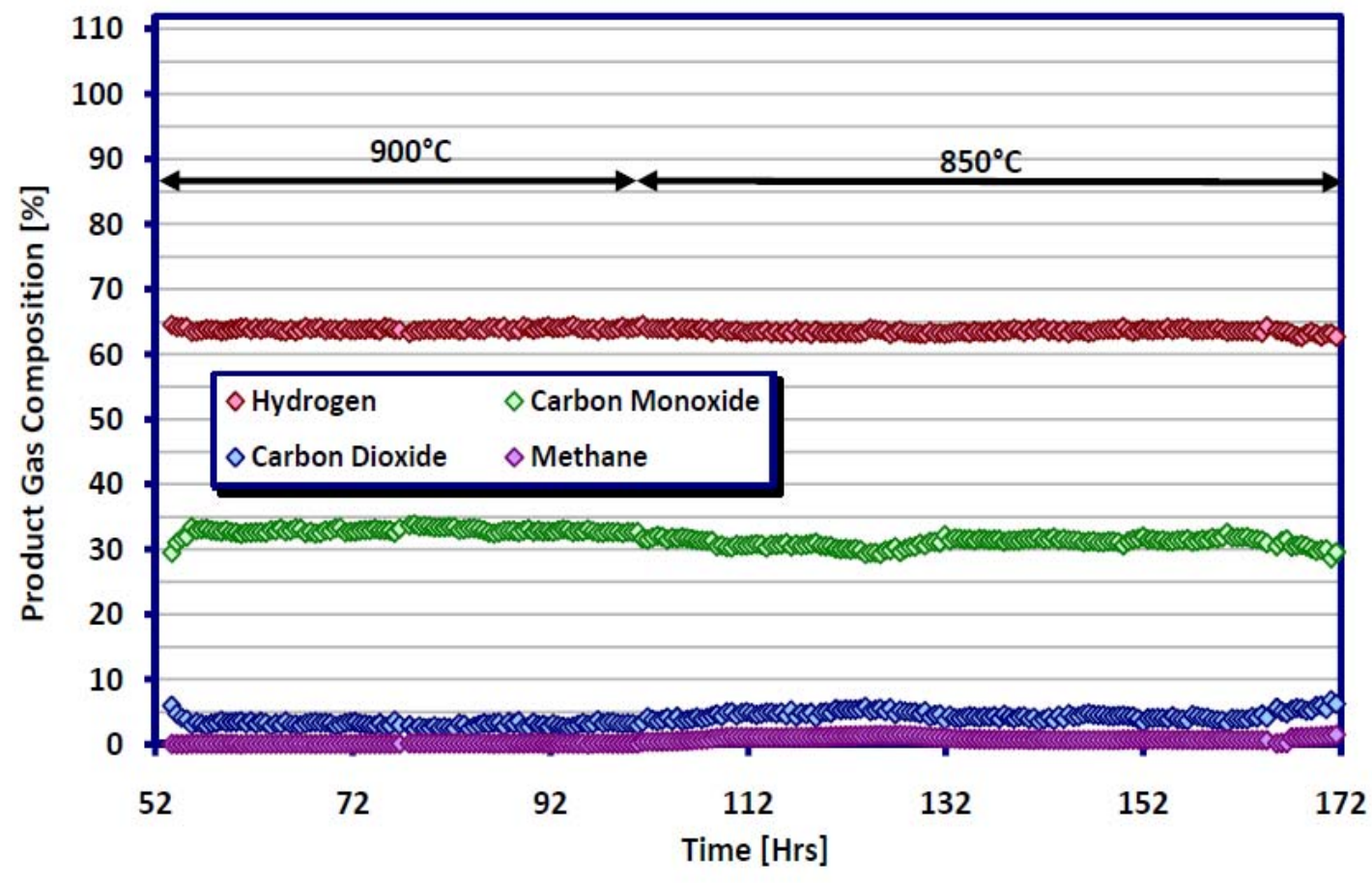

Figure 42 - Combination Reforming Test 2 
As shown in Figure 43, the catalyst was found to be stable when operating under a gas composition of $\mathrm{CO}_{2} / \mathrm{CH}_{4} / \mathrm{H}_{2} \mathrm{O}(0.6 / 1.0 / 1.4)$ from $900^{\circ} \mathrm{C}$ to $800^{\circ} \mathrm{C}$.

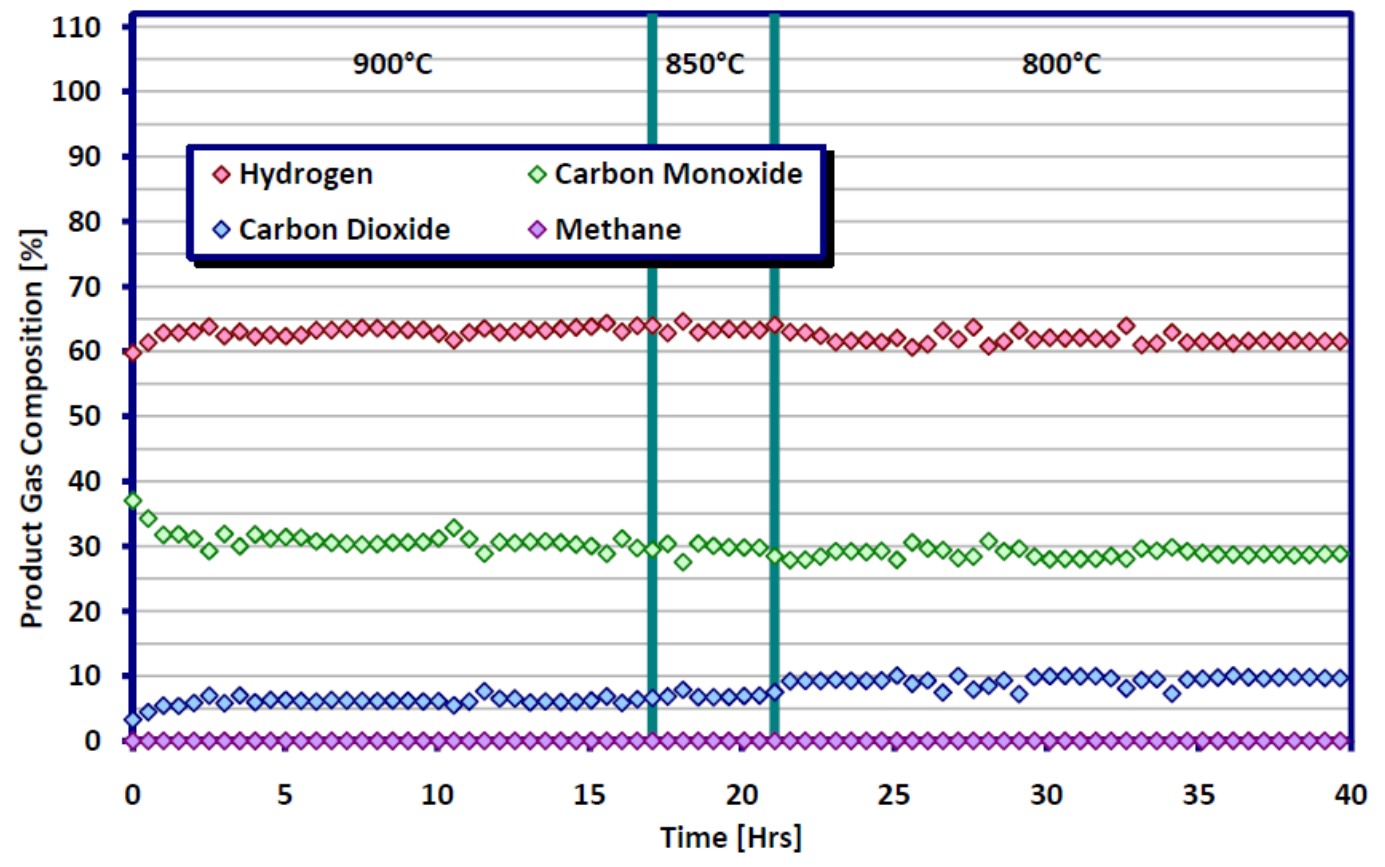

Figure 43 - Combination Reforming Test 3

Additional testing was carried out with the same gas composition of $\mathrm{CO}_{2} / \mathrm{CH}_{4} / \mathrm{H}_{2} \mathrm{O}$ $(0.6 / 1.0 / 1.4)$ at $800^{\circ} \mathrm{C}$ (see Figure 44). Post-testing Temperature Programmed Oxidation (TPO) and optical analysis did not show any signs of carbon deposition. 


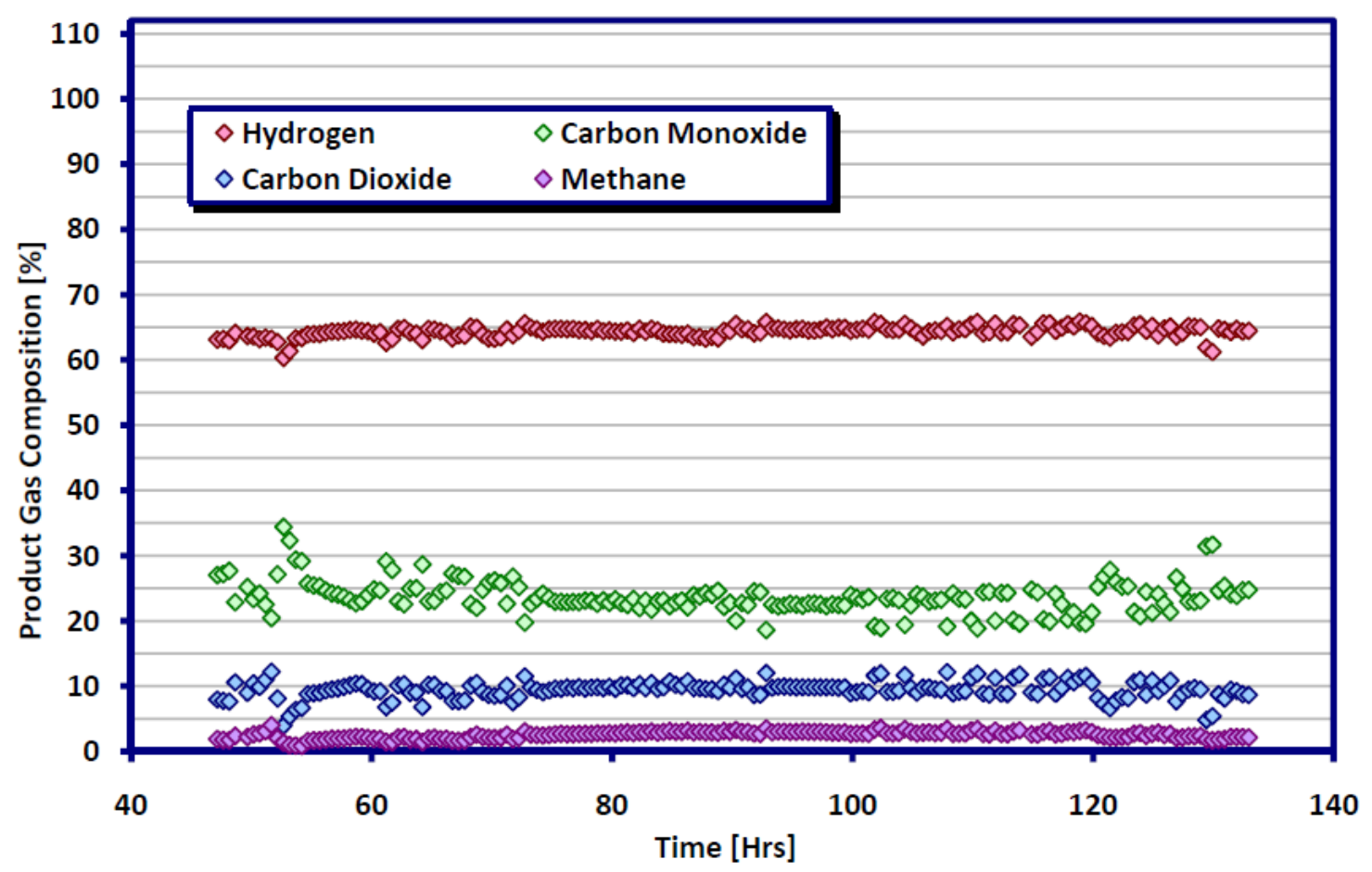

Figure 44 - Combination Reforming Test 4

In conclusion, it was found that a combination of steam methane and dry reforming (including the reactants $\mathrm{CO}_{2}, \mathrm{CH}_{4}$, and $\mathrm{H}_{2} \mathrm{O}$ ) produce a syngas with a $\mathrm{H}_{2} / \mathrm{CO}$ ratio of $1.8-2.0$ that is ideal for subsequent liquid fuel production. Typically a $\mathrm{H}_{2} \mathrm{O} / \mathrm{CO}_{2}$ ratio of $2.0-1.0$ would be targeted in order to produce syngas in this ratio.

\section{Catalyst Stability Tests}

To determine if any carbon deposition (coking) occurred during catalyst reforming, pressure drop across the reactor was monitored. In addition, TPO experiments were performed on the catalyst following selected test runs. In these tests, $100 \mathrm{mg}$ of post-tested catalyst was loaded into a $1 / 4$-inch tube reactor and heated to $650^{\circ} \mathrm{C}$ under an air flow of 100 standard cubic centimeters per minute $(\mathrm{sccm})$. The exhaust from the reactor was analyzed with a mass spectrometer to monitor the formation of $\mathrm{CO}_{2}$ and consumption of oxygen, which would be consistent with carbon burning off.

The only tests that showed any carbon deposition (coking) were in the dry reforming category as discussed above. All other tests including steam methane reforming (SMR), combination reforming and tri-reforming showed no carbon formation indicating long term stability. This is consistent with known results and literature studies, however it should be noted that the Sunexus catalyst performed very well under dry reforming conditions at or above a ratio of 1.5/1.0 $\mathrm{CO}_{2} / \mathrm{CH}_{4}$ and above $800^{\circ} \mathrm{C}$ operation. 
Results of the TPO analysis that were conducted for dry reforming are discussed below. For dry reforming tests where $\mathrm{CO}_{2}: \mathrm{CH}_{4}$ was greater than 1.5/1.0, no $\mathrm{CO}_{2}$ was formed during the TPO process as shown below in Figure 45.

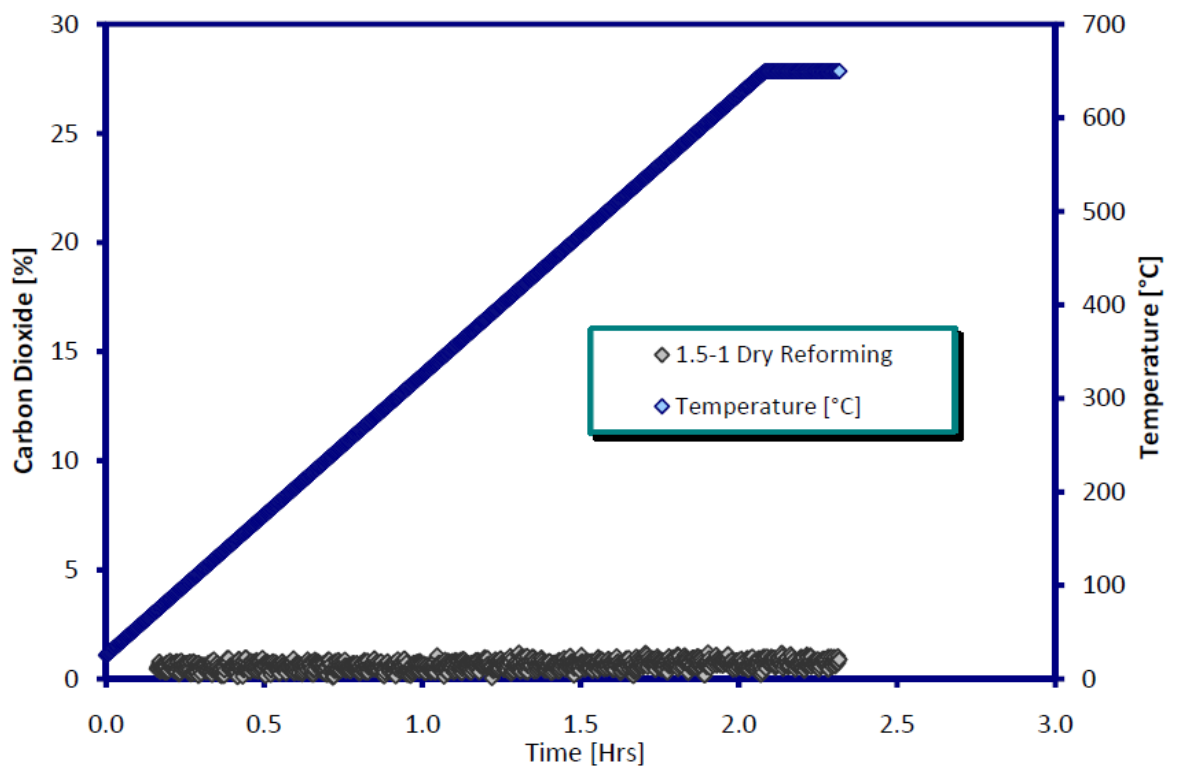

Figure 45 - TPO Analysis of a Sample after Testing under Dry Reforming Conditions

However, the samples run at 1.0/1.0 ratios of $\mathrm{CO}_{2}$ to $\mathrm{CH}_{4}$ showed obvious signs of carbon deposition (see Figure 46). The large amount of carbon dioxide produced is consistent with a sample where nearly half the mass is carbon. Based on these dry reforming results, it can be recommended that the operating temperature should be at least $800^{\circ} \mathrm{C}$ and the $\mathrm{CO}_{2} / \mathrm{CH}_{4}$ ratio should be 1.5/1.0 or higher to avoid carbon deposition.

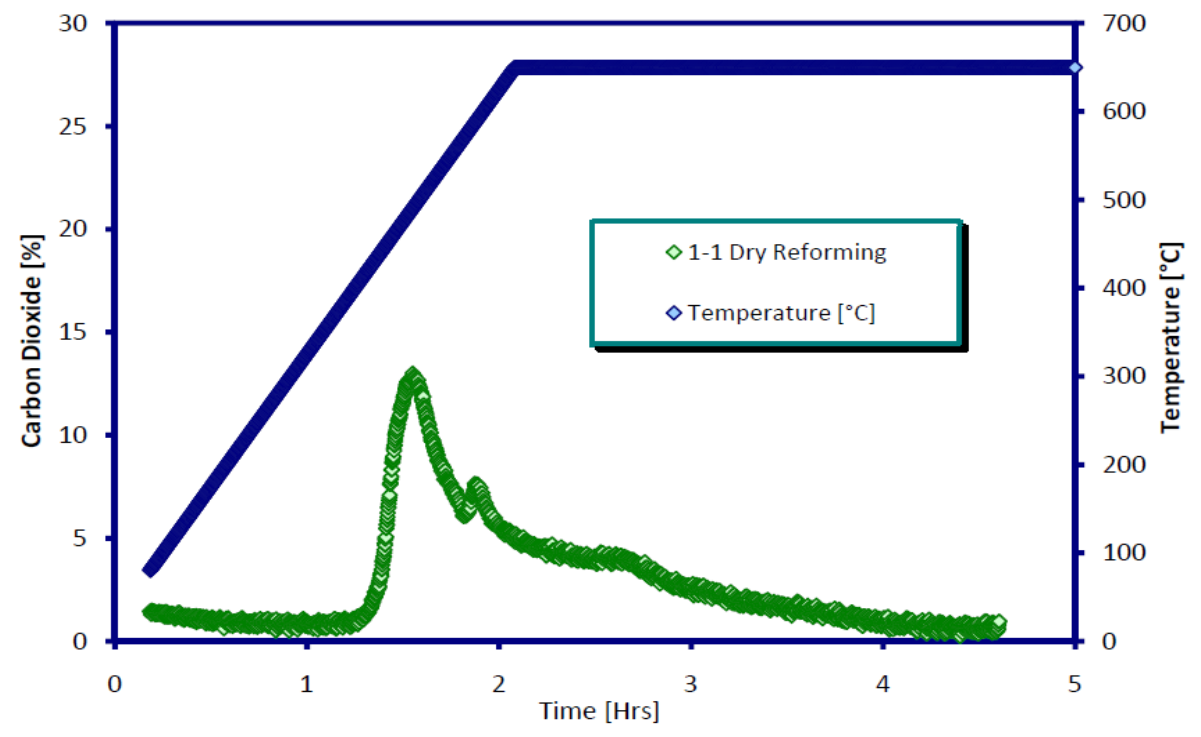

Figure 46 - TPO Analysis of a Sample after Testing under Dry reforming conditions

Other conditions discussed above exhibited no coking or carbon deposition. The physical appearance of the catalysts supported the TPO analysis results. 


\section{Conclusions}

As based upon the results from the tests presented in Sections II.D.1 to II.D.4, it can be concluded that the Sunexus solar reformer can be used to efficiently reform a variety of feed streams into synthesis gas that can subsequently be used to produce diesel fuel or chemicals.

Tri-reforming using the Sunexus catalyst produced syngas with the appropriate ratio for subsequent diesel fuel production $(\sim 2.0)$. Full methane conversion was achieved and $\mathrm{CO}_{2}$ conversions between $50-75 \%$ per pass (with recycle of tail gas as outlined in the Process Flow Diagram $>95 \% \mathrm{CO}_{2}$ conversion is achieved in integrated systems).

In the integrated process for commercial plants, water from the F-T process is recycled back to the Sunexus Solar Reformer so that after start up the system does not require any additional supplies of water.

Future demonstration flue gas streams (for example, at the oxy-combustion power plant in Bakersfield) may contain oxygen and since this flue gas will be used without separation, oxygen will be used as part of the feed gas. As mentioned above, while oxygen will be used as part of the demonstration effort since it already exists in the flue gas stream, oxygen is not required in the feed stream to achieve the syngas ratio required for subsequent liquid fuel production.

Other reactant gas mixes were found to be attractive as well which shows that the Sunexus can work with a variety of feed gas streams for a variety of industrial applications. 


\section{E. Design \& Integration of the Sunexus Solar Reformer SR2 with the 12kW Solar Dish}

As a result of the extensive testing on the Sunexus Solar Reformer SR1, it was decided that some improvements could be made in heat transfer from the concentrated solar radiation to the catalyst as well as energy efficiency. Therefore, a second generation solar reformer, called SR2, was designed for installation on an Infinia solar concentrating dish. The SR2 reactor uses the same proprietary Ni-based reforming catalyst but instead of tubes, a series of micro-channels is used to facilitate better heat transfer in the solar reformer. Figure 47 illustrates the $\boldsymbol{S R} 2$ reactor design.

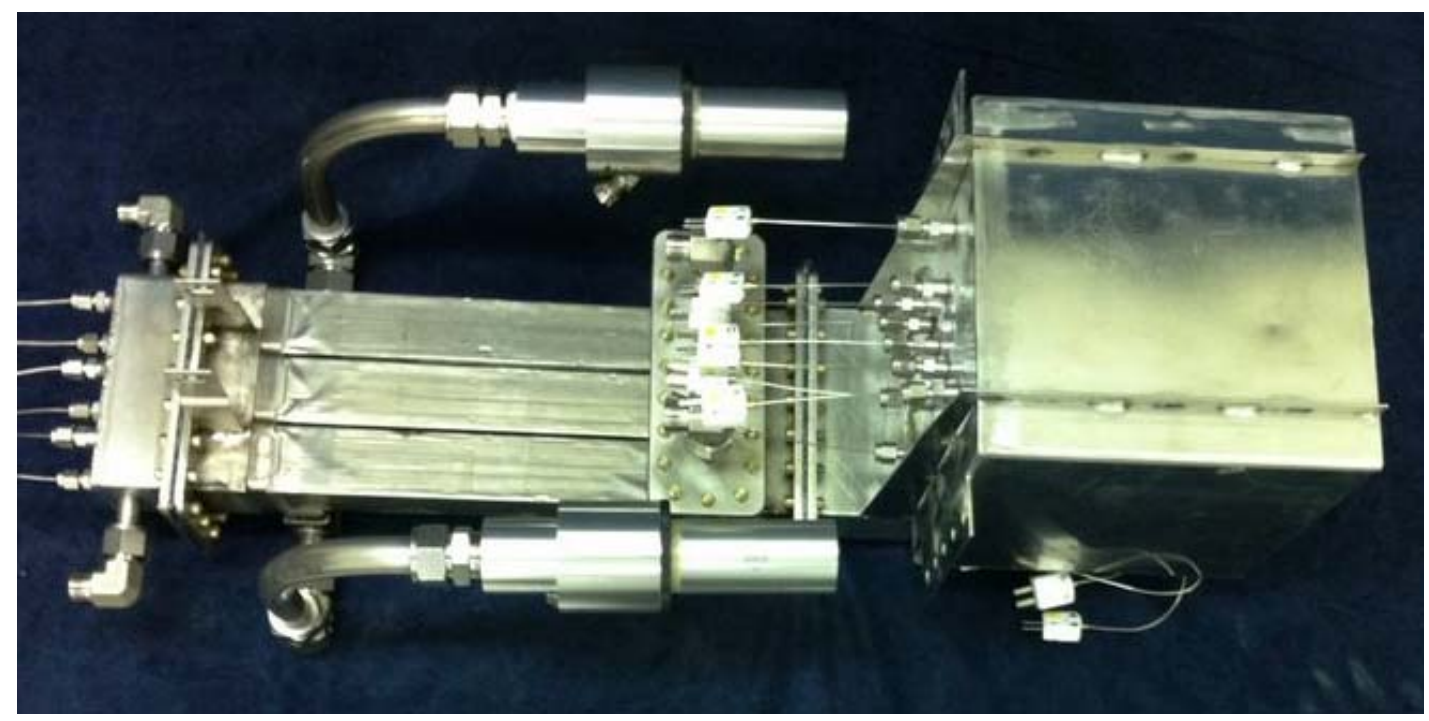

Figure 47 - Sunexus Solar SR2 Catalytic Reactor Assembly

The $\boldsymbol{S R} 2$ reactor and a $12 \mathrm{~kW}$ solar dish from Infinia was installed at the Pacific Renewable Fuels and Chemicals testing site near Sacramento, CA. Figure 48 shows the installation of the boom arm and frame for the solar concentrating dish. In addition to Infinia, several dish manufacturers have starting mass production of this equipment and capital costs have declined considerably over the past several years.

For the installation of the dish, the mirrors on the frame were installed and the jig for lifting the dish was put in place. Mirrors were bolted to the frame and tightened correctly to ensure a good fit. Figure 48 shows the dish with the mirrors installed. 


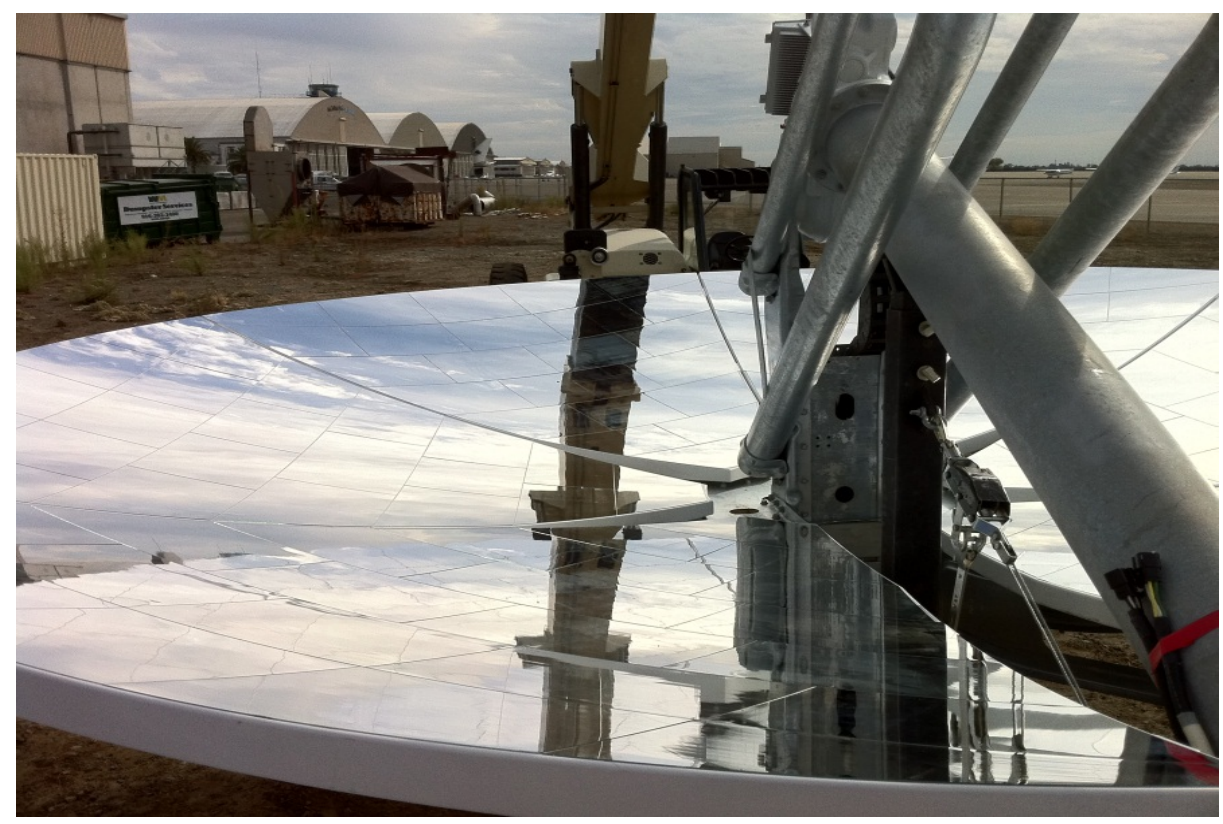

Figure 48 - Mirror Assembly of the Dish

Prior to installing the dish a raised, movable foundation was designed and poured. Figure 49 shows the design of the foundation. Next the dish was lifted into place and placed on the foundation where it was bolted in place. Figure 50 shows the lifting and positioning of the dish.

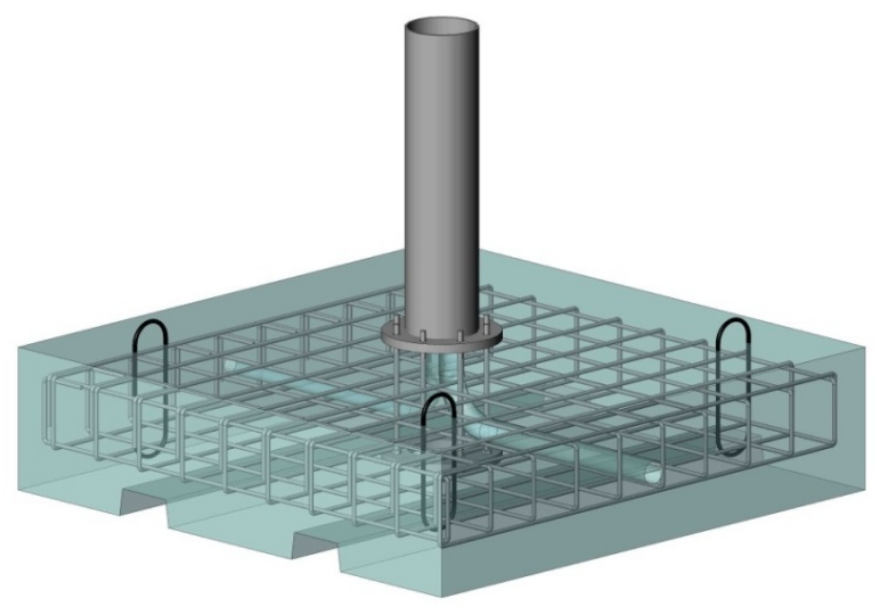

Figure 49 - Integrated Solar Reformer Foundation Design 


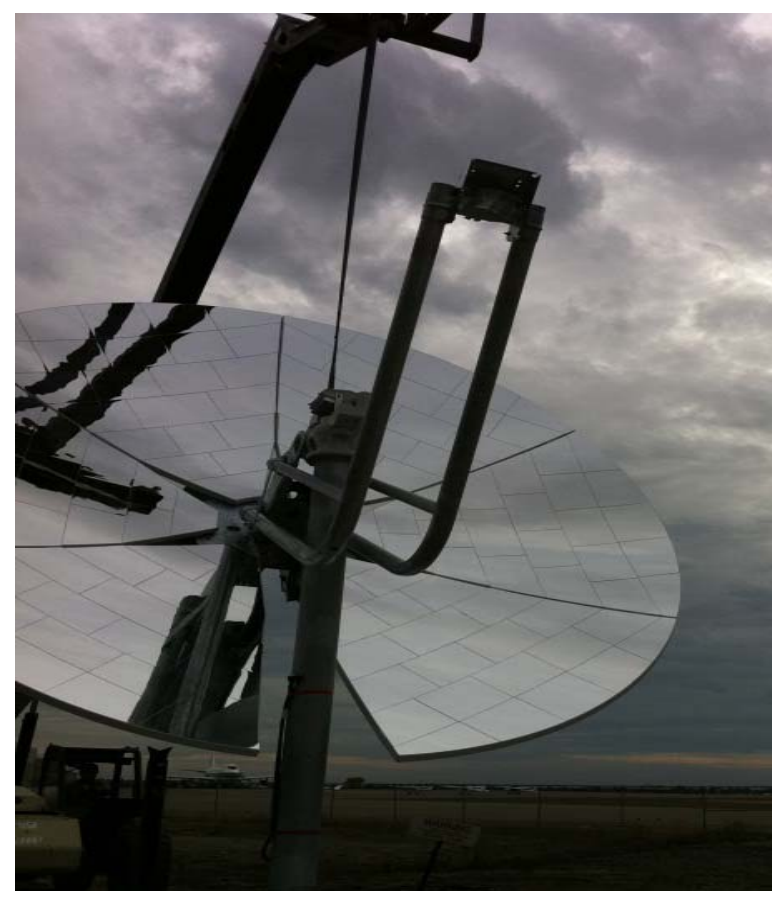

Figure 50 - Solar Dish Being Lifted Into Place

Final checks on all components of the dish were completed and a test reactor was installed on the dish to validate the control logic for the dish and ensure temperature profiles in the reactor. Figure 51 shows the final installation of the $\boldsymbol{S R} \mathbf{2}$ reformer mounted on the fully assembled solar concentrating dish at the Pacific Renewable Fuels and Chemicals (PRFC) test site near Sacramento, CA.

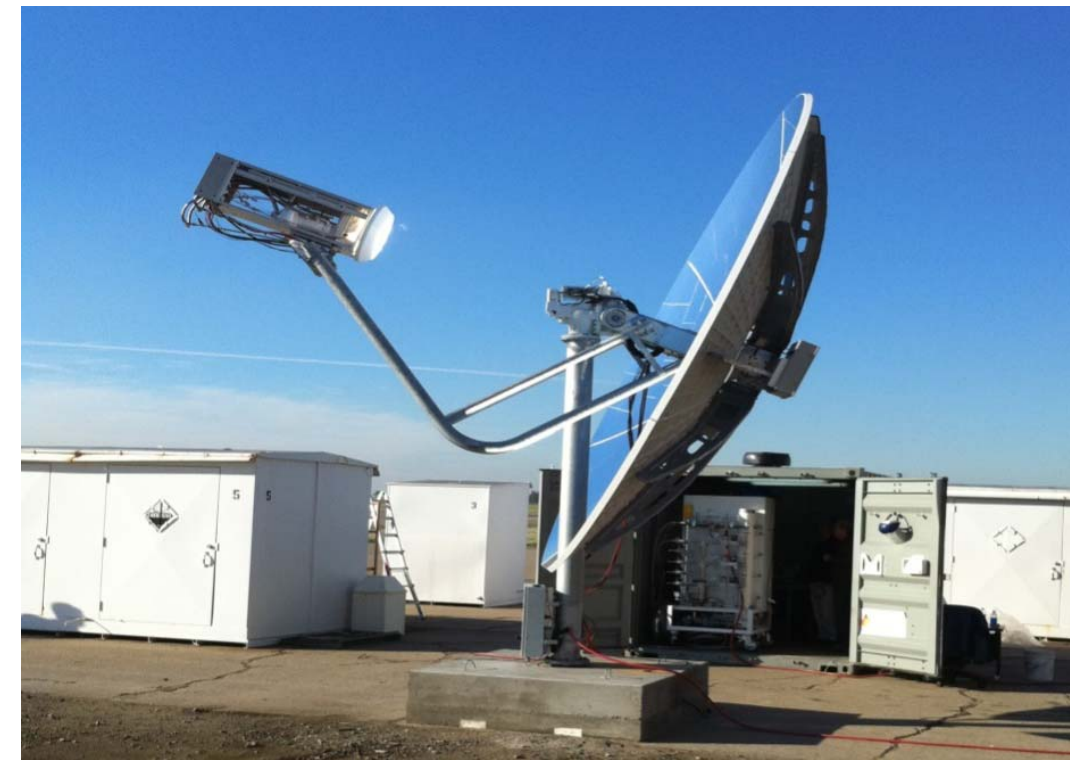

Figure 51 - Sunexus Solar Reformer SR2 Installed on the Infinia Solar Dish 


\section{F. Testing of the Sunexus Solar Reformer $S R 2$ with the $12 \mathrm{~kW}$ Solar Dish}

Testing of the integrated system was carried out during December 2010 at the PRF test site. Over the course of several sunny days, the control scheme for the dish (including automated sun tracking) was validated and the temperature profiles within the reactor head were established. After temperatures were confirmed and the sun tracking system was tuned to achieve the desired results, the Sunexus Solar $\mathrm{CO}_{2}$ Reformer $\boldsymbol{S R 2}$ was installed on the dish. Figure 52 shows the control center for the Sunexus Integrated Solar Reformer SR2 with the solar dish.

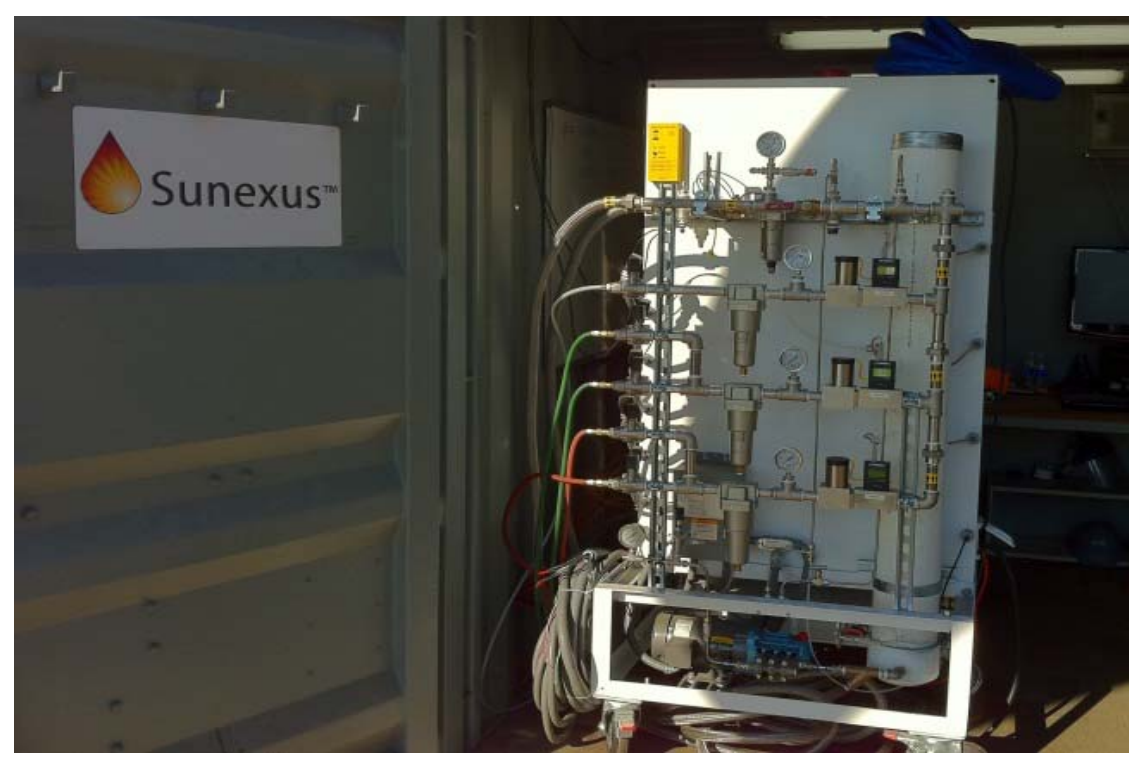

Figure 52 - Control Center for the Sunexus Integrated Solar

The concentrating dish focuses solar energy at a "focal point" at the front of the Sunexus solar reactor. During a series of test runs, the Sunexus solar reformer was brought to temperature and nitrogen was flowed through the reactor to characterize temperature profiles in the catalyst reaction channels before running the test on live gas.

Temperatures at the front of the Sunexus solar reformer reached up to $1,210^{\circ} \mathrm{C}$, three inches from the front of the reactor. Temperature readings at the front of the reactor cannot be taken directly due to elevated temperatures so the first set of thermocouples is positioned three inches from the front (focal point) but it is estimated that temperatures achieved $>1,650{ }^{\circ} \mathrm{C}$ at the front of the reactor. The reaction channels achieved temperatures ranging from $600{ }^{\circ} \mathrm{C}$ during early tests to $875^{\circ} \mathrm{C}$ during later checkout tests.

Following temperature testing, reforming test runs were conducted by first bringing the reactor to temperature, then running hydrogen through the catalyst bed to first reduce the catalyst at a GHSV of $10,000 \mathrm{hr}^{-1}$. Following reduction, nitrogen was run through the reactor before starting the reforming testing. The goal of the testing was to replicate previous test results (catalyst activity \& selectivity to products). For all test runs, results closely matched the catalyst test results carried out in the laboratory (see Section II C). Figures 53 and 54 show actual test runs underway. 


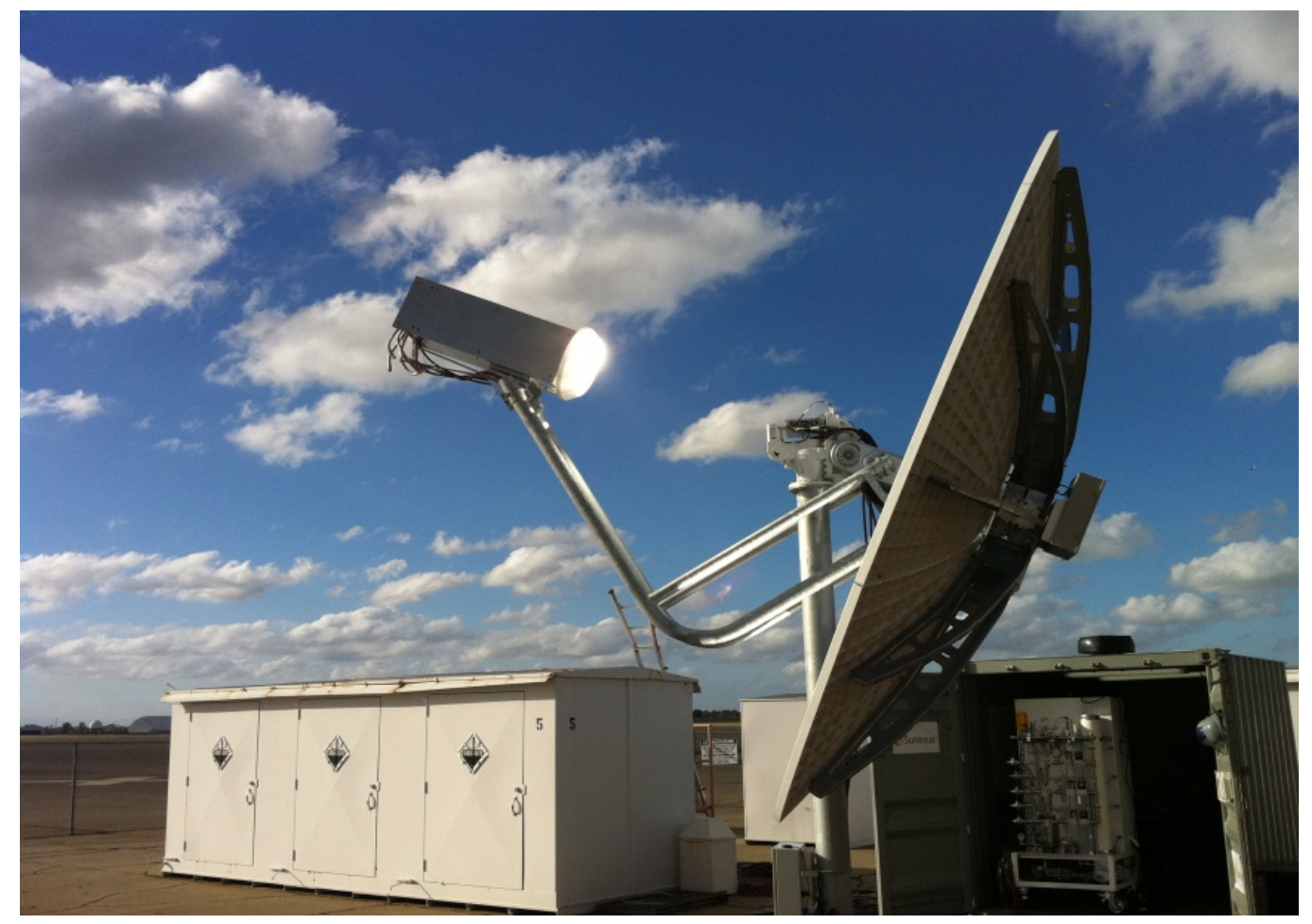

Figure 53 - Sunexus Solar Reformer Testing

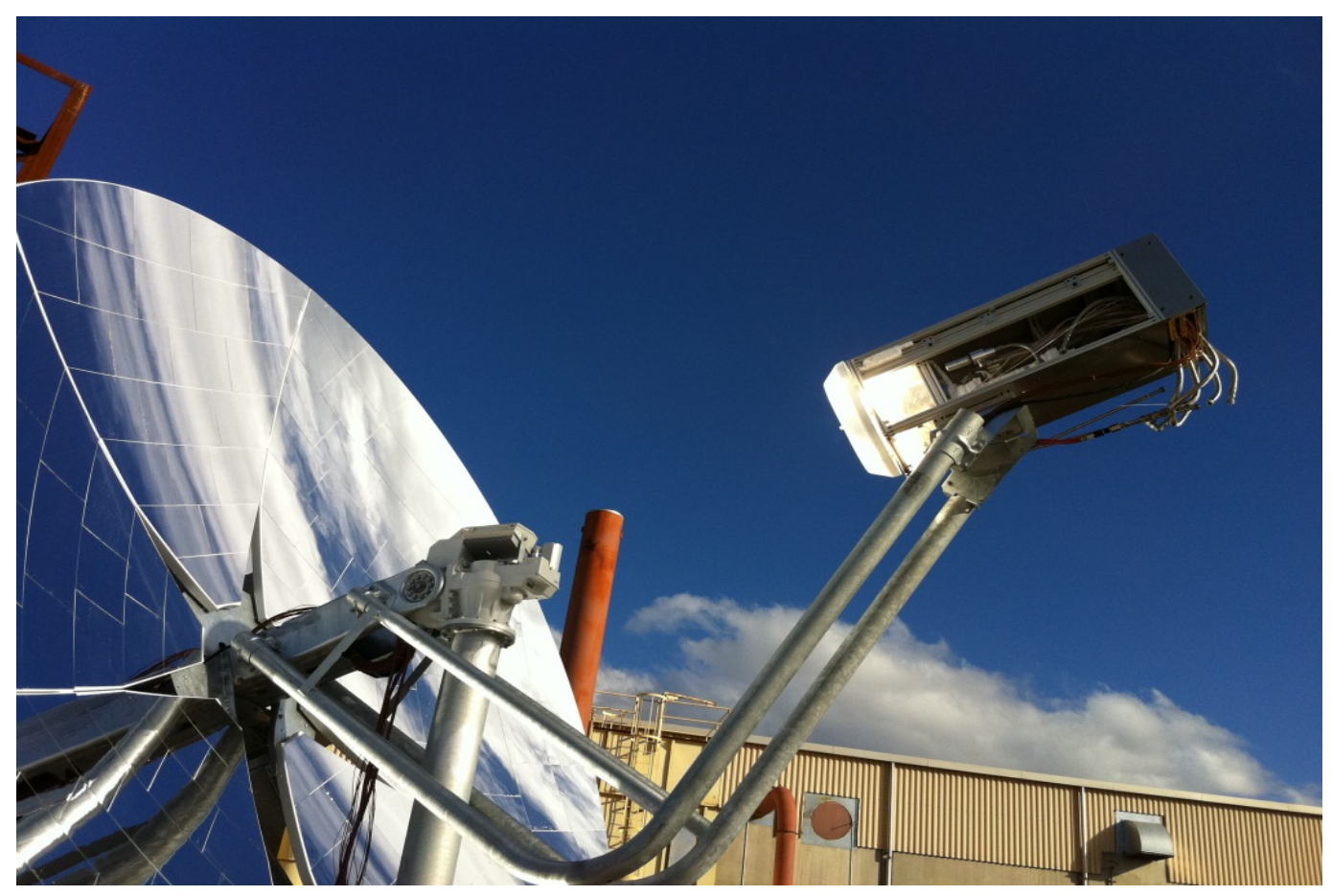

Figure 54 - Sunexus Solar Reformer Testing 
Figure 55 shows the control screen for the Sunexus Solar $\mathrm{CO}_{2}$ Reformer Control System. This system was used to control the operation of the reformer and to log test data. System temperatures, pressures and syngas composition $\left(\mathrm{H}_{2}, \mathrm{CO}, \mathrm{CH}_{4}\right.$ and $\left.\mathrm{CO}_{2}\right)$ were monitored in real-time. Figure 56 illustrates some data output from the system during an actual solar test carried out during December 2010 in the Sacramento, CA area.

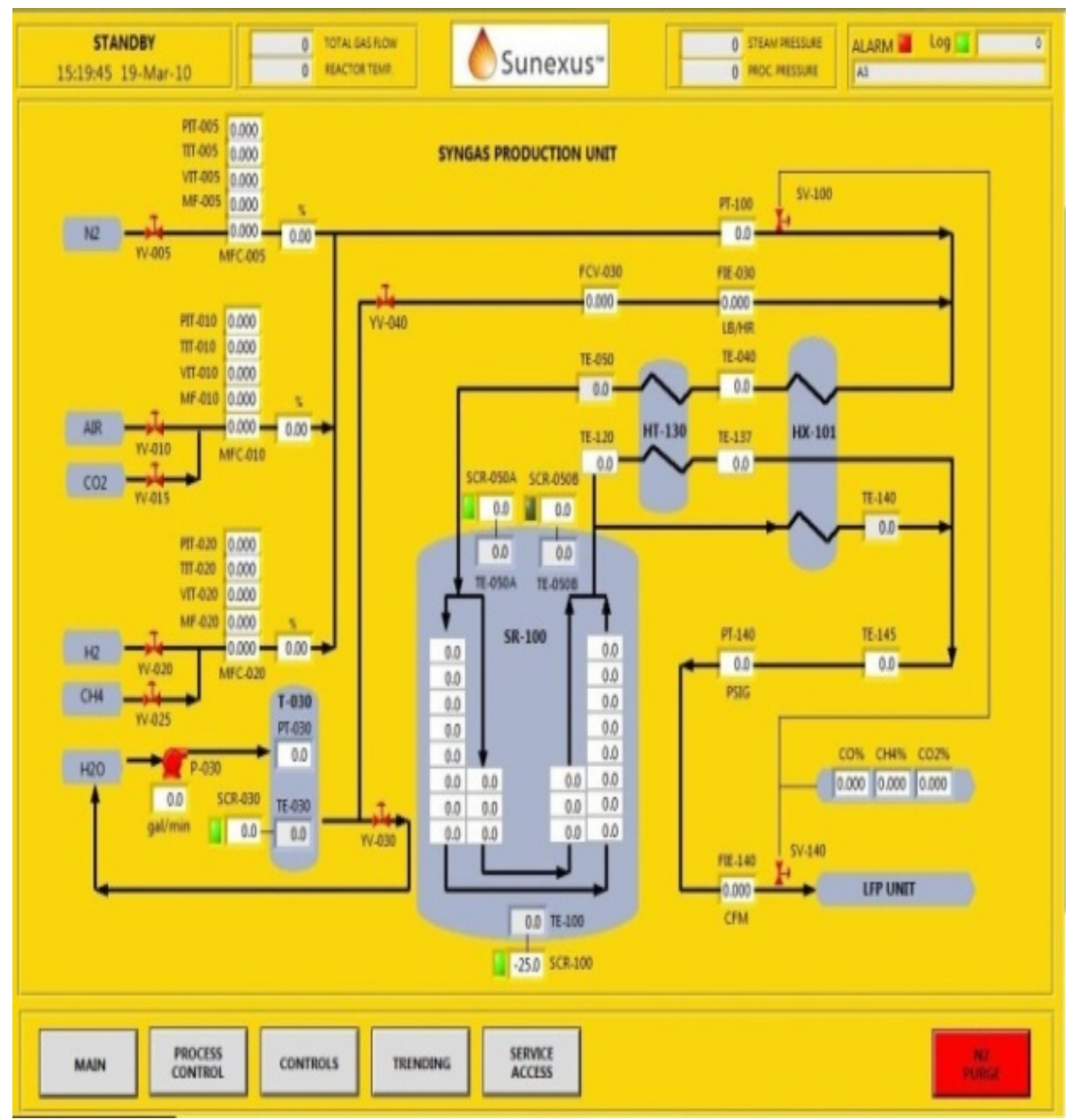

Figure 55 - Sunexus Solar CO2 Reformer Data Output 


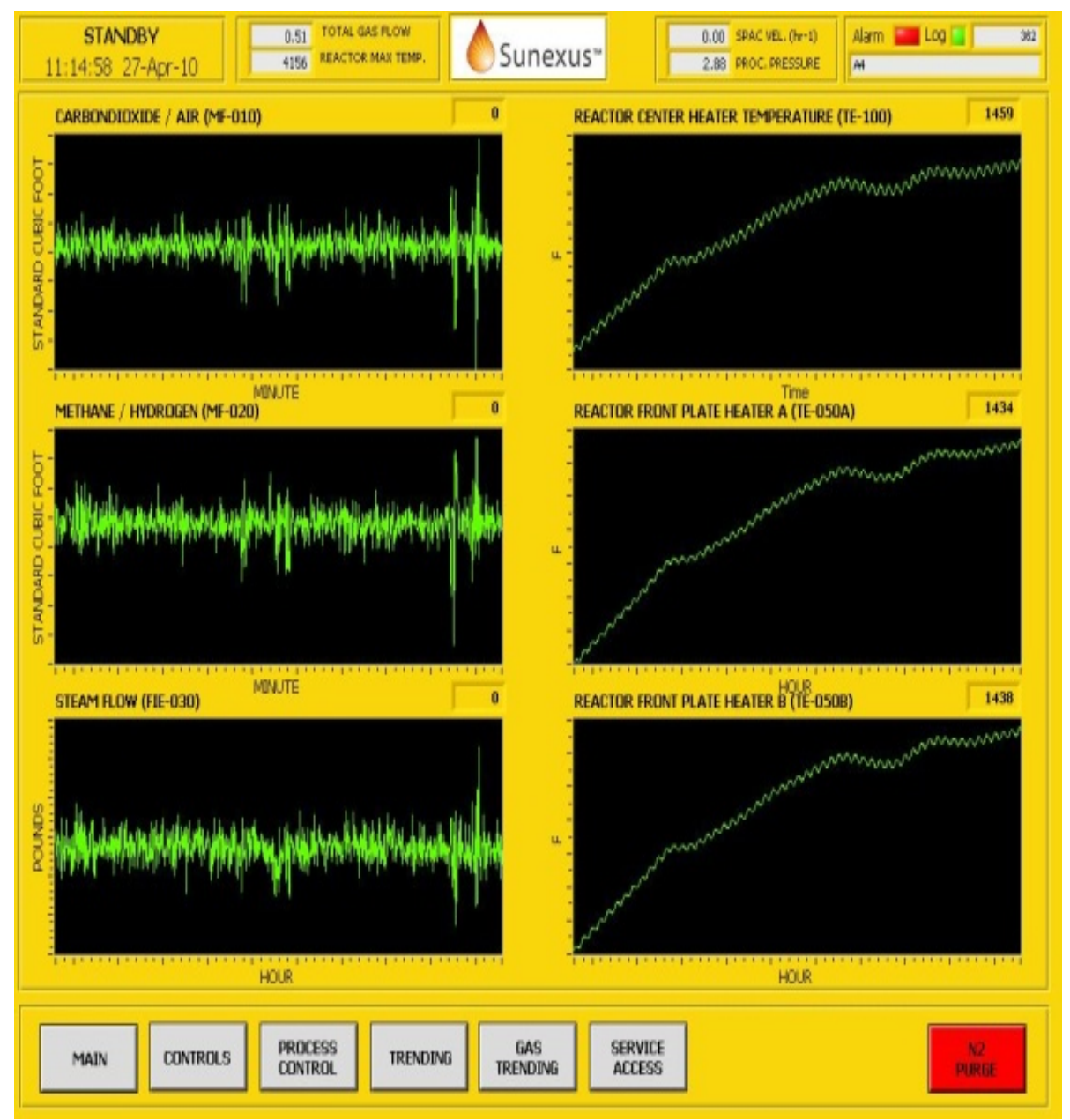

\section{Figure 56 - An Example of Time Control System Screen with Data from a Solar $\mathrm{CO}_{2}$ Reforming Test}

Under previous funding, syngas, with a composition similar to that generated from the Sunexus Solar $\mathrm{CO}_{2}$ Reformer, was directly converted to synthetic diesel fuel using Pacific Renewable Fuels and Chemicals (PRFC) Process Development Unit (PDU) illustrated in Figure 57. The development and design of this PDU was supported by the Department of Energy (contract \# DE-FC36-03GO13071) and private funding sources.

The diesel fuel produced from this system is a high quality, synthetic diesel fuel, not a biodiesel. This synthetic diesel fuel has a high cetane value, good lubricity and no sulfur. Figure 58 shows a comparison between this synthetic diesel fuel (Terra fuel) and a traditional \#2 diesel fuel. The commercial models discussed below include the integration of the Sunexus Solar Reformer with the PRFC syngas to diesel fuel process at commercial scale. 

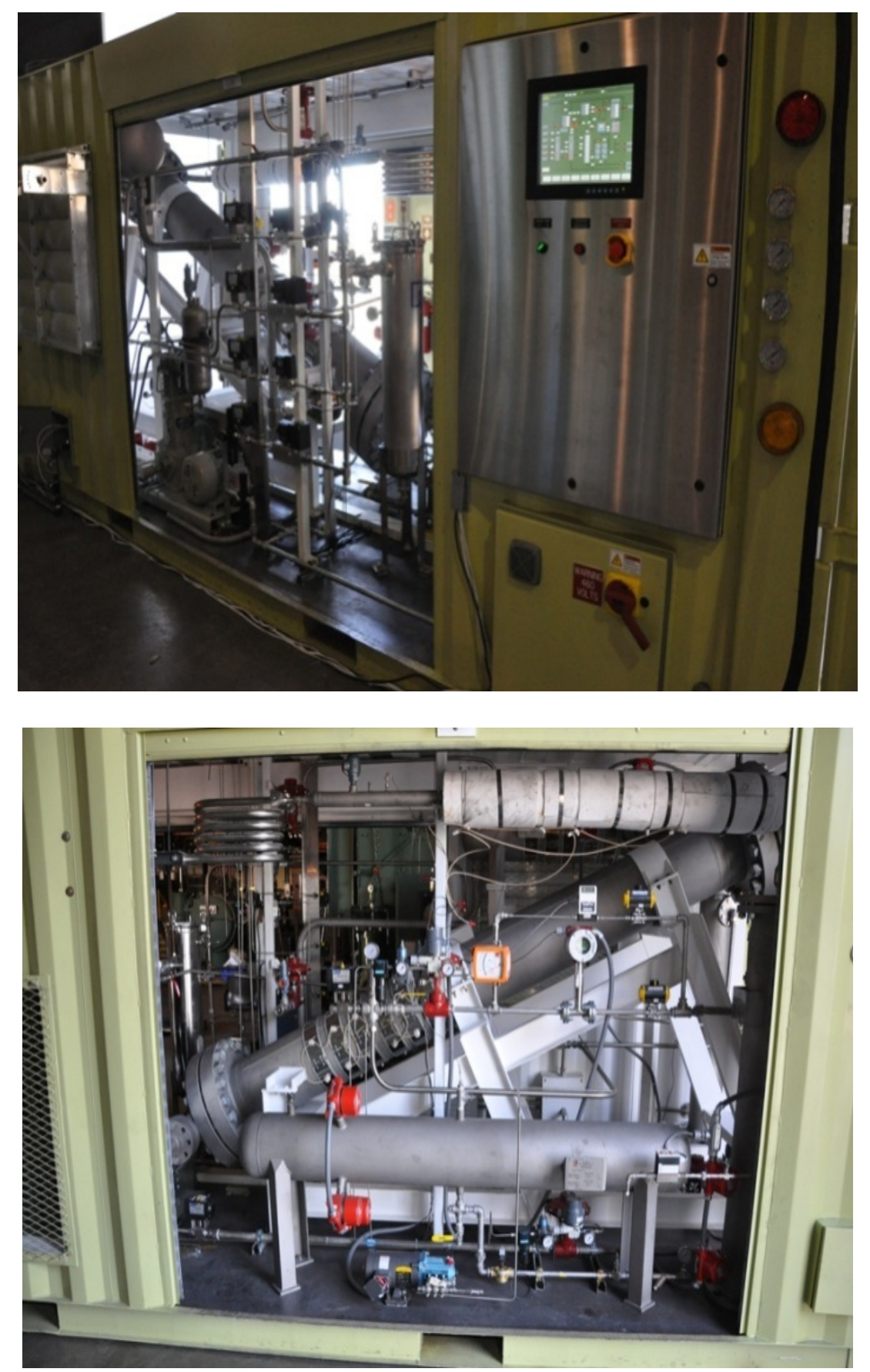

Figure 57 - The PRFC Process Development Unit (PDU) for the Conversion of Syngas to Synthetic Diesel Fuel 


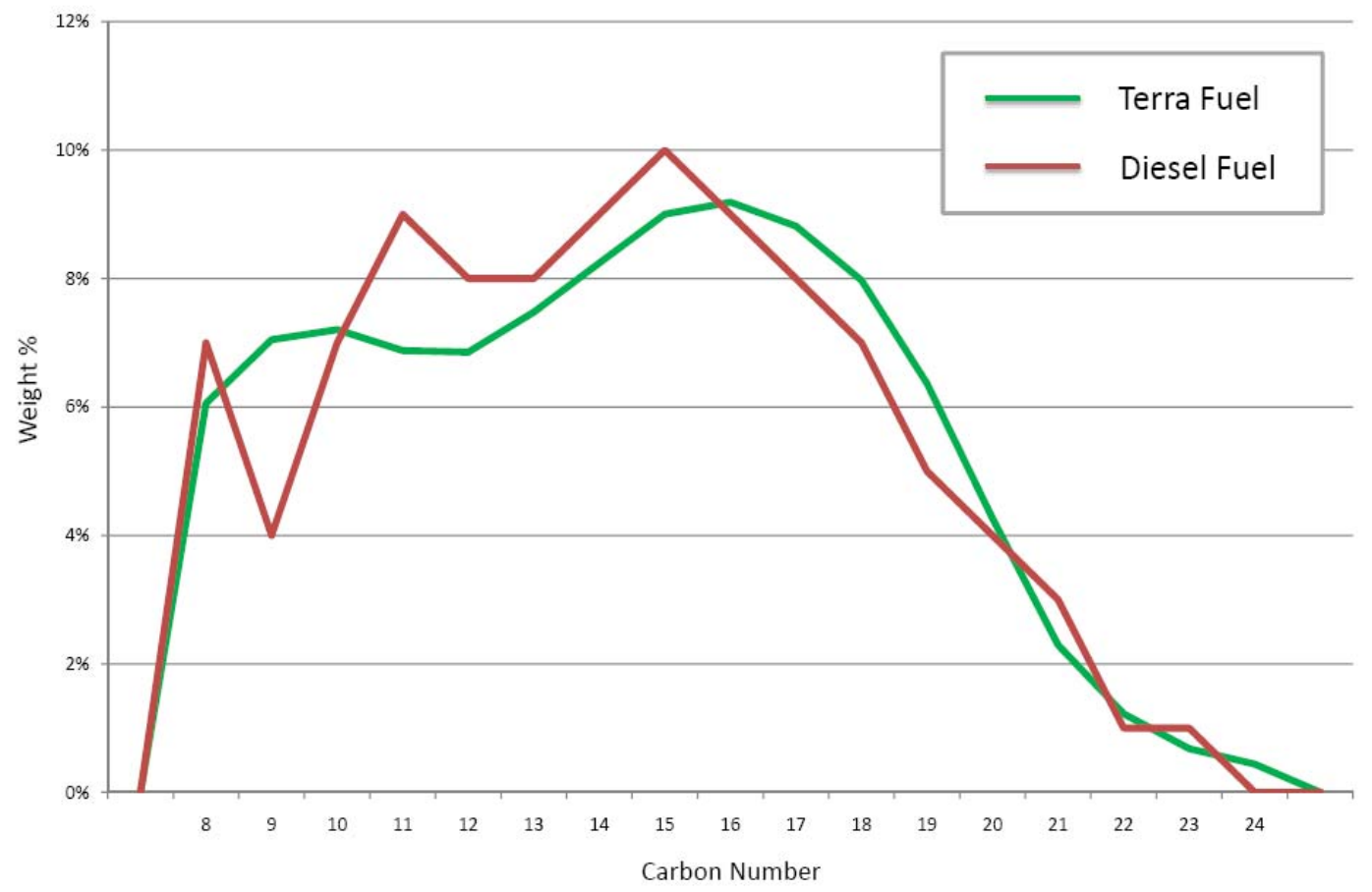

Figure 58 - The Composition (carbon \# vs. weight \%) of Synthetic Diesel Fuel (Terra Fuel) Produced from Syngas Generated Compared to Traditional \#2 Diesel Fuel 


\section{COMMERCIALIZATION PLAN}

\section{A. Integrated Process Model for the Commercial Deployment of Sunexus Technologies}

This section reviews the integrated process model that was developed for this project as well as commercialization aspects of the Sunexus technologies including an industry analysis, economic analysis, and a discussion of advantages over other processes that could utilize $\mathrm{CO}_{2}$ for the production of products. A petroleum displacement analysis and jobs creation analysis are also provided.

A fully integrated process model, using catalyst kinetics and Sunexus test data, was developed and is illustrated in Figure 59. The demonstration system flows were run and this model was used to calculate diesel fuel production yields and requirements for commercial systems at a variety of industrial sources. This model was developed using an integrated mass and energy balance models that have components that calculate solar energy requirements, commercial economics and other elements of integrated systems. In addition, a ChemCad model was developed to show flows through the fully integrated system for both the demonstration plant as well as commercial facilities.

The modeling activities performed to date show that the system will perform as expected at commercial scales and produce commercial economics that will be required for profitable plant operation (without incentives) - see the commercial economic models in Section IIIE. 
(53)

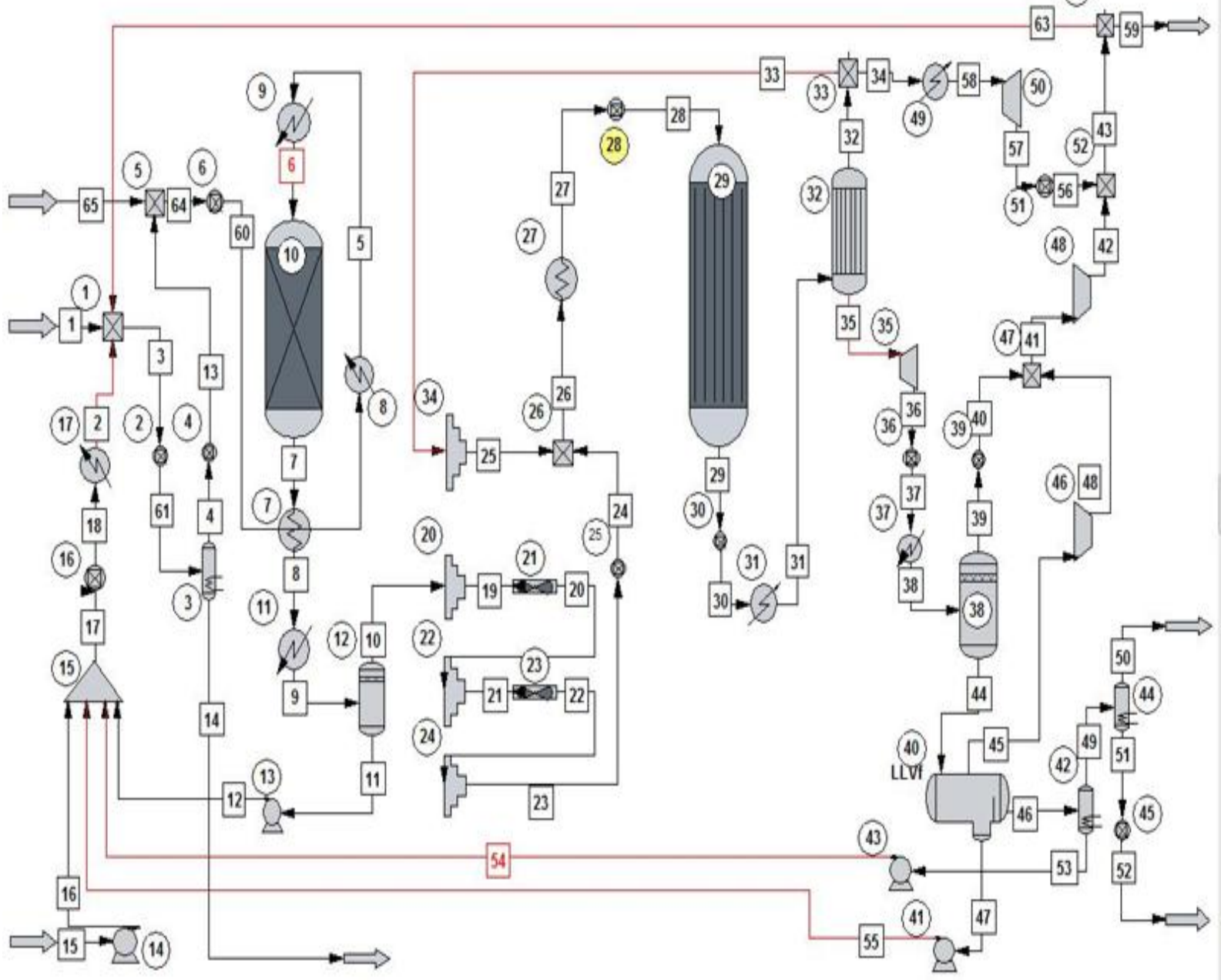

Figure 59 - Sunexus Fully Integrated Process Model

\section{B. Process Flow Diagram}

The following Process Flow Diagram (PFD) is focused around commercial systems. Note that where $\mathrm{CH}_{4}$ is discussed, Natural Gas (NG) was used and modeled as well. The substitution of $\mathrm{NG}$ for pure $\mathrm{CH}_{4}$ did not significantly change the syngas output or performance of the Solar Reformer.

A detailed Process Flow Diagram (PFD) and description is provided in Figure 60 which includes the following:

- Description of the Unit Processes and Operating Conditions (temperatures, pressures, compositions of major streams)

- Mass and Energy Balances for each Unit Process

- Equipment Descriptions 
The mass and energy balances are for the Demonstration System. In the mass and energy balance tables, streams are denoted as $[\mathrm{MX} . X]$ for mass and [HX.X] for energy. Mass balance streams are shown both in weight $(\mathrm{kg} /$ day) and mole $(\mathrm{kmol} / \mathrm{day})$. Gas and liquid product streams are discussed in both wt. \% and mol \%. Energy balance is shown in $\mathrm{MJ} / \mathrm{day}$ and enthalpy and Lower Heating Value (LHV) are shown.

The key Sunexus system metrics determined from the life cycle assessment (LCA) presented in Section IIIG. is summarized in Table 8 below:

Table 8 - A Summary of the Sunexus System Metrics

\begin{tabular}{|l|c|}
\hline Sunexus System Metric & Value \\
\hline Overall system energy efficiency* & $74.4 \%$ \\
\hline $\begin{array}{l}\mathrm{CO}_{2} \text { Utilized per Gallon of Diesel Fuel Pro- } \\
\text { duced }\end{array}$ & $2.3 \mathrm{~kg}(5.0 \mathrm{lbs})$ \\
\hline Overall $\mathrm{CO}_{2}$ balance $*$ & $90.7 \%$ Reduction \\
\hline
\end{tabular}

* See discussion in system Lifecycle Analysis (LCA).

This is the total $\mathrm{CO}_{2}$ input/sinks minus $\mathrm{CO}_{2}$ outputs/emissions. 


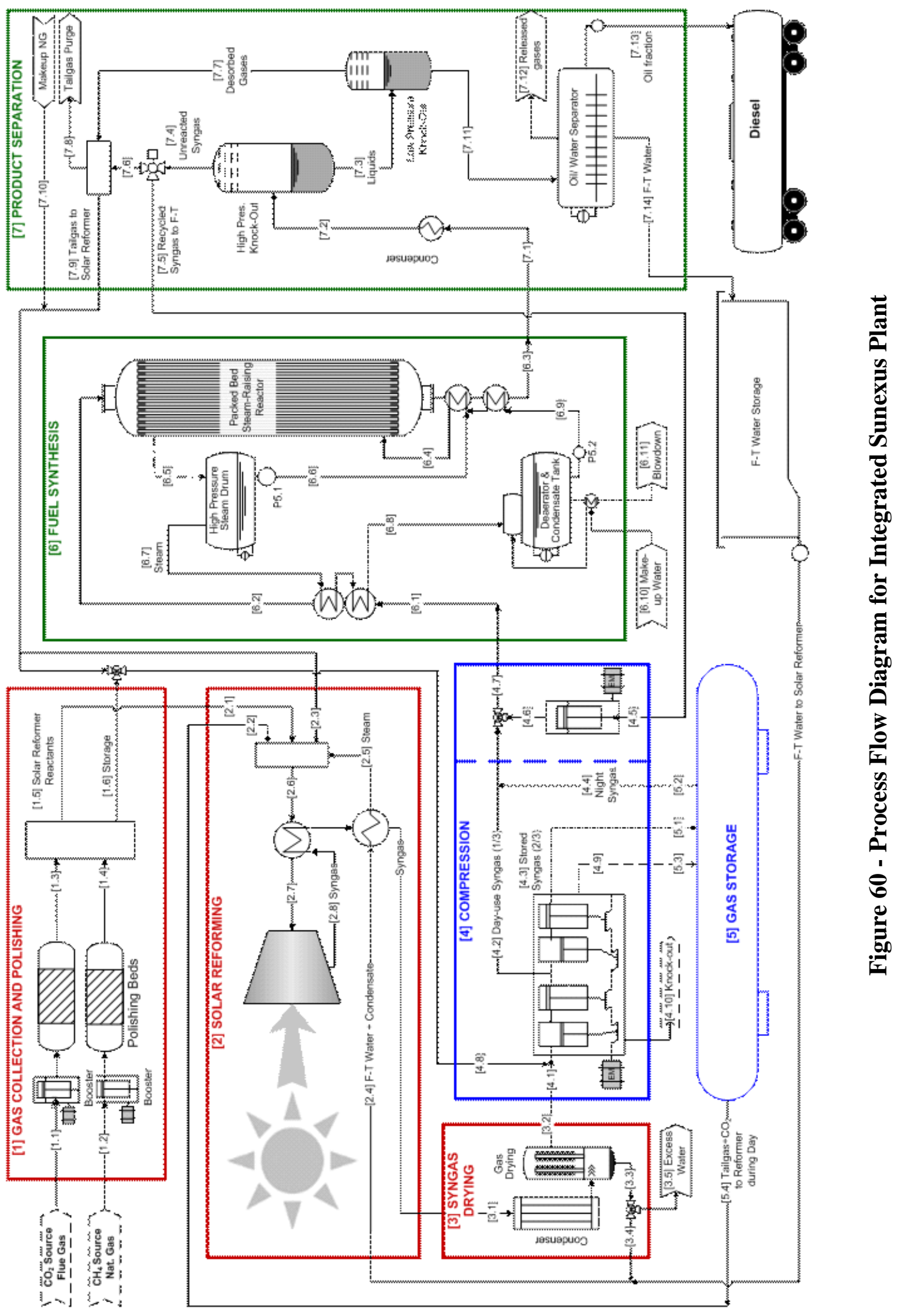




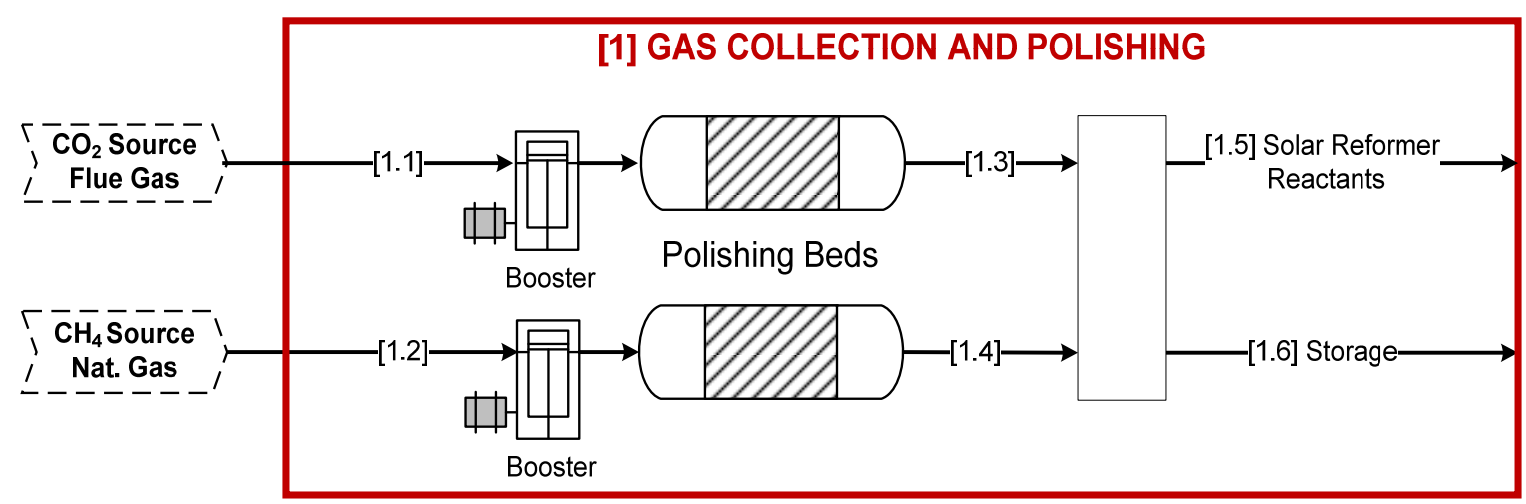

Figure 61 - Unit Process 01: Gas Collection and Polishing

\section{Description of the Unit Operation and Operating Conditions}

Unit Process 1 involves the collection, cleaning, and blending of the reactant gases.

The $\mathrm{CO}_{2}$-rich flue gas [1.1] is delivered from an oxy-combustion power plant to the Sunexus system at just above ambient pressure and temperature. A booster pump is used to get the flue gas stream up to 2 barg [29 psig] and ambient temperature. The flue gas composition is shown in Table 9.

Table 9 - Flue Gas Composition from the Oxy-combustion Power Plant

\begin{tabular}{|l|l|l|l|}
\hline Component & Units (Mole) & Value & Analysis Method \\
\hline $\mathrm{CO}_{2}$ & $\%$ & 93.6 & Orsat Analysis \\
\hline $\mathrm{O}_{2}$ & $\%$ & 5.7 & Fuel cell analyzer \\
\hline $\mathrm{H}_{2}$ & $\%$ & 0 & GC-TCD \\
\hline $\mathrm{N}_{2}$ & $\%$ & 0.7 & by difference \\
\hline $\mathrm{CO}$ & ppm & 430 & $\begin{array}{l}\text { Gas filter correlation } \\
\text { analyzer }\end{array}$ \\
\hline $\mathrm{C}_{1}\left(\mathrm{CH}_{4}\right)$ & ppm & 59.5 & GC-FID \\
\hline $\mathrm{C}_{2}$ & ppm & $<1$ & GC-FID \\
\hline $\mathrm{C}_{3}$ & ppm & $<1$ & GC-FID \\
\hline $\mathrm{C}_{4}$ & ppm & $<1$ & GC-FID \\
\hline $\mathrm{C}_{5}$ & ppm & $<1$ & GC-FID \\
\hline $\mathrm{C}_{6+}$ & ppm & $<1$ & GC-FID \\
\hline
\end{tabular}

The flue gas stream includes $\mathrm{CO}_{2}(93.6 \mathrm{~mol} \%), \mathrm{O}_{2}(5.7 \mathrm{~mol} \%)$ and the balance of the flue gas includes Carbon Monoxide (CO), Nitrogen $\left(\mathrm{N}_{2}\right)$, and $\mathrm{C} 1-\mathrm{C} 6$ hydrocarbons. Since oxygen is already in the feed stream and the flue gas stream will be used directly, without separation, oxygen will be used as part of the reactant gas stream. 
The feed gases are sent through catalytic/absorption polishing beds to remove contaminants such as sulfur and any particulate matter. The flue gas stream and the natural gas feed both contain small levels of mercaptans, a sulfur containing compound that is added to pipeline natural gas. A commercially available sulfur clean up system is used (see details below).

Gases are blended and consist of 62.2 wt. $\% \mathrm{CO}_{2}$ flue gas [1.2] and 37.8 wt. \% natural gas [1.4] (or $37.5 \mathrm{~mol} \%$ flue gas and $62.5 \mathrm{~mol} \%$ natural gas). The combination of these gases is the clean, dry reactant gases that are sent to the solar reformer [1.5].

During nighttime operation, flue gas is blended with tail gas [1.6] and is stored in a gas storage array. Unit Operation 5 below discusses gas storage.

Use of high pressure gas storage allows for 24 hour fuel production instead of operation only during sunlight hours, which can vary from 8 to 12 hours per day depending on location and time of year. For Commercial System designs, plants achieve target profitability of $>18 \%$ Internal Rate of Return (IRR) and > 18\% first year Return on Investment (ROI) without gas storage.

However, inclusion of a gas storage option at some project sites for Commercial Systems improves economics and operations (see Unit Operation 5 for discussion). The decision to use gas storage for Commercial Systems will ultimately depend on several variables including site conditions (soil, seismic), location and average solar insolation values, target diesel fuel production, and others.

During day time operation, cleaned reactant gases [1.5] are sent to Unit Operation 2, Solar Reforming.

\section{Mass and Energy Balance}

Table 10 - Mass and Energy Balance for Unit Operation 01

\begin{tabular}{|c|c|c|c|c|c|c|}
\hline \multirow{2}{*}{\multicolumn{2}{|c|}{ Material Balance }} & \multirow[b]{2}{*}{$\mathrm{kg} /$ day } & \multirow[b]{2}{*}{$\mathrm{kmol} /$ day } & \multicolumn{3}{|c|}{ Energy Balance (MJ/day) } \\
\hline & & & & & Enthalpy & LHV \\
\hline [M1.1] & $\mathrm{CO}_{2}$ source (Flue gas) & 119.72 & 2.720 & {$[\mathrm{H} 1.1]$} & $\begin{array}{l}- \\
1071.8\end{array}$ & 0 \\
\hline [M1.2] & Clean Flue gas & 119.72 & 2.720 & [H1.2] & -1071.8 & 0 \\
\hline [M1.3] & CH4 source (Natural gas) & 72.72 & 4.533 & [H1.3] & -340.5 & 3,637 \\
\hline [M1.4] & Clean Nat. gas & 72.72 & 4.533 & [H1.4] & -340.5 & 3,637 \\
\hline [M1.5] & $\begin{array}{l}\text { Daytime Reactants to Solar } \\
\text { Reformer }\end{array}$ & 112.63 & 5.440 & [H1.5] & -697.8 & 3,637 \\
\hline [M1.6] & $\begin{array}{l}\text { Nighttime Flue gas to } \\
\text { Storage }\end{array}$ & 79.81 & 1.813 & {$[\mathrm{H} 1.6]$} & -714.5 & 0 \\
\hline
\end{tabular}

\section{Equipment Descriptions}

This plant's flue gas composition is appropriate for use directly as supplied and no $\mathrm{CO} 2$ separation equipment is required. 
Pressure vessels house the catalysts for the polishing system. The Demonstration System will use the TSR-122 catalyst from Unicat Catalyst Technologies which functions under ambient temperature to remove mercaptans from natural gas and the flue gas source. No other contaminants are expected in either gas stream. The TSR-122 catalyst will efficiently remove sulfur contaminants in the $\mathrm{CO}_{2}$ gas stream until the mass of these contaminants reach about $21 \%$ of the catalyst weight. For example, if the $\mathrm{CO}_{2}$ gas stream, described in Table 10 [M1.1], contains 2 ppm of gaseous sulfur contaminants, then 400 grams of this catalyst will effectively remove these sulfur contaminants for 1.0 year of continuous system operation. The project team has used this catalyst in a variety of commercial applications and has seen good long term performance. The system hardware also includes a micron filter stage to remove any particulate matter. Other equipment includes basic piping and controls, and a booster pump to increase natural gas pressure to specified conditions. 


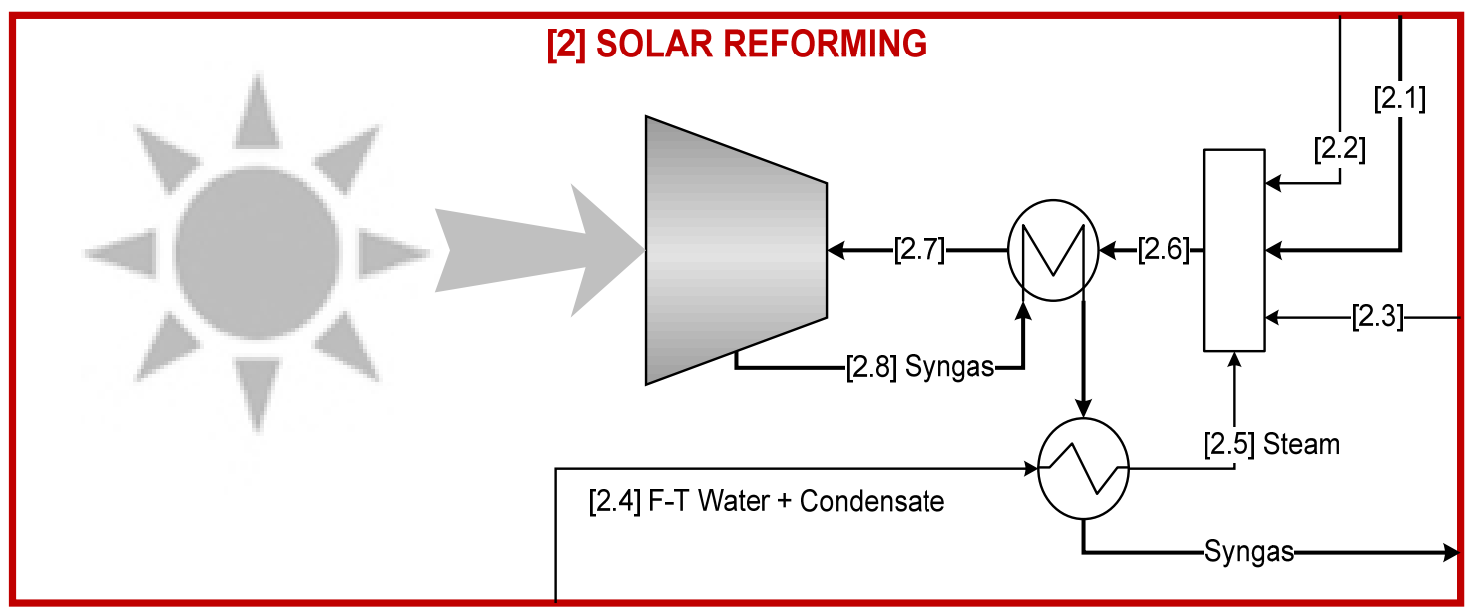

Figure 62 - Unit Process 02 (Solar Reforming)

\section{Description of the Unit Process and Operating Conditions}

Unit process 2 involves the production of syngas using the Sunexus Solar Reformer. Clean reactant gases [2.1] consisting of $62.2 \mathrm{wt} . \% \mathrm{CO}_{2}$ flue gas and $37.8 \mathrm{wt} . \%$ natural gas enter the solar reforming step.

Tailgas streams [2.2 \& 2.3] from the liquid fuel production system are merged with the feed gas stream. Tailgas composition and details discussed under Unit Operation 7, liquid fuel production product separation.

Steam is blended into the feed gas stream at a $1.4: 1 \mathrm{H}_{2} \mathrm{O}: \mathrm{CH}_{4}$ ratio. The water for the reforming is supplied by recycling the F-T water [2.4] from the liquid fuel production process as well as some condensate from the drying process. No additional outside fresh water is required after the system reaches steady state. This is important since solar concentrating installations are usually located in areas where water is a limited and expensive resource. Heat exchange is used to produce steam [2.5] from the water and to superheat the steam and gases to the receiver inlet temperature of approximately $650^{\circ} \mathrm{C}\left(1,202^{\circ} \mathrm{F}\right)$.

The F-T water [2.4] also contains emulsified wax particles and alcohols and these carbons are re-converted into syngas thus improving overall production yields. F-T water from previous programs was used during Phase 1 testing to ensure that results closely mimic an integrated system. Details on this recycle loop are discussed in Unit Processes 6 \& 7.

Hot gas exiting the Solar Reformer is used to heat the incoming gas (using heat exchange) from ambient temperature to approximately $650^{\circ} \mathrm{C}\left(1,202^{\circ} \mathrm{F}\right)$.

Merged gases enter the Sunexus Solar Reformer [2.7]. The Sunexus Solar Reformer uses concentrated solar thermal energy to catalytically reform the reactants and produce a synthesis gas of $\mathrm{H}_{2}$ and $\mathrm{CO}$. The reforming reactions take place at an average temperature of $900^{\circ} \mathrm{C}$ $\left(1,652^{\circ} \mathrm{F}\right)$ and a gas hourly space velocity (GHSV) of $13,850 \mathrm{hr}-1$. These relatively high space velocities allow for high throughput in the Solar Reformer. 
The syngas produced from the reforming process consists of $\mathrm{H}_{2}(63.4$ mole \%), $\mathrm{CO}$ (31.5 mole \%), methane $\left(0.1\right.$ mole \%) and $\mathrm{CO}_{2}(5.2 \%)$. Oxygen is completely consumed during the reforming process and no oxygen was detected during testing after the reformer. The 2:1 syngas is ideal for subsequent diesel fuel production.

Tailgas from the liquid fuel production system is recycled and with recycle loops, total $\mathrm{CO}_{2}$ conversion through the system is $98.7 \%$ and total methane conversion is 99.8 .

\section{Mass and Energy Balance}

Table 11 - Mass and Energy Balance for Unit Operation 02

\begin{tabular}{|ll|c|c|l|c|c|}
\hline \multicolumn{2}{|c}{ Material Balance } & \multicolumn{2}{c}{ kg/day } & \multicolumn{3}{c|}{ Energy Balance (MJ/day) } \\
& & 112.63 & 5.44 & {$[\mathrm{H} 2.1]$} & -698 & 3,637 \\
\hline$[\mathrm{M} 2.1]$ & Daytime Reactants & 242.39 & 8.72 & {$[\mathrm{H} 2.2]$} & $-1,630$ & 3,773 \\
\hline$[\mathrm{M} 2.2]$ & Gases stored during night & 81.29 & 3.46 & {$[\mathrm{H} 2.3]$} & -458 & 1,887 \\
\hline$[\mathrm{M} 2.3]$ & Daytime Tailgas from F-T & 285.31 & 15.84 & {$[\mathrm{H} 2.4]$} & $-4,525$ & -700 \\
\hline$[\mathrm{M} 2.4]$ & F-T Water + Condensate & 285.31 & 15.84 & {$[\mathrm{H} 2.5]$} & $-3,769$ & -700 \\
\hline$[\mathrm{M} 2.5]$ & Steam $\left(289^{\circ} \mathrm{C}\right)$ & 721.62 & 33.45 & {$[\mathrm{H} 2.6]$} & $-6,554$ & 8,597 \\
\hline$[\mathrm{M} 2.6]$ & Combined reactants & 721.62 & 33.45 & {$[\mathrm{H} 2.7]$} & $-5,782$ & 8,597 \\
\hline$[\mathrm{M} 2.7]$ & Heated reactants & 721.62 & 54.85 & {$[\mathrm{H} 2.8]$} & $-2,782$ & 11,156 \\
\hline$[\mathrm{M} 2.8]$ & Syngas & & & & & \\
\hline
\end{tabular}

\section{Equipment Descriptions}

For Commercial Systems, two plant configurations are possible. Either an array of concentrating dishes or a power tower technology is used. Renderings of commercial plants are shown in the Summary. Power towers, or central receiver systems, use thousands of individual suntracking mirrors, called heliostats, to reflect solar energy onto a receiver located atop a tall tower. The solar reactor in power tower applications consists of a larger array of tubes packed with catalyst. Tube length and diameter may change, but overall design concepts stay the same between dish and power tower Sunexus Solar Reactors. 


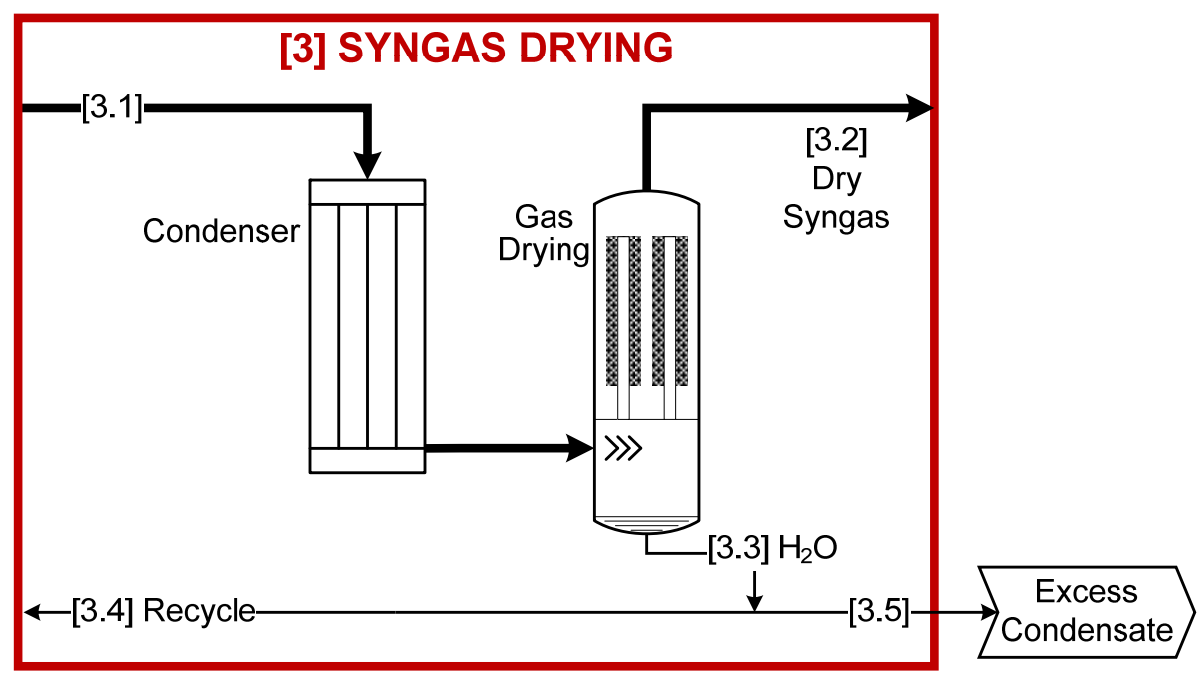

Figure 63 - Unit Process 03 (Syngas Drying)

\section{Description of the Unit Process}

Syngas drying involves preparing the gas for subsequent conversion to diesel fuel by eliminating water before the compression step. The incoming syngas [3.1] is cooled to condense out excess water [3.3] and is then sent through a coalescing filter to dry the syngas.

Some water is recycled [3.4], but since there is excess water in the system some of the clean water is discharged [3.5]. Dry syngas [3.2] enters the compression step.

\section{Mass and Energy Balance}

Table 12 - Mass and Energy Balance for Unit Operation 03

\begin{tabular}{|cl|c|c|c|c|c|}
\hline \multicolumn{2}{|c|}{ Material Balance } & \multicolumn{3}{c|}{ kg/day } & \multicolumn{3}{c|}{ kmol/day } & \multicolumn{3}{c|}{ Enthalpy } & LHV \\
\hline$[\mathrm{M} 3.1]$ & Wet Syngas & 721.62 & 54.85 & {$[\mathrm{H} 3.1]$} & $-4,757$ & 11,156 \\
\hline$[\mathrm{M} 3.2]$ & Dry Syngas & 603.26 & 48.28 & {$[\mathrm{H} 3.2]$} & $-2,872$ & 11,442 \\
\hline$[\mathrm{M} 3.3]$ & Condensate & 118.36 & 6.569 & {$[\mathrm{H} 3.3]$} & $-1,884$ & -286.0 \\
\hline$[\mathrm{M} 3.4]$ & Cond. Recycled & 41.94 & 2.328 & {$[\mathrm{H} 3.4]$} & -665 & -102.9 \\
\hline$[\mathrm{M} 3.5]$ & Cond. Excess & 76.42 & 4.241 & {$[\mathrm{H} 3.5]$} & $-1,219$ & -183.1 \\
\hline
\end{tabular}

\section{Equipment Descriptions}

The condenser is built from a counter flow stainless steel heat exchanger. Chilled water is used to cool the syngas and condense water. Coalescing filter vessel and filter media are standard gas drying components in the industry. Other equipment includes piping, valves, and controls.

Commercial projects will have similar hardware as the demonstration project: condensers; coalescing vessels; piping; valves; and controls. 


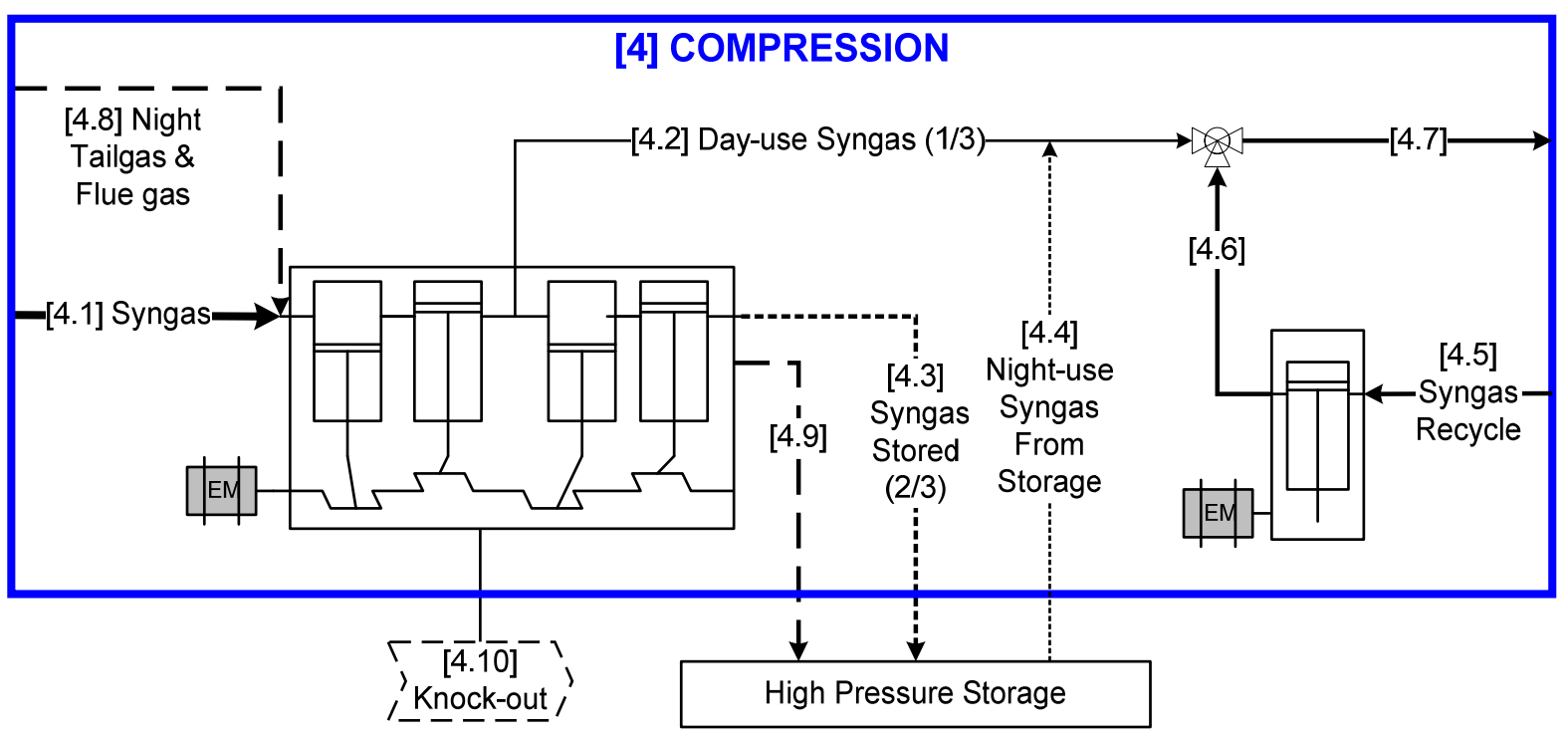

Figure 64 - Unit Process 04 (Compression)

\section{Description of the Unit Process}

In Unit Process 4, a multistage compressor is used for compressions of the syngas for fuel synthesis as well as compression of gas for storage operations.

During daytime operation, clean, dry syngas [4.1] enters the compression step. Approximately $1 / 3$ of the syngas [4.2] is compressed up to the operating pressure for liquid fuel production, 27.6 barg (400 psig), and the remainder (2/3) is compressed and stored [4.3] in high pressure storage vessels for use during nighttime F-T operation, as described below.

During the nighttime operation, this same multistage compressor is used to compress and store in the high pressure vessels the recycled tailgas produced by the liquid fuel production process and the flue gas produced by the power plant during the night [4.8]. Note that since an array of individual tubes is used, tubes can be emptied of syngas and then refilled with tailgas.

A single stage booster compressor is used to continuously recycle unreacted syngas from the liquid fuel production process. 


\section{Mass and Energy Balance}

Table 13 - Mass and Energy Balance for Unit Operation 04

\begin{tabular}{|ll|l|l|l|l|l|}
\hline \multicolumn{2}{|c|}{ Material Balance } & \multicolumn{2}{c}{ kg/day } & \multicolumn{3}{c|}{ Energy Balance (MJ/day) } \\
& \multicolumn{2}{|c|}{$\begin{array}{l}\text { Enthalpy } \\
\text { LHV }\end{array}$} \\
\hline$[\mathrm{M} 4.1]$ & Dry Syngas & 603.26 & 48.28 & {$[\mathrm{H} 4.1]$} & $-2,872$ & 11,442 \\
\hline$[\mathrm{M} 4.2]$ & $\begin{array}{l}\text { 1/3 Syngas to F-T during day } \\
\text { time }\end{array}$ & 201.09 & 16.09 & {$[\mathrm{H} 4.2]$} & -957 & 3,814 \\
\hline$[\mathrm{M} 4.3]$ & $\begin{array}{l}\text { 2/3 Syngas store for F-T night } \\
\text { operation }\end{array}$ & 402.17 & 32.19 & {$[\mathrm{H} 4.3]$} & $-1,915$ & 7,628 \\
\hline$[\mathrm{M} 4.4]$ & $\begin{array}{l}\text { Nighttime flow of stored } \\
\text { syngas }\end{array}$ & 402.17 & 32.19 & {$[\mathrm{H} 4.4]$} & $-1,915$ & 7,628 \\
\hline$[\mathrm{M} 4.5]$ & Recycled Syngas & 3,154 & 122.4 & {$[\mathrm{H} 4.5]$} & $-19,044$ & 47,950 \\
\hline$[\mathrm{M} 4.6]$ & Compressed Recycled Syngas & 3,154 & 122.4 & {$[\mathrm{H} 4.6]$} & $-19,033$ & 47,950 \\
\hline$[\mathrm{M} 4.7]$ & Combined Syngas to F-T & 3,749 & 170.3 & {$[\mathrm{H} 4.7]$} & $-21,106$ & 59,418 \\
\hline$[\mathrm{M} 4.8]$ & $\begin{array}{l}\text { Nighttime Flue gas and F-T } \\
\text { Tailgas }\end{array}$ & 242.39 & 8.723 & {$[\mathrm{H} 4.8]$} & $-1,630$ & 3,773 \\
\hline$[\mathrm{M} 4.9]$ & Compressed Night gases & 242.39 & 8.723 & {$[\mathrm{H} 4.9]$} & $-1,630$ & 3,773 \\
\hline$[\mathrm{M} 4.10]$ & Compressor knock-out & 7.940 & 0.441 & {$[\mathrm{H} 4.10]$} & -126.23 & -19.00 \\
\hline
\end{tabular}

\section{Equipment Descriptions}

The existing liquid fuel production system includes three Corken compressors that can achieve 68.9 barg [1000 psi]. These system compressors will be upgraded to accommodate higher pressure (approximately 151.9 barg [2200 psi]) for demonstration of the syngas storage option. The existing liquid fuel production system booster compressor will be used as-is. For commercial systems, compressors may be steam driven to reduce external energy requirements.

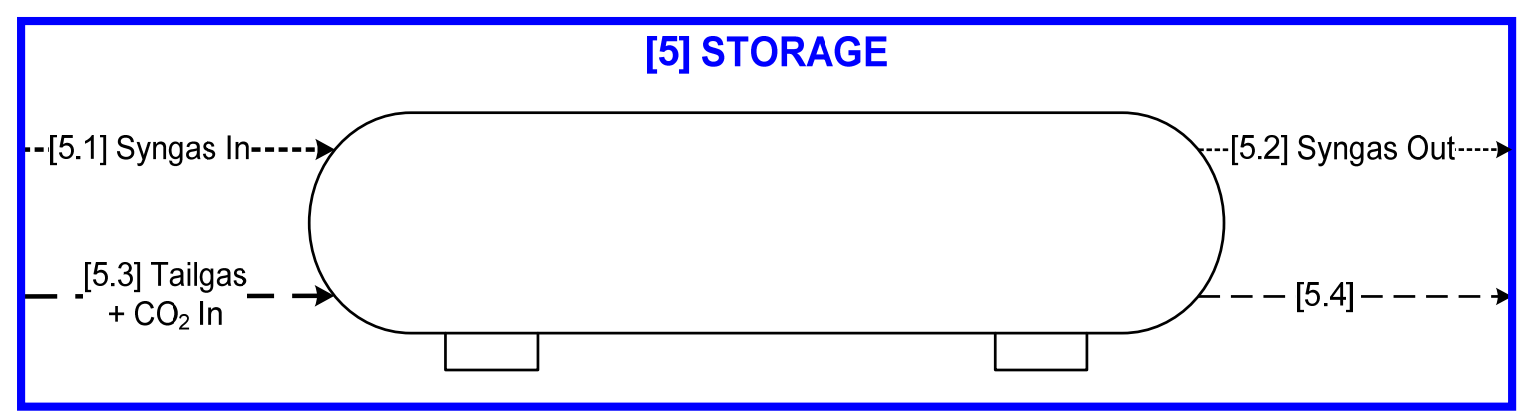

Figure 65 - Unit Process 05 (Storage) 


\section{Description of the Unit Process}

Use of high pressure syngas storage allows for 24 hour fuel production instead of operation only during sunlight hours, which can vary from 8 to 12 hours per day depending on location and time of year. For Commercial System designs, plants achieve target profitability of $>$ $18 \%$ Internal Rate of Return (IRR) and $>18 \%$ first year Return on Investment (ROI) without gas storage.

However, inclusion of a gas storage options at some project sites for Commercial Systems improves economics and operations. The decision to use gas storage for Commercial Systems will ultimately depend on several variables including site conditions (soil, seismic), location and average solar insolation values, target diesel fuel production, and others.

Since this option may be used in some Commercial Systems, the project team felt that demonstration of gas storage was important as part of the Demonstration System in Bakersfield, California. However, this option is not required for profitable commercial operation.

A 2008 DOE/NETL report, "An Engineering-Economic Analysis of Syngas Storage"” highlights the benefits of using syngas storage with an IGCC facility in order to store syngas (in high pressure storage vessels) and produce power when daily prices are high. As summarized in the paper, "Adding a second turbine to use the stored syngas to generate electricity at peak hours and implementing 12 hours of above ground high pressure syngas storage significantly increases the ROI ( $\sim 13$ percentage points over the non-storage option) and increases net present value." Although this is a different application, the economic benefits were found to be attractive for syngas storage at some Sunexus plants and therefore this feature will be demonstrated during future planned work.

The high pressure storage system consists of an array of tubes similar to those found in tube trailers. During daytime operations, syngas [5.1] is stored for subsequent nighttime usage. During nighttime operations, stored syngas [5.3] is regulated down to $27.6 \mathrm{barg}$ (400 psig) for use in the liquid fuel production system. While syngas is being emptied from the storage array, empty tubes are filled with a mix of tailgas and flue gas [5.2] that will then be used during daytime operations [5.4].

The configuration described above allows for 24 hour capture of flue gas and 24 hour diesel fuel production, thus maximizing plant capital investment.

The project team has developed control system strategies to accommodate this feature and will demonstrate this option at the plant site in Bakersfield.

The project team has calculated that compression energy for storing the gases is $<5 \%$ of the energy in the stored gas, thus the energy consumption for implementing a storage option is not unreasonable. Steam driven compressors can be used in commercial applications to reduce energy requirements. Note again that gas storage is not needed for profitable Commercial Systems and systems can be designed to be run continuously during daytime operations. However, in some cases inclusion of storage provides economic benefits. For this reason, the 
team feels that it is important to demonstrate this feature as part of a fully integrated system during future work.

\section{Mass and Energy Balance}

Table 14 - Mass and Energy Balance for Unit Operation 05

\begin{tabular}{|c|c|c|c|c|c|c|}
\hline \multirow{2}{*}{\multicolumn{2}{|c|}{ Material Balance }} & \multirow[b]{2}{*}{$\mathrm{kg} /$ day } & \multirow[b]{2}{*}{$\mathrm{kmol} /$ day } & \multicolumn{3}{|c|}{ Energy Balance (MJ/day) } \\
\hline & & & & & Enthalpy & LHV \\
\hline [M5.1] & Syngas stored during day & 402.17 & 32.19 & {$[\mathrm{H} 5.1]$} & $-1,915$ & 7,628 \\
\hline [M5.2] & Syngas to F-T system at night & 402.17 & 32.19 & [H5.2] & $-1,915$ & 7,628 \\
\hline [M5.3] & $\begin{array}{l}\text { Flue gas and Tailgas stored at } \\
\text { night }\end{array}$ & 242.39 & 8.723 & [H5.3] & $-1,630$ & 3,773 \\
\hline [M5.4] & Flue + Tailgas to Solar Reformer & 242.39 & 8.723 & [H5.4] & $-1,630$ & 3,773 \\
\hline
\end{tabular}

\section{Equipment Descriptions}

High pressure tubular gas vessels (as shown below) will be procured to store approximately $774,000 \mathrm{~L} /$ day $\left(27,000 \mathrm{ft}^{3} /\right.$ day $)$ at standard conditions of gas. The system is sized for daytime storage volumes of syngas. Night time storage volumes are $<20 \%$ of daytime requirements, which allows the gas to be stored at lower pressures $(<1,000 \mathrm{psi})$. This enables the night time $\mathrm{CO} 2$ rich gas to be stored at pressures well below the liquefaction pressure of $\mathrm{CO} 2$ if this is desired in the final design.

While several storage options were reviewed for this project, compressed gas storage using a storage array is the simplest and most economical solution and only requires a compressor and storage array. An expander can be used to recover energy from the pressurized gas.

For this demonstration project, high pressure tube array was designed and quotes from several vendors were provided for vessels capable of storing the target gas mixes (Figure 65).

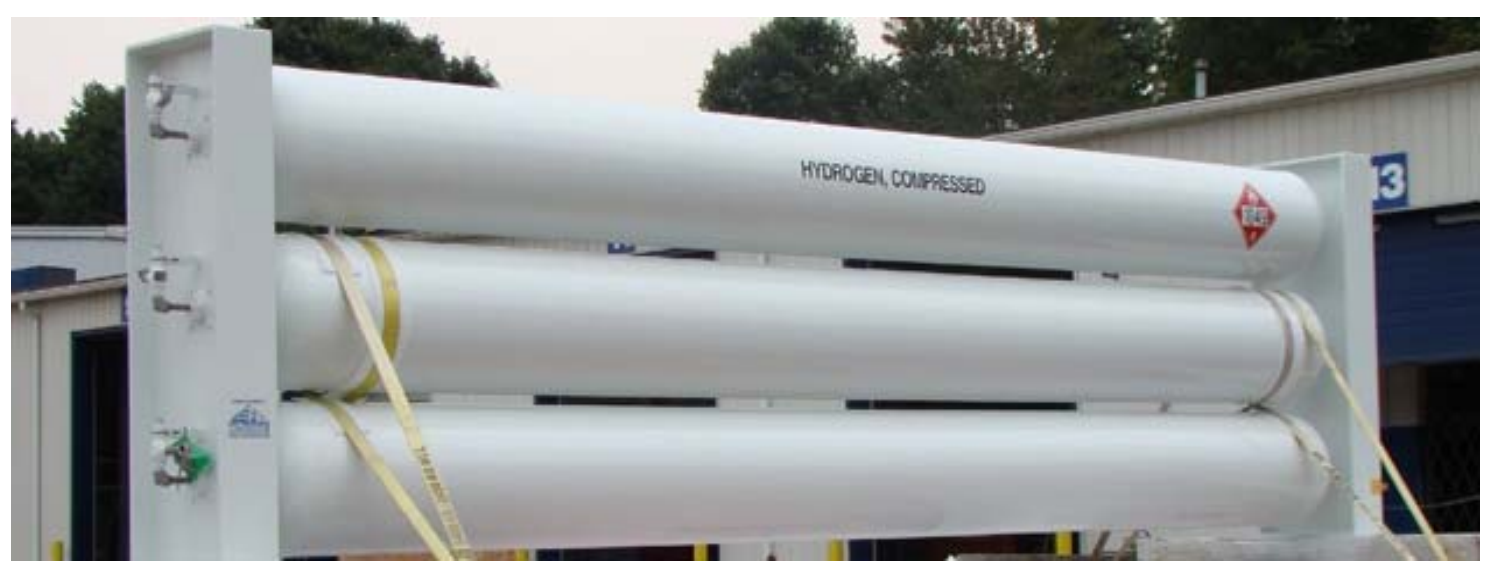

Figure 66 - Gas storage array for Demonstration System 


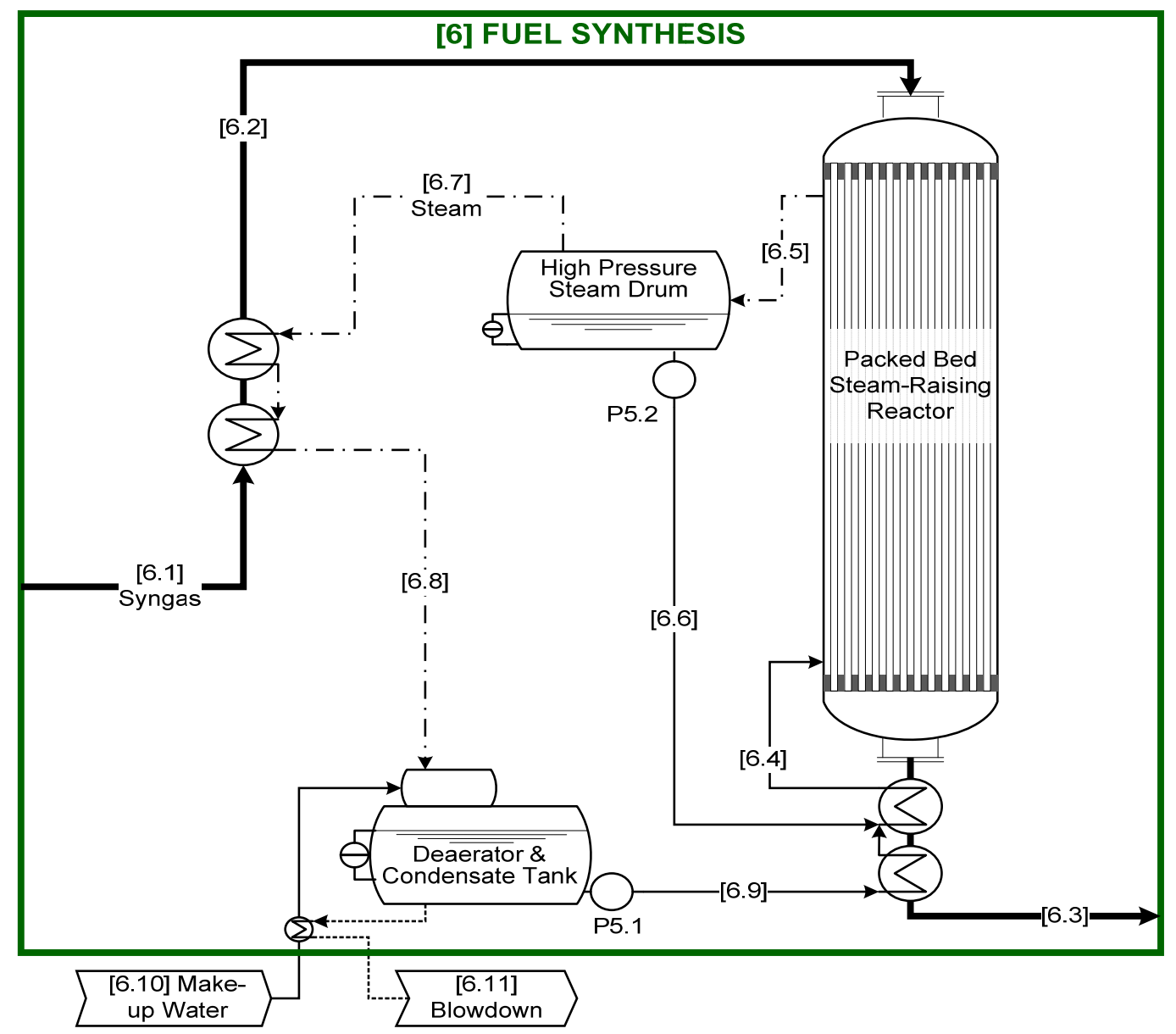

Figure 67 - Unit Process 06 (Fuel Synthesis)

\section{Description of the Unit Process}

Unit Process 6 includes production of diesel fuel and byproducts from syngas. Syngas [6.1] enters this unit process at 27.6 barg (400 psig) and enters a series of heat exchangers that heat the gas to a target temperature of $210^{\circ} \mathrm{C}\left(410^{\circ} \mathrm{F}\right)$ before entering the top of the reactor. In the reactor, the exothermic heat of reaction is removed via boiling of pressurized water in the shell. The shell-side pressure is controlled so that the water bubble point temperature and heat removal rate create the desired average catalyst temperature of $210^{\circ} \mathrm{C}\left(410^{\circ} \mathrm{F}\right)$. Coolant water [6.4] is actively pumped through the shell to maintain good heat transfer rates and $1 \%$ steam quality (mass basis). 


\section{Mass and Energy Balance}

Table 15 - Mass and Energy Balance for Unit Operation 06

\begin{tabular}{|c|c|c|c|c|c|c|}
\hline \multirow{2}{*}{\multicolumn{2}{|c|}{ Material Balance }} & \multirow[b]{2}{*}{$\mathrm{kmol} /$ day } & \multirow[b]{2}{*}{$\mathrm{kg} /$ day } & \multicolumn{3}{|c|}{ Energy Balance (MJ/day) } \\
\hline & & & & & Enthalpy & LHV \\
\hline [M6.1] & Syngas to F-T & 212.7 & 4,610 & [H6.1] & $-31,377$ & 65,366 \\
\hline [M6.2] & Preheated Syngas & 212.7 & 4,610 & [H6.2] & $-30,095$ & 65,366 \\
\hline [M6.3] & F-T Reactor exit & 184.2 & 4,610 & [H6.3] & $-32,282$ & 62,419 \\
\hline [M6.4] & $\begin{array}{l}\text { Cooling water into reactor } \\
\text { shell }\end{array}$ & 6,657 & 119,932 & {$[\mathrm{H} 6.4]$} & 101,614 & \\
\hline [M6.5] & Exit cooling water + steam & 6,657 & 119,932 & [H6.5] & 105,435 & \\
\hline [M6.6] & Recycled cooling water & 6,591 & 1,199 & [H6.6] & 102,086 & \\
\hline [M6.7] & Steam & 66.5 & 118,733 & [H6.7] & 3,349 & \\
\hline [M6.8] & Steam condensate & 66.5 & 118,733 & [H6.8] & 752.0 & \\
\hline [M6.9] & Feed water & 67.8 & 118,757 & [H6.9] & 753.0 & \\
\hline [M6.10] & Cooling water make-up & 1.3 & 24.0 & [H6.10] & 3.0 & \\
\hline [M6.11] & Blow down & 1.3 & 24.0 & [H6.11] & 4.0 & \\
\hline
\end{tabular}

\section{Equipment Description}

For Commercial Systems, all system components will be appropriately sized and multiple catalytic reactors will be used depending on the throughput capacity of the plant. The larger reactors use the same tube and shell design and same tube diameter (1"), therefore limiting scale up risk. This is one of the major advantages of tube-in-shell reactor designs.

All other system components are similar for Commercial Systems, which will be appropriately sized for the capacity of the plant. 


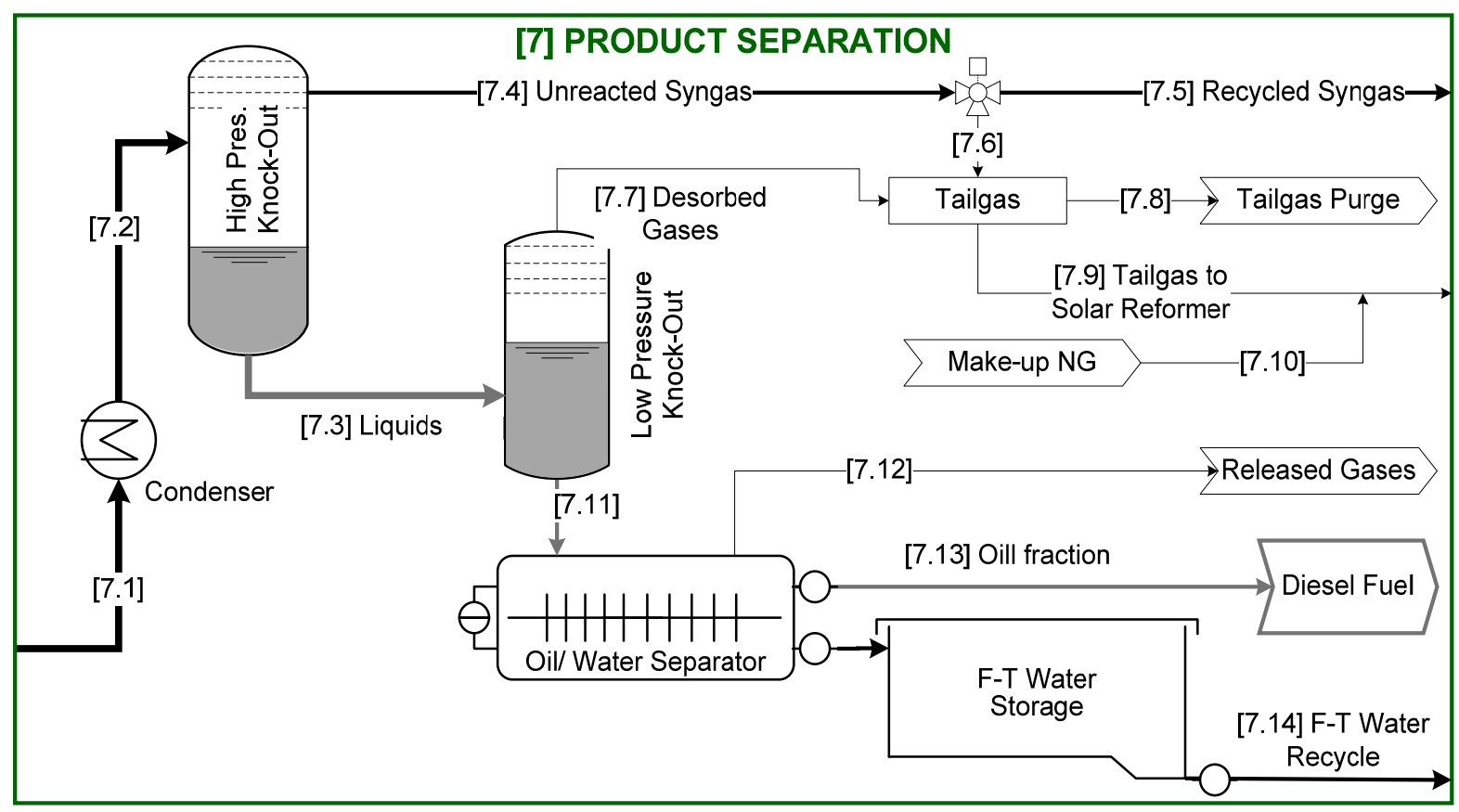

Figure 68 - Unit Process 07 (Product Separation)

\section{Description of the Unit Process}

Following the catalytic reaction, the products [7.1] are cooled and condensed to separate the liquid from unconverted syngas and gaseous products. The cooled stream is first sent to a high pressure knock-out vessel to separate the two phases. The pressurized liquids are then depressurized into a low pressure knock out vessel which releases absorbed gases.

Gases from the knock-out (KO) vessels are collected and recycled. The high pressure KO gas is unreacted syngas and is directly recycled back to the F-T reactor. The un-recycled syngas is then combined with the low pressure KO gases and the combination (called "tailgas") is recycled to the Solar Reformer for reconversion to syngas.

The Tailgas is comprised of $36 \% \mathrm{CO}_{2}$ and $19 \% \mathrm{CH}_{4}$, with the balance of $28 \% \mathrm{H}_{2}, 13 \% \mathrm{CO}$, and light hydrocarbons. Make up methane or natural gas is added to get the tailgas $\mathrm{CO}_{2}: \mathrm{CH}_{4}$ ratio to 0.7 : 1 . When recycled, the $\mathrm{CO}_{2}, \mathrm{CH}_{4}$, and light hydrocarbons are converted to syngas.

Diesel fuel is the only product exiting the Sunexus process, all other streams are able to be recycled and reused. The fugitive emissions [7.12] are those gases still entrained in the liquids that eventually will release. Tailgas purge [7.8] can be used in commercial systems to produce electricity with an attached genset. Emissions capture technology installed on storage tanks and transport vessels can mitigate these being released to the atmosphere. 


\section{Mass and Energy Balance}

Table 16 - Mass and Energy Balance for Unit Operation 07

\begin{tabular}{|ll|l|l|l|l|l|}
\hline \multicolumn{2}{|c}{ Material Balance } & \multicolumn{2}{c}{ kg/day } & \multicolumn{2}{c|}{ kmol/day } & \multicolumn{3}{c|}{ Energy Balance (MJ/day) } \\
\hline$[\mathrm{M} 7.1]$ & F-T products & 3,749 & 143.9 & {$[\mathrm{H} 7.1]$} & $-22,619$ & 56,766 \\
\hline$[\mathrm{M} 7.2]$ & Cooled products & 3,749 & 143.9 & {$[\mathrm{H} 7.2]$} & $-24,534$ & 56,766 \\
\hline$[\mathrm{M} 7.3]$ & F-T liquids, high pressure & 429.8 & 15.07 & {$[\mathrm{H} 7.3]$} & $-4,451$ & 6,286 \\
\hline$[\mathrm{M} 7.4]$ & Unreacted syngas & 3,319 & 128.9 & {$[\mathrm{H} 7.4]$} & $-20,046$ & 50,474 \\
\hline$[\mathrm{M} 7.5]$ & Syngas recycled to F-T & 3,154 & 122.4 & {$[\mathrm{H} 7.5]$} & $-19,044$ & 47,950 \\
\hline$[\mathrm{M} 7.6]$ & Syngas purged & 165.6 & 6.443 & {$[\mathrm{H} 7.6]$} & $-1,002$ & 2,524 \\
\hline$[\mathrm{M} 7.7]$ & Desorbed Low Pressure gases & 25.23 & 0.590 & {$[\mathrm{H} 7.7]$} & -137.7 & 436.0 \\
\hline$[\mathrm{M} 7.8]$ & Tailgas Purged for stability & 1.91 & 0.070 & {$[\mathrm{H} 7.8]$} & -11.29 & 29.6 \\
\hline$[\mathrm{M} 7.9]$ & $\begin{array}{l}\text { Tailgas Recycled to Solar } \\
\text { Reformer }\end{array}$ & 188.87 & 6.963 & {$[\mathrm{H} 7.9]$} & $-1,129$ & 2,930 \\
\hline$[\mathrm{M} 7.10]$ & Make-up NG & 54.59 & 3.402 & {$[\mathrm{H} 7.10]$} & -256 & 2,730 \\
\hline$[\mathrm{M} 7.11]$ & F-T liquids, low pressure & 404.5 & 14.48 & {$[\mathrm{H} 7.11]$} & $-4,284$ & 5,849 \\
\hline$[\mathrm{M} 7.12]$ & Entrained released gases & 3.408 & 0.079 & {$[\mathrm{H} 7.12]$} & -12.24 & 89.00 \\
\hline$[\mathrm{M} 7.13]$ & Oil fraction (Diesel fuel) & 157.8 & 0.700 & {$[\mathrm{H} 7.13]$} & -411.2 & 6,818 \\
\hline$[\mathrm{M} 7.14]$ & F-T Water fraction & 243.4 & 13.70 & {$[\mathrm{H} 7.14]$} & $-3,861$ & -597.0 \\
\hline
\end{tabular}




\section{Geographical Information System (GIS) Analysis for the Applicability of Sunexus to Industrial Sources in the United States}

Strategies for reduction of Greenhouse Gases (GHG) include carbon capture and storage (CCS), and beneficial use of carbon. With the right technology and business model, beneficial use of carbon is advantageous since it can reduce emissions along with a profitable operation.

Sunexus technology offers a beneficial use of carbon by converting the carbon dioxide into high quality diesel fuel. The Sunexus technologies are compatible with some of the largest stationary sources of $\mathrm{CO}_{2}$ emissions, which include plants for electricity generation (coal and natural gas), natural gas processing, cement production, ethanol production, landfills, and other stationary sources.

Key site requirements for a commercial Sunexus facility are a high solar insolation location, the availability of natural gas or a methane source (bio-gas) and available co-located land. Two types of concentrating solar technologies can be used with the Sunexus platform, concentrating dishes and power towers. An array of concentrating dishes is viable for smaller plants producing $<75$ million gallons of fuel per year. Power towers are applicable for larger plants at $>75$ million gallons of diesel fuel per year.

Insolation is a measure of solar radiation energy received on a given surface area in a given time, and is typically measured in kilowatt hours per meter squared per day $\left(\mathrm{kWh} / \mathrm{m}^{2} /\right.$ day). An adequate solar insolation value at the site location is necessary to achieve the required solar reformer temperatures, year-round plant operation, and to keep the syngas storage requirement to a feasible amount.

A GIS (Geographical Information System) analysis was conducted by the project team in order to establish the potential for use of the Sunexus platform in the United States for utilization of waste $\mathrm{CO}_{2}$ at industrial point sources. An ArcGIS software platform was used to conduct this quantitative analysis.

Solar isolation values for each square mile in the United States were imported into the model. Zones were created based on the required annual average solar energy needed for a viable project. Average and peak insolation values were analyzed as part of the model. Figure 69 below shows the United States broken into five solar insolation zones based on average, year round solar insolation values.

The red, orange, and yellow zones have average solar insolation values that will provide enough solar energy to create opportunities for commercial projects. At this time, the two green zones shown in Figure 69 would not be likely to produce enough solar energy to result in profitable commercial economics in today's market environment without incentives factored into the model. However, if incentives are factored into the model (including renewable fuels credits or for example if a cap in trade system was implemented that puts a cost on carbon) some projects in these green zones may become economically viable in the future. 


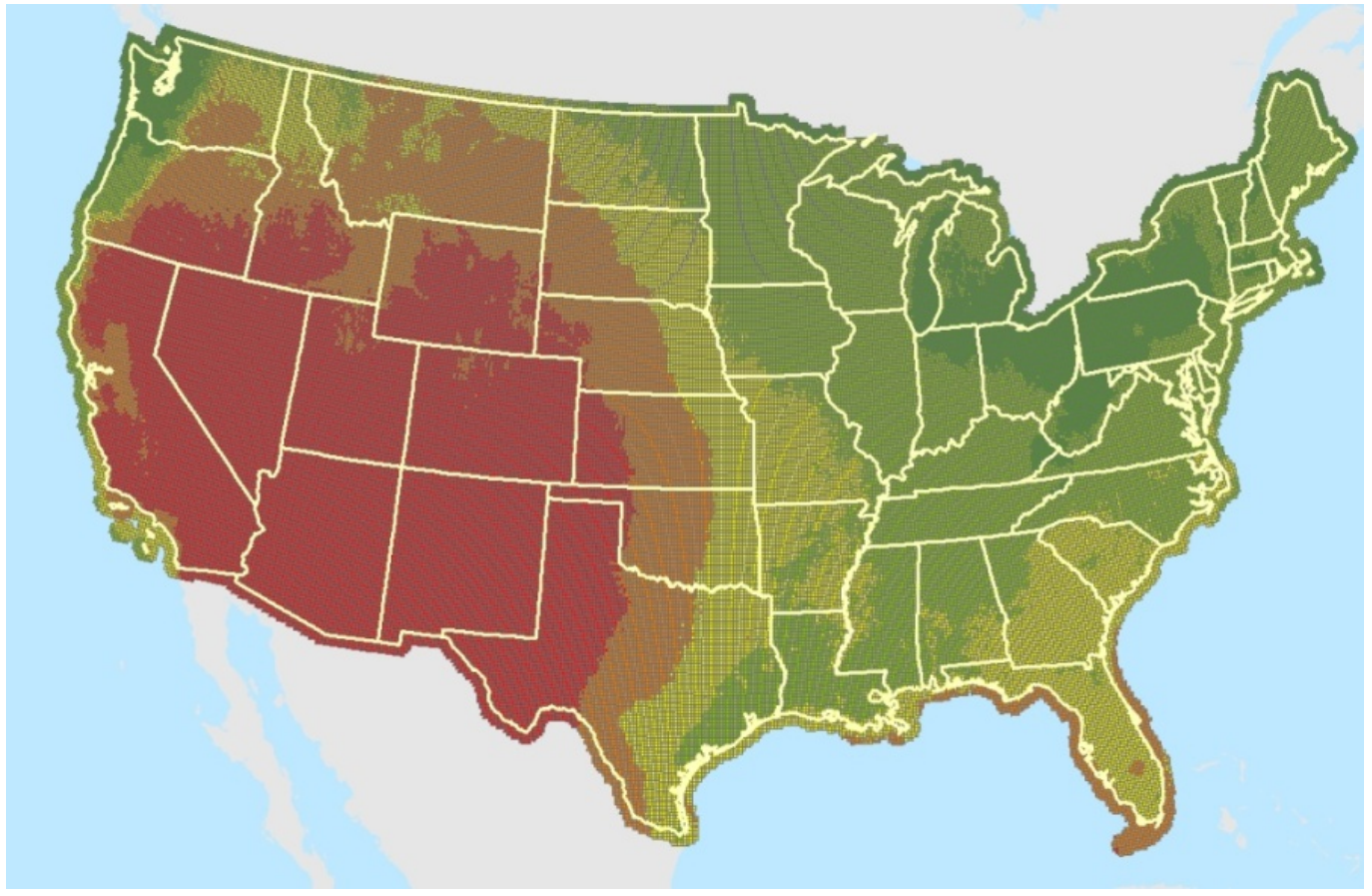

Figure 69 - Average Annual Solar Insolation Values in the United States

The Sunexus project team will focus its first commercial efforts in the red, orange and yellow zones and look at expanding into opportunities in the green zones in the future. In order to calculate the total amount of stationary $\mathrm{CO}_{2}$ from industrial that could be used by the Sunexus platform in the United States, a stationary $\mathrm{CO}_{2}$ emissions layer is built in the GIS model that shows the aggregate industrial $\mathrm{CO}_{2}$ emissions data by county as shown in Figure 70.

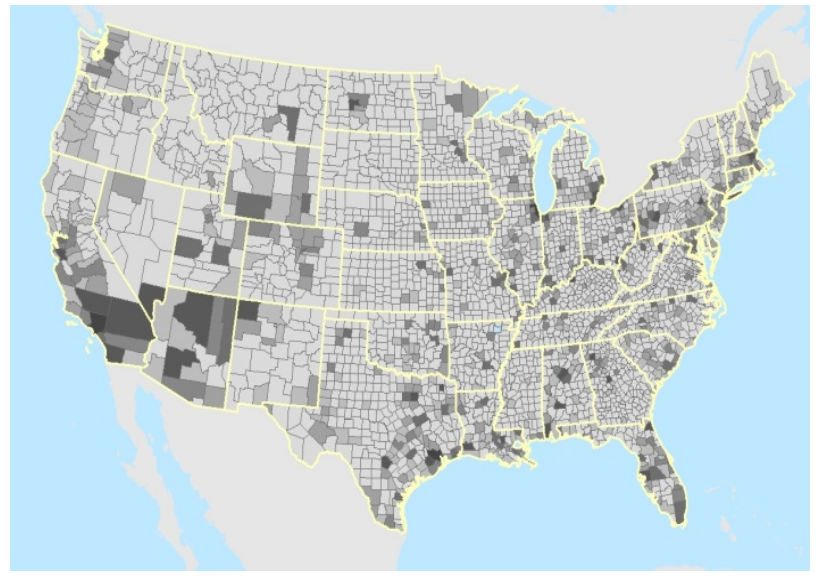

Figure 70 - U.S. Industrial CO2 emissions by County

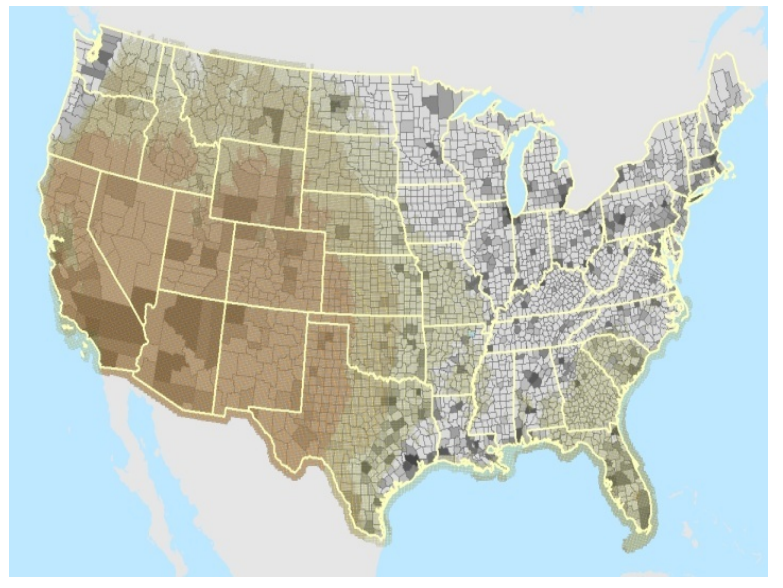

Figure 71 - U.S. Industrial CO2 emissions by County with Solar Insolation Zones

As shown in Figure 71, when the red, orange, and yellow solar insolation zones are overlaid on the map, the model calculates that $\mathbf{5 7 . 6 \%}$ of total $\mathrm{CO}_{2}$ or $2073 \mathrm{MMTons}$ of $\mathrm{CO}_{2}$ per year from industrial resources located within these zones and could theoretically be utilized by the 
Sunexus process. With future cap and trade or incentives factored in, larger geographies are possible thus expanding the reach of the Sunexus platform.

Next, industrial emission point sources from several sources were then loaded into the GIS model. Data sets from NatCarb, a program funded by NETL, which includes ethanol plants, cement plants, power plants and other industrial types were used. A data set of Natural Gas Processing facilities in the Western United States with detailed metadata was also acquired and loaded into the map. Figure 72 shows that there are 1932 point sources in the target solar insolation zones. This data set does not include landfills, waste water treatment plants, and other industrial sources that provide additional opportunities for the Sunexus platform.

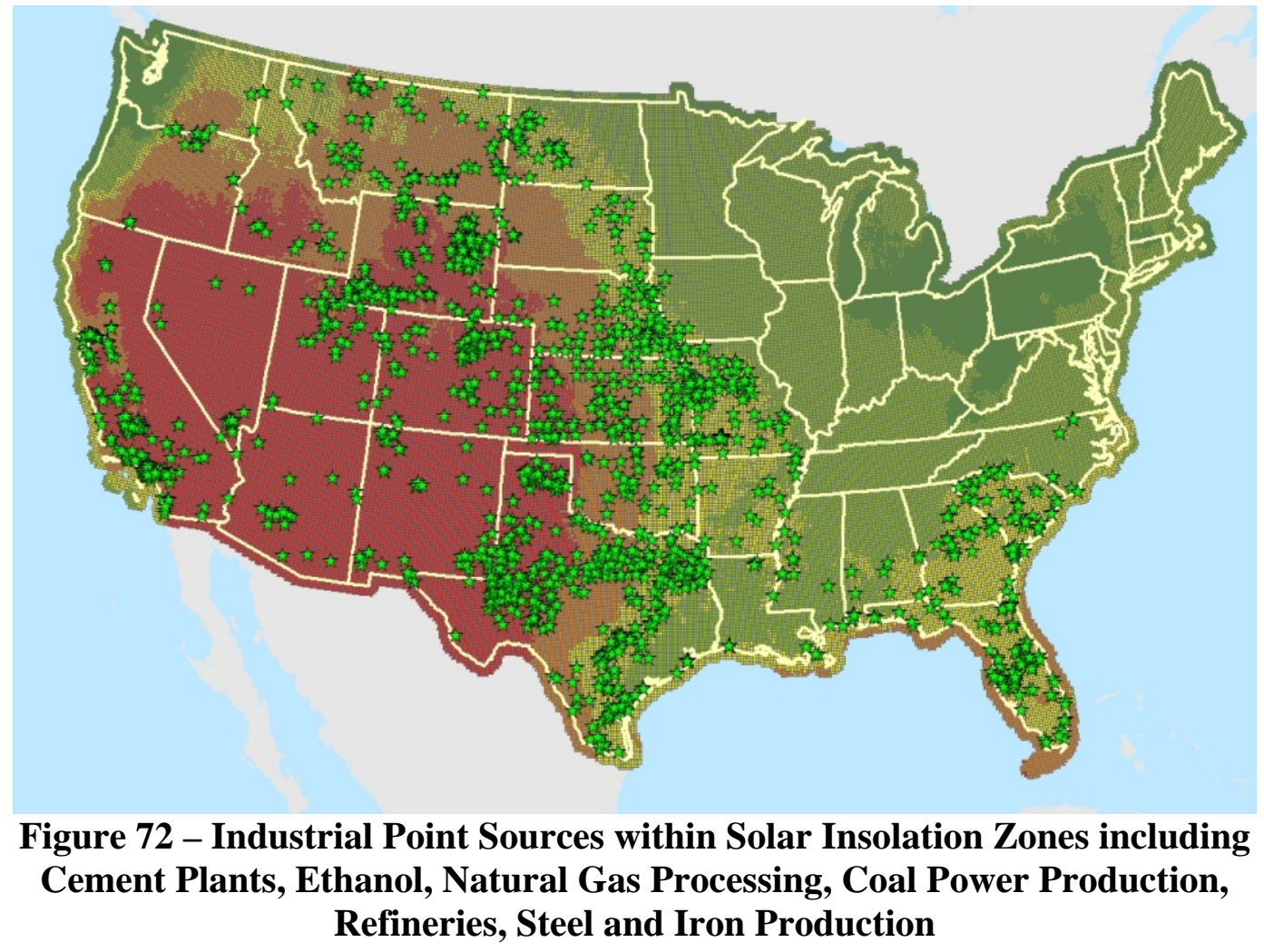

The project team has secured commitments from several commercial partners in various industries including ethanol production, cement production, a major landfill, natural gas processing and distribution, existing and next generation power production (including coal and natural gas), and others.

These companies have committed to also encouraging their partners and providers, including several major coal power plants and natural gas processing facilities to work with the Sunexus project team on assessing the viability of the platform at specific project sites.

Technology providers have also signed up to become Sunexus partners for deployment of commercial platform. The project team is in conversation with several other industrial partners including owners of coal fired and natural gas fired power plants as well as refineries. The project team estimates that work on the first commercial plants can begin in 2013. 


\section{Applicability of Sunexus Technologies to a Variety of Industrial Applications}

This section discusses the Sunexus technologies applicability to a variety of industrial applications including coal fired power, natural gas processing facilities, ethanol production, cement plants, and others.

\section{Coal-Fired Power Plants}

The flexibility of the Sunexus technology to accept a range of feed gas streams make it ideal for use with coal-fired power plant flue gas in conventional power production as well as next generation technologies such as Integrated Gasification Combined Cycle (IGCC) and oxycombustion plants.

Currently in the United States, there are about 600 coal fired power plants ${ }^{4}$ which provide over $50 \%$ of our electricity ${ }^{5}$. They represent the single largest source of greenhouse gas emissions in the U.S. Electricity from coal was responsible for about $34 \%$ of total $\mathrm{CO}_{2}$ emissions and $57 \%$ of stationary source $\mathrm{CO}_{2}$ emissions in 2007.

There are two main processes that exist today for generating electricity from coal: Pulverized Coal (PC) and Integrated Gasification Combined Cycle (IGCC). Pulverized coal power plants have been in operation since the 1920s and remain the workhorse of the U.S. power sector. These are refered to as 'conventional' power plants. The technology is relatively simple coal is crushed into a fine powder, then fed into a boiler and burned to create steam which drives the turbines.

IGCC is a newer technology that heats the coal under pressure to create a syngas, which is then cleaned and used in a combined-cycle unit (gas and steam turbines). Although costs are currently higher for IGCC, the efficiency is better and it offers promises of less water consumption, less GHG emissions, and easier/cheaper $\mathrm{CO}_{2}$ capture. There are currently two commercial size IGCC plants operating in the U.S., however as of Oct. 2009 there were five progressing (Permitted, Near-, and Under Construction), and fifteen more planned ${ }^{6}$.

The three approaches for capturing $\mathrm{CO}_{2}$ from a coal-fueled power plant are post-combustion capture, oxy-combustion, and pre-combustion capture.

Post-Combustion $\mathrm{CO}_{2}$ Capture - Post-combustion capture is most applicable to pulverized coal plants. In this approach the $\mathrm{CO}_{2}$ is removed from the flue gas which is at atmospheric pressure and typically has a concentration of less than 15\%. An amine treatment process using alkanolamines such as monoethanolamine (MEA), diethanolamine (DEA) or methyldiethanolamine (MDEA) can be used to scrub $\mathrm{CO}_{2}$ from the other flue gases. This technology is well established and widely used for other applications. Research is being carried out to develop systems that are less energy intensive and more cost effective.

The Sunexus technology can provide an economic driver to implement post-combustion capture at existing pulverized coal plants, since the cost of capital and operation of these systems can be partially deferred by the operation of an economically viable Sunexus plant. 
Oxy-Combustion $\mathrm{CO}_{2}$ Capture - Oxy-combustion is an emerging technology that is also applicable for pulverized coal plants. Oxy-combustion plants utilize pure oxygen in place of air whch which results in a flue gas that consists primarily of carbon dioxide, a small amount of oxygen, and water. The water is easily removed by cooling and condensation. There are several projects underway to further develop this technology and several large demonstration projects have been announced. Particular R\&D efforts have the objective of reducing the cost of the oxygen seperation and $\mathrm{CO}_{2}$ pressurization systems. Flue gas from oxy-combustion plants can be used directly, without separation, in the Sunexus system.

IGCC Pre-Combusion Capture - This process is regarded as a more cost-effective way of capturing $\mathrm{CO}_{2}$ from newer IGCC power plants. After the coal is gassified into carbon monoxide and hydrogen syngas, a water shift reactor converts it into carbon dioxide and hydrogen. The modified syngas is almost all $\mathrm{CO}_{2}$ and hydrogen, which can be seperated with physical sorbents. The hydrogen is used for combustion in the gas turbine and the $\mathrm{CO}_{2}$ is captured and pressurized. Research is going into refractory improvements (ceramic liner for gasifier), ion transport membranes (improved systems to produce oxygen), warm gas clean up (to remove $\mathrm{H}_{2} \mathrm{~S}$ ), and hydrogen turbine development. Several large-scale IGCC with $\mathrm{CO}_{2}$ capture demos are being explored. Membrane seperation systems are also being explored as a viable option for both pre-combustion and post-combustion capture.

The Sunexus platform would be ideal for use with IGCC power plants since the flue gas stream composition may decrease the amount of methane needed to be blended into the feed gas, thus improving economics.

The efforts that are underway now to improve the cost and efficiency for carbon capture from coal power plants are expected to pave the way for widespread implementation in the future. The Sunexus technology will provide a way to utilize the $\mathrm{CO}_{2}$ stream in a productive manner as an alternative to sequestration/storage.

\section{Natural Gas Processing}

Natural gas processing plants take raw natural gas from wells and refine it to remove impurities such as water, carbon dioxide, nitrogen, and hydrogen sulfide, as well as to remove some natural gas liquid (NGL) by-products such as ethane, propane, and butane. Typical $\mathrm{CO}_{2}$ concentrations in natural gas are between $0-8 \%{ }^{7}$ although in some areas it can be as high as $20 \%$. To meet specifications for pipeline/commercial natural gas the $\mathrm{CO}_{2}$ concentration is typically reduced to less than $2 \%$. While there are some examples of $\mathrm{CO}_{2}$ being captured for enhanced oil recovery (EOR) and other commercial uses, the vast majority is treated as a waste gas and vented into the atmosphere. Natural gas processing facilities are one of the largest emitters of $\mathrm{CO}_{2}$ in the U.S.; in 2007 they emitted $28.7 \mathrm{MMT} \mathrm{CO}_{2}$ Equivalents ${ }^{9}$.

Separating $\mathrm{CO}_{2}$ from raw natural gas is generally easier and cheaper than separating from post-combustion flue gas (e.g. from coal plants). Estimates of the cost of capture for natural gas cost are around $\$ 5-15$ per ton ${ }^{10}$. A critical part of natural gas processing involves removing Hydrogen Sulfide $\left(\mathrm{H}_{2} \mathrm{~S}\right)$ which is a corrosive and toxic compound. A gas 'sweetening' 
process is used to remove the acid gas $\mathrm{H}_{2} \mathrm{~S}$ which also removes the other acid gas, $\mathrm{CO}_{2}$. Amine treatment is used for the vast majority of acid gas removal, although physical solvents such as Selexol and Rectisol can also be used. These have the advantage of selectively recovering the hydrogen sulfide and carbon dioxide as separate streams.

Most of the natural gas processing facilities operating in the United States are located in the South, Southwest, and Rocky Mountain states. This corresponds with the locations of the largest natural gas basins such as the Gulf Coast Basin, Permian Basin, and Hugoton Field. The states with the most processing capacity, in decreasing order, are Louisiana, Texas, Wyoming, Kansas, and New Mexico. In general these areas have excellent solar insolation values.

Total diesel fuel production potential from just natural gas processing facilities in the Southwest United States from currently vented $\mathrm{CO}_{2}$ at these facilities would total 6.76 Billion gallons of diesel fuel per year. Considering their high solar insolation locations, existing capabilities for $\mathrm{CO}_{2}$ removal, low cost natural gas/methane source at the site, and proven ability to provide captured $\mathrm{CO}_{2}$ at a relatively low cost, natural gas processing facilities are a good option for co-locating Sunexus plants.

\section{Ethanol Production}

The production of ethanol in the United States from primarily corn has grown substantially over the past 10 years and has become a significant source of $\mathrm{CO}_{2}$ emissions. There are approximately 163 ethanol plants ${ }^{11}$ in the U.S. releasing approximately 38 million metric tons/year of carbon dioxide ${ }^{12}$.

In the ethanol production process, $\mathrm{CO}_{2}$ is produced during fermentation where yeast converts the sugar into large amounts of carbon dioxide gas. This is a very pure $\mathrm{CO}_{2}$ stream that does not need to go through expensive amine treatment or other purification/separation processes. The cost of capture is significantly lower, and for this reason industrial facilities such as ethanol plants that produce high purity $\mathrm{CO}_{2}$ streams are often seen as early opportunities for Carbon Capture and Storage (CCS) deployment. This claim is supported by a number of applications where the $\mathrm{CO}_{2}$ has been captured from ethanol plants and transported via pipeline for use in Enhanced Oil Recovery (EOR).

Co-locating Sunexus plants with ethanol plants would be attractive primarily for the supply of low-cost, high purity $\mathrm{CO}_{2}$ feedstock. Sunexus plants that are co-located with ethanol plants provide a dual benefit of consuming a $\mathrm{CO}_{2}$ emission and also providing a new renewable fuel product that can be marketed, sold, and distributed to existing customers that are interested in adding a low carbon, renewable fuel.

\section{Cement Production}

The United States is the world's third largest cement producer, with production occurring in 37 states and Puerto Rico ${ }^{13}$. Cement production is one of the largest sources of $\mathrm{CO}_{2}$ emissions at 44.5 MMT CO $\mathrm{Mq}_{2}$. per year ${ }^{14}$. 
In the cement production process, crushed limestone or calcium carbonate $\left(\mathrm{CaCO}_{3}\right)$ is heated in a kiln to a temperature of about $1,450^{\circ} \mathrm{C}\left(2,400^{\circ} \mathrm{F}\right)$. This process known as calcination forms lime or calcium oxide $(\mathrm{CaO})$ and carbon dioxide $\left(\mathrm{CO}_{2}\right)$. The lime is combined with silica-containing materials to produce clinker which is an intermediate product. It is then cooled and mixed with a small amount of gypsum to create cement.

Carbon dioxide emissions are created both as a result of the calcination process and from fossil fuel combustion to fire the kiln. Typical $\mathrm{CO}_{2}$ concentrations in the flue gases range from 14 to $33 \%{ }^{15}$.

The 44.5 MMT figure accounts for the chemical process (i.e. calcination) emissions and does not include emissions from combustion. The cement industry is regarded as a good opportunity for utilization of $\mathrm{CO}_{2}$ due to the large size of cement plants (translating into fewer individual point sources and better economies of scale), their relatively high concentration of $\mathrm{CO}_{2}$ in the flue gas, and the unavoidable production of $\mathrm{CO}_{2}$ from the mineral decomposition during calcination (i.e. alternative processes that emit no $\mathrm{CO}_{2}$ do not currently exist). A business case for co-location of a Sunexus plant at a cement production facility is provided below.

\section{Other Applications}

Other industries including wastewater treatment plants, landfills, agricultural operations can produce a biogas that is approximately $35-50 \% \mathrm{CO}_{2}$ and $50-65 \%$ methane and can be used efficiently in the proposed process. Figure 73 shows methane emissions from landfills alone, creating additional opportunities for co-location of Sunexus technologies. 


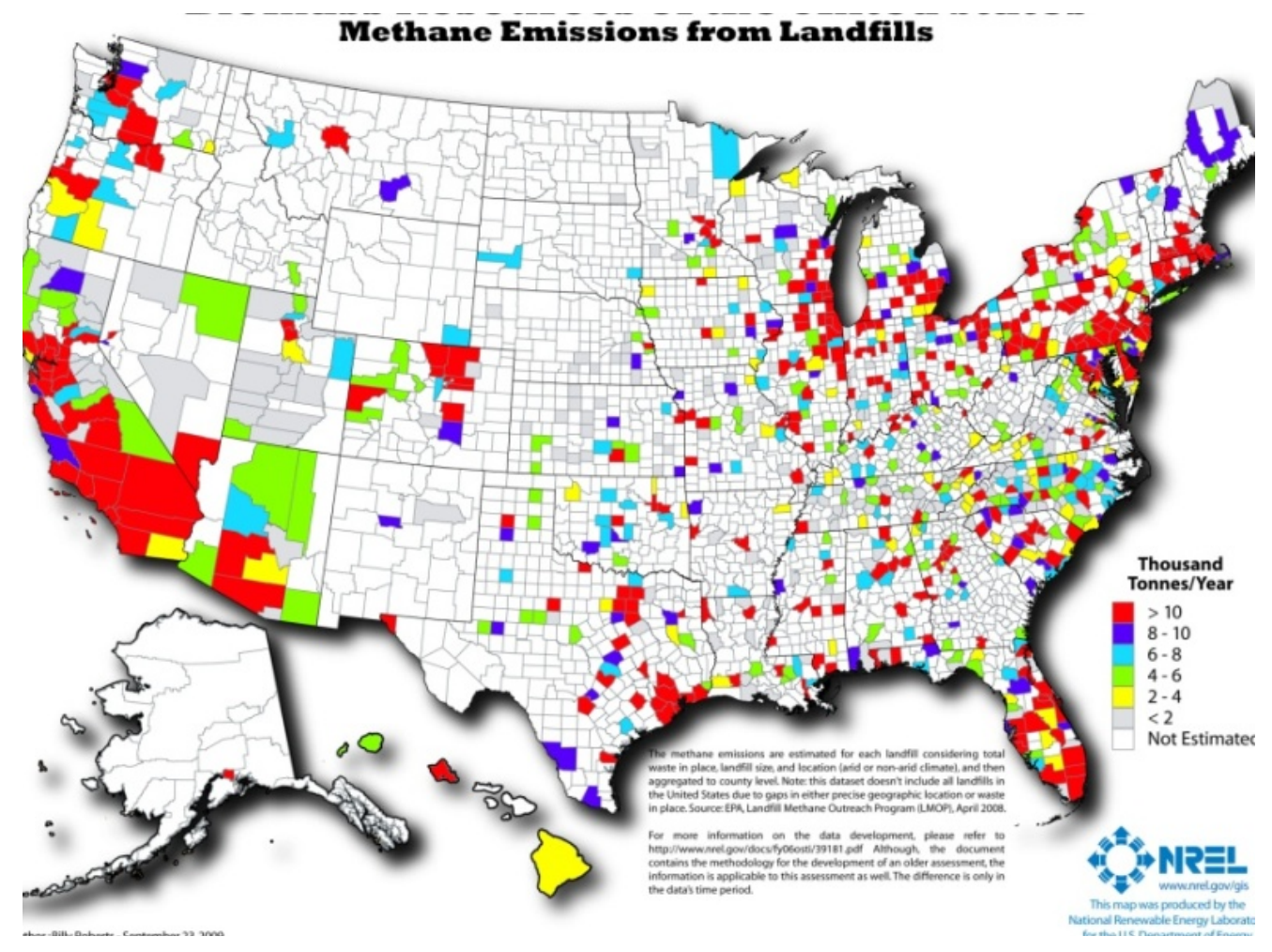

Figure 73 - NREL Map Showing Waste Methane Emissions from Landfills (note landfill gas is approximately $50 \% \mathrm{CO} 2$ and $50 \% \mathrm{CH} 4$ )

The project team estimates that based on successful demonstration of the proposed technologies and ongoing technology development, a majority of diesel fuel in the United States could be produced from waste gas sources over the next several decades. The economic models summarized in Section III.E demonstrate strong fundamentals in the form of return on investment, payback period and gross margin which should motivate the required investment to bring a large number of commercial units online during the next decade.

\section{E. Petroleum Displacement Analysis}

This analysis estimates the barrels of oil that could be displaced from commercial Sunexus facilities over time through the commercialization of the proposed technologies. The project team has secured interest from major industrial partners that are interested in deploying the Sunexus technologies at project sites following successful demonstration. For this analysis, an average commercial plant that utilizes 902,500 tons of $\mathrm{CO}_{2}$ per year and produces 356.6 million gallons of diesel fuel per year is used as a baseline "average" plant.

Table 17 highlights the output of this commercial facility, the BTU output equivalent, and the equivalent oil displaced per year from this plant. 
Table 17 - Petroleum Displacement Analysis for the First Commercial Plant at which 902,500 tons of $\mathrm{CO}_{2}$ are Captured and Converted to Synthetic Diesel Fuel

\begin{tabular}{|l|c|c|c|c|}
\hline \multicolumn{1}{|c|}{ Product } & $\begin{array}{c}\text { Diesel Fuel } \\
\text { Energy } \\
\text { Content } \\
\text { (BTU/gallon) }\end{array}$ & $\begin{array}{c}\text { Synthetic } \\
\text { Diesel Fuel } \\
\text { Production } \\
\text { (Millions of } \\
\text { gallons/year) }\end{array}$ & $\begin{array}{c}\text { Synthetic } \\
\text { Diesel Fuel } \\
\text { Production } \\
\text { (BTU/year) }\end{array}$ & $\begin{array}{c}\text { Equivalent } \\
\text { Million } \\
\text { Barrels of } \\
\text { Oil }^{\mathbf{2}}\end{array}$ \\
\hline $\begin{array}{l}\text { Sunexus } \\
\text { Synthetic } \\
\text { Diesel Fuel }\end{array}$ & 123,670 & 356.6 & $4.41 \times 10^{13}$ & 8.10 \\
\hline
\end{tabular}

${ }^{1}$ Lower Heating (BTU/Gallon) Value for Fischer-Tropsch fuel from Hydrogen Analysis Resource Center and GREET Model. 2 Calculated using 129,670 BTU/gal of oil (Hydrogen Analysis Resource Center) and $42 \mathrm{gal} / \mathrm{bbl}$.

A comprehensive Geographical Information System (GIS) analysis was conducted for stationary industrial sources in the United States that would be suitable for the Sunexus process. This analysis looked at site requirements for a commercial Sunexus plant including solar insolation values, feed gas availability, land availability, and other variables. Based on this analysis, it was determined that 1932 large stationary industrial sources in the United States would be suitable for the Sunexus process (not including smaller sources such as landfills). The Sunexus process would be potentially be viable at plants that emit 2073 MMTons of $\mathrm{CO}_{2}$ annually, or $57.6 \%$ of total U.S. stationary emissions. This does not include landfills, waste water treatment plants, and other industrial sources that were not analyzed as part of this analysis.

This number represents the theoretical potential for Sunexus plants. The project team believes that $1 \%$ of these industrial sites can have Sunexus technologies implemented by end of 2030; representing 45.9 MMTons of $\mathrm{CO}_{2}$ utilized annually which will produce 1.818 Billion gallons of diesel fuel per year. By 2040, the project team believes that it is reasonable to capture 5\%, representing 103.5 MMTons of $\mathrm{CO}_{2}$ utilized annually to produce 9.09 Billion gallons of diesel fuel per year. Table 18 summarizes these figures and calculates the equivalent barrels of oil. 
Table 18 - Projected 2020 and 2025 Scenarios for U.S. Petroleum Displacement from the Commercial Deployment of Sunexus Solar $\mathrm{CO}_{2}$ Conversion to Diesel Fuel Production Plants

\begin{tabular}{|c|c|c|c|c|}
\hline Year & Product & $\begin{array}{c}\text { Diesel Fuel } \\
\text { Energy Content } \\
\text { (BTU/gallon) }^{\mathbf{1}}\end{array}$ & $\begin{array}{c}\text { Synthetic Diesel } \\
\text { Fuel Production } \\
\text { (Billions of } \\
\text { gallons/year) }\end{array}$ & $\begin{array}{c}\text { Equivalent } \\
\text { Million } \\
\text { Barrels of }\end{array}$ \\
\hline $\mathbf{\text { Oil } ^ { 2 }}$
\end{tabular}

${ }^{1}$ Lower Heating Value for Fischer-Tropsch fuel from Hydrogen Analysis Resource Center and GREET Model. 2 Calculated using 129,670 BTU/gal of oil (Hydrogen Analysis Resource Center) and $42 \mathrm{gal} / \mathrm{bbl}$.

\section{F. Commercial Economic Analysis}

The REII project team defines economic merit as a commercial plant's ability to utilize $\mathrm{CO}_{2}$ as a valuable feedstock while producing $>18 \%$ Internal Rate of Return (IRR) and $>18 \%$ first year Return on Investment (ROI) without including incentives in the economic analyses. These attractive economics at a commercial scale could enable widespread commercialization of the platform using private investment capital.

Economics for each of these commercial projects are different depending on location, land costs, flue gas streams, $\mathrm{CO}_{2}$ separation costs, and other site variables. However, these projects are expected to yield an IRR $>18 \%$ and a first year ROI $>18 \%$.

Another driving factor in the economic viability of the Sunexus platform is the rapid growth of the concentrating solar industry in which technologies are quickly maturing and production costs declining. As mentioned above, capital costs for concentrating solar technologies including concentrating dishes and power tower components (ex. Heliostats) have declined significantly.

Figure 74 shows expected growth in concentrating solar projects by country through 2014 . Note that the United States is expected to capture most of the market growth. As more vendors of these components move to mass production and deployment of utility scale projects, costs will decline further. 


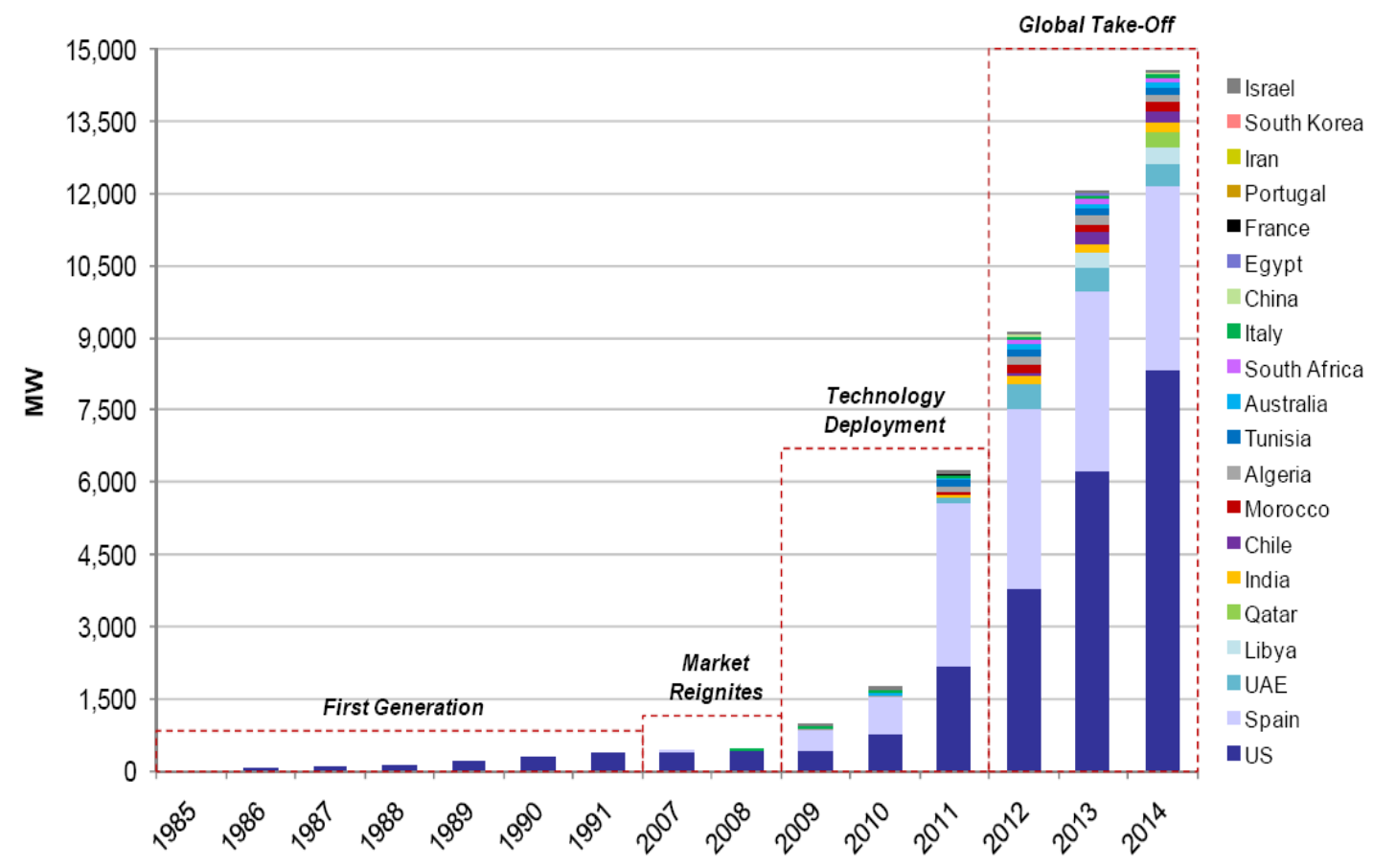

Figure 74 - The Projected Future Growth in Global Concentrating Solar Power Technologies during the Next 3 Years

The rapid acceleration of deployment for concentrating solar projects worldwide, which will include a large portion of power tower technology, will drive costs of heliostats and tower technology down and have a positive impact on the overall economics of the proposed technology platform for conversion of $\mathrm{CO}_{2}$ to fuels.

Two representative examples are discussed below in more detail for illustrative purposes. These examples were chosen since they differ considerably in $\mathrm{CO}_{2}$ separation costs and the size of the emissions source. The two business cases and respective economics that are discussed below include:

- Ethanol Plant; Madera, California; 180,000 tons of $\mathrm{CO}_{2}$ per year

- Cement Plant; Mojave, California; 902,500 tons of $\mathrm{CO}_{2}$ per year

\section{Pro-Forma for $\mathrm{CO}_{2}$ Capture and Conversion to Diesel Fuel from an Operating Ethanol} $\underline{\text { Plant }}$

Industrial sites, such as ethanol plants, provide a lower volume of $\mathrm{CO}_{2}$ as a feedstock, but have lower costs for separation of the $\mathrm{CO}_{2}$ as well. Table 19 summarizes the pro-forma for the solar conversion of $\mathrm{CO}_{2}$ to diesel fuel from a typical ethanol production plant located in the Western United States. 
Site Conditions - This ethanol plant is located in an area with good solar insolation, it has natural gas available at the project site, and has inexpensive land available for lease next to the plant.

Operating and Maintenance (O\&M) Costs - The O\&M costs include feedstock, insurance, taxes, other. $\mathrm{CO}_{2}$ separation and purification costs from ethanol plants are lower than with other industrial applications. The $\mathrm{CO}_{2}$ is $80 \%$ pure and 180,000 tons of $\mathrm{CO}_{2}$ from this ethanol plant is utilized as feedstock for the Sunexus plant. $\mathrm{CO}_{2}$ separation costs are estimated at $\$ 15 /$ ton for a total cost of $\$ 2,700,000$ delivered to the co-located Sunexus plant.

Natural gas prices during 2009 and 2010 have averaged \$4.50/MCF (thousand cubic feet) at the well head and $\$ 5.50 / \mathrm{MCF}$ at the plant site. It is anticipated that gas prices will decline in coming years due to added supply in the United States. In this model, a conservative price of $\$ 8.00 / \mathrm{MCF}$ was used which amounts to $\$ 99,220,000 /$ year (which would be closer to a historical maximum for industrial supply) is used in the model. In addition, factors for system operations and maintenance, operations staff, taxes, insurance, other customary operations costs, and contingency are included in operating costs. The personnel and maintenance costs are estimated at $\$ 30,300,000$ per year. In addition, a contingency of $\$ 27,740,000$ is added to cover unseen costs. Therefore, the total operating costs (excluding debt services, which are accounted for above) are $\$ 159,960,000$ per year. Inflation factors of $3 \%$ are used for all costs.

Capital Costs - Capital costs for the plant total $\$ 153,670,000$ which includes all of the hardware as described in the Process Flow Diagram (Figure 68) as well as land and operations facilities.

Financing - It is assumed that the project is financed using $60 \%$ debt and $40 \%$ equity, which is typical for projects of this type. Debt rate is assumed at $8 \%$ per year and the loan term is 20 years. Therefore, the total annual debt service is $\$ 7,380,000$.

Products - The plant produces 71,313,000 gallons per year of diesel fuel. All byproducts (including F-T water) are recycled as discussed in the Process Flow Diagram (Figure 62) and there are no other by-products.

Revenues - Revenues are calculated using conservative pricing of diesel fuel at $\$ 2.55$ per gallon. DOE EERE estimated a sale price in mid-2010 of \$3.09 (without incentives) for Fischer Tropsch diesel fuel with an energy content of 123,760 BTU/gallon at \$3.09. This does not include the renewable fuels credits (RFS2) and price premiums related to California's Low Carbon Fuels Standard (LCFS) that will be going into effect.

With incentives, $\$ 4.00$ per gallon is a reasonable estimate, however, as discussed above the project team looks for viable commercial projects without factoring in incentives and a price of $\$ 2.55$ per gallon was used in this pro-forma. The plant produces $71,313,000$ gallons per year and at $\$ 2.55$ per gallon total plant revenue is $\$ 181,840,000$. Inflation factors of $3 \%$ year are used for all revenue calculations. 
Net Operating Income - A total net operating income of $\$ 14,500,000$ for the first year is achieved resulting in an $27 \%$ Internal Rate of Return (IRR) and first year Return on Investment (ROI) of $23 \%$. As mentioned above, no incentives have been factored into the development of this model. This relatively small Sunexus plant shows that even at smaller scales, the process can be economical. The type of concentrating solar technology used for this project is a concentrating solar dish and a rendering of this plant configuration is shown Figure 75 below.

Table 19 - Proforma for the Solar Conversion of $\mathrm{CO}_{2}$ to Diesel Fuel from a Typical Ethanol Production Plant

\begin{tabular}{|l|c|}
\hline \multicolumn{1}{|c|}{ OPERATION AND MAINTENANCE COST } & AMOUNT \\
\hline & $\$ 2.70 \mathrm{M}$ \\
\hline A.1 $\mathrm{CO}_{2}$ Separation (\$15/ton) & $\$ 99.22 \mathrm{M}$ \\
\hline B.1 Natural Gas (\$8.00/MMBTU) & $\$ 30.30 \mathrm{M}$ \\
\hline E.2-E.3 Plant Operations & $\$ 27.74 \mathrm{M}$ \\
\hline E.4 Contingency & $\$ 159.96 \mathrm{M}$ \\
\hline \multicolumn{1}{|c|}{ Total } & \\
\hline \multicolumn{1}{|c|}{ CAPITAL COST } & \\
\hline \multicolumn{1}{|c|}{ NET OPERATING INCOME } & $\$ 76.20 \mathrm{M}$ \\
\hline Reformers & $\$ 73.15 \mathrm{M}$ \\
\hline C.2 Plant for Conversion of Syngas to Diesel Fuel & $\$ 5.51 \mathrm{M}$ \\
\hline C.3 Land and Facilities & $\$ 153.67 \mathrm{M}$ \\
\hline D.1 Total Capital Investment & $60 \%$ \\
\hline D.2 Debt (\%) & $40 \%$ \\
\hline D.3 Equity (\%) & $8 \%$ \\
\hline D.4 Debt Rate (\%) & 20 \\
\hline D.5 Debt Term (Years) & $\$ 7.38 \mathrm{M}$ \\
\hline D.6 Annual Debt Payments (\$/year) & \\
\hline & \\
\hline & $71.31 \mathrm{M} \mathrm{Gallons}$ \\
\hline & $\$ 2.55 / \mathrm{Gallon}$ \\
\hline F.1 Diesel Fuel Production & $\$ 181.84 \mathrm{M}$ \\
\hline F.2 Diesel Fuel Sales Price (\$/gallon) to Fuel Distributors & $\$ 167.34 \mathrm{M}$ \\
\hline F.3 Annual Revenue (1 1 Year) & $\$ 14.50 \mathrm{M}$ \\
\hline G.1 Total Expenses (E.4 + D.6) & $27 \%$ \\
\hline G.2 Net Operating Income (F.3-G.1) & $23 \%$ \\
\hline G.3 Cumulative Cash Flow & \\
\hline G.4 Internal Rate of Return (IRR) & \\
\hline G.5 First Year ROI & \\
\hline
\end{tabular}




\section{Pro-Forma for $\mathrm{CO}_{2}$ Capture and Conversion to Diesel Fuel from an Operating Cement $\underline{\text { Plant }}$}

The following is a business case for a commercial plant based around utilization of a flue gas source from a cement production facility located in Mojave, California. This business case provides an illustrative example of capital and operating costs as well as other project development considerations such availability of infrastructure, land and other requirements needed for a viable project.

This cement plant example was chosen to illustrate commercial economics associated with a plant with high $\mathrm{CO}_{2}$ separation costs. In this example, it is assumed that separation costs are $\$ 50.00 /$ ton of $\mathrm{CO}_{2}{ }^{1}$ based on industry estimates of costs (including capital and operating expenses for deploying separation technologies) and this cost is the cost of delivery of the $\mathrm{CO}_{2}$ to the Sunexus plant gate which is located next to the cement plant.

The cement plant in Mojave, California currently produces approximately 1 million tons of cement annually. It is estimated that this facility produces approximately $0.9 \mathrm{lb}$. of $\mathrm{CO}_{2}$ per $\mathrm{lb}$. of cement. Approximately 902,500,000 tons of $\mathrm{CO}_{2}$ are emitted annually from this plant. Therefore, 902,500 tons of $\mathrm{CO}_{2}$ are used as an input to the Sunexus system.

Site Conditions - Mojave is in California's high desert and has strong solar insolation values and available land that is relatively inexpensive. Natural gas is provided to the project site by Southern California Edison and for this project a long term industrial supply contract will be purchased for natural gas supplies, similar to the way that natural gas is purchased for existing cement plant operations.

Operating and Maintenance (O\&M) - Operating costs include gas inputs, insurance, taxes, staff, and other O\&M costs customary in plants of this type. Gas input costs include $\mathrm{CO}_{2}$ and natural gas. 902,500 tons of $\mathrm{CO}_{2}$ from the plant will be utilized as feedstock for the Sunexus plant. $\mathrm{CO}_{2}$ capture costs are estimated at $\$ 50 /$ ton of $\mathrm{CO}_{2}$ as based on published economic analysis of $\mathrm{CO}_{2}$ capture in the cement industry. This cost is included as a feedstock cost delivered to the Sunexus commercial plant. Over time, the costs of separation are expected to decline, further helping commercial economics.

Natural gas prices during 2009 and 2010 have averaged $\$ 4.50 / \mathrm{MCF}$ (thousand cubic feet) at the well head and $\$ 5.50 \mathrm{MCF}$ at the cement plant site. It is anticipated that gas prices will decline in coming years due to added supply in the United States. In this model, a conservative price of $\$ 8.00 / \mathrm{MCF}$ (which would be closer to a historical maximum for industrial supply) is used in the model. In addition, factors for system operations and maintenance, operations staff, taxes, insurance, other customary operations costs, and contingency are included in operating costs. Total operating costs (excluding debt services, which are accounted for above) are $\$ 826,678,288$ per year. Inflation factors of 3\% are used for all costs.

\footnotetext{
${ }^{1}$ Mahasenan, N., Dahowski, R., \& Davidson, C. (2005). The Role of Carbon Dioxide Capture and Storage in Reducing Emissions from Cement Plants in North America. (E. Rubin, D. Keith, \& C. Gilboy, Eds.) Greenhouse Gas Control Technologies, Volume I.
} 
Capital Costs - This plant uses solar a power tower to provide the concentrated solar energy for the Sunexus process. Total capital costs for the plant total $\$ 517,211,040$ which includes the hardware as described in the Process Flow Diagram (Figure 62) for a commercial plant. These estimates were developed based on capital costs for the power tower, Sunexus solar reformer, diesel fuel production system, land, and operations facilities. Pratt Whitney Rocketdyne provided costs for the power tower and Sunexus reactor systems and liquid fuel production system estimates were developed based on the team's engineering models for similar sized plants.

The capital costs of the overall system were compared to known commercial costs for F$\mathrm{T}$ plants. Aasberg-Peterson, et. Al. ${ }^{16}{ }^{2}$ provides estimates for capital costs based on existing, known F-T technologies. While the technologies proposed to be used for this project are next-generation and will achieve capital cost reductions and better, the overall capital cost estimates for this plant are in line with the costs of existing, legacy plants and therefore provide a very conservative and reasonable basis for this estimate.

Financing - It is assumed that the project is financed using $60 \%$ debt and $40 \%$ equity, which is typical for projects of this type. Debt rate is assumed at $8 \%$ per year and term is 20 years. Total annual debt service is $\$ 24,826,130$.

Products - The plant produces 356,565,805 gallons per year of diesel fuel. All byproducts (including F-T water) are recycled as discussed in the Process Flow Diagram and there are no other by-products.

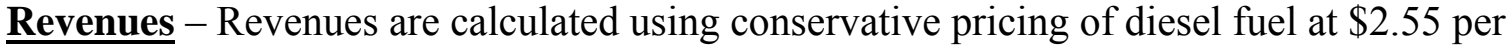
gallon. DOE EERE estimates that the current sale price of Fischer-Tropsch diesel with an energy content of 123,760 BTU / gallon at \$3.09 (without incentives). DOE EERE estimated a sale price in mid-2010 of $\$ 3.09$ (without incentives) for Fischer Tropsch diesel fuel with an energy content of 123,760 BTU/gallon at \$3.09. This does not include the renewable fuels credits (RFS2) and price premiums related to California's Low Carbon Fuels Standard (LCFS) that will be going into effect.

With incentives, $\$ 4.00$ per gallon is a reasonable estimate however as discussed above the project team looks for viable commercial projects without factoring in incentives and a price of $\$ 2.50$ per gallon is used here. Note that $\$ 2.55$ per gallon diesel equates approximately to $\$ 60$ per barrel oil. U.S Energy Information Administration (EIA) futures for diesel prices in 2011 are $\$ 3.12$ per gallon (or 83.50 per barrel oil prices).

The plant will produce 356 million gallons of synthetic diesel per year and at a selling price of $\$ 2.55$ per gallon, the total plant revenue is $\$ 907,800,000$. Inflation factors of $3 \%$ are used for all revenue calculations.

\footnotetext{
${ }^{2}$ Aasberg-Peterson, K., Christensen, T., Dybkjaer, I., Sehested, J., Ostberg, M., Coertzen, R., et al. (2004). Synthesis Gas Production for FT Synthesis; Fischer-Tropsch Technology (Vol. 152). (A. Steynberg, \& M. Dry, Eds.) Elsevier. pp. 442-447.
} 
Net Operating Income $-A$ total net operating income of $\$ 64,734,212$ per year is achieved, resulting in 35\% Internal Rate of Return (IRR) and first year Return on Investment (ROI) of $31 \%$, which is calculated as first year net operating income over equity (cash) invested in the project.

The pro-forma is sensitive to diesel fuel selling price, however conservative long term factors have been used and no incentives have been factored into the development of this model. Furthermore, cement plants have some of the highest $\mathrm{CO}_{2}$ capture costs in the industry and if the economics can work today at a cement plant site, then other sites are likely to be viable as well including coal power plants, natural gas power plants, and other facilities.

\section{Conclusions}

Figure 74 illustrates the proposed design of the Sunexus commercial scale plant using an array of Sunexus Solar $\mathrm{CO}_{2}$ Reformers integrated with 2,900 large parabolic dishes. Our mass and energy models estimate that this plant will produce approximately 71 million gallons/year of synthetic diesel fuel from the conversion of 180,000 tons of captured $\mathrm{CO}_{2}$ generated from the representative ethanol production plant.

Figure 75 illustrates the proposed design of the Sunexus commercial scale plant using a power tower. The mass and energy models estimate that this plant will produce approximately 71 million gallons/year of synthetic diesel fuel from the conversion of 902,500 tons of captured $\mathrm{CO}_{2}$ generated from the representative cement production plant. A single power tower will provide the solar energy input.

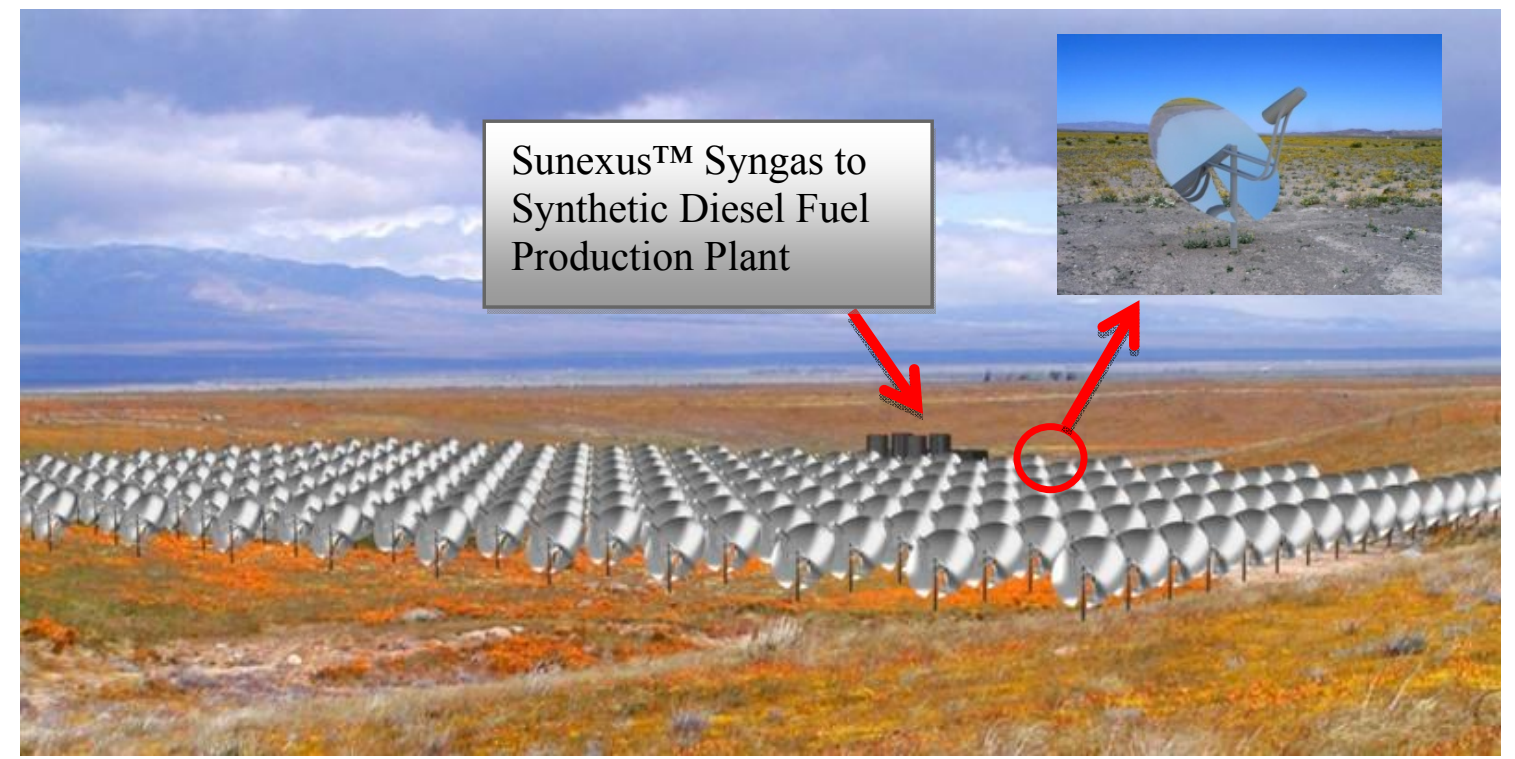

Figure 75 - Configuration for Sunexus Commercial-Scale Solar Reformer for the Production of 71.3 million gallons/year of Synthetic Diesel Fuel from 180,000 tons/year of Captured $\mathrm{CO}_{2}$ using an Array of Parabolic Dishes 


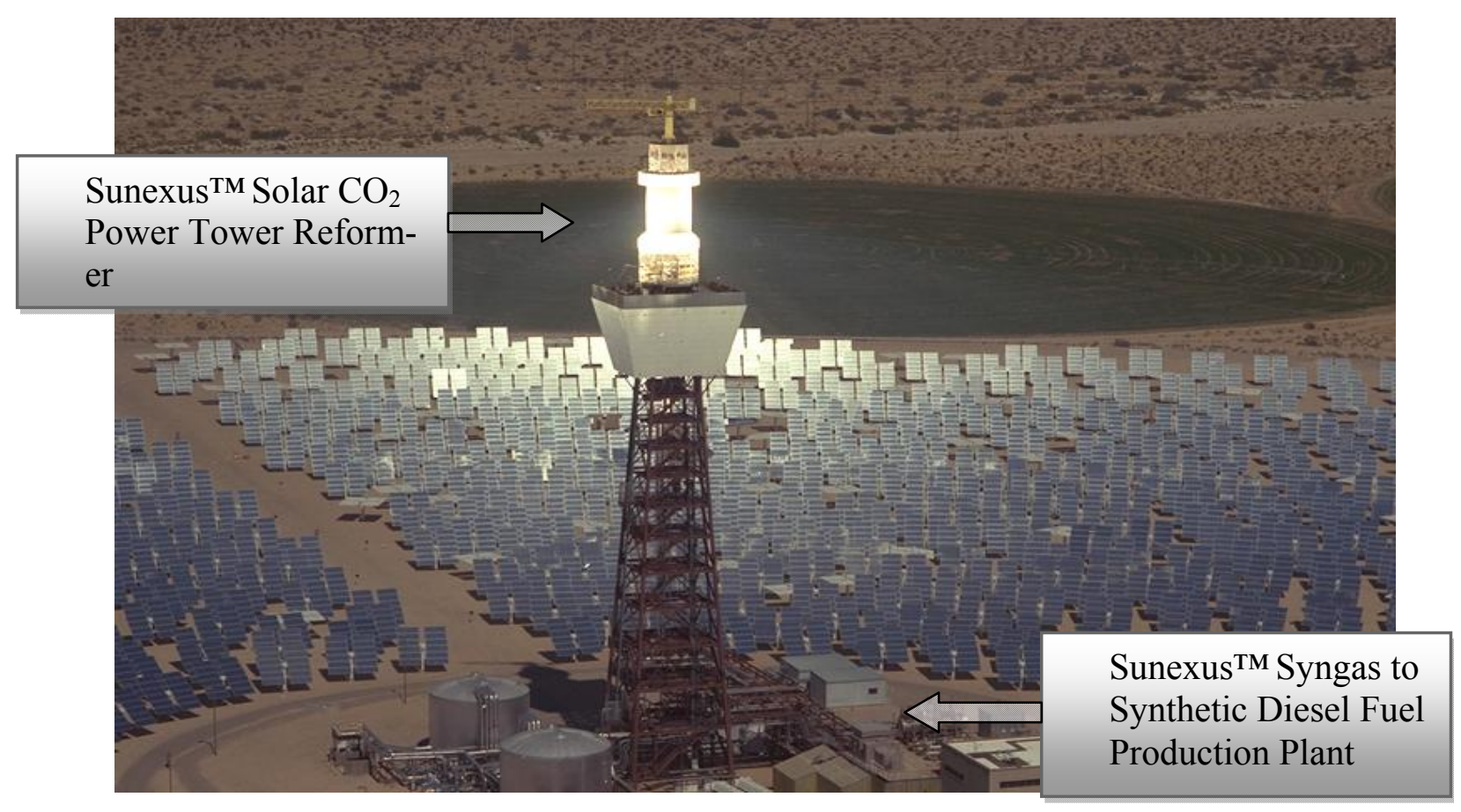

Figure 76 - Configuration of Sunexus Commercial-Scale Solar Reformer for the Production of 356.6 Million Gallons/Year of Synthetic Diesel Fuel from 902,500 tons/year of Captured $\mathrm{CO}_{2}$ using Power Tower Technology

\section{G. $\underline{\text { A Comparison of Sunexus } \mathrm{CO}_{2}} \underline{\text { Conversion Technology with Other Processes }}$}

This section compares the Sunexus $\mathrm{CO}_{2}$ conversion technology to diesel fuel with other processes that are currently under development. The other processes chosen for this comparison include the production of algal oils, production of carbonates, and production of synthetic natural gas. A discussion of each of these categories, as well as existing commercial approaches such as enhanced oil recovery (EOR), is included below and the discussion summarizes the pros and cons of each of these compared to the Sunexus process. Table 20 compares the advantages of several competing technology platforms and approaches that are discussed in detail below. 
Table 20 - An Assessment of Various Methods for the Conversion of Captured $\mathrm{CO}_{2}$ to Various Products

\begin{tabular}{|c|c|c|c|c|}
\hline Assessment Criteria & $\begin{array}{l}\text { Sunexus } \\
\text { Diesel Fuel } \\
\text { Production }\end{array}$ & $\begin{array}{l}\text { Biodiesel } \\
\text { from Algae }\end{array}$ & $\begin{array}{l}\text { Carbonate } \\
\text { Production }\end{array}$ & $\begin{array}{l}\text { Synthetic } \\
\text { Natural Gas } \\
\text { Production }\end{array}$ \\
\hline $\begin{array}{l}\text { Captured } \mathrm{CO}_{2} \text { is used as a } \\
\text { Feedstock for Product } \\
\text { Production }\end{array}$ & Yes & Yes & Yes & Yes \\
\hline $\begin{array}{l}\text { External Fossil Energy } \\
\text { Requirements }\end{array}$ & $\begin{array}{l}\text { Low }(\sim 10 \%) \\
\text { (high solar } \\
\text { insulation } \\
\text { areas) }\end{array}$ & $\begin{array}{l}\text { Low(mild } \\
\text { climates) }\end{array}$ & High & Moderate \\
\hline $\begin{array}{l}\text { \% Energy Efficiency } \\
\text { [(Product Energy Content - } \\
\text { Fossil Energy Input)/Fossil } \\
\text { Energy Input] x } 100\end{array}$ & $74 \%$ & $\begin{array}{l}\text { Not } \\
\text { Determined }\end{array}$ & -20 to +20 & $\begin{array}{l}\text { Not } \\
\text { Determined }\end{array}$ \\
\hline $\begin{array}{l}\text { Water Requirements } \\
\text { (lbs of external water } \\
\text { required/lb. of product } \\
\text { produced) }\end{array}$ & $\begin{array}{l}\text { Low } \\
(<0.1)\end{array}$ & $\begin{array}{l}\text { High } \\
(>10)\end{array}$ & $\begin{array}{l}\text { High } \\
(>10)\end{array}$ & $\begin{array}{l}\text { Moderate } \\
(2-4)\end{array}$ \\
\hline $\begin{array}{l}\text { Can Utilize Captured } \mathrm{CO}_{2} \\
\text { from a Wide Variety of } \\
\text { Industrial Sources Located } \\
\text { in Various U.S. Regions } \\
\end{array}$ & Yes & No & No & Yes \\
\hline $\begin{array}{l}\text { Product Meets Existing } \\
\text { Commercial Product } \\
\text { Standards and Uses the } \\
\text { Existing U.S. Transport } \\
\text { Infrastructure }\end{array}$ & Yes & No & No & Yes \\
\hline $\begin{array}{l}\text { Product is Projected to Cost } \\
\text { No More than Competitive } \\
\text { Products }\end{array}$ & Yes & No & No & $\begin{array}{l}\text { Not } \\
\text { Determined }\end{array}$ \\
\hline $\begin{array}{l}\text { Produces a Product that } \\
\text { Potentially helps US energy } \\
\text { security }\end{array}$ & Yes & Yes & No & Yes \\
\hline $\begin{array}{l}\mathrm{CO}_{2} \text { Reduction as } \\
\text { Determined using Life Cycle } \\
\text { Assessment Models }\end{array}$ & $>91 \%$ & $\begin{array}{l}\text { Not } \\
\text { Determined }\end{array}$ & $\begin{array}{l}-20 \% \text { to } \\
+20 \%\end{array}$ & $>50 \%$ \\
\hline
\end{tabular}

\section{Biodiesel from Alqal Oil Production}

Algae are considered to be promising feedstocks for the production of biomass or algal oils that could be someday turned into fuels with the right conversion technology. Algae consume 
carbon dioxide during photosynthesis thereby offering a beneficial use of waste $\mathrm{CO}_{2}$. Algae hold some promise; however there are significant challenges to achieving commercial scale production that will be economically viable.

While algae to bio-fuel technologies have been demonstrated at a lab or small scale, it has not yet shown promise for a successful commercial scale operation. One expert that worked on NREL's algae to biodiesel program concluded recently that further improvements on the order of ten times will be necessary to bring this platform to commercial reality ${ }^{17}$.

The main challenges in commercializing algae platforms include:

- Ability to produce a viable product or fuel with mass-market potential from algae

- Reducing the risk of culture collapse from contamination and invasive species

- Reducing water loss by evaporation in open systems

- Optimizing growth rates, oil production and contaminant resistance through species selection or genetic modifications

- Reducing the large capital cost requirements of the photo-bioreactor systems

- Reducing large overall energy requirements from pumping, $\mathrm{CO}_{2}$ transfer, harvesting, extraction, and conversion

- Risk of incorporating flue gas with potential poisonous compounds such as $\mathrm{NO}_{\mathrm{x}}$ and $\mathrm{SO}_{\mathrm{x}}$.

The ability for algal oils to produce a viable energy product, such as a fuel, is one of the largest challenges that this technology faces. Algae can be processed to produce algal oils which can then be esterified to produce bio-diesel. However, bio-diesel is not a "drop in replacement" fuel that can be directly used as a neat fuel using the existing transportation infrastructure and engines (Shaikh, R. et. al., "The Future of Vehicle Fuels and Technologies," Health Effects Institute, Boston, MA (Feb. 2011).

Current bio-diesel production facilities in the U.S. are struggling at about two-thirds of capacity $^{18}$, in part due to the lack of demand. Attempts to produce other fuels have only been carried out at a research and development scale (from hydro-processing of algal oils), but scale up costs are a challenge and there is limited evidence that ASTM and SAE fuel specifications can be met. Further, adoption of a new fuel or blend in the marketplace and winning regulatory approval is likely to take many years.

Unlike emerging fuels, Fischer Tropsch, synthetic diesel fuel is sold worldwide today and has very well-known characteristics. Decades of work in emissions studies have been conducted on these fuels and the fuel can meet existing ASTM, SAE and other fuel specifications for sale into the marketplace immediately.

Algae's use as a biomass feedstock for gasification to produce a syngas and subsequent conversion to Fischer-Tropsch fuels is a viable pathway, but in these scenarios dry algae is competing with biomass feedstocks such as agricultural wastes, forest residues, and energy 
crops which can be delivered cheaply to biomass plants in the existing marketplace. The U.S. Department of Energy along with the U.S. Department of Agriculture has estimated that over 1.3 billion tons of biomass can be produced in the United States today for use in biomass plants, while continuing to meet all food, feed, and export demands ${ }^{19}$. This consists of about 368 million dry tons of sustainably removable biomass from forestlands and about 998 million dry tons from agricultural lands, and is enough to displace 30 percent or more of the country's petroleum consumption. If alternate biomass feedstocks are needed in the United States, energy crops such as switch grass, wild king grass, and others are likely to provide better economics.

As noted in Biomass Magazine April 2010 article on Algae "Great Green Hope", "Many highly qualified researchers caution that widespread commercial use of algae for biofuels could be 10 years away. Even non-fuel uses for chemicals, carbon capture, and nutraceuticals are problematic and not ready for commercialization. Issues such as energy balance, water usage, invasive species and land use must be addressed before algae can become a viable feedstock for fuels. ${ }^{20}$

\section{Carbonate Production}

Another $\mathrm{CO}_{2}$ conversion path under development involves the production of solid carbonate products. This approach is also referred to as mineral sequestration. In this process captured $\mathrm{CO}_{2}$ is reacted with oxides and/or hydroxides of calcium or magnesium to create a stable carbonate form (such as calcium carbonate $\left[\mathrm{CaCO}_{3}\right]$, the primary component of limestone). Naturally occurring minerals

The production of carbonates from the reaction of captured $\mathrm{CO}_{2}$ with naturally occurring minerals, such as serpentine $\left[\mathrm{Mg}_{3} \mathrm{Si}_{2} \mathrm{O}_{5}(\mathrm{OH})_{4}\right]$ or olivine $\left[\mathrm{Mg}_{2} \mathrm{SiO}_{4}\right]$, and processed materials such as $\mathrm{MgO}$ and $\mathrm{CaO}$, is a relatively new concept. This $\mathrm{CO}_{2}$ conversion concept has the following significant challenges that need to be overcome in order to be economically viable on a commercial scale:

- The availability and cost of raw materials

- Slow reaction rates

- Net balance of $\mathrm{CO}_{2}$

- Commercial economics

- Limited market for products

The reaction of $\mathrm{CO}_{2}$ with pure magnesium oxide $(\mathrm{MgO})$ or calcium oxide $(\mathrm{CaO})$ is ideal but adds a number of challenges as follows:

- These compounds do not exist in a natural form and are not easily produced in the amounts that would be required for commercial scale production plants. 
- The production of these materials involves either dissolving the raw mineral in an acidic solution such as hydrochloric acid $(\mathrm{HCl})$, and/or heating to a very high temperature (as in cement manufacturing).

These approaches are unattractive due to the large energy requirements, production of significant quantities of $\mathrm{CO}_{2}$ as part of the production process, and/or creation of acidic toxic waste. Therefore, the reaction of $\mathrm{CO}_{2}$ with a pre-treated but not fully reduced mineral is therefore seen as the best possible option. Different starting materials and pre-treatments have been tested in an attempt to find an optimal approach; however none of the approaches have yet proven they can form the basis of an economical, environmentally sound, commercial process.

Another key technical challenge is the slow reaction rate of the raw mineral with $\mathrm{CO}_{2}$, which can require from hours to days, depending upon the composition of the raw material and the temperatures employed in the conversion process.

Large scale sequestration of $\mathrm{CO}_{2}$ into mineral carbonates will also require enormous amounts of material. To give an idea of the scale, it is estimated that to use the $\mathrm{CO}_{2}$ produced from each pound of coal fired in a power plant, would require about eight times its mass in minerals to absorb the $\mathrm{CO}_{2}$ emissions generated ${ }^{21}$. Put another way, a single $500 \mathrm{MW}$ power plant generating approximately 10,000 tons/day of $\mathrm{CO}_{2}$ would require about 300,000 tons/day of magnesium silicate ore ${ }^{22}$.

While there are significant deposits of such ores available in the U.S., it is agreed that such large scale mining would have huge environmental consequences. The transport of such large amounts of raw material and the final carbonate product would also be expensive, impose environmental issues and therefore would not likely be practical.

A $\mathrm{CO}_{2}$ life cycle assessment (LCA) of this technology requires $\mathrm{CO}_{2}$ generated from mining, materials transport, material pre-treatment and other processing, and transport of the final carbonate product to market. Several industry experts question whether there will be a $\mathrm{CO}_{2}$ reduction at all and claim that a net increase could result.

The proposed products created from this process are low value materials such as aggregates for concrete or building materials. These products would have to compete with materials from much lower cost production methods. For instance, an aggregate produced simply by crushing and screening limestone would be comparable and does not involve the large energy inputs that carbonation does. Fixing $\mathrm{CO}_{2}$ in the rock does not create a higher value product as far as its material properties, and attempts to fetch significant price premiums with claims of green credentials has not been very successful in the construction industry. Considering all of the factors, commercial economics are not likely to be viable without significant incentives. 
Some groups propose to use sea water as a primary feedstock for the production of carbonates. While the science is unclear, a plant using this technology must have direct ocean water access via pipeline to be viable. To install a new intake and discharge line would likely be uneconomical. Permitting and approvals for a new intake/discharge would take years to complete. Even adding capacity for intake/discharge for a commercial plant would add excessive cost and permitting time to a project. Most industrial emissions sources on U.S. coastlines or waterways were permitted decades ago and new effluent requirements to the ocean or waterways in today's environment would be stringent and difficult to meet.

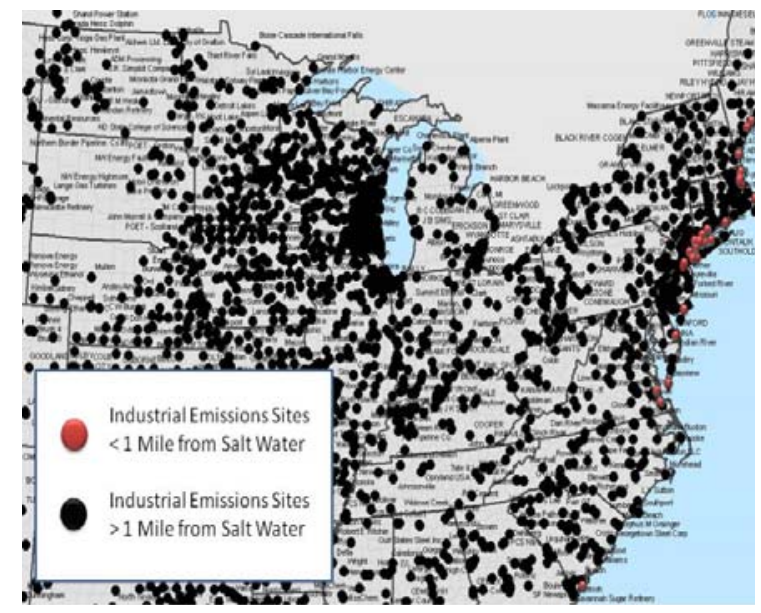

Figure 78 - Eastern Seaboard Project Sites $<1$ Mile from Salt Water

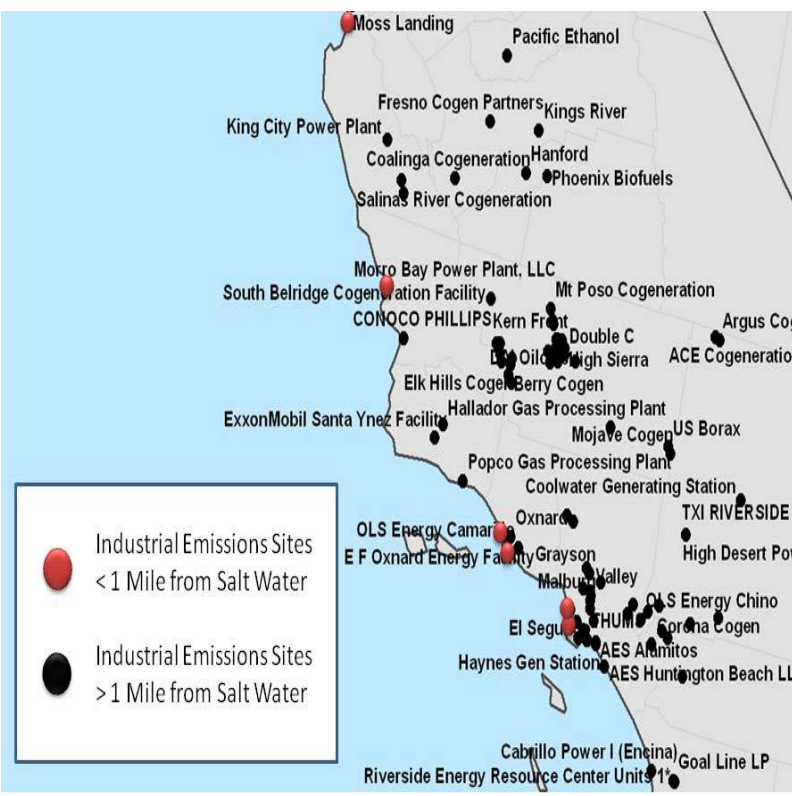

Figure 77 - California Central Coast Project Sites < 1 Mile from Salt Water

Based on a GIS analysis of industrial sites, there are 79 industrial emissions sites less than one (1) mile from U.S. salt water bodies to be considered for this type of approach. This GIS analysis was done by looking at industrial sites $<1$ mile from the coastline as shown in the Figures 68 and 69. Red dots indicate sites that are $<1$ mile and black dots $>1$ mile. Further analysis would have to be done on the ability for these sites to intake and discharge from water bodies, but 79 sites would seem to be the theoretical maximum.

\section{Enhanced Oil Recovery}

The commercial use of $\mathrm{CO}_{2}$ for enhanced oil recovery (EOR) is a mature market that has existed for over 35 years. The main goal has been to improve the yields from oil reservoirs, by going after 'stranded' oil that cannot be extracted by mechanical means alone (e.g. pumping). The process involves pumping $\mathrm{CO}_{2}$ into the reservoir under high pressure. This reduces the viscosity of the oil trapped in the pores of the rock formation, improving mobility and enabling some of it to be pumped out. In recent years EOR has also been investigated as a possible path for $\mathrm{CO}_{2}$ sequestration, since post-monitoring has shown leakage rates to be low. Although the technology has been successfully proven for oil recovery and carbon storage, 
large scale adoption as a beneficial use of waste $\mathrm{CO}_{2}$ runs into critical limitations in terms of Geographic's, economics, and overall capacity.

Not all domestic oil reservoirs are amenable to enhanced oil recovery. Deep formations with lighter / low viscosity oil are favorable over shallower, heavy oil fields. A recent study by NETL showed that only about half of U.S. reservoirs would be geologically suitable for $\mathrm{EOR}^{6}$. The vast majority of the operations have been centered on the Permian Basin of New Mexico and West Texas, which has accounted for about $75 \%$ of enhanced oil recovery production ${ }^{6}$. Most power plants and other large $\mathrm{CO}_{2}$ sources looking to sell or store their captured $\mathrm{CO}_{2}$ in the future would not be within a reasonable distance to an EOR suitable oil field.

Other beneficial uses of the $\mathrm{CO}_{2}$ that would garner the same price without costly construction and operation of long-distance pipelines would be preferable. The economics of EOR in particular have been a major limitation to its widespread adoption. Enhanced oil recovery projects are generally only profitable when oil prices are high. They are risky plays with substantial investment costs, unpredictable yields and oil price fluctuations. An inexpensive source of carbon dioxide is also important for profitable operations. About $90 \%$ of the $\mathrm{CO}_{2}$ used in EOR operations ${ }^{23}$ come from low cost natural sources such as the Bravo dome in northeastern New Mexico or the Jackson dome in Mississippi. Sourcing from a natural $\mathrm{CO}_{2}$ reservoir such as these, of course, does not result in any net emission reductions. The other $10 \%$ is supplied by the lowest cost industrial sources such as natural gas processing and ammonia plants. Sources with much higher $\mathrm{CO}_{2}$ capture costs such as power plants and cement production plants would not be competitive without significant cost reductions and/or incentives.

The total storage capacity of $\mathrm{CO}_{2}$ in depleted oil reservoirs in the United States has been estimated at about 12 billion tons ${ }^{24}$, which is equal to about 2 years of U.S. $\mathrm{CO}_{2}$ emissions. This limited capacity makes EOR a short-lived solution. Most experts agree that 50 years or more of storage potential will be required to stabilize atmospheric $\mathrm{CO}_{2}$ levels.

\section{H. Lifecycle Assessment for the Capture and Conversion of $\mathrm{CO}_{2} \underline{\text { to Diesel Fuel }}$}

A lifecycle assessment (LCA) for the Sunexus process was developed showing total $\mathrm{CO}_{2}$ consumption by the process through the utilization of the diesel fuel. The Life Cycle Analysis (LCA) accounts for all inputs and outputs to the system.

International Standards Organization (ISO) standards 14040:2006 and 14044:2006 for Lifecycle Analysis were used as guidance in the development of this LCA. According to ISO standards, there are four phases of an LCA:

- Goal and Scope Definition

- Inventory Analysis

- Impact Assessment Phase

- Interpretation Phase 


\section{$\underline{\text { LCA Goal and Scope }}$}

The goal of the LCA is to provide a quantitative estimate of the overall reduction in greenhouse gases resulting from the production and utilization of diesel fuel using $\mathrm{CO}_{2}$ as a primary feedstock. The $\mathrm{CO}_{2}$ that is used as a feedstock would have otherwise been emitted. The reason to carry out this study is to determine the overall $\mathrm{CO}_{2}$ balance of the system including $\mathrm{CO}_{2}$ consumed/utilized and any $\mathrm{CO}_{2}$ created/emitted from the integrated Sunexus system and the subsequent utilization of the diesel as transportation fuel.

These results are intended for decision makers to compare the overall benefits of the Sunexus process with other processes that may be able to utilize or otherwise sequester $\mathrm{CO}_{2}$. The scope or boundary of this LCA begins at the "plant gate" of an operational Sunexus system and ends with an analysis of the utilization of the diesel fuel and its offset of petroleum derived diesel.

Figure 79 shows the LCA scope and system boundaries for the Sunexus process. Life cycle elements outside of the boundary conditions and not quantitatively addressed here include: the manufacturing energy, emissions, and impacts of materials used to build commercial Sunexus plant; the onsite construction energy, emissions, and impacts for the Sunexus plants; and elements relating to industrial processes that result in the $\mathrm{CO}_{2}$ emissions which feed the Sunexus process. The $\mathrm{CO}_{2}$ that is used as a feedstock for the Sunexus process would have otherwise been emitted. Potential contaminants in the captured $\mathrm{CO}_{2}$ are not considered in LCA's. 


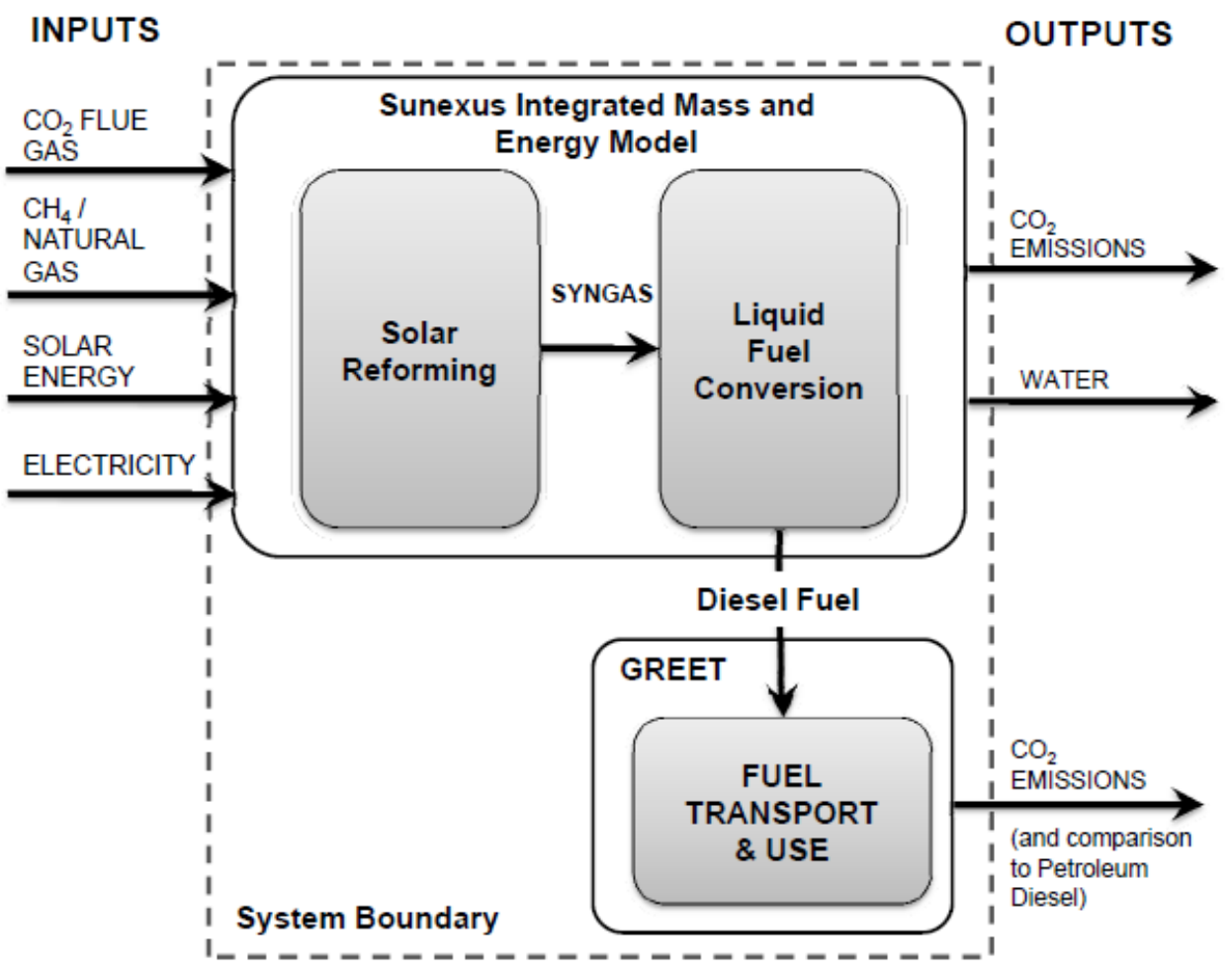

Figure 79 - LCA System Boundary for the Sunexus TM Commercial Plant to convert 180,000 Tons/Year of $\mathrm{CO}_{2}$ into 71.3 Million Gallons/Year of Synthetic Diesel Fuel

\section{$\underline{\text { LCA Inventory }}$}

To conduct the LCA, first the Sunexus Integrated Mass and Energy Model (Section IIIA) was used to analyze the inputs and outputs for the integrated Sunexus process and the plant gate is used as a boundary. A flow sheet model was developed that tracks mass and energy flows through each unit process of the Sunexus system including $\mathrm{CO}_{2}$ consumption and $\mathrm{CO}_{2}$ production.

\section{Model Inputs}

$\underline{\mathrm{CO}}_{2}$ Flue Gas: The $\mathrm{CO}_{2}$ that is used as a feedstock for the Sunexus process would have otherwise been emitted.

$\underline{\mathrm{CH}}_{4}$ (Natural Gas): Methane or natural gas is used as feedstock for the process.

Renewable bio-gas or pipeline natural gas can be used. In this model, pipeline natural gas is used as the input.

Solar Energy: Solar energy is used to provide the main energy input to the process to reform the $\mathrm{CO}_{2}$ rich gas stream into syngas. 
Electricity: A small electricity input is required for system operation to run chillers, pumps, and other auxiliary equipotent.

\section{Model Outputs}

$\mathrm{CO}_{2}$ Emissions (from System): Emissions come from the use of electricity and some fugitive emissions that come off of the diesel fuel during storage.

Water: The system (after start up) has excess water (most is recycled) and some of this water can be used for crop irrigation or discharged to a wastewater treatment plant.

Diesel Fuel: A high cetane, low sulfur diesel fuel is the product produced from the Sunexus process.

The Argonne National Lab's GREET model (version 1.8c.0) was then used to analyze transportation and use of the Sunexus diesel fuel and the $\mathrm{CO}_{2}$ balance is compared to petroleum derived diesel fuel.

\section{$\underline{\text { LCA Impact Assessment }}$}

For this LCA impact assessment, a commercial plant utilizing 902,500 tons of $\mathrm{CO}_{2}$ per year is used as an example. A discussion of the commercial economics of this plant is shown in Section 3 (D). The overall percent $\mathrm{CO}_{2}$ reduction is independent of the plant size, except for the fact that larger plants are somewhat more efficient in their electricity usage.

\section{Sunexus System Inputs}

The Sunexus system inputs for the LCA Impact Assessment are as follows:

Captured $\mathrm{CO}_{2}: 902,500$ tons/year of $\mathrm{CO}_{2}$ are input to the Sunexus plant

Solar Energy: Annual solar thermal energy input into the system totals 18.8 million Gigajoules annually (0.018 Exajoules). This energy input results in zero $\mathrm{CO}_{2}$ emissions.

Electricity: Some electricity is needed to power auxiliary system components including chillers, heaters, valves, controls, and other components. $153,335,478 \mathrm{kWh}$ of power per year is needed for this commercial plant for system components.

Natural Gas [NG]: NG input to the process totals 957,000 tons / year. The NG is used as feedstock for the production of diesel fuel and is not combusted, therefore no $\mathrm{CO}_{2}$ emissions result from this input.

\section{Sunexus System Outputs}

The Sunexus system outputs for the LCA Impact Assessment are as follows: 
$\underline{\mathrm{CO}}_{2}$ Emissions (fugitive emissions): Fugitive emissions come from unconverted $\mathrm{CO}_{2}$ and $\mathrm{CO}_{2}$ that off-gas from the stored diesel fuel. Fugitive $\mathrm{CO}_{2}$ emissions total 19,337 tons/year which equates to $2.1 \%$ of total input $\mathrm{CO}_{2}$ emissions.

$\underline{\mathrm{CO}}_{2}$ Emissions (from electricity usage): Electricity is needed for auxiliary components such as chillers, heaters, valves, controls, and other components. If grid electricity is used for this power requirement, then annual equivalent emissions will total 64,586 tons of $\mathrm{CO}_{2}$ per year or $7.2 \%$ of the feed input. It is assumed that natural gas is the source of energy for this electricity. However, the proportion of electricity generated at a particular commercial plant site would likely include a combination of energy from coal and natural gas and the amount of $\mathrm{CO}_{2}$ emitted from this combination of electrical power sources would need to be used.

Since the Sunexus system is located in an area of high solar insolation values, a traditional solar energy system (Photovoltaic or other) system could be implemented to power the system resulting in zero $\mathrm{CO}_{2}$ emissions. However, the cost of this possible option was not determined in this study. In this model, it is assumed that grid electricity is used and 64,586 tons of $\mathrm{CO}_{2}$ are counted as an emission (7.2\% of input).

- Water: A total of 136 million gallons of clean condensate water is discharged per year. Note that 516 million gallons of water are recycled from the liquid fuel production system to the Sunexus solar reformer internally and used for conversion.

- Diesel Fuel: 356,565,805 gallons of diesel fuel are produced from this plant on an annual basis.

A total of all inputs and outputs/emissions from the Sunexus plant equates to $90.7 \%$ reduction of total $\mathrm{CO}_{2}$. This results in a reduction of 816,300 tons $\mathrm{CO}_{2} /$ year.

Next, an analysis of the transportation and utilization of the diesel fuel is completed and is compared to $\mathrm{CO}_{2}$ emissions from petroleum derived diesel fuel.

Using the Argonne National Labs GREET Model (v1.8) shows that when the Sunexus derived diesel fuel $(356,565,805$ gallons per year) displaces petroleum derived diesel fuel, this results in an overall $\mathrm{CO}_{2}$ reduction of $1,852,894$ tons $\mathrm{CO}_{2} /$ year, which is a significant additional benefit. 


\section{Jobs Analysis}

This jobs analysis is based upon the deployment of one 'Hub and Spoke' plant each year in the U.S. from 2015-2030. Therefore, 17 plants would produce 1.49 billion gallons of synthetic diesel fuel per year by the end of 2030 . If a wholesale value of $\$ 3.03 /$ gallon (based on $\$ 75.00 /$ barrel oil) is used, then the value of this diesel fuel is $\$ 4.51$ billion. The generation of jobs from the deployment of these plants by 2030 is determined as follows:

- 3,145 jobs for the construction of each plant per year, including supporting industries for the manufacturing of components.

- 125 jobs for full time operations, management and maintenance of each plant which would be 2,125 jobs for the 17 plants in operation by the end of 2030 .

- 20 supporting jobs in fuel storage, transportation and distribution for each plant which would be 340 jobs for the 17 plants by the end of 2030 .

- 42 supporting jobs in the local communities such as hotels, restaurants and other businesses. This number of jobs was estimated using 1 support job in the community per 1 job created from the deployment of each plant. Therefore, the total number of supporting jobs by the end of 2030 would be $\underline{31,875}$.

- 45,450 jobs created by the improvement in the U.S. balance of trade as result of a reduction in the need for imported oil. This number of jobs was estimated from 10 jobs created per $\$ 1,000,000$ in avoided oil import costs as based upon a yearly diesel fuel production in 2030 of 1.818 billion gallons valued at $\$ 4,545,000,000$ using a wholesale diesel fuel value of $\$ 2.50$ /gallon.

In addition, it is estimated that 20,000 new jobs in research and development for the manufacturing of components to support the continuous improvement of the technologies for these commercial plants for a total of 132,445 from the deployment of these Sunexus plants by the end of 2030.

The American Solar Energy Society (ASES) in 2009 predicted that 1,211 million tons of $\mathrm{CO}_{2}$ emissions would need to be reduced each year in the U.S. by 2030 if the $\mathrm{CO}_{2}$ concentration in the atmosphere is to be held at a level of 450-500 ppm. ASES estimated the potential $\mathrm{CO}_{2}$ reductions that could be achieved from the various clean and renewable energy approaches and these estimates are provided in Table 21. ASES then carried out a jobs analysis to estimate the potential jobs supported by the deployment of these clean and renewable energy approaches. They determined that 4,513,000 jobs could be created from the successful implementation of these technologies, which amounts to 3,758 jobs for each 1,000,000 tons of $\mathrm{CO}_{2}$ reduced each year in the U.S. by 2030 .

Therefore as based upon this ASES study, 172,492 jobs would be created from the reduction of $45,900,000$ tons of $\mathrm{CO}_{2} /$ year, which is in reasonable agreement of our estimation of 132,445 jobs. 
Table 19 - Potential $\mathrm{CO}_{2}$ Reductions from the Deployment of Various Clean and Renewable Energy Approaches in 2030

\begin{tabular}{|l|c|}
\hline \multicolumn{1}{|c|}{$\begin{array}{c}\text { Clean and Renewable } \\
\text { Energy Approach }\end{array}$} & $\begin{array}{c}\text { Potential Carbon Reductions } \\
\text { (Million Tons CO }\end{array}$ /year) \\
\hline Improve Energy Efficiency & 688 \\
\hline Concentrating Solar Power & 63 \\
\hline Photovoltaic Solar Power & 63 \\
\hline Wind Power & 181 \\
\hline $\begin{array}{l}\text { Biofuels from Biomass Residues } \\
\text { and Biomass Crops }\end{array}$ & 58 \\
\hline Biomass Power & 75 \\
\hline Geothermal Power & 83 \\
\hline Total & 1,211 \\
\hline
\end{tabular}

Table 20 - Potential Jobs Supported by the Deployment of Various Clean and Renewable Energy Approaches in 2030

\begin{tabular}{|l|c|}
\hline $\begin{array}{c}\text { Clean and Renewable Energy } \\
\text { Approach }\end{array}$ & $\begin{array}{c}\text { Jobs Supported } \\
\text { (Thousands) }\end{array}$ \\
\hline Improve Energy Efficiency & 3,360 \\
\hline Concentrating Solar Power & 93 \\
\hline Photovoltaic Solar Power & 257 \\
\hline Wind Power & 172 \\
\hline $\begin{array}{l}\text { Biofuels from Biomass Residues } \\
\text { and Biomass Crops }\end{array}$ & 340 \\
\hline Biomass Power & 147 \\
\hline Geothermal Power & 144 \\
\hline Total & 4,513 \\
\hline
\end{tabular}




\section{J. Conclusions}

The Sunexus commercial plants utilize waste $\mathrm{CO}_{2}$ as a feedstock for the efficient and economical production of diesel fuel using solar thermal energy as the primary energy input to the system. When diesel fuel is produced that displaces petroleum derived diesel fuel, additional GHG reduction benefits are achieved.

The most immediate path to rapid greenhouse gas (GHG) reduction is to turn captured carbon from a liability to a feedstock for the production of valuable energy products with the right technology and business model. The appropriate model must be able to work at a variety of industrial sources on a range of feed gas streams and projects must be profitable without factoring in incentives.

Deployment of Sunexus plants will utilize $\mathrm{CO}_{2}$ from industrial sources while producing a directly usable diesel fuel that replaces petroleum derived fuel on a one-to-one basis, thus improving United States energy security while also sequestering carbon dioxide (and waste methane where available).

Since Sunexus commercial plants will be profitable without incentives, private capital markets will finance commercial facilities and these plants will be operated at a profit while sequestering $\mathrm{CO}_{2}$. High paying, clean energy jobs will be created in the manufacturing of system components, construction and operation of the proposed Sunexus plants.

Overall a commercial Sunexus plant that utilizes 900,000 tons / year of $\mathrm{CO}_{2}$ will produce 356 million gallons of diesel fuel. The Sunexus plant utilizes $90.7 \%$ of the total $\mathrm{CO}_{2}$ input (counting inputs and outputs/emissions, such as those from electricity used in the plant).

Sunexus derived diesel fuel displaces petroleum derived diesel fuels on a gallon per gallon basis. When a well-to-wheels analysis of the Sunexus diesel fuel is conducted and compared to petroleum diesel fuel, a total reduction of $\mathrm{CO}_{2}$ emissions of $1,852,894$ tons of $\mathrm{CO}_{2}$ per year are achieved.

Using the plant gate as a boundary, total $\mathrm{CO}_{2}$ reduction is $90.7 \%$ of total $\mathrm{CO}_{2}$ that goes into the process is utilized (this counts inputs and outputs as discussed below).

Use of the Sunexus system to produce diesel fuel provides significant $\mathrm{CO}_{2}$ reduction from both the operation of the plant and the displacement of the petroleum derived diesel fuel by the Sunexus diesel fuel. 


\section{SUPPORTING TECHNICAL ASSESSMENTS}

Several technical assessments were carried out in support of the commercial deployment of the Sunexus $\mathrm{CO}_{2}$ Solar Reforming technology. These technical assessments are presented in Sections A-D.

\section{A. An Assessment of Contaminants in Captured $\mathrm{CO}_{2}$ Gas Streams from Various $\underline{\text { Industrial Processes and Their Possible Effect on Sunexus } \mathrm{CO}_{2}} \underline{\text { Reforming Catalysts }}_{2}$}

Carbon dioxide capture and storage (CCS) and carbon dioxide capture and conversion (CCC) are two technologies that have the potential of reducing $\mathrm{CO}_{2}$ emissions from human activities. These processes can be applied to $\mathrm{CO}_{2}$ emissions from large power plants or industrial facilities. The CCS process involves three main steps:

- Capturing $\mathrm{CO}_{2}$, at its source, by separating it from other gases produced by an industrial process

- Transporting the captured $\mathrm{CO}_{2}$ to a suitable storage location (typically in compressed form)

- Storing the $\mathrm{CO}_{2}$ for long periods of time, for instance in underground geological formations, in the deep ocean, or within certain mineral deposits.

- Whereas, the CCC process may be carried out with two main steps:

- Capturing $\mathrm{CO}_{2}$, at its source, by separating it from other gases produced by an industrial process

- Transporting the captured $\mathrm{CO}_{2}$ to a commercial scale plant that converts the $\mathrm{CO}_{2}$ to a gaseous and/or liquid fuel. This plant is likely to be co-located near the industrial source of the $\mathrm{CO}_{2}$, thus reducing the gas transportation costs.

Two types of catalysts are used in this project for the solar reforming of $\mathrm{CO}_{2}$ to produce diesel fuel. The first catalyst, developed in support of this project, is used in the solar reformer to convert $\mathrm{CO}_{2}$ (with methane and steam) to syngas (primarily $\mathrm{H}_{2}$ and $\mathrm{CO}$ ). The second catalyst, supported under other funding sources, is used to convert the syngas to diesel fuel. These catalysts can be poisoned and deactivated when certain types and levels of contaminants are present in the syngas. The degree of catalyst poisoning is dependent upon the specific contaminant present and its concentration. Once the gas is cleaned to address the purity requirements for the first reforming catalyst, the gas will then be clean enough for the second catalyst (diesel fuel production catalyst). Therefore, addressing the cleanliness requirements of the first catalyst is the objective of this analysis.

The proprietary, Ni-based $\mathrm{CO}_{2}$ reforming catalyst validated for this program has been tested under a variety of contaminated feed streams. Sulfur compounds are the biggest risk to catalyst deactivation. Sulfur $\left(\mathrm{H}_{2} \mathrm{~S}\right)$ levels of up to $20 \mathrm{ppm}$ have been tested and no deactivation has occurred in the reforming catalysts. However, F-T catalysts are more susceptible to sulfur in the gas stream and it is recommended that levels be kept lower. Maximum allowable 
catalyst contamination specifications were listed in Tables 2 and 3 for the $\mathrm{CO}_{2}$ reforming catalyst and the syngas to diesel fuel production catalyst, respectively.

Clean up efforts for each of these industrial gas streams are proposed based on known technologies and costs for implementation of these systems are summarized and used as inputs to the commercial economic model. It was determined that known, commercially available gas clean up technologies can be used with the Sunexus process at a variety of industrial sites in order to scrub syngas of catalyst contaminants. In no case did additional costs associated with feed gas cleanup have a major effect on commercial economics.

Before other industrial emissions sources are discussed, gas composition and contaminants for the CES oxy-combustion facility are reviewed below. $\mathrm{CO}_{2}$ capture processes typically scrub contaminants as well as separate $\mathrm{CO}_{2}$, so a discussion around currently available technologies is provided below.

Although the end-to-end processes of carbon dioxide capture and storage (CCS) and carbon dioxide capture and conversion (CCC) are still in the early stages of deployment, carbon capture by itself has a long history. Carbon dioxide has been captured to serve a commercial market that, in the U.S., currently consumes about 8 million tons of carbon dioxide per year ${ }^{25}$. The $\mathrm{CO}_{2}$ is used in a wide variety of applications in areas such as food \& beverage, medicine, chemicals, and research. Different grades are available depending on the need, from $95 \%$ up to $99.9999 \%$ purity. Considered separately from the merchant market, $\mathrm{CO}_{2}$ has also had widespread use in enhanced oil recovery (EOR) operations. It is estimated that over 35 years, about 600 million tons of $\mathrm{CO}_{2}$ have been injected into wells for $\mathrm{EOR}^{26}$.

Given this history, there are effective, proven technologies available for $\mathrm{CO}_{2}$ capture and cleaning today. However, the costs vary considerably depending on the source. Commercial $\mathrm{CO}_{2}$ is captured from the cheapest sources such as hydrogen plants, ethanol plants, natural gas processing plants, or from natural sources (reservoirs).

These sources have relatively high concentrations of $\mathrm{CO}_{2}$ in their waste streams making it economical for capture. Other sources with lower concentrations of $\mathrm{CO}_{2}$ such as cement plants and coal power plants have capture costs that are considered prohibitively high using current state of the art technology. Since the demand for commercial $\mathrm{CO}_{2}$ is relatively small there has been no need to consider these higher cost sources. Of course with the emphasis on reducing greenhouse gases via $\mathrm{CCS}$ or $\mathrm{CCC}$, these sources must now be considered, since they contribute such as large percentage of the overall emissions. Much effort is being directed towards the research and development of new technologies for carbon capture, in particular for lowering the cost of capture from fossil fueled power plants.

For comparison and discussion purposes, it is useful to group the technologies and approaches for $\mathrm{CO}_{2}$ capture. Technologies for $\mathrm{CO}_{2}$ separation from other chemical components can be grouped into four main categories: absorption, adsorption, cryogenics and membranes. The approaches or strategies for capture can also be grouped into four main categories: postcombustion capture, oxy-fuel combustion capture, and pre-combustion capture (from the 
conversion of fossil fuel to syngas using thermochemical processes) and industrial capture (from industrial sources).

The following sections will discuss the applicability of these technologies and approaches to the different sources under consideration, with a focus on costs and possible catalyst contaminants that may be found in the captured $\mathrm{CO}_{2}$. Although there is a much smaller body of knowledge on post-capture contaminant levels (vs. capture economics), there has been some work done to examine these in the context of transport and storage impacts: groundwater contamination (i.e. from $\mathrm{CO}_{2}$ stored in geological formations), worker safety, pipeline corrosion, etc. These studies can be leveraged for our purposes, to ascertain whether further $\mathrm{CO}_{2}$ purification steps will be needed.

\section{Natural Gas and Coal Power Plants}

Natural gas and coal power plants offer the most potential for significant reductions in greenhouse gas emissions via carbon capture. There are several plants in the U.S. demonstrating carbon dioxide capture technologies with more planned. Many of these are sponsored under DOE/NETL's Clean Coal Power Initiative (CCPI).

Chemical absorption with amines is the best option available today for post-combustion $\mathrm{CO}_{2}$ capture from natural gas or coal power plants. The $\mathrm{CO}_{2}$ concentrations in the flue gas are relatively low (Table 21) and are close to atmospheric temperature and pressure. As shown in Table 22, chemical absorption is the most suitable approach for these conditions and is one that has been used extensively in other applications. It is commonly referred to as amine treatment or 'gas sweetening' when used for natural gas processing.

Amines such as monoethanolamine (MEA), diethanolamine (DEA) and methyldiethanolamine (MDEA) have been the most commonly used chemical absorbents. Amine treatment is a two stage process where the $\mathrm{CO}_{2}$ is absorbed by the amine solution and separated from other flue gas constituents in one tower and then stripped from the amine with high temperature steam in another tower. This second step requires a lot of energy and is mostly responsible for the large parasitic power load and high cost of treatment.

Table 21 - Typical Concentrations of Gas/Pre-Separation $\mathrm{CO}_{2}$ Concentrations in Flue Gases from Various Emission Sources

\begin{tabular}{|l|l|}
\hline \multicolumn{1}{|c|}{ Emission Source } & \multicolumn{1}{c|}{$\mathbf{C O}_{2}$ Concentration } \\
\hline PC Boiler Power Plant & $10-12 \%$ \\
\hline Oxy-Fired Coal Power Plant & $90-95 \%$ \\
\hline IGCC Coal Power Plant & $30-32 \%$ \\
\hline NGCC Power Plant & $3-6 \%$ \\
\hline Natural Gas Processing Plant & $0-8 \%$ \\
\hline Cement Production Plant & $14-33 \%$ \\
\hline Ethanol Production Plant & $99 \%$ \\
\hline
\end{tabular}


Table 22 - $\mathrm{CO}_{2}$ Separation Process Conditions ${ }^{27}$

\begin{tabular}{|l|l|l|l|}
\hline \multicolumn{1}{|c|}{ Emission Source } & \multicolumn{1}{|c|}{$\begin{array}{c}\mathbf{C O}_{2} \\
\text { Concentration }\end{array}$} & \multicolumn{1}{|c|}{$\begin{array}{c}\text { Pressure } \\
(\mathbf{M P a})\end{array}$} & \multicolumn{1}{c|}{$\begin{array}{c}\text { Temperature } \\
\left({ }^{\circ} \mathbf{C}\right)\end{array}$} \\
\hline Physical Absorption & $>20 \%$ & $>2$ & 50 \\
\hline Chemical Absorption & $>3 \%$ & $>0.1$ & Low -10 \\
\hline Adsorption & $>30 \%$ & Moderate & Low to moderate \\
\hline Cryogenic & $>50 \%$ & Moderate & Low \\
\hline Membrane & $>15 \%$ & $>0.7$ & Feed temperature \\
\hline
\end{tabular}

Table 23 summarizes some of typical contaminants in stack gases generated from various industrial processes. Sulfur dioxide $\left(\mathrm{SO}_{2}\right)$ and nitrogen oxides $\left(\mathrm{NO}_{\mathrm{x}}\right)$ are the two most abundant contaminants found in industrial processes that operate at high temperatures and under oxidizing conditions. The sulfur and nitrogen are naturally occurring in the fossil fuel in varying amounts and are oxidized during combustion. In addition, atmospheric nitrogen is converted to nitrogen oxides during the combustion processes.

The contaminant levels should be relatively low after amine treatment at around $10 \mathrm{ppm}$ for $\mathrm{SO}_{2}$ and $20 \mathrm{ppm}$ for $\mathrm{NO}_{\mathrm{x}}$. This is not as a result of the amine treatment itself but pretreatments that are implemented to avoid excessive solvent losses during the amine treatment. The solvent/amine loss is caused by the $\mathrm{SO}_{2}$ and $\mathrm{NO}_{\mathrm{x}}$ compounds that combine with the amine to form heat stable salts. Methods typically used are flue-gas desulfurization (FSD) for $\mathrm{SO}_{2}$ reduction and low-NOx burners and/or selective catalytic reduction (SCR) for $\mathrm{NO}_{\mathrm{x}}$ reduction. Above around $100 \mathrm{ppm}$ it is seen as more cost-effective to implement these pretreatments than to suffer the loss of expensive solvent. Although further cleanup would still have to be done on these contaminants to meet the catalyst specifications, the effort will be greatly reduced as a result of these pre-treatments. In this respect the amine treatment approach has advantages over other technologies that do not require significant reductions of $\mathrm{SO}_{2}$ and $\mathrm{NO}_{\mathrm{x}}$. Commercial clean up technologies can be implemented in order to reduce these levels below the operable levels required for the catalyst systems. 
Table 23 - Typical Contaminants in Stack Gases Generated from Various Industrial Processes (before $\mathrm{CO}_{2}$ Separation)

\begin{tabular}{|l|c|c|c|c|c|}
\hline \multicolumn{1}{|c|}{$\mathbf{C O}_{2}$ Source } & $\mathbf{H}_{\mathbf{2}} \mathbf{S}$ & $\mathbf{S O}_{2}$ & $\mathbf{N O}_{\mathbf{X}}$ & $\mathbf{N H}_{\mathbf{3}}$ & HCl \\
\hline $\begin{array}{l}\text { PC Boiler Power } \\
\text { Plant }\end{array}$ & $\begin{array}{c}\text { Not } \\
\text { Detected }\end{array}$ & $\begin{array}{c}500-3,000 \\
\mathrm{ppm}\end{array}$ & $10-40 \mathrm{ppm}$ & & $5-100 \mathrm{ppm}$ \\
\hline $\begin{array}{l}\text { Oxy-Fired Coal } \\
\text { Power Plant }\end{array}$ & $\begin{array}{c}\text { Not } \\
\text { Detected }\end{array}$ & $\begin{array}{c}500-3,000 \\
\mathrm{ppm}\end{array}$ & & & \\
\hline $\begin{array}{l}\text { IGCC Coal Power } \\
\text { Plant* }\end{array}$ & $<50 \mathrm{ppb}$ & $<50 \mathrm{ppb}$ & $<100 \mathrm{ppb}$ & $<100 \mathrm{ppb}$ & \\
\hline NGCC Power Plant & $\begin{array}{c}\text { Not } \\
\text { Detected }\end{array}$ & $15 \mathrm{ppm}$ & $119 \mathrm{ppm}$ & & \\
\hline $\begin{array}{l}\text { Natural Gas } \\
\text { Processing Plant }\end{array}$ & $\begin{array}{c}0-50,000 \\
\mathrm{ppm}\end{array}$ & & & & \\
\hline $\begin{array}{l}\text { Cement Production } \\
\text { Plant }\end{array}$ & $\begin{array}{c}\text { Not } \\
\text { Detected }\end{array}$ & $\begin{array}{c}10-3,500 \\
\mathrm{mg} / \mathrm{m} 3\end{array}$ & $\begin{array}{c}200-3,000 \\
\mathrm{mg} / \mathrm{m} 3\end{array}$ & & \\
\hline $\begin{array}{l}\text { Ethanol Production } \\
\text { Plant** }\end{array}$ & $\begin{array}{c}\text { Not } \\
\text { Detected }\end{array}$ & & & & \\
\hline
\end{tabular}

*Contaminant data presented for pyrolysis/steam reforming IGCC technology under reducing conditions (no oxygen or air input)

**Impurities are in the forms of organic compounds, such as ethanol, methanol and sulphur compounds including H2S and dimethyl sulphide (DMS)

\section{Natural Gas Processing Plants}

Natural gas processing involves cleaning of raw natural gas from the well head to produce a high quality 'pipeline ready' natural gas that is mostly free of impurities and that meets the utilities' specifications for BTU rating. The composition of raw natural gas varies based on the source but typically consists of $70-90 \%$ methane (natural gas), $0-20 \%$ other light hydrocarbons such as ethane, propane and butane, $\sim 0-20 \%$ carbon dioxide, $0-5 \%$ nitrogen, $\sim 0-5 \%$ hydrogen sulphide $\left(\mathrm{H}_{2} \mathrm{~S}\right), 0-0.2 \%$ oxygen, and trace amounts of rare gases argon, helium, neon, and xenon ${ }^{28}$. The removal of hydrogen sulfide is a primary objective due to its toxicity and potential for pipeline corrosion. Carbon dioxide can also cause corrosion in the presence of water and will lower the BTU content of the natural gas. Customers demand natural gas that has no more than about $2 \%$ carbon dioxide ${ }^{29}$, therefore any excess amounts must be removed.

Most natural gas processing facilities (about 95\%) use an amine treatment process for their $\mathrm{CO}_{2}$ removal. As discussed earlier, chemical absorption with amines is currently the best available technology for streams that have low $\mathrm{CO}_{2}$ concentrations and are at lower temperatures and pressures. This is a proven technology that has been employed over several decades. Since amines are non-selective for acid gases such as carbon dioxide and hydrogen sulfide, the amine treatment process removes these at the same time. The raw natural gas is 
dehydrated before being fed into the amine treatment unit. In the first stage the $\mathrm{H}_{2} \mathrm{~S}$ and $\mathrm{CO}_{2}$ are absorbed by the amines in a tall column. The 'rich' amine is then fed into a second column where it is stripped from the acid gases under high temperature. The amine is recycled back into the absorber and the $\mathrm{H}_{2} \mathrm{~S} / \mathrm{CO}_{2}$ stream moves on for further treatment. At this point a Claus process is typically used to remove the $\mathrm{H}_{2} \mathrm{~S}$ and to produce elemental sulfur. The resulting $\mathrm{CO}_{2}$ stream is relatively pure, on the order of $99 \% \mathrm{CO}_{2}$.

While $\mathrm{CO}_{2}$ concentrations are usually in the $0-8 \%$ range, they can be much higher in some natural gas fields. For example, the Shute Creek Natural Gas Processing Plant in La Barge, Wyoming processes streams that contain approximately $65 \% \mathrm{CO}_{2}^{30}$. Facilities such as these, that have concentrations of more than about $20-30 \% \mathrm{CO}_{2}$, can take advantage of other technologies such as physical absorption or membrane separation.

The estimated capital and $\mathrm{O} \& \mathrm{M}$ costs for capturing $\mathrm{CO}_{2}$ from the large point sources are shown in Table 24. The costs do not include transport, storage and monitoring, which are smaller cost components in the overall cost for Carbon Capture \& Storage $(\sim 20 \%)$. The cost of capture depends primarily on the concentration and pressure of $\mathrm{CO}_{2}$ in the flue gas or process stream from which it is being separated. In general higher concentrations and pressures will require less treatment and compression, lowering the cost of capture. Plant size, location, contaminant levels, and separation technology being employed are also contributing factors.

Table 24 - $\mathrm{CO}_{2}$ Capture Costs from Various Industrial Sources

\begin{tabular}{|lc|}
\hline \multicolumn{1}{|c|}{ Emission Source } & \$/Ton $\mathbf{C O}_{2}$ \\
\hline PC Boiler Power Plant & $\$ 25-60$ \\
\hline Oxy-Fired Coal Power Plant & $\$ 37$ \\
\hline IGCC Coal Power Plant & $\$ 11-32$ \\
\hline NGCC Power Plant & $\$ 33-57$ \\
\hline Natural Gas Processing Plant & $\$ 5-15$ \\
\hline Cement Production Plant & $\$ 30-55$ \\
\hline Ethanol Production Plant & $\$ 6-12$ \\
\hline
\end{tabular}

The estimated cost for $\mathrm{CO}_{2}$ capture from natural gas processing is in the range of $\$ 5-15$ per ton of $\mathrm{CO}_{2}{ }^{31}$. This cost is significantly lower than capture from power plants or cement production plants. The primary reason for this is that the $\mathrm{H}_{2} \mathrm{~S} / \mathrm{CO}_{2}$ removal is already an integral part of natural gas processing and therefore not included in the $\mathrm{CO}_{2}$ capture cost. The cost represents final dehydration, compression and possibly some final scrubbing depending on the use (i.e., Enhance Oil Recovery (EOR) or commercial grade $\mathrm{CO}_{2}$ ). 
In a captured $\mathrm{CO}_{2}$ stream produced from natural gas processing, hydrogen sulfide is the only (known) contaminant of concern for the reforming catalysts. However, adsorption, absorption and catalytic reduction processes are commercially available and are widely used and can remove this contaminant to very low levels $(<20 \mathrm{ppb})$.

\section{Cement Production Plants}

In cement production, carbon dioxide emissions come from both fossil fuel combustion and as a result of a chemical reaction that converts crushed limestone (calcium carbonate) into lime (calcium oxide) and $\mathrm{CO}_{2}$. The reaction requires temperatures of around $1,450^{\circ} \mathrm{C}\left(2,400^{\circ} \mathrm{F}\right)$. A variety of fuels are burned, such as oil, natural gas, coal, tires, etc. and sometimes a mix of these to provide the heat. About half of the emissions come from combustion and half from the calcination process.

The $\mathrm{CO}_{2}$ concentrations in the flue gas are estimated to be in the range of $14-33 \%$. It is mix of the lower concentration combustion gas and higher concentration calcination gas. This $\mathrm{CO}_{2}$ concentration is higher than in power plant flue gas, however it would still be at around atmospheric pressure and therefore most likely would not be suitable for technologies such as membrane separation or physical absorption. As in power plants, amine treatment is seen as the most viable and economical option. Table 24 shows the estimated capture costs for cement plants are around par with the natural gas and coal power plants. While economics may be somewhat better due to the higher $\mathrm{CO}_{2}$ concentrations, this is negated by the lower economies of scale from the much lower $\mathrm{CO}_{2}$ emissions per plant.

As with traditional power plants, the most promising near term option for $\mathrm{CO}_{2}$ capture from cement plants may be oxy-combustion. The plants could be retrofitted in the same way with air separation units and a flue gas recycle system to remove most of the nitrogen before combustion. As discussed below, emerging technologies such as oxy-combustion could significantly lower the cost of capture to a reasonable level.

\section{Ethanol Production Plants}

Ethanol plants use feedstocks such as corn, sorghum, sugar cane, and other grains and starches to create ethanol. In the United States corn is the primary feedstock. For every bushel of corn used (56 pounds), approximately $18 \mathrm{lbs}$. of carbon dioxide is produced ${ }^{32}$. The $\mathrm{CO}_{2}$ is a by-product of the fermentation process and is almost $100 \%$ pure without any scrubbing or separation processes. If it is being captured for commercial uses, the only steps involved are typically removal of residual alcohols, dehydration, and compression, resulting in a low cost of capture relative to other industrial processes (see Table 24).

Carbon dioxide from ethanol production may have some trace amounts of sulfur compounds including $\mathrm{H}_{2} \mathrm{~S}$ and dimethyl sulphide (DMS). However these would most likely be in the low parts per million (ppm) levels and would not require high cost treatment efforts.

\section{Integrated Gasification Combined Cycle (IGCC) Power Plants (Coal)}

IGCC power plants thermochemically convert (gasify) fossil fuel into a syngas (carbon monoxide and hydrogen) for combustion instead of direct fossil fuel combustion seen in 
traditional power plants. This technology holds promise for cheaper $\mathrm{CO}_{2}$ capture since it can be done prior to combustion when the concentration and pressure of the $\mathrm{CO}_{2}$ is much greater. The $\mathrm{CO}_{2}$ can then be captured using physical solvents such as Selexol or Rectisol, with the remaining $\mathrm{H}_{2}$ and $\mathrm{CH}_{4}$ used for the production of power. Physical absorption requires much less energy than chemical absorption and it has significant cost benefits since energy is a primary cost driver for carbon capture technologies.

As shown in Table 24, the estimates for the cost of capture are about one half to one third of the costs for traditional power plants. Currently, capital costs for IGCC plants are higher than that of traditional power plants and therefore the overall increase in the cost of electricity is still seen as prohibitively high when carbon capture is included.

Currently there are only two commercial IGCC plants operating in the United States ${ }^{33}$. Several more plants are planned or underway, and as more research is done and the technology gains more widespread adoption costs should come down significantly. In a future environment where power plants will be required to reduce $\mathrm{CO}_{2}$, it is expected that IGCC will be the technology of choice for the construction of new plants.

As with traditional coal or natural gas power plants, the expected contaminants of concern in the $\mathrm{CO}_{2}$ stream are sulfur dioxide $\left(\mathrm{SO}_{2}\right)$ and nitrogen oxides $\left(\mathrm{NO}_{\mathrm{x}}\right)$. The concentrations may be significantly higher in this stream, up to around $750 \mathrm{ppm}$ for $\mathrm{SO}_{2}$ and 2,500 ppm for $\mathrm{NO}_{\mathrm{x}}$. This can be attributed to the fact that physical absorption systems do not require very low levels of these to prevent solvent loss as chemical absorption (MEA) does.

However, the same techniques employed prior to chemical absorption such as selective catalytic reduction (SCR), flue gas de-sulfurization (FSD), and low-NOx burners (LNB) could be used here after the physical absorption. Further cleaning with distillation or other approaches could then be used to reach the required parts per billion levels.

It has been demonstrated recently that thermochemical systems which utilize pyrolysis/steam reforming processes in a reducing environment (no oxygen) produce reduced sulfur and nitrogen species (e.g., $\mathrm{H}_{2} \mathrm{~S}$ and $\mathrm{NH}_{3}$ ), which can be economically removed to very low levels $(<50 \mathrm{ppb})$ with high efficiency water scrubbers and adsorbents.

\section{Oxy-Combustion Power Plants (Natural Gas and Coal)}

Oxy-Combustion plants combust the natural gas or coal in oxygen instead of air. As a result, the stack gases consist primarily of carbon dioxide and water vapor, the latter of which is condensed through cooling. The result is an almost pure carbon dioxide stream which will be used for our pilot process.

\section{B. Recommended Methods for Assessing Contaminant Levels in Captured $\mathrm{CO}_{2} \underline{\text { Streams }}$}

Some of the major industrial processes for which CCC is beneficial include Natural Gas Combined Cycle (NGCC) power Plants, Pulverized Coal (PC) Power Plants, Natural Gas

Processing Plants, Cement Production Plants, Integrated Gasification Combined Cycle 
(IGCC) Coal Power Plants and Gasification Plants for Fuel and Chemical Production. Some of the proven technologies for separation of $\mathrm{CO}_{2}$ include: physical absorption, chemical absorption, adsorption, cryogenics and membranes. However, contaminant species such as $\mathrm{H}_{2} \mathrm{~S}, \mathrm{SO}_{2}, \mathrm{NO}_{\mathrm{x}}, \mathrm{NH}_{3}$ and $\mathrm{HCl}$ will remain in the $\mathrm{CO}_{2}$ stream depending on the industrial process being used. These species can also persist through the solar reforming process and remain in the produced $\mathrm{CO}_{2}$, where they can interfere with subsequent catalytic conversion processes.

It is the task of this section to describe how to monitor, in real-time, contaminant species in $\mathrm{CO}_{2}$ at the ppb level. The main focus will be on gas-phase sulfur containing compounds, nitrogen containing compounds and PM2.5 (particulates with aerodynamic diameter $<2.5$ $\mu \mathrm{m})$. The report includes recommendations for instrumentation, capital and operating costs and an analysis of other species that may interfere when measuring these contaminants.

Based on the known contaminant gases and their maximum allowable levels, a compilation of analytical instruments and their principles of operation were constructed to assess their suitability for monitoring industrial $\mathrm{CO}_{2}$ streams and syngas.

Real-Time instruments analyze samples in real-time and present the result continuously onsite. Although data output times may vary, all instruments included in this category present a read-out in two minutes or less. On-Site Integrated Instruments can produce a result on-site but require a batch sample for analysis. Although on-line gas chromatography (GC) instruments fall into this category, we are comparing different detector tubes.

The common method for detector tubes to display their result is through color change over time with a known flow rate. Detector tubes have the advantage that they are very inexpensive and can measure species to very low levels. However, they are also disposable and have a very restricted range. Detector tubes also tend to have more interference, which for $\mathrm{CO}_{2}$ streams may pose a problem. For example, $\mathrm{CO}_{2}$ interferes with Gastec's 5LB which measures $\mathrm{SO}_{2}$ down to $0.05 \mathrm{ppm}$.

A tried and true method for gas analysis involves use of sampling media which can be analyzed by instruments in a laboratory. Through the use of canisters, various filters and cartridges, all of the identified contaminants can be analyzed. Laboratory analysis usually takes long periods of time but has proven procedures that ensure reliability and accuracy.

It is important to note that instruments, detectors, filters, etc. typically cannot handle much positive pressure. Closed-loop industrial processes typically run under some amount of positive pressure, so sample line pressures may have to be reduced prior to sampling. In the event that the industrial process is under vacuum pressure, the user will have to ensure that the instruments' sampling pumps can overcome this vacuum to maintain a reliable flow through the instrument or sampling media. 
Other parameters to consider while sampling are:

- Dilution Ratios - This becomes an issue when there are differing instruments/sensors that require differing dilution ratios for the same sample flow.

- Gas stream temperature - This is important not only for condensation temperature of a particular gas stream, but the individual instruments' varying requirements. The calibration curve for many instruments is only valid up to $40^{\circ} \mathrm{C}$ which may be close to the condensation temperature of water vapor in syngas. If there is not a way to remove excess water vapor from the sample stream before sampling, then the manufacturer should be contacted to verify instrument accuracy above the recommended temperature range.

- Moisture Level - Water can have an effect not only on the accuracy of the instrument, but the durability and lifespan of the detectors and sensors as well.

- Isokinetic Sampling - Isokinetic sampling refers to maintaining a sample stream velocity that is the same as the bulk gas stream velocity from which the sample is taken. It is preferred to sample through a button hook shaped probe, but this is not always practical depending on the process and surrounding environment. For accurate sampling of PM, efforts should be taken to minimize disruptions of the sample flow.

The categories are organized by contaminant species that were chosen from Table 1 as well as other possible contaminants. Each presents information on each of the instruments used to measure each species. Each table includes parameters relevant to selecting the proper instrument as follows:

- Species - The selected gas contaminant species that the instrument can monitor

- Instrument Make/Model - Manufacturer and product number of the chosen instrument

- Principle of Operation - Technology the instrument uses to measure the selected species

- Measurement Range - Contaminant level that the instrument measures for the selected species

- Data Output - Time required to measure the species level and present the value

- Sample Flow - Required sample flow for the instrument in L/min.

- Interferences - Any gases that may cause substantial interference with the instruments' ability to measure the selected species (based on information from the manufacturer). These interferences are typically associated with the technology and 
not the individual instrument. Some companies were willing to share more information on interferences than others.

- Other Species - Other species that the instrument can measure at the same time. This can be associated with the technology as well as the individual instrument.

Equipment Required - Additional equipment, such as pumps, filters and pressure regulators that is necessary for sampling. Typically these items are available from the instrument manufacturer as options and need to be considered when ordering.

Purchase Price - The estimated list price of the instrument. If a range is given, that will include the listed equipment required that the manufacturer offers. All additional equipment that is desired should be considered before making a decision based on cost.

Operating Cost - The cost of using the equipment not accounting for capital investment. This has been lumped into three categories of low, medium and high.

- Low - longer lifespan of sensors, power supply, routine maintenance and calibration intervals. A low initial cost is taken into consideration as some instruments are not designed for longevity.

- Medium - Typical or average lifespan of sensors, routine maintenance, etc.

- High - Short lifespan of sensors, calibration, maintenance, etc.

The following is a break-down of the principles of operation or technologies associated with measuring the species and a description of some available instruments capable of meeting the needs of contaminants measured in $\mathrm{CO}_{2}$ gas stream.

\section{Hydrogen Sulfide $\left(\mathrm{H}_{2} \underline{S}\right)$}

The common method for measuring $\mathrm{H}_{2} \mathrm{~S}$ is fluorescence detection, effective down to less than $1 \mathrm{ppb}$. When the gas stream enters the instrument, $\mathrm{SO}_{2}$ is scrubbed out and the $\mathrm{H}_{2} \mathrm{~S}$ is then thermally converted (some low temperature and some high temperature) to $\mathrm{SO}_{2}$ which is measured using fluorescence technology. $\mathrm{SO}_{2}$ is measured by a photomultiplier tube sensing the amount of light emitted at a lower energy level than the amount of UV that was projected onto it.

- Ecotech Serinus 55 - Issues have been known to arise when high moisture content or heavy particulate loads are present. Data is stored on a removable flash drive and this is the most portable instrument in the group.

- Ecotech EC9852 - This unit allows for stream switching to quickly measure levels of $\mathrm{SO}_{2}$ and total sulfur (TS). Internal data storage allows for greater capacity compared to the Serinus 55.

- $\quad$ Thermo Scientific 450i - This instrument has the fastest data output at 10 seconds. 
- Teledyne API 101E - This unit has the largest range from $0.4 \mathrm{ppb}$ to $10 \mathrm{ppm}$ and a fast data output time of 20 seconds.

\section{Sulfur Dioxide ( $\left.\mathrm{SO}_{2}\right)$}

These instruments also use fluorescence detection, as do the $\mathrm{H}_{2} \mathrm{~S}$ instruments.

- Ecotech EC9850 - This is a similar unit to the Serinus 55 and can be powered by both $\mathrm{AC}$ and $\mathrm{DC}$

- Ecotech EC9852 - Same unit as reported for $\mathrm{H}_{2} \mathrm{~S}$

- Thermo Scientific 43i - Measures up to $100 \mathrm{ppm}$. The pulsations of the lamp allow for greater detection, and the reflective band pass filters are less subject to photochemical degradation and more selective in wavelength isolation resulting in both increased detection specificity and long term stability. This instrument has a very fast 10 second data output.

- Teledyne API 100E - A hydrocarbon "kicker" and advanced optical design combine to prevent inaccuracies due to interferences. There is also a fast response, at $20 \mathrm{se}-$ conds.

\section{Total Sulfur (TS)}

Total sulfur represents the sum of $\mathrm{SO}_{2}$ and all total reduced sulfur (TRS) species. These units use fluorescence detection as well, without the $\mathrm{SO}_{2}$ scrubber. Thermal conversion is done at very high temperatures to ensure all sulfur compounds are converted to $\mathrm{SO}_{2}$.

- Ecotech EC9850TS - This unit accounts for any effects due to variable lamp intensity or optical interference by having two optical detectors for a more precise measurement

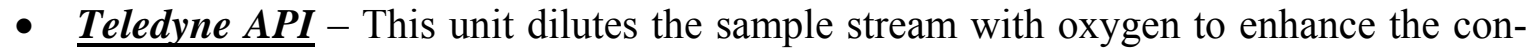
version of sulfur compounds to $\mathrm{SO}_{2}$. It also has a 20 second data output.

- Applied Analytics TSA-100 - Using similar technology as the other instruments in this category, the TSA-100 can measure total sulfur from $0 \mathrm{ppm}$ to $100 \%$. The total sulfur reading includes $\mathrm{H}_{2} \mathrm{~S}, \mathrm{COS}$, mercaptans, and $\mathrm{SO}_{2}$

\section{Sulfate (SO 4$)$}

The two instruments selected use different technologies. The Thermo Scientific instrument uses fluorescence detection as previously described and the URG uses ion chromatography (IC). In IC, ions and polar molecules are separated based on their charge. These are captured on a stationary phase material before being eluted and measured by conductivity.

- Thermo Scientific $\mathbf{5 0 2 0}-\mathrm{SO}_{4}$ is converted to $\mathrm{SO}_{2}$ and measured by fluorescence detection. The Model 5020 uses isokinetic extraction of the sample to assure complete capture of the particulate laden flow. 
- URG 9000NS - The URG 9000NS Ambient Nitrate \& Sulfate Monitor provides $1 \mathrm{hr}$ direct measurements of anion particulate nitrate and sulfate contained in PM2.5. A sample is drawn through a liquid diffusion denuder where interfering acidic and basic gases are removed. Particles are grown to larger size by water condensation and are stored in an aerosol sample collector, and the water soluble ions are analyzed by ion chromatography.

\section{Nitrogen Dioxide $\left(\mathrm{NO}_{2}\right)$}

$\mathrm{NO}_{2}$ can be detected by chemiluminescence. $\mathrm{NO}_{2}$ must first be converted to $\mathrm{NO}$ and reacted with ozone $\left(\mathrm{O}_{3}\right)$ which luminesces broadband visible to infrared light. A photomultiplier then counts the photons which are proportional to the amount of NO.

- Ecotech Serinus 40 - This instrument can also measure NO and NOx and has a wide range from $0.05 \mathrm{ppb}$ to $1000 \mathrm{ppm}$.

- $\quad$ Thermo Scientific 42i TL - This instrument incorporates a single photomultiplier design that can switch back and forth between NO and NOx. It also has a zero-mode for long-term stability and low detection limits.

- $2 B$ Technologies 401 - The detection principle of the Model 401/410 is based on the selective reaction of NO with ozone. The resulting ozone depletion is measured using the absolute method of UV absorbance and thus requires only infrequent calibration. By comparison, chemiluminescence NOx instruments require nearly continuous calibration using a standard gas.

\section{Nitrogen Oxides (NOx)}

The same instruments and technology used to measure $\mathrm{NO}_{2}$ are applied to measuring NOx.

- Teledyne API 200E - This system uses chemiluminescence technology, has a good data output time and a low detection limit down to $0.4 \mathrm{ppb}$.

- $\quad$ Thermo Scientific 17i - In the NOx Mode, the sample is passed through a molybdenum converter which reduces any $\mathrm{NO}_{2}$ in the sample to $\mathrm{NO}$. The $\mathrm{NO}$ is then transported to the reaction chamber where the sample is measured as NOx $(\mathrm{NO}+$ $\mathrm{NO}_{2}$ ). Data output is at a slower rate than other instruments at 2 minutes.

\section{Nitrate ( $\left.\mathrm{NO}_{3}\right)$}

- URG 9000NS - This instrument was chosen to measure $\mathrm{NO}_{3}$ using IC technology. This instrument has previously been described as an instrument that also measures $\mathrm{SO}_{4}$. A limitation of this instrument is the one hour data output.

- Nitric Acid ( $\mathrm{HNO}_{3}$ - A variation of the URG 9000, the $9000 \mathrm{C}$ is used to measure nitric acid. A limitation of this instrument is the one hour data output. 


\section{Ammonia ( $\left.\mathrm{NH}_{3}\right)$}

The preferred method of detecting $\mathrm{NH}_{3}$ is chemiluminescence which has previously been described. This method typically allows for the measure of other nitrogen compounds as well.

- Ecotech EC9842 - The EC9842 Chemiluminescence $\mathrm{NH}_{3}$ Analyzer combines an ammonia converter and chemiluminescence detection to measure ammonia $\left(\mathrm{NH}_{3}\right)$, oxides of nitrogen (NOx) and total nitrogen compounds $(\mathrm{Nx}) . \mathrm{Nx}$ is the sum of $\mathrm{NO}+\mathrm{NO}_{2}+\mathrm{NH}_{3}$, i.e. total oxides of nitrogen including ammonia. To measure $\mathrm{Nx}$ concentration, $\mathrm{NO}_{2}$ and $\mathrm{NH}_{3}$ are converted to $\mathrm{NO}$ in a quartz converter heated to $750^{\circ} \mathrm{C}$. In a separate reaction, $\mathrm{NOx}\left(\mathrm{NO}+\mathrm{NO}_{2}\right)$ is passed through a molybdenum converter heated to approximately $325^{\circ} \mathrm{C}$. The resulting $\mathrm{NH}_{3}$ concentration is determined by subtracting the Nx result from the NOx. The 9842 displays $\mathrm{Nx}\left(\mathrm{NH}_{3}+\mathrm{NO}_{2}+\mathrm{NO}\right)$, $\mathrm{NOx}\left(\mathrm{NO}+\mathrm{NO}_{2}\right)$ and $\mathrm{NH}_{3}(\mathrm{Nx}-\mathrm{NOx})$ concentrations.

- $\quad$ Thermo Scientific 17i - This instrument was previously described.

- Teledyne API 201E - This device was previously described.

\section{Ammonium (NH$)_{4}$ and Hydrochloric Acid (HCl)}

- URG 9000D/C - While capable of measuring very low levels, the instrument takes 1 hour for data output and is the heaviest instrument in the study at 65-85 lbs., depending on accessories.

\section{Particulate Matter (PM2.5)}

Each instrument selected uses its own method for detection of PM concentration.

- $\quad$ TSI DustTrak DRX 8533 - The DustTrak DRX simultaneously measures PM1, PM2.5, PM4, PM10, and TPM based on light scattering. It is a combination of a photometer and an optical particle counter (OPC) in one device. The advantages of this instrument are that it measures a wide concentration range $\left(0.001-150 \mathrm{mg} / \mathrm{m}^{3}\right)$ and has a fast response ( 1 second). The disadvantage is that its response depends on aerosol size distribution and composition. A custom calibration with a reference method (e.g., gravimetric method) using the aerosol under test is needed for best mass concentration accuracy.

- Grimm Dust Monitor 1.108 - This Dust Monitor is an optical particle counter (OPC). It measures PM size distribution between $0.3-20 \mu \mathrm{m}$ by measuring the amount of light scattered by individual particles, which is related to the particle diameter. Particles are assigned to one of 15 size bins. The instrument can report the size distribution in either number or mass concentration. The advantage of the OPC is that it has more size channels than the DustTrak DRX. A disadvantage is that it has a relatively low concentration range (Number: 0.001 to 2,000 particle $/ \mathrm{cm}^{3}$; Mass: 0.0001 to 100 $\mathrm{mg} / \mathrm{m}^{3}$ ). The OPC reports sizes in optical diameter, which is different from the aerodynamic diameter that is used to define $\mathrm{PM}_{2.5}$. 
- Thermo Scientific TEOM $1400 a b$ - The TEOM is based on the Tapered Element Oscillating Microbalance (TEOM) technology. It measures mass concentrations directly, and is designated by USEPA as an equivalent method to the FRM samplers for $\mathrm{PM}_{10}$ and $\mathrm{PM}_{2.5}$. It has a heated inlet, which may cause volatile or semi-volatile particle compositions to evaporate thus causing measurement errors.

- Thermo Scientific FH 62 C14 - The Beta Gauge aerosol monitor measures PM concentration by measuring the beta ray attenuation through a filter. The beta attenuation is proportional to PM mass deposited on the filter. It is a USEPA approved FRM equivalent method for $\mathrm{PM}_{10}$ measurement. The disadvantage is its slow time response ( $\sim 30$ minutes).

\section{Black Carbon (BC)}

Although $\mathrm{BC}$ is not expected to be found in this particular $\mathrm{CO}_{2}$ stream, it is an important contaminant in $\mathrm{CO}_{2}$ created through incomplete combustion of fossil fuels and biomass.

\section{Organic Carbon/Elemental Carbon (OC/EC)}

Although $\mathrm{OC}$ and $\mathrm{EC}$ are not expected to be contaminants in most captured $\mathrm{CO}_{2}$ streams, instruments for measurement of these species have been added to Table 5 .

\section{$\underline{\text { Particle Number }}$}

- $\quad$ CPC (Model 3007, TSI Inc.) - This instrument measures particle number concentration in real time based on the principle of condensation growth followed by optical counting. An aerosol sample is drawn continuously at 0.7 liter/minute through a heated saturator, in which alcohol is vaporized and diffuses into the sample stream. Together, the aerosol sample and alcohol vapor pass into a cooled condenser where the alcohol vapor becomes supersaturated and ready to condense. Particles present in the sample stream serve as condensation sites for the alcohol vapor. Once condensation begins, particles grow quickly into larger alcohol droplets $(>1 \mu \mathrm{m})$ and pass through an optical detector where they are counted. The particle concentration is calculated from the number of particles counted in a given time interval. The CPC 3007 can measure particles larger than $10 \mathrm{~nm}$ for concentrations up to 100,000 particles $/ \mathrm{cm}^{3}$. Extra dilution can be applied for measuring higher concentrations.

\section{$\underline{\text { Oxygen }\left(\mathrm{O}_{2}\right)}$}

Several instruments are capable of measuring oxygen, using electrochemistry, to below the maximum allowable level of 1,000 ppm. A typical oxygen sensor consists of a cathode, usually a noble metal, an electrode, such as lead, and a diffusion barrier. Based on Faraday's Law, the instrument measures the amount of current produced as oxygen is consumed. These units only have a 1-2 year lifespan as the lead is slowly converted to lead oxide. Most sensors are affected by prolonged exposure to high concentrations of $\mathrm{CO}_{2}(>25 \%)$. Some of the differences in this category come down to size, weight and ruggedness. Some highlights of each instrument are: 
- $\quad$ AMI 2010BR (trace) - This instrument is designed for harsh environments and easy maintenance. It does not require any tools for cartridge installation and replacement while calibration takes less than 1 minute. On the other hand, the sensor only comes with a 6-month warranty and a 1-2 year life expectancy.

- Advanced Instruments GPR-1000 - This unit is lighter and smaller than the AMI, costs the least, and is also water resistant. Power for the unit is supplied by rechargeable batteries and the sensor is warranted for one year. A lower pressure is required for this instrument compared to the others which could be a limiting factor when a cluster of instruments are being used to characterize the $\mathrm{CO}_{2}$ stream.

- Alpha Omega 3520 - This instrument is designed to be portable; weighs less than 4 pounds, is water-proof and can be run from $\mathrm{NiCad}$ batteries. Isolation allows for the unit to remain in idle when not in use, so there is no warm-up period.

\section{Volatile Organic Carbons (VOC's)}

- $\quad$ HNU PID Instrument 102 - This instrument was found to meet the requirements for sampling $\mathrm{CO}_{2}$ streams. This instrument utilizes Photo Ionization Detection (PID) to measure VOCs. The instrument measures the electric current that is produced when positively charged ions are formed as the sample gas stream is bombarded with high energy photons in the Ultra-Violet (UV) range.

\section{$\underline{\mathrm{CO}, \mathrm{CO}_{2}} \underline{\mathrm{HC}, \mathrm{NO}, \mathrm{O}_{2}} \underline{\text { and }}_{\mathrm{SO}_{2}}$}

- Testo Emission Analyzer (Model 350) - This instrument hosts up to 6 gas sensors for real-time gas monitoring (Table 27). The $\mathrm{CO}_{2}$ sensor is a non-dispersive infrared (NDIR) sensor; the others are electrochemical sensors based on the principle of ion selective potentiometry. Each sensor contains an electrolytic matrix that is designed for a specific gas to be detected. Two or three gas-specific electrodes are placed in this matrix and an electrical field is applied. Sample gas enters the sensor and chemically reacts (via oxidation or reduction) on the electrode, releasing electrically charged particles. This reaction causes the potential of the electrode to rise or fall with respect to the counter electrode. With a resistor connected across the electrodes, a current is generated that is proportional to the concentration of gas present. The output is converted and displayed as a concentration. The nominal specifications of the Testo 350 Emission Analyzer are listed below. Some of the sensors do not reach the required sensitivity level, so they are listed in this separate table. 
Table 25 - Specifications of the Testo 350 Emissions Analyzer

\begin{tabular}{|c|c|c|c|c|}
\hline Gas & Range & Accuracy & Resolution & \begin{tabular}{|l} 
Response \\
Time
\end{tabular} \\
\hline $\mathrm{CO}$ & $0-10,000 \mathrm{ppm}$ & $\begin{array}{l} \pm 5 \mathrm{ppm}(0 \ldots 99 \mathrm{ppm}) \\
\pm 5 \% \text { of reading }(100 \ldots 2,000 \mathrm{ppm}) \\
\pm 10 \% \text { of reading }(2001 \ldots 10,000 \\
\mathrm{ppm})\end{array}$ & $1 \mathrm{ppm}$ & $40 \mathrm{~s}$ \\
\hline \multirow{2}{*}{$\mathrm{CO}_{2}$} & \multirow{2}{*}{$0-50$ vol. $\%$} & $\begin{array}{l} \pm 0.3 \text { vol. } \%+1 \% \text { of reading } \\
(0.00 \ldots . .25 .00 \text { vol. } \%)\end{array}$ & 0.01 vol. $\%$ & \multirow{2}{*}{$10 \mathrm{~s}$} \\
\hline & & $\begin{array}{l} \pm 0.5 \text { vol. } \%+1.5 \% \text { of reading } \\
(25.1 \ldots 50.0 \text { vol. } \%)\end{array}$ & 0.1 vol. $\%$ & \\
\hline $\mathrm{C}_{\mathrm{x}} \mathrm{H}_{\mathrm{y}}$ & $\begin{array}{l}100-40,000 \mathrm{ppm} \\
\text { (methane) } \\
100-21,000 \mathrm{ppm} \\
\text { (propane) } \\
100-18,000 \mathrm{ppm} \\
\text { (butane) }\end{array}$ & $\begin{array}{l} \pm 400 \mathrm{ppm}(100 \ldots 4,000 \mathrm{ppm}) \\
\pm 10 \% \text { of reading (rest of range) }\end{array}$ & $10 \mathrm{ppm}$ & $40 \mathrm{~s}$ \\
\hline NO & 0-300 ppm & $\begin{array}{l} \pm 2 \mathrm{ppm}(0.0 \ldots 39.9 \mathrm{ppm}) \\
\pm 5 \% \text { of reading }(40.0 \ldots 300.0 \mathrm{ppm})\end{array}$ & $0.1 \mathrm{ppm}$ & $30 \mathrm{~s}$ \\
\hline $\mathrm{O}_{2}$ & $0-25$ vol. $\%$ & $\pm 0.2 \%$ of reading & 0.1 vol. $\%$ & $20 \mathrm{~s}$ \\
\hline $\mathrm{SO}_{2}$ & $0-5000 \mathrm{ppm}$ & $\begin{array}{l} \pm 5 \mathrm{ppm}(0 \ldots 99 \mathrm{ppm}) \\
\pm 5 \% \text { of reading }(100 \ldots 2,000 \mathrm{ppm}) \\
\pm 10 \% \text { of reading }(2,001 \ldots . .5,000 \\
\mathrm{ppm})\end{array}$ & $1 \mathrm{ppm}$ & $30 \mathrm{~s}$ \\
\hline
\end{tabular}

\section{On-Site Integrated Sampling}

Integrated samples collected using detector tubes appear to be a practical method for measuring low levels of contaminants in $\mathrm{CO}_{2}$ streams. While good for determining whether or not a contaminant exists in the $\mathrm{CO}_{2}$ stream, they cannot provide an accurate measure of real-time concentrations.

\section{Laboratory Monitoring Instruments}

All of the listed contaminant species can be collected in canisters (gaseous species), Teflon filters (PM), $\mathrm{AgNO}_{3}$ impregnated filters $\left(\mathrm{H}_{2} \mathrm{~S}\right), \mathrm{K}_{2} \mathrm{CO}_{3}$ impregnated filters $\left(\mathrm{SO}_{2}, \mathrm{H}_{2} \mathrm{SO}_{4}, \mathrm{HCl}\right.$, $\mathrm{HNO}_{3}$ ), quartz filters (PM, ions), citric acid impregnated filters $\left(\mathrm{NH}_{3}\right)$ and optional DNPH (Carbonyls) and Tenax cartridges (VOCs). After sampling, the media can then be brought to a lab for analysis. The following are the Desert Research Institute's procedures for collection and analysis for laboratory based measurements from captured $\mathrm{CO}_{2}$ streams and in flue gas. 


\section{Canister Samples}

Sampling systems with internal surfaces upstream of the collection media (e.g., canister sampler) must be cleaned and certified for cleanliness prior to sampling. The canister sampling systems are cleaned prior to field sampling by purging with humidified zero air for 48 hours, followed by purging with dry UHP zero air for one hour. Each canister sampling system is certified clean by the GC/FID analysis of humidified zero air collected through the system. The system is considered clean if the concentration of each individual targeted compound is less than $0.2 \mathrm{ppbv}$, and total non-methane organic compound (NMOC) concentration is less than $10 \mathrm{ppbC}$. Before shipping to a field site for use, the canisters are evacuated (by connection to a vacuum line). When collecting $\mathrm{CO}_{2}$ streams or syngas, the evacuated canister is opened by a solenoid valve, and the flow is regulated through a critical orifice.

\section{Canister Analysis of Permanent Gases (CO, $\left.\mathrm{CO}_{2}, \mathrm{~N}_{2}, \mathrm{CH}_{4}, \mathrm{H}_{2}\right)$}

Methane $\left(\mathrm{CH}_{4}\right)$, carbon monoxide $(\mathrm{CO})$ and carbon dioxide $\left(\mathrm{CO}_{2}\right)$ are measured from the canister samples using GC/FID (Shimadzu GC-17A). Since the FID does not respond to CO and $\mathrm{CO}_{2}$, these species are converted to methane by a methanator, positioned right after a $\mathrm{GC}$ column, but ahead of the FID. The methanator comprises a firebrick powder impregnated with nickel catalyst, through which a stream of hydrogen gas flows continuously at approximately $450{ }^{\circ} \mathrm{C}$. Hydrogen $\left(\mathrm{H}_{2}\right)$ and nitrogen $\left(\mathrm{N}_{2}\right)$ concentrations are measured using a SRI 8610C gas chromatograph with a $0.5 \mathrm{ml}$ sample loop and a thermal conductivity detector. A SRI Molecular Sieve 13x (6 ft. x 1/8 in ID) GC column is used.

\section{Carbonyls}

Carbonyl Collection - Carbonyl compounds are collected by drawing air through silica gel Sep-Pak cartridges impregnated with acidified 2,4-dinitrophenylhydrazine (DNPH), available commercially from Waters, Inc. The resulting products (hydrazones) in the cartridges are measured in the laboratory using high performance liquid chromatography (HPLC). In order to obtain a sample, check valves, solenoid valves and a pump are required. When the exposed cartridges are removed from the sampler, they are immediately plugged, put into vials, and stored in a container designated for exposed cartridges. The exposed cartridges are stored inside a refrigerator and returned to the laboratory in a cooler.

Carbonyl Analysis - After sampling, the DNPH Sep-Pak cartridges are eluted with 2-mL acetonitrile to remove the hydrazone products produced during sampling of carbonyl compounds. An aliquot of the eluent is transferred into a 2-mL septum vial and injected with an auto sampler into a high performance liquid chromatography (HPLC; Waters 2690 Alliance System with 996 Photodiode Array Detector) for separation and quantification of the hydrazones. $\mathrm{C}_{1}$ through $\mathrm{C}_{7}$ carbonyl compounds are analyzed, including the following: formaldehyde, acetaldehyde, acetone, acrolein, propionaldehyde, crotonaldehyde, methyl ethyl ketone, methacrolein, butyraldehyde, benzaldehyde, glyoxal, valeraldehyde, mtolualdehyde, and hexanaldehyde. The original carbonyl concentrations in the $\mathrm{CO}_{2}$ stream (in units of ppb) are computed from the amounts measured after blank correction, and after accounting for the volume of $\mathrm{CO}_{2}$ stream/syngas sampled. 


\section{$\underline{\text { Tenax Semi-Volatile Organic Carbon (SVOC) Samples }}$}

Tenax Collection - Tenax sampling and analysis is employed for compounds that are too heavy to be quantitatively retrieved from canisters. These materials are called semi-volatile organic compounds (SVOC). Prior to use, the Tenax-TA solid adsorbent is cleaned, and dried in a vacuum oven. Mass flow controllers, which allow for individual flow control of each cartridge, are required for sampling as well as a check valve upstream, and a solenoid valve downstream. When the exposed cartridges are removed, they are immediately plugged with Swagelok caps, and stored in a container designated for exposed cartridges with activated charcoal on the bottom. The exposed cartridges are stored inside a refrigerator and returned to the laboratory in a cooler containing blue ice.

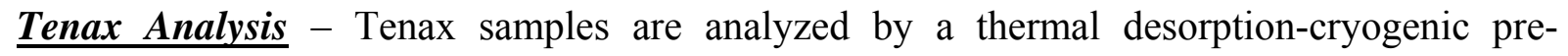
concentration method, followed by high-resolution gas chromatographic separation and mass spectrometric detection (GC/MS) of individual compounds. For calibration of the GC/MS standard, Tenax cartridges are spiked with a methanol solution of standard hydrocarbons, prepared from high-purity commercially available $\mathrm{C}_{8}-\mathrm{C}_{20}$ aliphatic, oxygenated and aromatic hydrocarbons. The solvent is then removed with a stream of $\mathrm{He}(2 \mathrm{~min}, 100 \mathrm{~mL} / \mathrm{min}$ at room temperature) and the Tenax cartridges are thermally desorbed into the GC system. The original concentrations of SVOCs in the $\mathrm{CO}_{2}$ (expressed in units of $\mu \mathrm{g} / \mathrm{m}^{3}$ ) are computed after accounting for the volume of $\mathrm{CO}_{2}$ sampled.

\section{Filter Samples}

Filter Sample Collection - No single filter medium is appropriate for all desired analyses, so it is necessary to sample on multiple substrates for chemical speciation. Filter packs containing Teflon-membrane, quartz fiber and cellulose filters are used for syngas sampling and analysis. All filter batches are conditioned and acceptance tested prior to use in sampling. The following three types of filters are used:

- Teflon-membrane filters are used for measurement of mass and elemental concentrations. These filters are obtained from Pall Corporation (Part No. R2PJ047) or Whatman Inc. (Part No. 7592-104).

- Quartz fiber filters are used for the determination of carbon fractions and ions in the particulate phase. These filters are obtained from Pall Corporation (Part No. 7202) or Whatman Inc. (Part No. 1851-047).

- Cellulose fiber filters are placed behind the more efficient particle-collecting filters (Teflon-membrane and quartz fiber). They are impregnated with gas-absorbing compounds, and are used to capture ammonia (with citric acid impregnation), acidic gases (with $\mathrm{K}_{2} \mathrm{CO}_{3}$ impregnation), and $\mathrm{H}_{2} \mathrm{~S}$ (with $\mathrm{AgNO}_{3}$ impregnation). These filters are obtained from Whatman Inc. (31ET and 41). 


\section{PM Mass by Gravimetric Analysis}

Particulate matter (PM) mass is determined by gravimetric analysis of blank and sampled Teflon-membrane filters. Before weighing, the filters are equilibrated at a temperature of 21.5 $\pm 1.5{ }^{\circ} \mathrm{C}$ and a relative humidity of $35 \pm 5 \%$ for a minimum of 24 hours prior to weighing. The charge on each filter is neutralized by exposure to a ${ }^{210}$ Po ionizing source for 30 seconds or more prior to the filter being placed on the balance pan.

\section{Elemental Analysis}

Individual elements are analyzed on Teflon membrane filters using a PANalytical Epsilon 5, energy dispersive $\mathrm{x}$-ray fluorescence (ED-XRF) analyzer. The emissions of $\mathrm{x}$-ray photons from the sample are integrated over time and yield quantitative measurements for 51 elements ranging from aluminum (Al) through uranium (U), and semi-quantitative measurements of sodium (Na) and magnesium $(\mathrm{Mg})$. A spectrum of x-ray counts versus photon energy is acquired and displayed during analysis, with individual peak energies corresponding to each element and peak areas corresponding to elemental concentrations. The advantages of XRF analysis include high sensitivity for a large number of elements, the ability to analyze small sample quantities, and the non-destructive nature of the analysis.

The source of $\mathrm{x}$-rays in the PANalytical Epsilon 5 analyzer is a side window, liquid cooled, $100 \mathrm{KeV}, 24$ milliamp gadolinium anode $\mathrm{x}$-ray tube. X-rays are focused on one of 11 secondary targets ( $\mathrm{Al}, \mathrm{Ca}, \mathrm{Ti}, \mathrm{Fe}, \mathrm{Ge}, \mathrm{Zr}, \mathrm{Mo}, \mathrm{Ag}, \mathrm{Cs}, \mathrm{Ba}$, and $\mathrm{Ce}$ ) which in turn emit polarized $\mathrm{x}$ rays to excite a sample. X-rays from the secondary target or the tube are absorbed by the sample, exciting electrons to higher level orbitals. As the electrons return to their ground state, photons are emitted which are characteristic of the quantum level jumps made by the electron; the energy of the emitted photons are, therefore, characteristic of the elements contained in the sample. The fluoresced photons are detected in a solid state germanium x-ray detector. Each photon that enters the detector generates an electrical charge whose magnitude is proportional to the photon's energy. The number of these photons is proportional to the number of atoms present.

\section{Elemental Carbon (EC) and Orqanic Carbon (OC)}

The thermal/optical reflectance and transmittance (TOR/TOT) method measures organic (OC) and elemental carbon (EC). This method is based on the principle that different types of carbon-containing particles are converted to gases under different temperature and oxidation conditions.

The thermal/optical reflectance carbon analyzer consists of a thermal system and an optical system. The thermal system consists of a quartz tube placed inside a coiled heater. Current through the heater is controlled to attain and maintain pre-set temperatures for given time periods. A portion of a quartz filter is placed in the heating zone and heated to different temperatures under non-oxidizing and oxidizing atmospheres. The optical system consists of a He-Ne laser, a fiber optic transmitter and receiver, and a photocell. The filter deposit faces a 
quartz light tube so that the intensity of the reflected laser beam can be monitored throughout the analysis.

\section{Water-Soluble Particulate Anions}

Water-soluble particulate anions (Cl-, NO2-, NO3-, PO43-, and SO42-) are collected on a quartz-fiber filter, and extracted into water using 15-mL of DDW. The anions are then analyzed using a Dionex ICS-3000 ion chromatograph (IC; Sunnyvale, CA). An ion exchange column is used to separate the ions for individual quantification by a conductivity detector. Prior to detection, the column effluent enters a suppressor column where the chemical composition of the component is altered, resulting in a matrix of low conductivity. The ions are identified by their elution/retention times and are quantified by the conductivity peak area, as compared with calibration curves derived from solution standards.

\section{Water-Soluble Particulate Cations}

Water-soluble particulate cations $\left(\mathrm{NH}_{4}{ }^{+}, \mathrm{K}^{+}, \mathrm{Na}^{+}, \mathrm{Mg}^{2+}\right.$, and $\left.\mathrm{Ca}^{2+}\right)$ are collected on the same quartz-fiber filters used for collection of particulate anions, and are isolated in the same water extract solution. Different analytical methods are then used to measure $\mathrm{NH}^{4+}$ (automated colorimetry) and the rest of the cations (atomic absorption). These methods are described below:

\section{Ammonium $\left(\mathrm{NH}_{4}^{+}\right)$Ion}

Ammonium concentrations are measured using the indol-phenol method with an automated colorimetric analyzer system (Astoria Analyzer AC; Astoria Pacific, Clackamas, OR, USA). The heart of the AC system is a peristaltic pump, which introduces air bubbles into the sample stream. A photomultiplier tube measures this absorbency through an interference filter that is specific to the species being measured.

When present in high concentrations $(>20 \%$ of the NH4+ level) formaldehyde has been found to interfere with $\mathrm{NH} 4+$ measurements. Hydrogen sulfide $(\mathrm{H} 2 \mathrm{~S})$ also interferes when it is present in concentrations that exceed $1 \mathrm{mg} / \mathrm{mL}$. Also, NO3- and $\mathrm{SO} 4+$ are potential interferents when present at levels that exceed 100 times the NH4+ concentration, although these levels are rarely observed. The precipitation of hydroxides of heavy metals such as calcium and magnesium is also a potential problem, but this is prevented by addition of sodium citrate/sodium potassium tartrate buffer solution to the sample stream.

\section{$\underline{\text { Ammonia }}$}

Ammonia is collected on a citric acid impregnated cellulosic fiber filter, where it is chemically reacted to produce ammonium citrate. The filter is then extracted with DDW, and the extract is analyzed for ammonium ion using the indol-phenol method with an automated colorimetric analyzer system. 


\section{$\underline{\text { Acid Gases }}$}

Acid gases $\left(\mathrm{HCl}, \mathrm{HNO}_{3}\right.$, and $\left.\mathrm{H}_{2} \mathrm{SO}_{4}\right)$ are collected on a cellulose fiber filter that is impregnated with potassium carbonate $\left(\mathrm{K}_{2} \mathrm{CO}_{3}\right)$. During collection, these acid gases react with the potassium carbonate to produce the corresponding potassium salts $\left(\mathrm{KCl}, \mathrm{KNO}_{3}\right.$, and $\left.\mathrm{K}_{2} \mathrm{SO}_{4}\right)$. This filter is then extracted with DDW, and the extract is analyzed for anions using the same ion chromatographic method described above. In addition, sulfur dioxide $\left(\mathrm{SO}_{2}\right)$ present in the gas phase will react on the filter to produce sulfate. Thus, the total sulfate measurement by IC represents the sum of $\mathrm{H}_{2} \mathrm{SO}_{4}$ and $\mathrm{SO}_{2}$ present in the original gas sample.

\section{Hydrogen Sulfide (H2S)}

Hydrogen sulfide $\left(\mathrm{H}_{2} \mathrm{~S}\right)$ is collected on a cellulosic fiber filter that is impregnated with silver nitrate $\left(\mathrm{AgNO}_{3}\right)$. During collection, the $\mathrm{H}_{2} \mathrm{~S}$ is reacted to produce silver sulfide (AgS). This filter is not extracted, but is analyzed directly by XRF, to quantify the sulfur on the filter, from which the original $\mathrm{H}_{2} \mathrm{~S}$ concentration in the sampled gas is computed.

\section{Integrated Systems}

Ecotech offers integration of multiple sensors. This allows for the simplification of electronics and controls as well as saving some space. They can mount the instruments together in a rack, or trailer such that the end-user does not need to do installation work.

\section{Conclusions}

The analytical procedures described in this section have been recently utilized to measure trace contaminants in syngas generated from a demonstration scale integrated biorefinery utilized for the conversion of biomass to syngas. The details of that study are included in a manuscript recently submitted to Environmental Science and Technology (Hoekman, S.K.et. al., "Characterization of Trace Contaminants in Syngas from the Thermochemical Conversion of Biomass." A summary of results from that study is included in Table 28. 
Table 26 - Average Concentrations of Contaminants Measured in a Syngas Stream Compared to Maximum Recommended Contaminant Levels for Efficient Diesel Fuel Production using Fisher-Tropsch Type Catalysts

\begin{tabular}{|l|l|l|}
\hline $\begin{array}{l}\text { Catalyst } \\
\text { Contaminants }\end{array}$ & $\begin{array}{l}\text { Maximum } \\
\text { Recommended } \\
\text { Contaminant } \\
\text { Levels }\end{array}$ & $\begin{array}{l}\text { Average } \\
\text { Contaminant } \\
\text { Concentration } \\
\text { (3-day Average) }\end{array}$ \\
\hline Hydrogen Sulfide $\left(\mathrm{H}_{2} \mathrm{~S}\right)$ & $<20 \mathrm{ppb}$ & $0.1 \mathrm{ppb}$ \\
\hline Sulfur Dioxide $\left(\mathrm{SO}_{2}\right)$ & $<20 \mathrm{ppb}$ & $0.7 \mathrm{ppb}$ \\
\hline Oxygen $\left(\mathrm{O}_{2}\right)$ & $<1,000 \mathrm{ppm}$ & $225 \mathrm{ppm}$ \\
\hline Toluene and $\mathrm{Xylenes})$ & $<5 \mathrm{ppm}$ & $0.22 \mathrm{ppm}$ \\
\hline Ammonia $\left(\mathrm{NH}_{3}\right)$ & $<50 \mathrm{ppb}$ & $53 \mathrm{ppb}$ \\
\hline Hydrogen $\mathrm{Chloride}(\mathrm{HCl})$ & $<50 \mu \mathrm{g} / \mathrm{m} 3$ & $<0.5 \mu \mathrm{g} / \mathrm{m} 3$ \\
\hline Nitric Acid $\left(\mathrm{HNO}_{3}\right)$ & $<50 \mu \mathrm{g} / \mathrm{m} 3$ & $13 \mu \mathrm{g} / \mathrm{m} 3$ \\
\hline Total Particulate $\mathrm{Matter}(\mathrm{PM})$ & $<500 \mu \mathrm{g} / \mathrm{m} 3$ & $12 \mu \mathrm{g} / \mathrm{m} 3$ \\
\hline
\end{tabular}

\section{An Assessment of Current Commercial Scale Fischer-Tropsch (F-T) Technologies for the Conversion of Syngas to Fuels}

The production of liquid products from coal and similar hydrogen deficient sources was driven by the transition from a coal based energy economy to an oil based energy economy which was occurring around the beginning of the $20^{\text {th }}$ century. The earliest documented conversion of carbon monoxide and hydrogen to liquid products was by Losanitsch and Jovitschitsch in 1897, when they used an electrical discharge and produced formaldehyde as the primary product ${ }^{34}$. This was followed by Sabatier and Senderens catalytic conversion of $\mathrm{CO}$ and $\mathrm{H}_{2}$ to methane over a nickel catalyst $\mathrm{t}^{35}$.

Germany's lack of oil made development of synthetic fuels a significant emphasis for German industry. Between 1913 and 1914, BASF was granted a series of patents for the conversion of $\mathrm{CO}$ and $\mathrm{H}_{2}$ to liquid products, especially formaldehyde over metal catalysts from the nickel and iron groups ${ }^{36}$. Research at the Kaiser Wilhelm Institute for Coal Research (now the Max Planck Institute) by Franz Fischer and Hans Tropsch successfully converted $\mathrm{CO}$ and $\mathrm{H}_{2}$ to liquid hydrocarbons over cobalt, iron, and ruthenium catalysts at 1 atmosphere of pressure ${ }^{37}$ in 1923. The general formula for this process is shown below, where $\mathrm{n}$ is a whole number.

$$
(2 \mathrm{n}+1) \mathrm{H}_{2}+\mathrm{nCO} \rightarrow \mathrm{C}_{\mathrm{n}} \mathrm{H}_{(2 \mathrm{n}+2)}+\mathrm{nH}_{2} \mathrm{O} \quad \text { (equation 1) }
$$

The first German patent on the process which bears their names was granted ${ }^{38}$ in 1925. Fischer and Tropsch recognized that one of the primary difficulties with the process was 
dealing with the large amount of heat produced ( 65 to $70 \mathrm{mBTU} / \mathrm{lbmol} \mathrm{CO}$ ) from the reaction. Attempts to improve the heat transfer by using liquid phase (slurry) reactors were conducted by Matthias Pier of IG Farben ${ }^{39}$ in 1928, and Fischer and Kuester in $1933^{40}$. By increasing the operating pressure to approximately $150 \mathrm{psig}$, Fischer and Pichler were able to shift the product distribution to higher hydrocarbons. This became the basis of the "medium pressure synthesis" process.

\section{Early Fischer-Tropsch Commercial Plants (1930’s through early 1950's)}

The first commercial Fischer-Tropsch plants were built in Germany between 1935 and 1936 following a Ruhrchemie design. These plants operated at atmospheric pressure using fixed bed reactors filled with cobalt based catalysts. They produced approximately 1,500 bpd of liquid products from synthesis gas derived from coal and coke. During the WWII war years a total of nine Ruhrchemie-design Fischer-Tropsch plants were built in Germany, one in occupied France, three under license in Japan, and two in Japanese occupied Manchuria. All of the plants were low or medium pressure facilities using fixed bed reactors and cobalt-based catalysts.

Development of both the reactor designs and the catalysts continued during the war. Pilotscale slurry reactor facilities were built by three different German groups to try to improve the heat removal. A 0.3 meter diameter reactor was built by Ruhrchemie, and cobalt and iron catalysts were studied. IG Farben constructed a 1.5 meter reactor and conducted tests on iron catalysts. A 1.3 meter diameter reactor was built at the Rheinpreussen synthetic fuels plant, and was used to study both iron and cobalt catalysts. The interest in iron catalysts was driven primarily by wartime shortages of cobalt, but the iron catalysts were never commercialized.

Following the end of WWII, there was considerable interest in development of synthetic fuels in the U.S., Russia, Germany, and South Africa. In the U.S., research was sponsored by the U.S. Bureau of Mines from 1944 through 1955 under the U.S. Synthetic Fuels Act. However, the collapse of oil prices in 1955 combined with increases in the price of natural gas resulted in discontinuation of large scale research on synthetic fuels in the U.S. and Western Europe until the 1970's.

\section{Commercial Fischer-Tropsch Plant Construction in South Africa}

Like Germany, South Africa lacks oil resources but is rich in coal. As a result, the South African government sponsored the continued commercialization of Fischer-Tropsch technology. In 1950 the South African Coal, Oil Gas and Gas Corporation (known as Sasol) was formed with the expressed purpose of converting the country' coal resources into chemicals and fuels. The commercial facility was built in Sasolburgh, South Africa, and first produced Fischer-Tropsch products in 1955. Synthesis gas was produced using Lurgi designed coal fed gasification units. These fed 5 low temperature, Arge designed tubular fixed bed reactors. At any one time, four reactors are in use, and one is held in standby. The reactors are 10 foot diameter, 43 foot high reactors each with 2000 tubes of 2 inch internal diameter packed with extruded iron catalyst ${ }^{41}$. The heat from the reaction is removed with boiler feed water which surrounded the tubes. The reactors operate at $375 \mathrm{psig}$, and at $230^{\circ} \mathrm{C}$, producing 500 to 550 $\mathrm{bbl} /$ day per reactor. Initially the majority of the product was converted to transportation fuels. In 1962 the final products were switched to chemicals. 
In 1980 Sasol started up a new series of Fischer-Tropsch reactors at their Sasol Two facility in Secunda, South Africa. Synthesis gas was again produced using the Lurgi process. However, the FT reactors were 3.8 meter circulating fluid bed reactors (CFB, Synthol reactors) using an iron catalyst. The reactors operated at approximately $340^{\circ} \mathrm{C}$ and $375 \mathrm{psig}$, with each reactor producing $\sim 7,300 \mathrm{bbl} /$ day of liquid products. In 1982 Sasol started up the Sasol Three facility at Secunda. This was essentially a clone of the Sasol Two facility. From 1995 through 1999 sixteen CFB reactors were replaced with turbulent fixed fluidized bed reactors (Sasol Advanced Synthol reactor). The CFB and SAS reactors will be described in detail later.

In 1992 the world's first fully commercial gas to liquids plant, named Mossgas was brought on stream in Mossel Bay, South Africa. Offshore natural gas was used as the feed for the plant. The plant was designed to produce fuel, although job creation was also a major consideration in construction of the plant by the South African government. The original plant utilized three SASOL designed Circulating Fluid Bed reactors operating at high temperature using an iron based catalysts. Each reactor was originally rated at 8,000 bbl/day capacity, giving a total capacity of about $24,000 \mathrm{bbl} /$ day. The current capacity is rated at approximately $30,000 \mathrm{bbl} /$ day. However, this has been increased to approximately $10,000 \mathrm{bbl} /$ day. Under its technology license agreement with SASOL, the plant could originally only produce bulk fuel. The facility currently produces primarily fuel, but also now produces anhydrous alcohols. In 2002, the South African government privatized the facility, which then became known as PetrolSA. The natural gas supply feeding the plant is expected to be exhausted by 2011. As a result, PetrolSA is currently seeking alternative feed stocks (e.g., LPG) to keep the plant in operation $^{42}$.

The PetrolSA facility is also the site of a slurry bubble column reactor system developed as a joint venture among PetrolSA, Statoil, and Lurgi AG. The system uses a cobalt based catalyst to produce paraffinic liquid and wax products which are converted to diesel fuel through hydroisomerization. The $1000 \mathrm{bbl} /$ day semi-commercial reactor is reported to be suitable to provide sufficient design data for scale-up to $15,000 \mathrm{bbl} /$ day commercial reactors ${ }^{43}$. However, given the limited gas supply to the Mossel Bay facility, it is unlikely that a commercial scale plant will be built at that location.

\section{Commercial Fischer-Tropsch Plants outside South Africa}

In 1993 Shell brought its commercial Fischer-Tropsch plant on-stream in Bibtulu Malaysia using their SMDS (Shell Middle Distillate Synthesis) technology. The plant utilized off-shore natural gas for production of syngas. The plant design consisted of four multi-tubular FischerTropsch reactors using cobalt-based catalysts with an initial capacity of 3,500 bbl/day each of high alpha (heavy paraffin) products. The Fischer-Tropsch products are converted to fuels, lubricants, and specialty products by hydro cracking. In 2002, an explosion in the oxygen plants in the syngas generation part of the plant causes the entire plant to be shut-down. When the plant was brought back on-line, the plant capacity was increased to approximately 15,000 $\mathrm{bbl} /$ day through the use of improved catalysts.

In 2006 the Oryx facility (a joint venture between SASOL and Qatar Petroleum) at Ras Laffan, Qatar was brought on-stream using cobalt based catalyst in low-temperature synthesis 
slurry bubble column reactors. The plant has two reactor trains, with each reactor train having $17,000 \mathrm{bbl} /$ day. Each of the two reactors is 10 meters in diameter, and 60 meters high. During the initial operation of the plant, the cobalt catalyst generated much higher fines than expected and operational problems resulted in lower productivity than expected. Following modifications to operating parameters, reactor design, and catalyst properties, the facility shipped commercial product in 2007 . It is currently operating near its design capacity.

An additional GTL plant is currently under construction in Qatar and is expected to come onstream in late 2010. This Peralt GTL facility in Ras Laffan, Qatar is a joint venture between Shell and Qatar Petroleum. Ultimately, its capacity is expected to be 140,000 bpd from two $70,000 \mathrm{bbl} /$ day reactor trains. The first train is expected to be on-stream in 2010 , and the second in 2011. For the Fischer-Tropsch reactors, 10 fold scale-up of the reactor design for the Shell Bintulu reactors are being used. These utilize cobalt catalyst in a multi-tubular reactor. The key issues considered for scale-up were the proven design, maintenance, and catalyst performance of the Bibtulu reactors.

\section{Current Commercial Fischer-Tropsch Reactor Designs}

There are currently four types of Fischer-Tropsch reactors in commercial operation. These reactor designs, and the type of catalyst used are given in Table 29. 
Table 27 - Current Commercial Fischer-Tropsch Reactor Designs and Catalysts

\begin{tabular}{|l|l|l|l|l|l|l|}
\hline $\begin{array}{l}\text { Reactor } \\
\text { Type }\end{array}$ & Operator & Location & $\begin{array}{c}\text { Operating } \\
\text { Temp } \\
\left({ }^{\circ} \mathbf{C}\right)\end{array}$ & $\begin{array}{c}\text { Catalyst } \\
\text { Form }\end{array}$ & $\begin{array}{l}\text { Active } \\
\text { Metal }\end{array}$ & $\begin{array}{c}\text { Plant } \\
\text { Capacity } \\
\text { (bbl/day) }\end{array}$ \\
\hline $\begin{array}{l}\text { Tubular } \\
\text { Fixed Bed }\end{array}$ & SASOL & $\begin{array}{l}\text { Sasolburgh, } \\
\text { SA }\end{array}$ & $220-250$ & Extrudate & Iron & \\
\hline $\begin{array}{l}\text { Tubular } \\
\text { Fixed Bed }\end{array}$ & Shell & $\begin{array}{l}\text { Bintulu, } \\
\text { Malaysia }\end{array}$ & $220-250$ & Extrudate & Cobalt & 14,700 \\
\hline $\begin{array}{l}\text { Tubular } \\
\text { Fixed Bed }\end{array}$ & Shell & $\begin{array}{l}\text { Pearl } \\
\text { Project, } \\
\text { Qatar }\end{array}$ & $220-250$ & Extrudate & Cobalt & 140,000 \\
\hline $\begin{array}{l}\text { Tubular } \\
\text { Fixed Bed }\end{array}$ & CHOREN & $\begin{array}{l}\text { Frieberg, } \\
\text { Germany }\end{array}$ & $220-250$ & Extrudate & Cobalt & \\
\hline $\begin{array}{l}\text { Circulating } \\
\text { Fluidized } \\
\text { Bed }\end{array}$ & Petrol SA & $\begin{array}{l}\text { Mossel Bay, } \\
\text { SA }\end{array}$ & $320-350$ & Fused Iron & Iron & \\
\hline $\begin{array}{l}\text { Two Phase } \\
\text { Fluidized } \\
\text { Bed }\end{array}$ & SASOL & $\begin{array}{l}\text { Secunda, } \\
\text { SA }\end{array}$ & $320-350$ & Fused Iron & Iron & \\
\hline $\begin{array}{l}\text { Slurry } \\
\text { Phase } \\
\text { Reactor }\end{array}$ & SASOL & $\begin{array}{l}\text { Oryx } \\
\text { Project, } \\
\text { Qatar }\end{array}$ & $220-250$ & $\begin{array}{l}\text { Al2O3 } \\
\text { Microspheres }\end{array}$ & Cobalt & 34,000 \\
\hline $\begin{array}{l}\text { Slurry } \\
\text { Phase } \\
\text { Reactor }\end{array}$ & Chevron & $\begin{array}{l}\text { Escravos } \\
\text { GTL, } \\
\text { Nigeria }\end{array}$ & $220-250$ & $\begin{array}{l}\text { Al2O3 } \\
\text { Microspheres }\end{array}$ & Cobalt & 34,000 \\
initial)
\end{tabular}

\section{Overview of Catalyst Considerations}

The Anderson-Schulz-Flory distribution, which can be expressed as (Equation 2):

$$
\mathrm{W}_{\mathrm{n}} / \mathrm{n}=(1-\alpha)^{2} \alpha^{\mathrm{n}-1}
$$

Where $\mathrm{W}_{\mathrm{n}}$ is the weight fraction of hydrocarbon molecules containing $\mathrm{n}$ carbon atoms and $\alpha$ is the chain growth probability or the probability that a molecule will continue reacting to form a longer chain. In general, $\alpha$ is largely determined by the catalyst and the specific process conditions. There are known deviations from ASF, but this can be used as a model for production distribution. Increasing $\alpha$ (high $\alpha$ catalysts) indicate increase in the production of long-chained hydrocarbons. At high values of alpha, long-chain hydrocarbon waxes are the predominant long chain hydrocarbons. 
A variety of transition metals have been used in catalysts for the Fischer-Tropsch process. Nickel is active for the reaction, but produces unacceptable levels of methane, and also migrates off the catalyst support due to formation of nickel carbonyl.

Ruthenium ( $\mathrm{Ru})$ is an ideal Fischer-Tropsch catalyst in terms of product yield as it produces very high alpha products. However, Ru is very limited in supply and so its cost is prohibitive for F-T applications other than as a minor constituent/promoter. In the patent literature it is often used as a catalytic promoter for cobalt-based catalysts. Table 28 lists approximate current prices for $\mathrm{Ru}, \mathrm{Co}$, and $\mathrm{Fe}$.

Table 28 - Catalytic Metal Pricing as of March 2010

\begin{tabular}{|ll|}
\hline Iron & $\$ 0.01 /$ troy ounce \\
\hline Cobalt & $\$ 1.41 /$ troy ounce \\
\hline Ruthenium & $\$ 190.00 /$ troy ounce \\
\hline
\end{tabular}

The only catalytic metals which have been commercialized for the F-T process are iron and cobalt. There are several factors which drive the selection of iron or cobalt. Iron was originally used in the F-T process because in most cases the feedstocks were hydrogen deficient coal or coke. In addition to catalyzing the F-T reaction, iron is an effective catalyst for the watergas shift reaction (Equation 3). This reaction is essential when using hydrogen deficient raw materials because the hydrogen in the water gets incorporated into the hydrocarbon products.

$$
\mathrm{CO}+\mathrm{H}_{2} \mathrm{O} \rightarrow \mathrm{CO}_{2}+\mathrm{H}_{2}
$$

Because they are able to operate over a very wide range of hydrogen to carbon monoxide ratios, iron based catalysts also produce a wide range of alphas. This is shown in Figure 80 . 


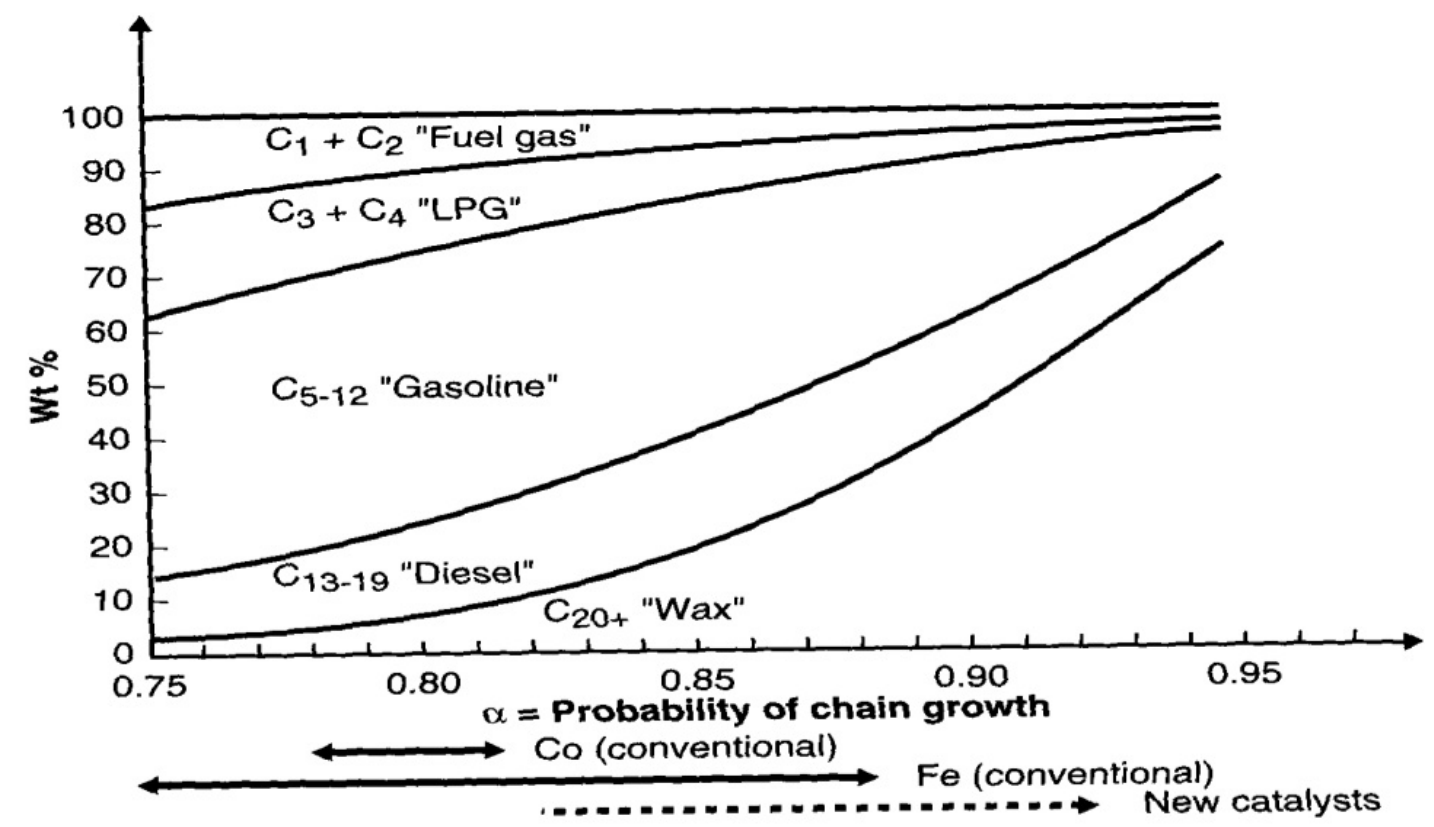

\section{Figure 80 - Product Distribution and Alpha for Cobalt and Iron Catalysts (“Natural Gas Production, Processing and Transport” by Rojey, et. al)}

Unlike cobalt, nickel, and ruthenium which remain in the metallic state during F-T synthesis, iron catalysts tend to form a number of chemical phases, including various iron oxides, carbides, and sulfides. Control of these phase transformations is important for maintaining catalytic activity and the mechanical integrity of the catalyst particles. In addition, they usually incorporate high surface area binders and supports such as alumina, silica, or zeolites to increase the metal's dispersion and thus its activity. Sulfur compounds are significant poisons for both iron and cobalt catalysts and thus are generally removed upstream. However, the low cost of iron catalysts often results in the operators allowing a portion of the reactor to be considered as a sacrificial sulfur scavenging bed. Iron catalysts often contain a wide range of promoters such as potassium and copper.

Cobalt catalysts are effective when there is high hydrogen to carbon monoxide ratios (1.82.2). In these cases, cobalt is the preferred metal because it is a much more active catalyst than iron, and there is no need for significant water-gas-shift activity (which can produce high volume \% of unwanted $\mathrm{CO}_{2}$ ). Cobalt is typically dispersed on high surface area support such as alumina, silica, zirconia, or titania to maximize the catalyst activity. During the catalyst manufacturing process, the cobalt is typically added to the catalyst as a salt which is then reduced to form the active cobalt metal. A variety of additives have been used with cobalt catalysts to perform a variety of functions including: stabilizing the support's surface area, improving the ease of cobalt reduction, increasing the cobalt dispersion, etc.

\section{Commercial Technology Platforms}

When evaluating Fischer-Tropsch technology there are several key areas to consider. The three primary considerations include: catalyst considerations, reactor systems, and upgrading pathways. Each of these will be discussed below. 


\section{Catalyst Considerations}

As previously discussed, there are two primary commercial catalyst systems for the FischerTropsch process: cobalt based catalysts and iron based catalysts. Iron based catalysts were the first to be used commercially, and remain in use in all of the commercial scale F-T reactors in operation in the three plants in South Africa. Cobalt catalysts are currently in use in Shell's tubular reactors in their plant in Bintulu, Malaysia, and in the slurry phase reactors in the SASOL-Qatar Petroleum joint venture Oryx plant in Qatar. A cobalt based catalyst is also scheduled to be used in the Shell-Qatar Petroleum Pearl GTL plant which is scheduled to be brought on stream in two stages in 2010 and 2011.

It is likely that both iron and cobalt based F-T catalysts will continue to be used for the indefinite future in commercial F-T plants. Because of the high activity and long life of the cobalt based catalysts, they are likely to be the catalyst of choice where the high hydrogen to carbon monoxide ratios are easily available such as with natural gas fed plants, Oryx in Qatar where the primary products are fuels.

Because of their water gas shift activity, and ability to produce products over a very broad product distribution (including very high alpha products), iron based catalysts are likely to continue in use, especially where the feed to the plant have low hydrogen to carbon ratios (e.g., coal, biomass, etc.). These plants are also capable of producing fuels as well as the preferred catalysts for producing linear alkenes in fluidized bed reactors ${ }^{44}$.

\section{Iron Catalyst Technology}

The iron catalyst currently used in both the fixed bed and slurry phase reactors at SASOL's South African F-T plants are very similar to the original F-T catalysts developed by Ruhrchemie and used in the Arge reactors in SASOL's original plant. These catalysts are precipitated iron catalysts containing silica, copper, and potassium.

The Ruhrchemie catalyst preparation procedure involved the following steps ${ }^{45}$ :

1. Dissolving scrap iron and copper in nitric acid to produce a solution of iron and copper nitrates.

2. Rapidly pouring a solution of nearly boiling iron and copper nitrates ( $40 \mathrm{~g}$ Fe and $2 \mathrm{~g}$ $\mathrm{Cu}$ per liter) into a hot solution of $\mathrm{Na} 2 \mathrm{CO} 3$ with stirring until the $\mathrm{pH}$ reaches 7 and the material precipitates.

3. The hydrated ferric oxide precipitate is washed with hot distilled water to remove most of the sodium.

4. The precipitate is re-slurried with water and potassium water-glass (potassium silicate solution) is added to give silica to iron ratios of $25 \mathrm{~g} \mathrm{SiO} 2$ per $100 \mathrm{~g} \mathrm{Fe}$.

5. Nitric acid is added to the slurry give a gel-like catalyst cake with a $\mathrm{K} 2 \mathrm{O}$ to iron ratio of $5 \mathrm{~g} \mathrm{~K} 2 \mathrm{O}$ per $100 \mathrm{Fe}$. 
If the catalyst is going to be used in Sasol's multi-tubular reactors, the catalyst cake is extruded and dried. If it is to be used in a slurry phase reactor (LTFT), the catalyst cake is reslurried in water and spray dried ${ }^{46}$.

Iron and cobalt based catalysts require reduction under mild conditions to give high metal surface areas for catalysis to occur. For iron based catalysts, copper is used as the promoter, and allows reduction of the $\mathrm{Fe}_{2} \mathrm{O}_{3} / \mathrm{CuO} / \mathrm{K}_{2} \mathrm{O} / \mathrm{SiO}_{2}$ catalyst at approximately $220{ }^{\circ} \mathrm{C}$. After reduction, the catalyst is coated with wax to prevent oxidation, and can be loaded into the reactors.

For SASOL's fluidized bed (HTFT) reactor system a fused iron catalyst is used. Iron oxide, potassium oxide, and structural promoters such as $\mathrm{MgO}$ or $\mathrm{Al}_{2} \mathrm{O}_{3}$ are fused together at about $1500{ }^{\circ} \mathrm{C}$. The molten mixture is ingots and rapidly cooled. The ingots are then crushed in a ball mill to between 10 and 100 microns, which is needed to allow fluidization.

The addition of magnesium oxide or aluminum oxide to the molten mix produces a catalyst where after reduction there are small aggregates of $\mathrm{MgO}$ or $\mathrm{Al}_{2} \mathrm{O}_{3}$ between the reduced iron crystallites. The alumina and magnesia inhibit sintering of the iron, and maintain higher surface areas for the catalysts

During high temperature operation, these fused iron catalysts experience significant deposition of elemental carbon at a relatively constant rate as a result of the Boudouard reaction (Equation 4).

$$
2 \mathrm{CO} \rightarrow \mathrm{C}+\mathrm{CO}_{2}
$$

Carbon deposition results in the generation of undesirable fines in the reactor. Addition of water, hydrogen, ethanol, or acetic acid can be done in small amounts, significantly reducing the deposition rate. The deposition rate can also be reduced through the addition of calcium oxide to the catalyst.

In operation, the fused iron catalyst in the HTFT reactor, operating at about $330{ }^{\circ} \mathrm{C}$ and $22 \mathrm{bar}$ pressure, changes phases with time. The iron metal is rapidly converted to iron carbines. Initially $\mathrm{Fe}_{3} \mathrm{C}$ is formed. This is unstable and is quickly converted to $\mathrm{Fe}_{5} \mathrm{C}_{2}$. Over time that is converted into $\mathrm{Fe}_{7} \mathrm{C}_{3}$. These carbides are all active for Fischer-Tropsch.

The performance of the iron catalysts is highly dependent on the alkali promoters added to the catalyst. For fused iron catalysts operating at high temperature, conversion increases with increasing alkali content. In contrast, at low temperatures activity is lower, but wax selectivity is increased. As the pores of the catalyst fill with long chain wax molecules, diffusion rates become lower, and the catalyst activity declines.

Studies by SASOL found ${ }^{47}$ that the reaction rate for the iron based catalyst can be given as:

$$
\mathrm{r}=\mathrm{mP}_{\mathrm{H} 2} \mathrm{P}_{\mathrm{CO}} /\left(\mathrm{P}_{\mathrm{CO}}+\mathrm{a} \mathrm{P}_{\mathrm{H} 20}\right)
$$


Where:
$\mathrm{r} \quad=$ reaction rate
$\mathrm{P}_{\mathrm{H} 2} \quad=$ partial pressure of hydrogen
$\mathrm{P}_{\mathrm{CO}} \quad=$ partial pressure of carbon monoxide
$\mathrm{P}_{\mathrm{H} 2 \mathrm{O}}=$ partial pressure of water
$\mathrm{m}=\mathrm{a}$ function of temperature, activation energy, and catalyst loading

The equation matched the actually measured profiles for both the commercial HTFT circulating fluidized bed reactor, and the LTFT fixed bed reactor.

\section{Cobalt Catalyst Technology}

Production of hydrocarbons over cobalt oxide at 120 atmospheres of pressure and 300 to 400 degrees C was reported by researchers at BASF as early as 1913. Since that time, there has been considerable research into optimization of the catalyst composition, catalyst activation, and catalyst regeneration.

Generally, cobalt catalysts are prepared by impregnating a porous support such as alumina or titania with an aqueous solution containing soluble cobalt salts such as nitrates or acetates. In addition to the cobalt, other salts such as rhenium or ruthenium salts are added with in combination with the cobalt solution, or in a separate step. The impregnated supports are then dried to remove the water under conditions that minimize the loss of surface area of the support. The dried support is then heated at higher temperature to decompose the metal salts into metal oxides on the support. This is usually called calcination. The active material for the Fischer-Tropsch reaction is actually the cobalt metal itself. Thus the cobalt oxide formed during calcination must be reduced to cobalt metal. This is typically done using hydrogen gas. The amount of cobalt metal on the support has a significant impact on the activity (turn over frequency, TOF) of the catalyst. Figure 80 shows the impact of cobalt loading on an alumina supported catalyst. The data showed rapidly increasing the turnover frequency with increasing levels of cobalt loading. Generally, cobalt levels between $15 \%$ and $25 \%$ are considered to be needed for effective commercial Fischer-Tropsch catalysts. 


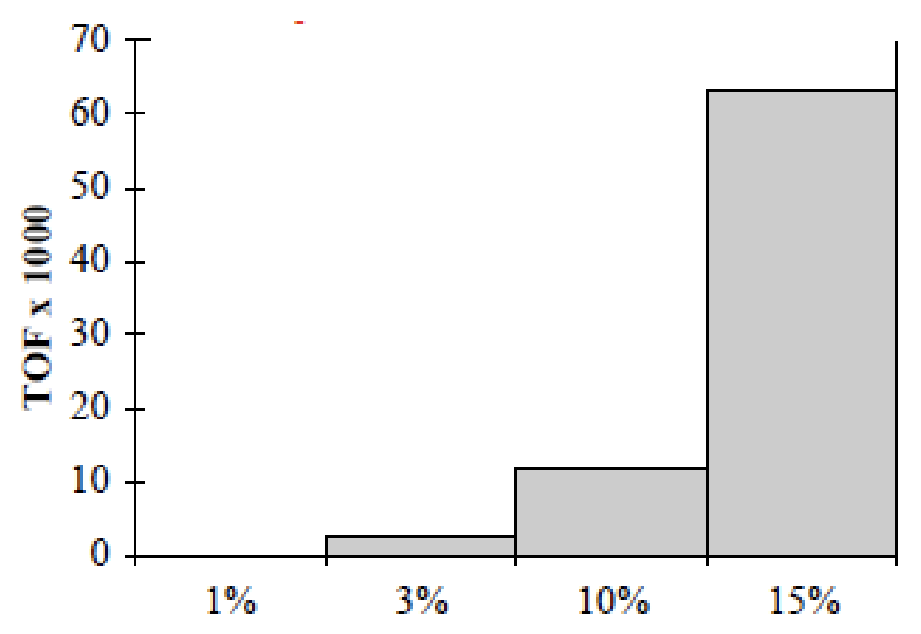

\section{Figure 81 - Effect of Cobalt Loading on the Activity of an Alumina Supported Fischer-Tropsch Catalyst ${ }^{48}$}

The primary role of the promoters such as rhenium, ruthenium, platinum, and palladium is primarily to ensure effective reduction of the cobalt to the active cobalt metal state. This is shown in Figure 81, which is the plot of the temperature programmed reduction of cobalt on silica catalyst. The reduction was conducted using $10 \%$ hydrogen in argon with the temperature being increased by 1 degree $\mathrm{C}$ per minute to a maximum of $800 \mathrm{C}$. The plot shows the results for un-promoted cobalt on silica catalyst (blue) and a platinum promoted catalyst of the same basic composition. The plot shows that the reduction for the promoted catalyst is essentially complete at 20 to 25 degrees $\mathrm{C}$ lower temperature than the un-promoted catalyst. This indicated that the promoter improves the reducibility of cobalt on the support. Generally, loadings of $\mathrm{Pd}, \mathrm{Pt}, \mathrm{Re}$, or $\mathrm{Ru}$ promoters between 0.1 to $0.5 \%$ are considered normal for commercial F-T catalysts. 


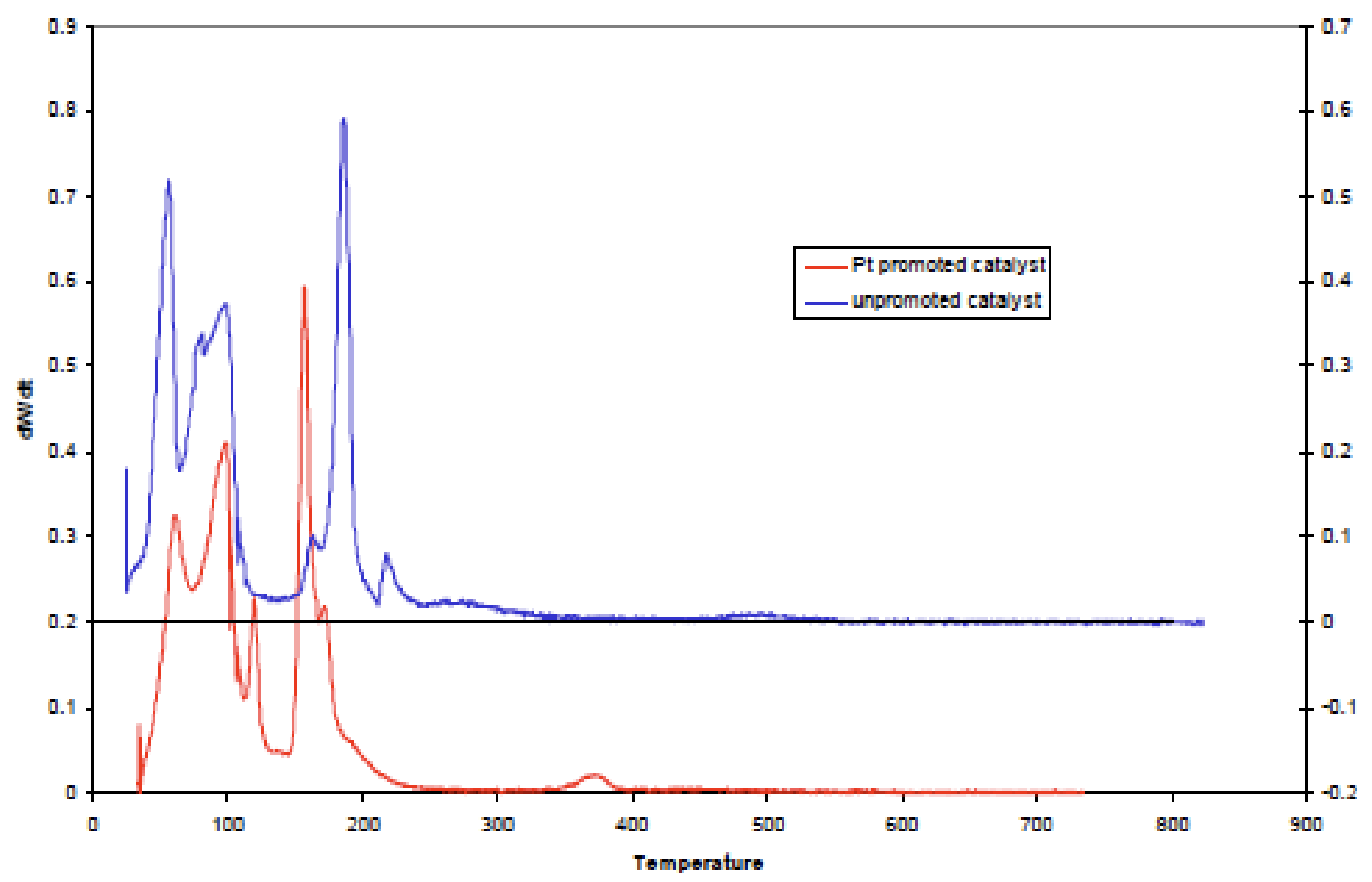

Figure 82 - The Effect of Promoter Addition on Cobalt Reduction ${ }^{49}$

In addition to promoting the cobalt catalysts with precious metals ( $\mathrm{Pd}, \mathrm{Pt}, \mathrm{Re}, \mathrm{Ru})$, rare earth oxides are often used to stabilize the catalysts. One of the main effects of the rare earths is to stabilize the alumina, silica, or Titania supports typically chosen with respect to surface area loss, both during the catalyst manufacturing process, and during operation. Typically, rare earth oxides are added at levels between $1 \%$ and $3 \%$ in commercial catalysts. Table 31 summarizes different methods for the optimization of cobalt based F-T catalysts. 
Table 29 - Optimization of Cobalt-based F-T Catalysts A Summary of Findings from Patents and Papers ${ }^{50}$

\begin{tabular}{|c|c|c|}
\hline $\begin{array}{l}\text { Desired Catalytic } \\
\text { Functions }\end{array}$ & $\begin{array}{l}\text { Proven Catalyst Components/ } \\
\text { Structural Features }\end{array}$ & $\begin{array}{l}\text { Critical Aspects of Preparation } \\
\text { and Pre-treatment }\end{array}$ \\
\hline High activity & $\begin{array}{l}\text { High cobalt surface area } \\
\text { High extent of reduction to metal } \\
\text { High cobalt site density (>10 wt. } \\
\%) \\
\text { Moderate dispersion }(10-15 \%) \\
\text { Optimum value of chi }\end{array}$ & $\begin{array}{l}\text { High surface area support } \\
\text { Low temperature, drying, inert } \\
\text { support } \\
\text { Slow reduction at high space } \\
\text { velocity } \\
\text { High metal loading } \\
\text { Addition of Re or Ru ( } 0.1 \mathrm{wt} . \%) \\
\text { Optimum particle size and } \\
\text { catalyst distribution }\end{array}$ \\
\hline High C5\% selectivity & $\begin{array}{l}\text { High extent of reduction of Co to } \\
\text { metal } \\
\text { Optimum value of chi }\end{array}$ & $\begin{array}{l}\text { High metal loading } \\
\text { Moderate dispersion } \\
\text { Addition of } \mathrm{Pd}, \mathrm{Pt}, \mathrm{Re} \text { or } \mathrm{Ru}(0.1 \\
\text { wt. \%) } \\
\text { Optimum particle size and } \\
\text { catalyst distribution }\end{array}$ \\
\hline $\begin{array}{l}\text { Low methane } \\
\text { selectivity }\end{array}$ & $\begin{array}{l}\text { High extent of reduction of Co to } \\
\text { metal } \\
\text { Low acidity support and basic } \\
\text { additives } \\
\text { Optimum value of chi }\end{array}$ & $\begin{array}{l}\text { Low acidity support (e.g. TiO2) } \\
\text { Basic additives, e.g. } \mathrm{ZrO} 2, \mathrm{TbO} 2 \\
\text { Optimum particle size and } \\
\text { catalyst distribution }\end{array}$ \\
\hline $\begin{array}{l}\text { Resistance to } \\
\text { oxidation }\end{array}$ & Addition of Pt, Pd, or Ru & Intimate mixing of $\mathrm{Co}$ and $\mathrm{Ru}$ \\
\hline $\begin{array}{l}\text { Resistance to } \\
\text { deactivation by } \\
\text { carbon }\end{array}$ & $\begin{array}{l}\text { Additives such as Ru which } \\
\text { gasify carbon }\end{array}$ & Intimate mixing of $\mathrm{Co}$ and $\mathrm{Ru}$ \\
\hline Regenerability & $\begin{array}{l}\text { Additives which increase } \\
\text { reducibility of cobalt oxide and } \\
\text { reactivity of carbon deposited }\end{array}$ & Intimate mixing of $\mathrm{Co}$ and $\mathrm{Ru}$ \\
\hline $\begin{array}{l}\text { High surface area and } \\
\text { mechanical integrity }\end{array}$ & Alumina, silica, and titania & $\begin{array}{l}\text { Support pretreatment, forming } \\
\text { methods, binders, and stabilizers, } \\
\text { drying temp.; alumina is favored }\end{array}$ \\
\hline
\end{tabular}


Table 29 provides a summary of the key parameters in the design of commercial cobalt based F-T catalysts. The data in the table was collected by Bartholomew based of reviews of numerous patents and papers. In the table, chi is a structural parameter which reflects the extent of olefin re-adsorption and can be used to correlate $\mathrm{C}_{5+}$ selectivity with catalyst structure $^{51}$. Basically, chi can be defined as:

$$
\chi=\operatorname{Ro} 2 \varepsilon \theta \mathrm{Co} / \text { rpore }
$$

Where:

$$
\begin{aligned}
& \text { Ro }=\text { the radius of the catalyst pellet } \\
& \varepsilon=\text { void fraction } \\
& \theta \mathrm{Co}=\text { density of Co sites per unit area } \\
& \text { rpore = pore radius }
\end{aligned}
$$

This shows that chi and olefin re-adsorption and C5+ selectivity increase with increasing Co site density, either as a result of increased cobalt loading or cobalt dispersion. This also indicates that the probability of chain termination to methane decreases with increasing cobalt loading. This is most likely due to the increased potential for reaction between olefins on adjacent cobalt surfaces rather than reactions with adsorbed monomer species which would otherwise desorb as methane.

According to Bartholomew, state of the art cobalt catalysts can be characterized by the parameters below:

- $\quad 15-25 \%$ cobalt and $0.1-0.5 \%$ of $\mathrm{Pd}, \mathrm{Pt}, \mathrm{Re}$ or $\mathrm{Ru}$

- $1-3 \%$ rare-earth oxides, e.g. $\mathrm{ZrO}_{2}, \mathrm{La}_{2} \mathrm{O}_{3}, \mathrm{ThO}_{2}$.

- extent of reduction of cobalt to the metal of about $80-90 \%$

- cobalt metal dispersion of $8-10 \%$

- stabilized alumina, silica or titania support with BET area of $150-250 \mathrm{~m} 2 / \mathrm{g}$

- productivity at $200-210^{\circ} \mathrm{C}, 20 \mathrm{~atm}$ of $1-2 \mathrm{~g} \mathrm{HC} / \mathrm{g}$ cat-h

- methane selectivity of $5 \mathrm{~mole} \%$

Bartholomew also gives typical properties of cobalt catalysts based on patent literature ${ }^{52}$. The rate equation for the cobalt-based catalysts is typically cited as:

$$
\mathrm{r}=\mathrm{aP}_{\mathrm{H} 2} \mathrm{P}_{\mathrm{CO}} /\left(1+\mathrm{bP}_{\mathrm{CO}}\right)^{2}
$$

or as:

$$
\mathrm{r}=\mathrm{c}\left(\mathrm{P}_{\mathrm{H} 2} \cdot{ }^{5} \mathrm{P}_{\mathrm{CO}}{ }^{2} /\left(1+.93 \mathrm{P}_{\mathrm{H} 2}+\mathrm{a} \mathrm{P}_{\mathrm{H} 20}\right)\right.
$$

These rate equations and the rate equation earlier cited for the iron catalyst (5) can be used to compare the conversion profiles for iron-based and cobalt-based catalysts. Figure 77 shows calculated reaction rates for four cases of cobalt and iron catalysts. One case each for the cobalt catalyst using equations (7) and (8), and two cases for the iron catalyst using equation (5). In one case, the iron has a normal activity, and in the other it is given a hypothetical rate 
that is five times the normal rate. Values of $\mathrm{m}$, a, and $\mathrm{c}$ were chosen so that $4 \%$ conversion was obtained at the same position near the inlet to the catalyst bed. The feed gas consisted of only $\mathrm{H}_{2}$ and $\mathrm{CO}$ and the ratio was constant at $2 / 1$, pressure was set to $3.0 \mathrm{MPa}$, and the same volumetric rate of syngas was fed. No tailgas recycle was used, and calculations were performed on a once-through basis. In the figure the bed length is in arbitrary units. The water gas shift reaction was taken into account for the iron catalyst, but not for the cobalt catalyst. The figure also includes a case for an iron catalyst that is five times more active than the other iron case.

Dry shows in the data in Figure 82 that the cobalt catalysts increasingly outperform the iron catalysts as the bed length increases. If the rate of the iron catalyst could be substantially increased, then there would be potential to outperform the cobalt catalyst. However, increasing the activity of the cobalt catalyst slightly is much more likely than increasing the activity of the iron catalyst fivefold. The data also shows that for the cobalt catalyst using equation (7), conversion reaches $80 \%$ at a bed length of 30 , and is still increasing. With equation (8) the cobalt catalyst is at $40 \%$ conversion. In both cases, the conversion is substantially higher than the base iron case. However, Dry notes that these calculations do not mean that high conversions cannot be obtained with commercial iron catalysts, stating that greater than $90 \%$ conversion can be obtained at the SASOL commercial LTFT conditions by using two reactors (fixed or slurry) in series with water knock-out between the reactors, and reactor operation in recycle mode.

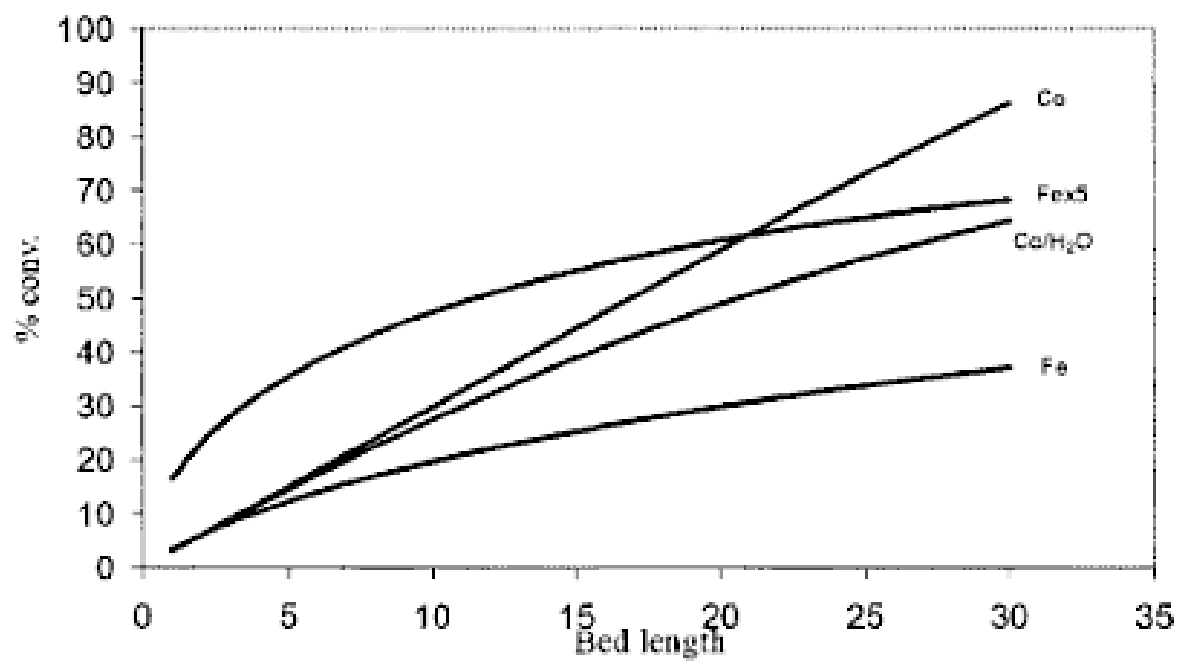

Figure 83 - Calculated reaction rates for Co and Fe catalysts

Dry goes on to further point out that the iron catalyst deactivates much more rapidly than the cobalt catalyst. Therefore, with increased time on stream the performance gap between the iron and cobalt catalyst will only increase, with the cobalt catalyst looking more effective. This can be offset in a slurry reactor by continuous addition of fresh catalyst. However, the lower activity of the iron catalyst will generally mean that for the same conversion levels larger reactors or multiple reactors would need to be employed for the iron catalysts, which significantly impacts capital costs. 
Both Shell and SASOL are currently using cobalt-based catalysts for their new commercial facilities. These catalysts are not available on the open market, but are only available in conjunction with the Shell and SASOL technologies. Since neither Shell nor SASOL license their F-T technology unless they have equity participation in the project, their catalysts are not available for general use or evaluation.

\section{F-T Reactor Considerations}

The choices of the current operators of commercial FT reactor systems provide significant insight into the key issues surrounding the choice of reactor design for new units. In Qatar Shell has chosen to build a cobalt catalyst based multi-tubular reactor system for what will become the world's largest gas-to-liquids plant. The design is a scale-up of their Bintulu, Malaysia plant which has been in operation since 1993. In contrast, SASOL, which has the most extensive experience in Fischer-Tropsch technology and technology development, has chosen to build a cobalt catalyst based slurry bubble column reactor system. This latter system has been on stream since 2006, although it had some substantial initial difficulties reaching performance goals. Catalyst and reactor improvements have allowed SASOL to essentially meet the design targets.

\section{Slurry Phase Reactors}

Slurry phase reactors can generally be thought of as large vessels with limited internal equipment in which relatively small catalyst particles are suspended and circulated within the reactor space due to the upward velocity of the gas and liquid within the reactor. Figure 83 shows a schematic of a slurry phase reactor system in F-T service.

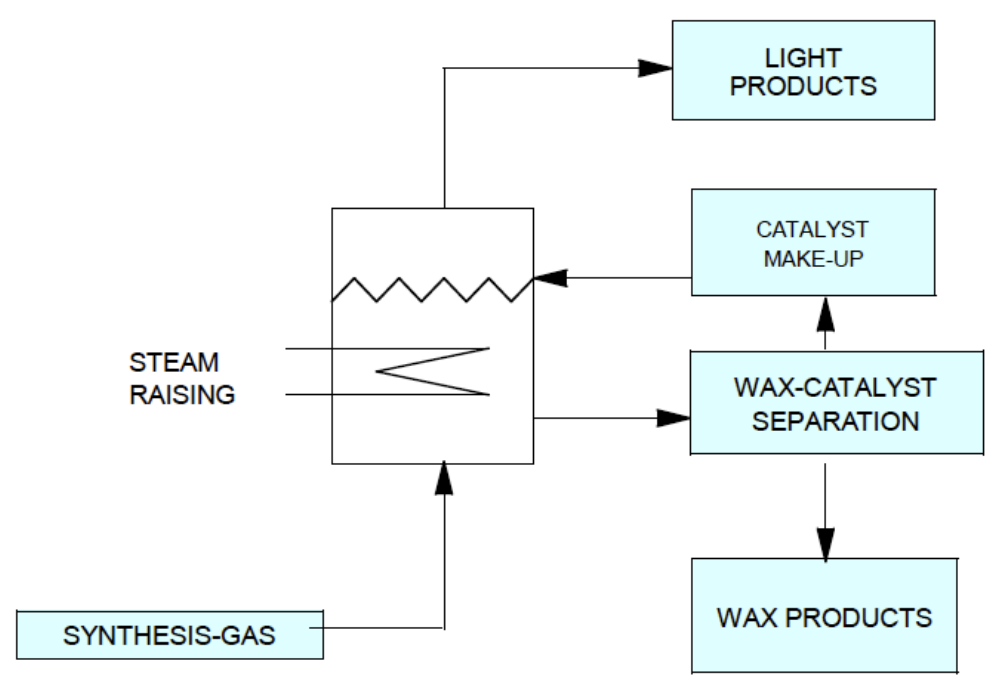

Figure 84 - Schematic of a slurry phase F-T reactor system

Some of the key advantages of the slurry reactor with respect to the F-T process are:

- Very efficient cooling of the highly exothermic reaction. The small catalyst particles are suspended and surrounded by liquid, which is a highly effective heat transfer medium. 
- The potential to continually add fresh catalyst and remove spent catalyst to maintain high activity.

- The potential to regenerate withdrawn catalyst to enhance the life of the catalyst.

- Reduced capital cost relative to multi-tubular reactors because of the limited internal equipment within the reactor.

- High conversion potential.

There are also some major disadvantages associated with slurry reactors for the F-T process. These include:

- Difficulties with scale-up - Among the scale-up problems are that as the diameter of the reactor is reduced, wall effects can begin to dominate the flow, and alter the results. Furthermore, ensuring good flow and full mixing within a smaller reactor is difficult.

- Catalyst attrition - The catalyst is in constant motion within the reactor system with multiple particle-particle and particle-internals collisions potentially resulting in attrition and fracture of the catalyst particles.

- Product separation - Separation of the solid catalyst from the liquid products can be difficult, especially if there is significant attrition.

- The need for external activation of the catalyst - Generally the reactor itself is not an appropriate vessel for catalyst reduction. Therefore additional vessels must be built for that process step.

- Integration issues - All of the new equipment items, materials transfers, catalyst activity, selectivity, and life need to be demonstrated at a level such that an EPC company can provide process guarantees to allow financing of the project.

- Commercialization of a slurry reactor system for the Fischer-Tropsch process is a challenging task. ExxonMobil and ConocoPhillips both have abandoned attempts to commercialize slurry technology after major expenditures. However, SASOL has successfully brought their Oryx plant on stream in Qatar. The plant capacity is $32,400 \mathrm{bbl} /$ day and the final cost for the plant was reported to be $\$ 900$ million.

Aasberg-Peterson, et. al. ${ }^{53}$ estimate that the capital costs for a commercial F-T plant, excluding initial catalyst costs, breaks down into:

- $50 \%$ Syngas Generation

- $\quad 30 \%$ F-T Synthesis and Tail Gas Processing

- $20 \%$ Product Upgrading

In calculating costs for a slurry reactor-based plant similar in capacity $(34,000$ to 36,000 bbl/day) to the Oryx plant in Qatar, Aasberg-Peterson, et. al. estimate a capital cost of approximately $\$ 25,000$ per barrel capacity excluding light hydrocarbon recovery from the 
natural gas feed into the plant. They speculate that plant expansion to double the capacity could approach $\$ 21,000$ per barrel capacity because of common utility and shared infrastructure costs.

It is difficult to effectively estimate the reactor capacity that represents a reasonable commercial scale. Because much of the economic advantage of the slurry phase reactor comes with the ability to use a large vessel with limited internals, cost advantages begin to decrease as the size of the reactor is decreased. In addition because the product distribution is probably more fuels oriented than specialty chemicals, the economics are again more favorable for larger units. From a practical standpoint, the minimum effective scale for a slurry phase reactor is probably on the order of 8,000 to $10,000 \mathrm{per} b b \mathrm{l} / \mathrm{day}$.

\section{Multi-tubular Fixed Bed Reactors}

The original Arge reactors operated by SASOL were multi-tubular fixed bed reactors. This reactor design is currently being operated by Shell at its Bintulu facility using cobalt based catalysts, and is expected to start-up at Shell-Qatar Petroleum's Pearl GTL plant.

The primary advantages of the multi-tubular reactors include:

- Simplified reactor scale-up - Typically pilot using full-scale (diameter and length) tubes but limited in number. With the Pearl GTL plant, the Bintulu reactors already had demonstrated the success of the design, so there was limited risk of failure.

- Highly efficient catalyst-product separation - Essentially no fines entrainment in the liquid products, and limited opportunities for fines generation

- Simplified catalyst reduction and regeneration - The reduction of the catalyst can occur within the tubes, and the entire reactor can have the product removed and can be reduced again to reactivate the catalyst. Separate vessels and associated transfer equipment are not required for reduction, regeneration, or separation from the product.

- Ability to close off problem reactor tubes - It is possible to take individual tubes off-line o deal with performance issues. This has potential to substantially extend the run length for the reactor, improving the operating economics.

The primary disadvantages of the multi-tubular fixed bed reactor design are the high cost of fabricating the reactors. Because the reactor vessels are filled with many tubes, the cost and weight of the reactors compared to a slurry phase reactor is significantly higher.

The disadvantage of the multi-tubular design is largely outweighed for Shell in using their SMDS technology because of the long history of operation at their Bibtulu plant. The four reactors were designed by Lurgi and are estimated to be 7 meters in diameter. The original capacity of the reactors was about $3000 \mathrm{bbl} / \mathrm{day}$, but Shell claims to have improved the catalyst and operating process and claim up to $8000 \mathrm{bbl} /$ day capacity for new reactors which are only slightly larger than the originals. 
Shell claims to have demonstrated CAPEX below $\$ 20,000$ per daily barrel for the Bintulu system as a result of increased catalyst productivity and long catalyst life, and indicate that they could get CAPEX down further to $\$ 16,000$ per daily barrel. However, the cost of the Pearl GTL plant is now set at $\$ 16$ billion for the 140,000 bbl/day facility, which is three times the original projection.

As with estimating the economics of the slurry phase reactors, it is difficult to estimate the economics of the multi-tubular reactor design. Because the initial capacity of the Shell Bintulu reactors was $3,000 \mathrm{bbl} /$ day we can estimate that this was viewed to be economically viable when it was started up. In addition, because the product slate from the tubular reactors tends to be more chemical/specialty products oriented than fuels, there may be more favorable economics at lower reactor sizes.

\section{Developmental Reactor Systems}

In addition to the commercial reactor systems, there are a variety of reactor systems currently under development. The potential for these to operate for long terms at high throughput remains to be demonstrated. One of the systems which may have significant potential is the micro-channel reactor system under development by Velocys. The technology uses structures which have micro-channels embedded in them. The active catalysts are deposited along the walls of the channels. The heat removal from the system is reported to be orders of magnitude better than current catalyst systems. However, questions remain regarding scale-up effectiveness, and with the ability to deal with fouling or plugging of the channels. In addition, since the reactor is a large ceramic device, the durability of the system needs to be demonstrated.

\section{Upgrading Pathways}

The choice of which basic technologies to employ depends primarily on the desired product slate, particularly whether the products are primarily specialty chemicals and lubricants, or fuels. Many upgrading pathways have been tried, some with limited success. One example is outlined below.

The F-T reactor product from the high temperature iron catalyzed synthesis can be characterized as ${ }^{54}$ :

- Essentially sulfur free

- Low in nitrogen-containing compounds

- Containing percentage level oxygenates

- High levels of olefins, especially alpha-olefins

- Low in aromatics and naphthenics

- Primarily linear compounds with low levels of branching

- Follows the Anderson-Shoultz-Flory distribution, weighted towards light hydrocarbons

- Aqueous products with short chain oxygenates 
The most difficult problem in processing these materials is the high level of oxygenates particularly the carboxylic acids. These oxygenates are difficult to remove through hydrotreating, and impact the metallurgy of the processing units, and can cause metal leaching and rapid deactivation of catalysts, especially those that are nickel promoted.

The gasoline range component generally is very low octane because of the linear nature of the products. The octane can be improved through isomerization of the olefins, which are can represent up to 50 percent of the gasoline range hydrocarbons. Because there are extremely low levels of aromatics, the isomerized products may represent good blending additives for gasoline.

The diesel range fraction generally has a high Cetane index because of its high content of linear paraffins. Generally this fraction is hydro-treated to remove the olefins and aromatics which may be present, and lightly isomerized. This is then used as a blending stock for diesel fuel. As a blending stock it has very low sulfur, which is desirable to meet low sulfur diesel standards.

There are also generally higher hydrocarbons $\left(\mathrm{C}_{22+}\right)$ products from the F-T synthesis. This material is generally hydro-cracked into the diesel range using conventional hydro-cracking technology.

The light hydrocarbons must also be effectively dealt with because they represent a substantial portion of the products. Some, such as the butanes may be recovered for use. However, the high olefin content makes the material a good candidate for oligomerization to higher molecular weight, higher value materials.

Processing the products from the low temperature iron catalyzed process is qualitatively similar to the high temperature synthesis except there is a significant difference in product distribution out of the F-T reactor. The low temperature synthesis produces light hydrocarbon gases, a liquid product stream, and a high temperature paraffin wax. These streams do contain olefins, but at lower levels than produced in the high temperature synthesis.

Typically the wax is generally hydro-cracked to either lubricating oils, or into the diesel or kerosene/jet fuel range. Treatment of the lighter products would be similar to what is done with the high temperature synthesis.

\section{Conclusions}

This information provided in Section IV demonstrates that there are several advantages of fixed bed reactors over slurry bed reactors. Therefore, Sunexus has chosen the fixed bed catalytic reactor approach for the proposed commercial plants. 


\section{An Overview of $\mathrm{CO}_{2}$ Capture Technologies from Various Industrial Sources}

Table 30 summarizes various technologies for the capture of $\mathrm{CO}_{2}$ from point different industrial processes. The levels of sulfur and other contaminants found in the gas streams are expected to be at levels that can be cleaned with commercial purification processes. Furthermore, $\mathrm{CO}_{2}$ capture technologies will, as part of the process, remove a large percentage of these contaminants, especially sulfur compounds. For the industrial applications outlined above, the addition of gas polishing or additional clean up technologies will not add technology risk or costs that would dramatically affect economics of commercial plants.

Table 30 - Applicable Capture Technologies for $\mathrm{CO}_{2}$ Point Sources

\begin{tabular}{|c|c|c|c|c|c|c|}
\hline Industrial Process & 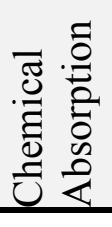 & 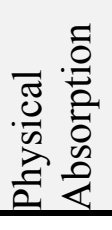 & 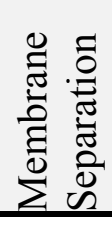 & 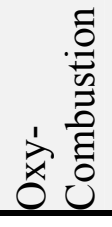 & 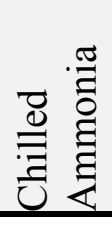 & 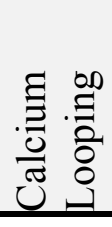 \\
\hline $\begin{array}{l}\text { Natural Gas Combined } \\
\text { Cycle (NGCC) Power Plant }\end{array}$ & $\checkmark$ & & & & & \\
\hline $\begin{array}{l}\text { Pulverized Coal (PC) Power } \\
\text { Plant }\end{array}$ & $\checkmark$ & & & $\checkmark$ & $\checkmark$ & \\
\hline $\begin{array}{l}\text { Natural Gas Processing } \\
\text { Plant }\end{array}$ & $\checkmark$ & $\checkmark$ & $\checkmark$ & & & \\
\hline Cement Production Plant & $\checkmark$ & & & $\checkmark$ & & $\checkmark$ \\
\hline $\begin{array}{l}\text { Integrated Gasification } \\
\text { Combined Cycle (IGCC) } \\
\text { Coal Power Plant }\end{array}$ & & $\checkmark$ & $\checkmark$ & & & \\
\hline $\begin{array}{l}\text { Gasification Plant for Fuel } \\
\text { and Chemical Production }\end{array}$ & $\checkmark$ & $\checkmark$ & $\checkmark$ & & & \\
\hline
\end{tabular}




\section{PROPOSED FUTURE EFFORTS}

Additional Sunexus reactor testing will be conducted during 2011 and beyond under separate funding. In adidtion, it is proposed that the technologies described in this report be scaled up and tested on flue gas generated from a pilot oxy-combustion plant, developed by CES.

A site layout of the CES power plant facility that will provide the flue gas for the Demonstration System is shown below in Figure 85. The Demonstration System will use $\sim 125 \mathrm{~kW}$ thermal concentrating solar energy from parabolic dish systems that use the Sunexus Solar Reformer. These systems will be installed and integrated with the existing liquid fuel production system hardware in Bakersfield, CA for the demonstration effort.

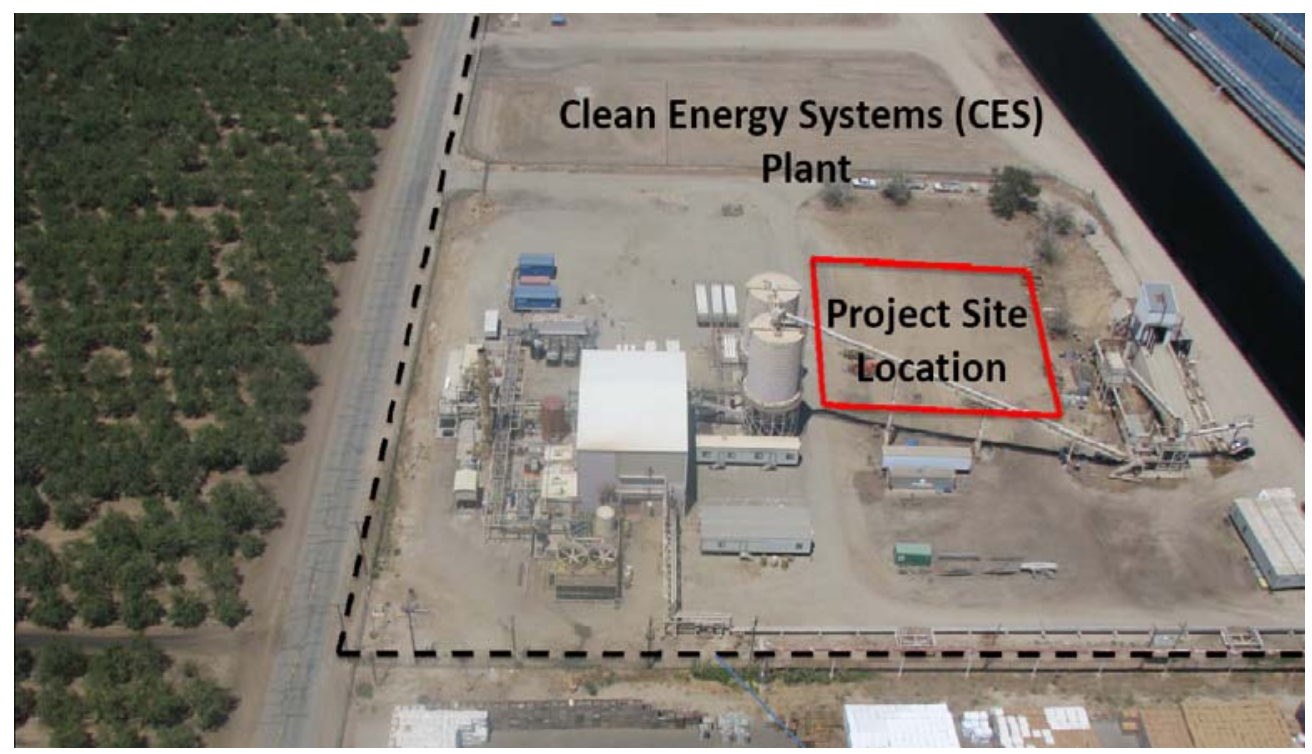

Figure 85 - Future Demonstration Site Layout

\section{ACKNOWLEDGEMENTS}

The authors of this Technical Report would like to acknowledge the noteworthy contributions of Kent Hoekman of the Desert Research Institute who prepared Section IVB on "Recommended Methods for Assessing Contaminant Levels in Captured $\mathrm{CO}_{2}$ Streams"; to Ramer Rodriquez who facilitated the design and assembly for the experimental hardware described in this paper; to Bill Schuetzle who wrote Section IVD on "An Overview of $\mathrm{CO}_{2}$ Capture Technologies from Various Industrial Sources," and who made signficant contributions to Sections IIIG and IVA; to Jim Dyer who provided expert input to the design of the solar reformer; and finally to Ellen Stechel, James Miler, Richard Diver and Daniel Dedrick of Sandia National Labs who provided valuable technical input throughout this project. 


\section{REFERENCES}

${ }^{1}$ Song, C., \& Pan, W. (2004). Tri-reforming of methane: a novel concept for catalytic production of industrially useful synthesis gas with desired $\mathrm{H} 2 / \mathrm{CO}$ ratios. Catalysis Today, 98, 463-484

${ }^{2}$ Choudhary, T., \& Choudhary, V. (2008). Energy-Efficient Syngas Production through Catalytic Oxy-Methane Reforming Reactions. Angewandte Chemie International Edition, 1828-1847.

${ }^{3}$ Apt, J., Newcomer, A., Lave, L., Douglas, S., \& Dunn, L. (2008). An Engineering-Economic Analysis of Syngas Storage. DOE/NETL.

${ }^{4}$ EIA. (2010). Electric Power Annual. Retrieved May 1, 2010, from U.S. Energy Information Administration Independent Statistics and Analysis: http://www.eia.doe.gov/cneaf/electricity/epa/epat5p1.html

${ }^{5}$ EIA. (2010). Electric Power Monthly. Retrieved May 1, 2010, from U.S. Energy Information Administration Independent Statistics and Analysis: http://www.eia.doe.gov/cneaf/electricity/epm/table1_1.html

${ }^{6}$ Shuster, E. (2009). Tracking New Coal-Fired Power Plants. National Energy Technology Laboratory, Office of Systems Analyses and Planning.

${ }^{7}$ NaturalGas.org. (2004). Overview of Natural Gas - Background. Retrieved May 1, 2010, from NaturalGas.org: http://www.naturalgas.org/overview/background.asp

${ }^{8}$ Herzog, H. (2000). The Economics of CO2 Separation and Capture. MIT Energy Laboratory, Cambridge, MA.

${ }^{9}$ EPA. Op. cit.

${ }^{10}$ IEA. (2006). CO2 Capture \& Storage. IEA Energy Technology Essentials.

${ }^{11}$ NETL. (2008). National Sources. Retrieved May 1, 2010, from NatCarb.org:

http://geoportal.kgs.ku.edu/natcarb/atlas08/summary_data/National\%20Sources.xls

${ }^{12}$ EPA. Op. cit.

${ }^{13}$ EPA. Op. cit.

${ }^{14}$ EPA. Op. cit.

${ }^{15}$ Hendriks, C., Worrell, E., de Jager, D., Blok, K., \& Riemer, P. (2004). Emission Reduction of Greenhouse Gases from the Cement Industry. ECOFYS, Lawrence Berkeley National Laboratory, IEA Greenhouse Gas R\&D Programme.

${ }^{16}$ Aasberg-Peterson, K., Christensen, T., Dybkjaer, I., Sehested, J., Ostberg, M., Coertzen, R., et al. (2004). Synthesis Gas Production for FT Synthesis; Fischer-Tropsch Technology (Vol. 152). (A. Steynberg, \& M. Dry, Eds.) Elsevier. pp. 442-447.

${ }^{17}$ Benemann, J. (2008). Overview: Algae Oil to Biofuels. NREL-AFOSR Workshop, "Algal Oil for Jet Fuel Production".

${ }^{18}$ Davis, A., \& Gold, R. (2009). U.S. Biofuel Boom Running on Empty. Wall Street Journal.

${ }^{19}$ Perlack, R., Wright, L., Turhollow, A., Graham, R., Stokes, B., \& Erbach, D. (2005). Biomass as Feedstock for a Bioenergy and Bioproducts Industry: The Technical Feasibility of a Billion-Ton Annual Supply. A Joint Study Sponsored by the U.S. Department of Energy \& U.S. Department of Agriculture.

${ }^{20}$ Taylor, T. (2010). Great Green Hope: The Corporate Love Affair With Algae. Biomass Magazine (April 2010).

${ }^{21}$ Herzog, H. (2002). Carbon Sequestration via Mineral Carbonation: Overview and Assessment. MIT

Laboratory for Energy and the Environment.

${ }^{22}$ Goldberg, P., Romanosky, R., \& Chen, Z.-Y. (2000). CO2 Mineral Sequestration Studies in US. Fifth

International Conference on Greenhouse Gas Control Technologies.

${ }^{23}$ IPCC. (2005). Carbon Dioxide Capture and Storage. Intergovernmental Panel on Climate Change. Cambridge, UK: Cambridge University Press.

${ }^{24}$ Dooley, J., Dahowski, R., Davidson, C., Wise, M., Gupta, N., Kim, S., et al. (2006). Carbon Dioxide Capture and Geologic Storage: A Core Element of a Global Energy Technology. Global Energy Strategy Program.

${ }^{25} \mathrm{Xu}$, Y., Isom, L., \& Hanna, M. (2009). Adding value to carbon dioxide from ethanol fermentations. Bioresource Technology.

${ }^{26}$ Parker, M., Meyer, J., \& Meadows, S. (2009). Carbon Dioxide Enhanced Oil Recovery Injection Operations Technologies. 9th International Conference on Greenhouse Gas Control Technologies (GHGT-9), 16-20 November 2008, Washington DC (pp. 3141-3148). Elsevier Energy Procedia.

${ }^{27}$ Mofarahi, M., Khojasteh, Y., Khaledi, H., \& Farahnak, A. (2006). Design of CO2 absorption plant for recovery of $\mathrm{CO} 2$ from flue gases of gas turbine. Energy $33,1311-1319$. 
${ }^{28}$ NaturalGas.org. (2004). Overview of Natural Gas - Background. Retrieved May 1, 2010, from NaturalGas.org: http://www.naturalgas.org/overview/background.asp

${ }^{29}$ Dooley, J., Davidson, C., \& Dahowski, R. (2010). An Assessment of the Commercial Availability of Carbon Dioxide Capture and Storage Technologies as of June 2009. Pacific Northwest National Labratory, prepared for the U.S. Department of Energy.

${ }^{30}$ Ibid.

${ }^{31}$ IEA. (2006). CO2 Capture \& Storage. IEA Energy Technology Essentials.

${ }^{32}$ Rosentrater, K. (2006). Economics and impacts of ethanol manufacture. BioCycle , 47, 44.

${ }^{33}$ Hutchison, F. (2009). About IGCC Power. Retrieved May 1, 2010, from clean-energy.us: http://www.cleanenergy.us/facts/igcc.htm

${ }^{34}$ Losanitsch and Jovitschitsch. (1897).

${ }^{35}$ Sabatier and Senderens

${ }^{36}$ BASF patents. $(1913,1914)$

${ }^{37}$ Fischer \& Tropsch. (1923).

${ }^{38}$ Fischer patent. (1925)

${ }^{39}$ Mathias Pier, IG Farben. (1928). slurry reactors.

${ }^{40}$ Fischer and Kuester. (1933). slurry reactors.

${ }^{41}$ DME. (2010). Energy Overview. Retrieved May 1, 2010, from Department of Minerals and Energy, Republic of South Africa: http://www.dme.gov.za/energy/liquid.stm

${ }^{42}$ Daily News. (2009). Mossel Bay gas stocks dwindling fast. Daily News (S. Africa).

${ }^{43}$ Veazey, M. (2010). PetroSA's de Wet: Expanding XTL. DownstreamToday.

${ }^{44}$ Steynberg, A., \& Dry, M. (2004). Fischer-Tropsch Technology (Studies in Surface Science and Catalysis). Elsevier Science.

${ }^{45}$ Frohning, C. D. (1977). Fischer-Tropsch Synthese aud Kohle, J. Flbe (ed.), Stuttgart, Thieme.

${ }^{46}$ Jager, B., \& Espinoza, R. (1995). Advances in low temperature Fischer-Tropsch synthesis. Catalysis Today, $23(1), 17-28$.

${ }^{47}$ Dry, M. (1981). Catalysis Science and Technology. (J. R. Anderson, \& M. Boudart, Eds.) Springer-Verlag.

${ }^{48}$ Ruel \& Batholamew. (1985).

${ }^{49}$ Bartholamew, C. (2003). History of Cobalt Catalyst Design for Fischer-Tropsch Synthesis. AIChE Spring National Meeting.

${ }^{50}$ Bartholamew. Op. cit.

${ }^{51}$ Iglesia. (1997).

${ }^{52}$ Oukaci, et. al. (1999).

${ }^{53}$ Aasberg-Peterson, K., Christensen, T., Dybkjaer, I., Sehested, J., Ostberg, M., Coertzen, R., et al. (2004). Synthesis Gas Production for FT Synthesis; Fischer-Tropsch Technology (Vol. 152). (A. Steynberg, \& M. Dry, Eds.) Elsevier. pp. 442-447.

${ }^{54}$ Dancuart, L., de Haan, R., \& de Klerk, A. (2004). Processing of primary FT products; Fischer-Tropsch Technology (Vol. 152). (A. Stayneberg, \& M. Dry, Eds.) Elsevier, pp. 501-527. 


\section{LIST OF ACRONYMS AND ABBREVIATIONS}

\begin{tabular}{|c|c|c|c|}
\hline${ }^{\circ} \mathrm{C}$ & Degrees Celsius & NSTTF & $\begin{array}{l}\text { National Solar Thermal } \\
\text { Test Facility }\end{array}$ \\
\hline${ }^{\circ} \mathrm{F}$ & Fahrenheit & $\mathrm{O} 2$ & Oxygen \\
\hline ASTM & $\begin{array}{l}\text { American Society for Testing } \\
\text { and Materials }\end{array}$ & P\&ID & $\begin{array}{l}\text { Process and } \\
\text { Instrumentation Drawing }\end{array}$ \\
\hline barg & bar gauge & PDU & Process Development Unit \\
\hline $\mathrm{CCS}$ & Carbon Capture Sequestration & PFD & Process Flow Diagram \\
\hline $\mathrm{CH}_{4}$ & Methane & PSIA & $\begin{array}{l}\text { Pounds Per Square Inch } \\
\text { Absolute }\end{array}$ \\
\hline FFRDC & $\begin{array}{l}\text { Federally Funded Research and } \\
\text { Development Centers }\end{array}$ & PSIG & $\begin{array}{l}\text { Pounds Per Square Inch } \\
\text { Gauge }\end{array}$ \\
\hline FOA & $\begin{array}{l}\text { Funding Opportunity } \\
\text { Announcement }\end{array}$ & $R \& D$ & Research and Development \\
\hline F-T & Fischer-Tropsch & $\mathrm{CO} 2$ & Carbon Dioxide \\
\hline GA & General Arrangement & $\mathrm{CS}$ & Concentrating Solar \\
\hline GHG & Greenhouse Gas & DARPA & $\begin{array}{l}\text { Defense Advanced } \\
\text { Research Projects Agency }\end{array}$ \\
\hline GHSV & Gas Hourly Space Velocity & DOE & Department of Energy \\
\hline GIS & $\begin{array}{l}\text { Geographical Information } \\
\text { System }\end{array}$ & DRI & Desert Research Institute \\
\hline $\mathrm{H}_{2} \mathrm{O}$ & Water & EJ & Exajoules \\
\hline $\mathrm{H}_{2} \mathrm{~S}$ & Hydrogen Sulfide & EPC & $\begin{array}{l}\text { Engineering, Procurement } \\
\text { and Construction Company }\end{array}$ \\
\hline $\mathrm{HC}$ & Hydrocarbon & REII & $\begin{array}{l}\text { Renewable Energy Institute } \\
\text { International }\end{array}$ \\
\hline IRR & Internal Rate of Return & ROI & Return on Investment \\
\hline LCA & Life Cycle Analysis & SMR & Steam Methane Reforming \\
\hline LFP & Liquid Fuel Production system & TIA & $\begin{array}{l}\text { Technology Investment } \\
\text { Agreement }\end{array}$ \\
\hline NATCARB & $\begin{array}{l}\text { National Carbon Sequestration } \\
\text { Database }\end{array}$ & WESTCARB & $\begin{array}{l}\text { West Coast Regional } \\
\text { Carbon Sequestration } \\
\text { Partnership }\end{array}$ \\
\hline NEPA & $\begin{array}{l}\text { National Environmental } \\
\text { Protection Act }\end{array}$ & WGS & Water Gas Shift \\
\hline NG & Natural Gas & & \\
\hline
\end{tabular}




\section{LIST OF FIGURES}

Figure 1 - Sunexus Solar Reformer Design SR1 .............................................................. 12

Figure 2 - Sunexus Solar Reformer Design SR1 Features .................................................... 12

Figure 3 - Solar Reformer SR1 Dimensions (front view)................................................... 13

Figure 4 - FLUENT Computational Mesh Used with Symmetry Boundary Conditions to Compute the Radiative Solar Flux Distribution ...................................................... 14

Figure 5 - Incident Solar Flux on Receiver Tubes ................................................................. 14

Figure 6 - Incident Solar Flux on Receiver Tubes (Reflector not shown to show back of

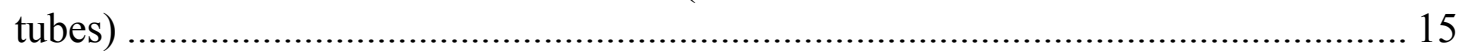

Figure 7 - Solar Irradiation Entering Aperture Applied as a "Virtual Radiative ....................... 15

Figure 8 - Comparison of Radiative Flux Fields within the Reformer ..................................... 16

Figure 9 - Sunexus SR1 Heater constructed of six Starbar ${ }^{\circledR}$ elements ..................................... 17

Figure 10 - Solid Model Showing Tubes and Back Plane Construction..................................... 18

Figure 11 - Additional Design Detail for the Sunexus Solar Reformer SR1 ............................. 18

Figure 12 - Sunexus SR1 Test Platform Design ............................................................... 19

Figure 13 - Sunexus Test Platform P\&ID .......................................................................... 20

Figure 14 - Sunexus Test Platform Control Panel................................................................... 20

Figure 15 - Sunexus SR1 Test Platform ............................................................................ 21

Figure 16 - Sunexus SR1 Back Plane ................................................................................ 22

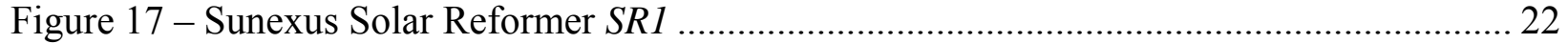

Figure 18 - Catalyst Loading into the Sunexus Reformer SR1 .......................................... 23

Figure 19 - Main Control Screen....................................................................................... 23

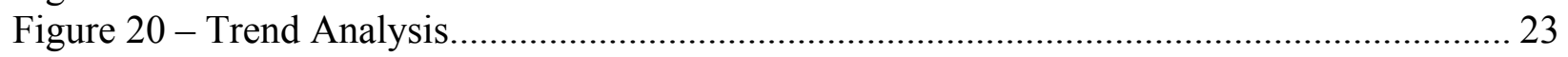

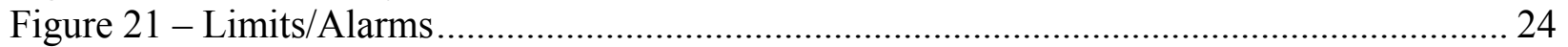

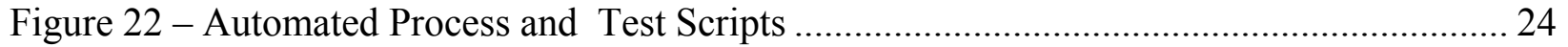

Figure 23 - Set Points and Manual Process Control................................................................ 24

Figure 24 - Safety, Logging, and Maintenance Settings ....................................................... 24

Figure 25 - Infrared Detector (real time $\mathrm{CO}_{2}, \mathrm{CO}, \mathrm{CH}_{4}$ ) ................................................. 25

Figure 26 - Gas Chromatograph................................................................................. 25

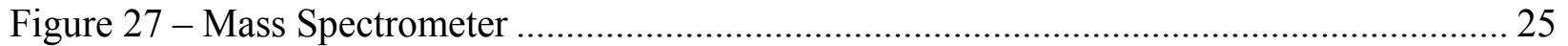

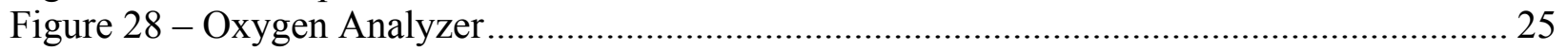

Figure 29 - Arrhenius Plot Results for the Sunexus Solar $\mathrm{CO}_{2}$ Reforming Catalyst ................. 29

Figure 30 - Arrhenius Plot Results for the Sunexus Solar $\mathrm{CO}_{2}$ Reforming Catalyst ................. 29

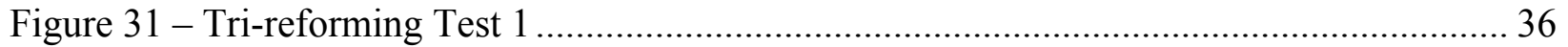

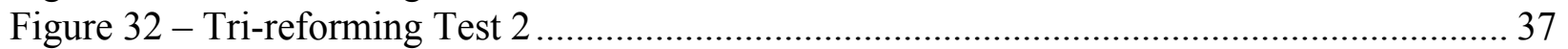

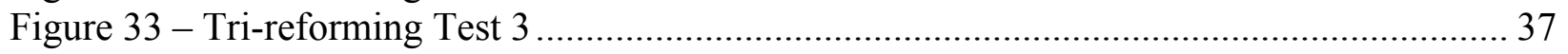

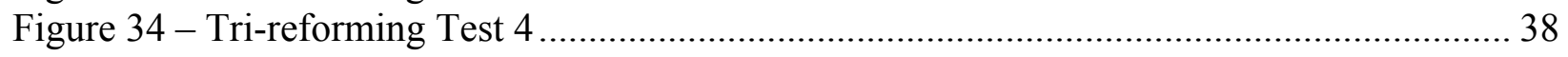

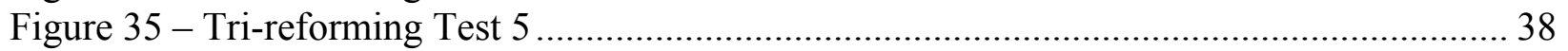

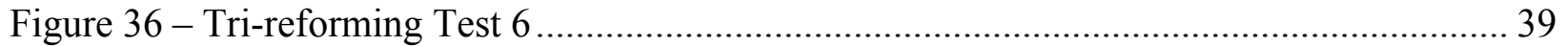

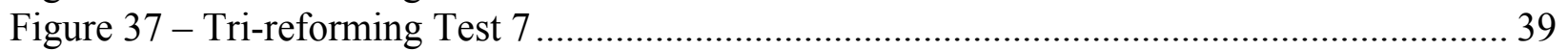

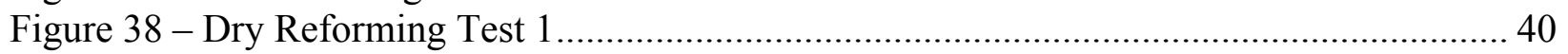

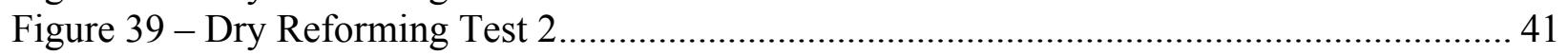

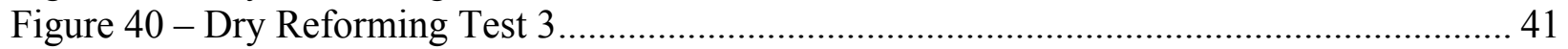

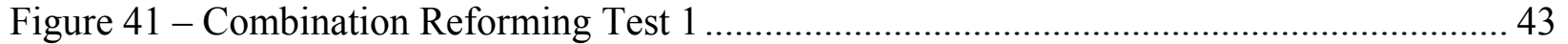

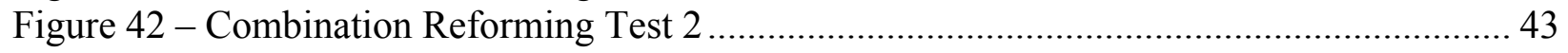


Figure 43 - Combination Reforming Test 3 ................................................................... 44

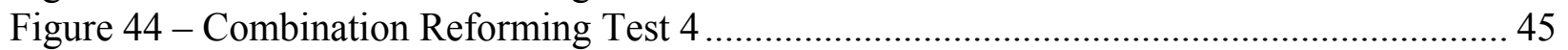

Figure 45 - TPO Analysis of a Sample after Testing under Dry Reforming Conditions ............. 46

Figure 46 - TPO Analysis of a Sample after Testing under Dry reforming conditions ................. 46

Figure 47 - Sunexus Solar SR2 Catalytic Reactor Assembly ..................................................... 48

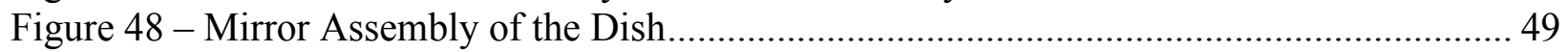

Figure 49 - Integrated Solar Reformer Foundation Design........................................................ 49

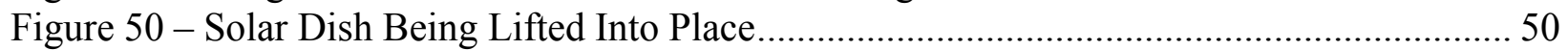

Figure 51 - Sunexus Solar Reformer SR2 Installed on the Infinia Solar Dish ............................ 50

Figure 52 - Control Center for the Sunexus Integrated Solar .................................................. 51

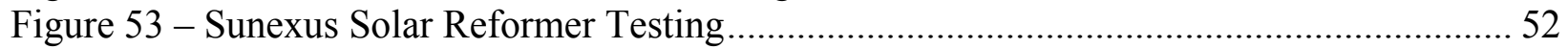

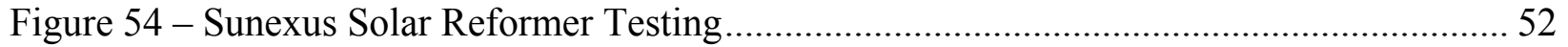

Figure 55 - Sunexus Solar CO2 Reformer Data Output.......................................................... 53

Figure 56 - An Example of Time Control System Screen with Data from a Solar $\mathrm{CO}_{2}$

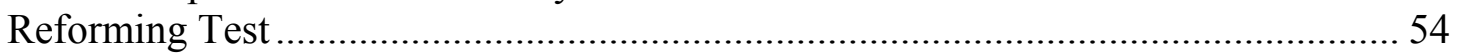

Figure 57 - The PRFC Process Development Unit (PDU) for the Conversion of Syngas to Synthetic Diesel Fuel.............................................................................................. 55

Figure 58 - The Composition (carbon \# vs. weight \%) of Synthetic Diesel Fuel (Terra Fuel)

Produced from Syngas Generated Compared to Traditional \#2 Diesel Fuel ............... 56

Figure 59 - Sunexus Fully Integrated Process Model ........................................................... 58

Figure 60 - Process Flow Diagram for Integrated Sunexus Plant.................................................... 60

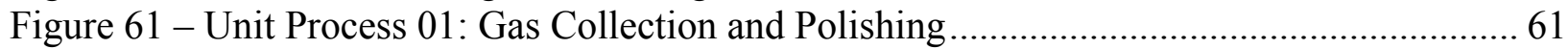

Figure 62 - Unit Process 02 (Solar Reforming) ........................................................................... 64

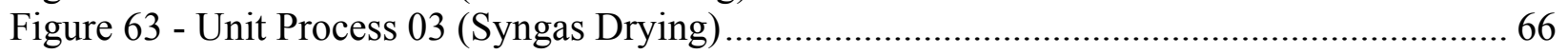

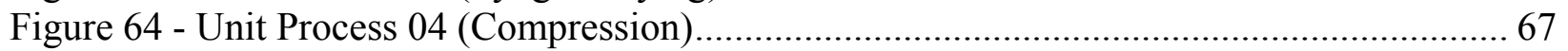

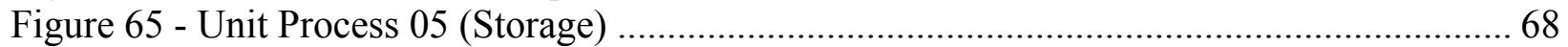

Figure 66 - Gas storage array for Demonstration System............................................................. 70

Figure 67 - Unit Process 06 (Fuel Synthesis) ........................................................................ 71

Figure 68 - Unit Process 07 (Product Separation) ……………………....................................... 73

Figure 69 - Average Annual Solar Insolation Values in the United States.................................... 76

Figure 70 - U.S. Industrial CO2 emissions by County............................................................... 76

Figure 71 - U.S. Industrial CO2 emissions by County with Solar Insolation Zones .................... 76

Figure 72 - Industrial Point Sources within Solar Insolation Zones including Cement Plants, Ethanol, Natural Gas Processing, Coal Power Production, Refineries, Steel and Iron Production ............................................................................................... 77

Figure 73 - NREL Map Showing Waste Methane Emissions from Landfills (note landfill

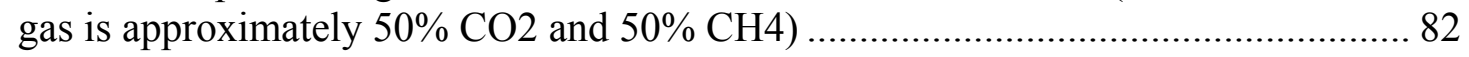

Figure 74 - The Projected Future Growth in Global Concentrating Solar Power Technologies during the Next 3 Years ................................................................... 85

Figure 75 - Configuration for Sunexus Commercial-Scale Solar Reformer for the Production of 71.3 million gallons/year of Synthetic Diesel Fuel from 180,000 tons/year of Captured $\mathrm{CO}_{2}$ using an Array of Parabolic Dishes..

Figure 76 - Configuration of Sunexus Commercial-Scale Solar Reformer for the Production of 356.6 Million Gallons/Year of Synthetic Diesel Fuel from 902,500 tons/year of Captured $\mathrm{CO}_{2}$ using Power Tower Technology ………………………………….... 91

Figure 77 - California Central Coast Project Sites $<1$ Mile from Salt Water …………............... 96 
Figure 78 - Eastern Seaboard Project Sites $<1$ Mile from Salt Water.

Figure 79 - LCA System Boundary for the Sunexus ${ }^{\text {TM }}$ Commercial Plant to convert 180,000 Tons/Year of $\mathrm{CO}_{2}$ into 71.3 Million Gallons/Year of Synthetic Diesel Fuel

Figure 80 - Product Distribution and Alpha for Cobalt and Iron Catalysts ("Natural Gas

Production, Processing and Transport" by Rojey, et. al).

Figure 81 - Effect of Cobalt Loading on the Activity of an Alumina Supported FischerTropsch Catalyst.

Figure 82 - The Effect of Promoter Addition on Cobalt Reduction ......................................... 138

Figure 83 - Calculated reaction rates for $\mathrm{Co}$ and Fe catalysts .................................................. 141

Figure 84 - Schematic of a slurry phase F-T reactor system ................................................. 142

Figure 85 - Future Demonstration Site Layout ………………….......................................... 148 


\section{LIST OF TABLES}

Table 1 - Sunexus System Metrics

Table 2 - Maximum Recommended Contaminant Levels for the Proprietary Ni-Based Reforming Catalyst 26

Table 3 - Maximum Recommended Contaminant Levels for the PRFC Terra Catalyst for the Conversion of Syngas to Synthetic Diesel Fuel 27

Table 4 - Matrix of Kinetic Catalyst Tests

Table 5 - Activation Energy and Pre-Exponential Factor Results for the Sunexus Solar $\mathrm{CO}_{2}$ Reforming Catalyst 30

Table 6 - Prediction of Space Velocity for 99\% Methane Conversion at Various Conditions 32 Table 7 - Predicted Equilibrium Product Calculation Results for Activity Test Conditions _ 33

Table 8 - A Summary of the Sunexus System Metrics 59

Table 9 - Flue Gas Composition from the Oxy-combustion Power Plant __ 61

Table 10 - Mass and Energy Balance for Unit Operation $01 \_62$

Table 11 - Mass and Energy Balance for Unit Operation $02 \quad 65$

Table 12 - Mass and Energy Balance for Unit Operation $03 \_66$

Table 13 - Mass and Energy Balance for Unit Operation $04 \_68$

Table 14 - Mass and Energy Balance for Unit Operation $05 \_70$

Table 15 - Mass and Energy Balance for Unit Operation $06 \_72$

Table 16 - Mass and Energy Balance for Unit Operation $07 \_74$

Table 17 - Petroleum Displacement Analysis for the First Commercial Plant at which 902,500 tons of $\mathrm{CO}_{2}$ are Captured and Converted to Synthetic Diesel Fuel 83

Table 18 - Projected 2020 and 2025 Scenarios for U.S. Petroleum Displacement from the Commercial Deployment of Sunexus Solar $\mathrm{CO}_{2}$ Conversion to Diesel Fuel Production Plants

Table 19 - Potential $\mathrm{CO}_{2}$ Reductions from the Deployment of Various Clean and Renewable Energy Approaches in 2030

Table 20 - Potential Jobs Supported by the Deployment of 103

Table 21 - Typical Concentrations of Gas/Pre-Separation $\overline{\mathrm{CO}_{2} \text { Concentrations in Flue Gases }}$ from Various Emission Sources

Table 22 - $\mathrm{CO}_{2}$ Separation Process Conditions 108

Table 23 - Typical Contaminants in Stack Gases Generated from Various Industrial Processes (before $\mathrm{CO}_{2}$ Separation)

Table $24-\mathrm{CO}_{2}$ Capture Costs from Various Industrial Sources

Table 25 - Specifications of the Testo 350 Emissions Analyzer 121

Table 26 - Average Concentrations of Contaminants Measured in a Syngas Stream Compared to Maximum Recommended Contaminant Levels for Efficient Diesel Fuel Production using Fisher-Tropsch Type Catalysts

Table 27 - Current Commercial Fischer-Tropsch Reactor Designs and Catalysts

Table 28 - Catalytic Metal Pricing as of March 2010

Table 29 - Optimization of Cobalt-based F-T Catalysts - A Summary of Findings from Patents and Papers

Table 30 - Applicable Capture Technologies for $\mathrm{CO}_{2}$ Point Sources 